Mariana Reis Balboni

\title{
POR DETRÁS DA INCLUSÃO DIGITAL
}

Uma reflexão sobre o consumo e a produção de informação em centros públicos de acesso à Internet no Brasil

Tese de Doutorado

São Paulo

2007 
Mariana Reis Balboni

\section{POR DETRÁS DA INCLUSÃO DIGITAL}

Uma reflexão sobre o consumo e a produção de informação em centros públicos de acesso à Internet no Brasil

Tese apresentada à Escola de Comunicações e Artes da Universidade de São Paulo para obtenção do título de Doutor, em Ciências da Comunicação. Área de concentração: Tecnologias da Comunicação e Redes Interativas.

Orientador: Prof ${ }^{a}$ Dr $^{a}$ Elizabeth Nicolau Saad Corrêa

São Paulo

2007 
Balboni, Mariana Reis

Por detrás da inclusão digital - Uma reflexão sobre o consumo e a produção de informação em centros públicos de acesso à Internet no Brasil / Mariana Reis Balboni. -- São Paulo: M. R. Balboni, 2007.

210 p. + anexos.

Tese (Doutorado) - Departamento de Jornalismo e Editoração/ Escola de Comunicações e Artes/USP, 07/02/2007.

Orientador: Prof ${ }^{\mathrm{a}} \mathrm{Dr}^{\mathrm{a}}$ Elizabeth Nicolau Saad Corrêa.

Bibliografia

1. Inclusão Digital 2. Tecnologia da Informação e Comunicação 3. Desenvolvimento 4. Inclusão social. I. Título.

CDD -302.2 
Autorizo:

[ ] divulgação do texto completo em bases de dados especializadas.

[ ] reprodução total ou parcial, por processos fotocopiadores, exclusivamente para fins acadêmicos e científicos.

Assinatura:

Data: 
Termos aprovação

Nome do Autor:

Título da Dissertação/Tese:

Presidente da Banca: Prof. Dr.

Banca Examinadora:

Prof. Dr.

Instituição:

Prof. Dr.

Instituição:

Prof. Dr.

Instituição:

Prof. Dr.

Instituição:

Prof. Dr. Instituição:

Aprovada em:

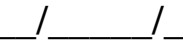


O desafio político global não é superar a exclusão digital, mas expandir o acesso e o uso da TIC para promover a inclusão social

Mark Warschauer 
Às minhas queridas avós, Quinha e Lucila (in memorian) 
Gostaria de agradecer às pessoas que partilharam comigo os momentos ao mesmo tempo difíceis e gratificantes transcorridos durante a redação desta tese.

Primeiramente à minha orientadora, Beth Saad, que me acolheu desde os tempos da graduação, por sua atenção, seus conselhos, paciência e confiança.

Também por ter me indicado o caminho da Cidade do Conhecimento, onde Gilson Schwartz me recebeu com sua genialidade e me abriu as portas da inclusão digital através da coordenação do programa Gestão de Mídias Digitais.

Gostaria especialmente de agradecer aos educadores e monitores que participaram do GMD e me mostraram a diferença e as possibilidades que o acesso à Internet trouxe para suas comunidades, para nossas vidas.

Aos meus entrevistados, que cederam seu tempo para minhas investigações.

À Drica Guzzi, Ricardo Kobashi e Hernani Dimantas pelas acaloradas discussões.

Aos amigos que me confortaram e acompanharam em diversos momentos, Gabriele Tischler, Virginie Fernandez, Julien Clausset, Heloísa Daniel, Juliana Saboia, Sandra Chemin, José Eduardo e a meu pai Aldo.

A finalização deste trabalho não teria sido possível sem a consideração de Hartmut Glaser e Demi Getschko, e de meus colegas do Comitê Gestor da Internet no Brasil, que colaboraram em diversos momentos e de diversas formas. Um agradecimento especial para Reinaldo Ferraz, Everton Rodrigues, Fabrício Tamusiunas e Juliano Cappi.

Especialmente agradeço à Lílian Starobinas e à minha mãe, Maria Cândida, pela leitura crítica e pelo conforto nos momentos mais importantes da tese. 
BALBONI, Mariana Reis. Por detrás da inclusão digital: uma reflexão sobre o consumo e a produção de informação em centros públicos de acesso à Internet no Brasil. São Paulo, 2007. 223 p. Tese (Doutorado em Ciências da Comunicação) Escola de Comunicações e Artes, Universidade de São Paulo

RESUMO: A tese apresenta uma visão geral da importância das TICs - sobretudo da Internet - para a participação do cidadão na “sociedade da informação". Nesse sentido é introduzida a questão da desigualdade de acesso, destacando o cenário da exclusão digital no mundo e sobretudo no Brasil. São apresentadas as discussões em torno da inclusão digital e o histórico do seu desenvolvimento no país, abordando a importância do letramento e da apropriação tecnológica para a produção de conhecimento. Foram também comparadas as opiniões de mentores, coordenadores, monitores e usuários de programas de inclusão digital, no que diz respeito à contribuição da Internet para a produção e consumo de informação e para o desenvolvimento social, econômico e político das comunidades de baixa renda, assim como identificados os interesses políticos e econômicos por trás da inclusão digital. Suas contribuições mais significativas estão na reflexão crítica e na historicização do desenvolvimento das iniciativas de inclusão digital no país, no registro do discurso e da opinião dos atores que elaboram e promovem esse processo, e principalmente na visão dos usuários desses programas, suas realizações e limitações, oferecendo pistas para a articulação de um plano nacional que envolva políticas públicas consistentes e que alavanque a inclusão social e o desenvolvimento do país.

Palavras-chave: inclusão digital, tecnologia da informação e da comunicação, desenvolvimento, inclusão social, centros públicos de acesso, Internet, acesso à informação 
BALBONI, Mariana Reis. Behind the Digital Inclusion: Reflections about information consumption and production in public Internet access centers in Brazil. São Paulo, 2007. 223 p. Thesis (Doctorate in Sciences of Communication) Escola de Comunicações e Artes, University of São Paulo

\begin{abstract}
The thesis offers an overall view on the importance of ICTs - especially of the Internet - for the citizen's participation in the "information society". The author introduces the issue of the digital divide, with emphasis on the scenario of digital exclusion around the world and particularly in Brazil. The document describes discussions about digital inclusion and the background of its development in the country, emphasizing how important education and technical appropriation are for the production of knowledge. Opinions of mentors, coordinators, tutors and users of digital inclusion programs were compared, examining the contribution of the Internet to the information production and consumption and also for the social, economic and political development of low-income communities, trying to identify the political and economic interests behind the digital inclusion. The most significant contributions of this document are the critical analysis and the historical organization on the development of digital inclusion initiatives in the country, the registration of speeches and opinions of those actors who develop and foster that process, and specially the view of program users, their accomplishments and limits, offering clues for the articulation of a national plan that should include consistent public policies and lever social inclusion and development all over the country.
\end{abstract}

Key words: Digital inclusion, information and communication technology, development, social inclusion, public access centers, Internet, access to information. 
LISTA DE QUADROS .................................................................................................

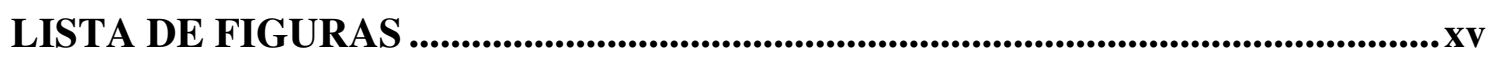

LISTA DE GRÁFICOS ...........................................................................................

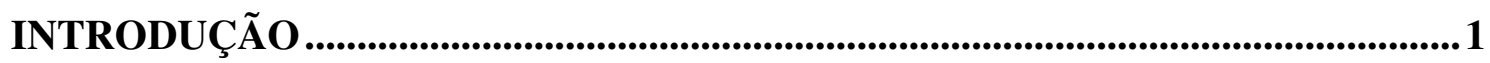

1. QUADRO TEÓRICO ........................................................................................6

1.1. O paradigma da sociedade da informação ...........................................................

1.1.1. Sociedade digital e globalização ..................................................................... 10

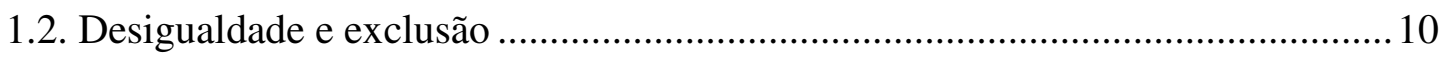

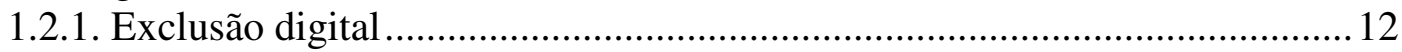

1.2.2. O Cenário da exclusão no mundo ……………………………………........ 13

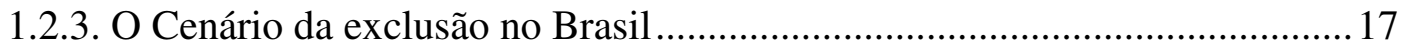

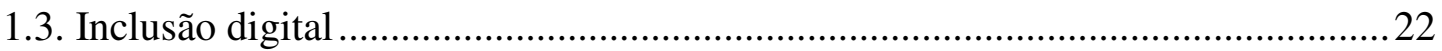

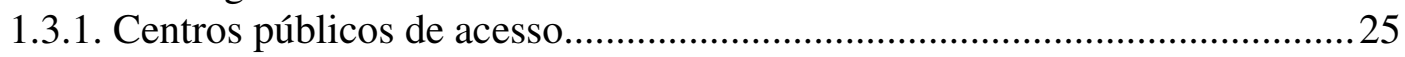

1.3.2. Histórico da inclusão digital no Brasil .........................................................2

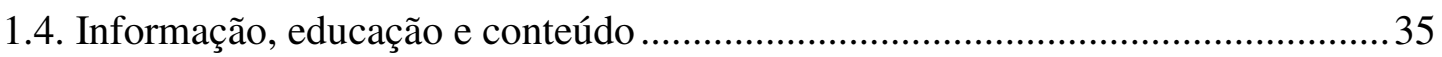

1.4.1. Produção de conhecimento e apropriação tecnológica ....................................38

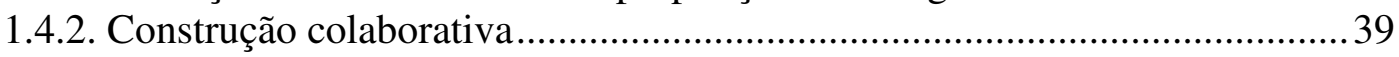

1.4.3. Em busca da cidadania digital ..................................................................... 41

2. PROBLEMÁTICA.......................................................................................................44

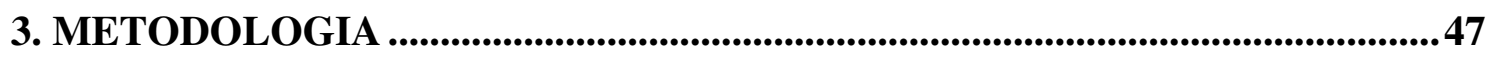

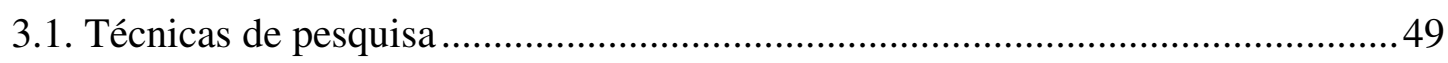

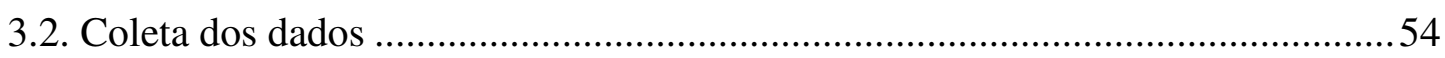

3.2.1. Seleção dos programas................................................................................

3.2.2. Seleção dos entrevistados e amostragem .....................................................55

3.2.3. Aplicação dos questionários..........................................................................57

4. APRESENTAÇÃO DOS DADOS …..................................................................63

4.1. Descrição dos programas de inclusão digital selecionados......................................63

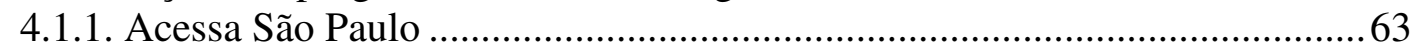

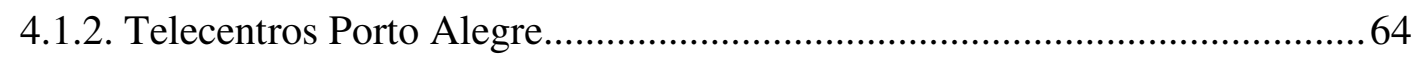

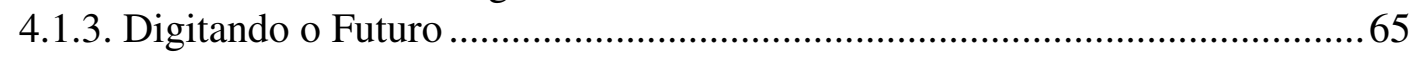

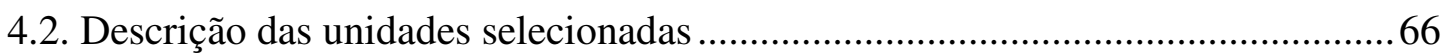

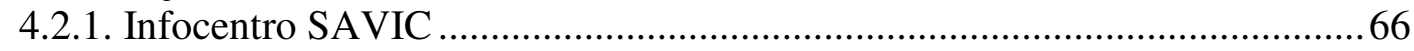

4.2.2. Infocentro Piracicaba ................................................................................... 69 
4.2.3. Telecentros Porto Alegre - Campo da Tuca ................................................. 70

4.2.4. Digitando o Futuro - Farol do Saber Aristides Vinholes...............................71

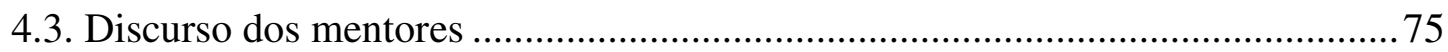

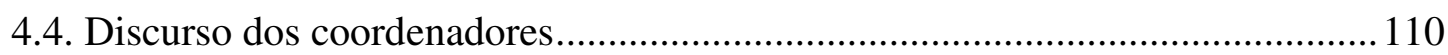

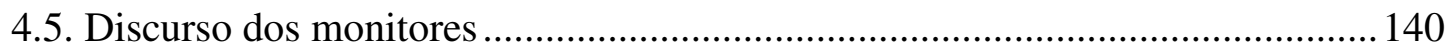

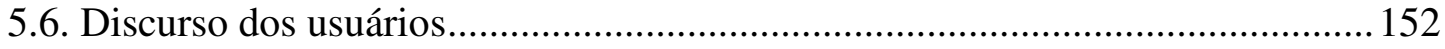

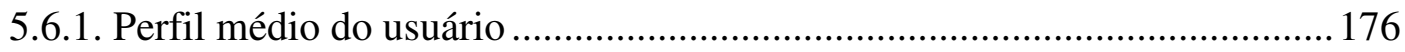

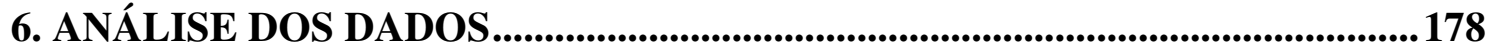

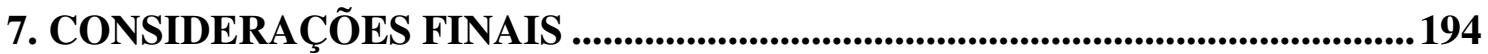

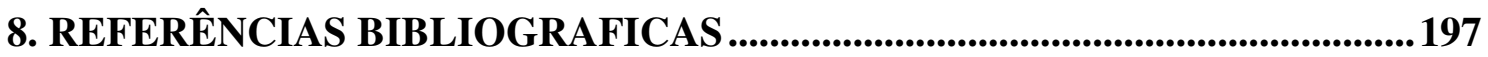

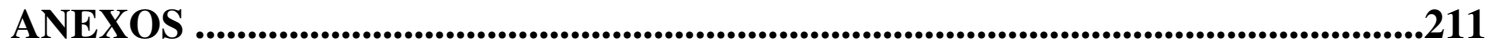

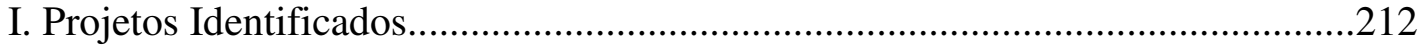

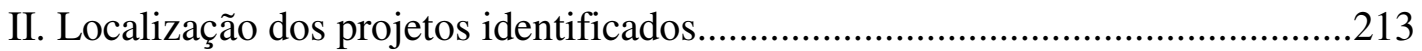

III. Roteiro de entrevista com mentores..............................................................214

IV. Roteiro de entrevista aberta para os coordenadores......................................215

V. Roteiro de entrevistas abertas para os monitores.............................................216

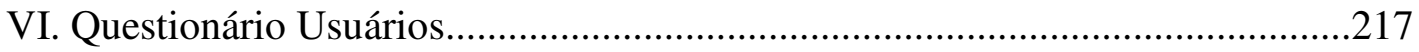




\section{LISTA DE QUADROS}

Quadro 1. Características socioeconômicas da população brasileira 2001/2005...........17

Quadro 2. Percentual de municípios com serviço de telefonia móvel no Brasil............20

Quadro 3. Penetração de computadores e Internet em domicílios................................21

Quadro 4. Penetração de computadores e Internet por indivíduos...............................21

Quadro 5. Atividades realizadas na Internet...............................................................22

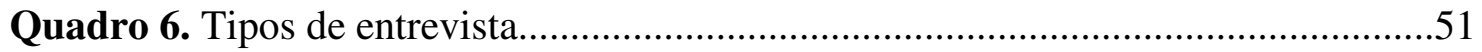

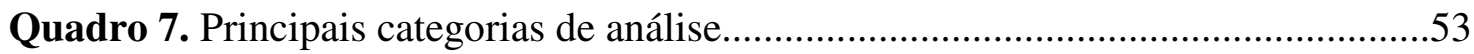

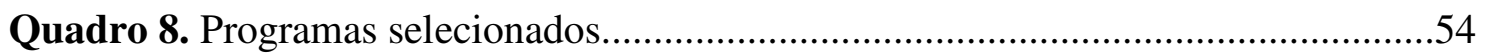

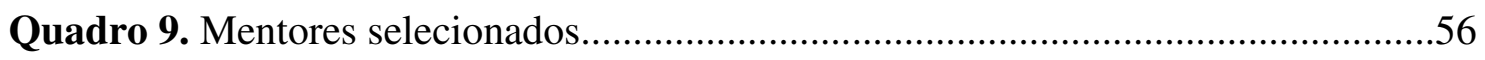

Quadro 10. Unidades, Monitores selecionados e Lideranças........................................57

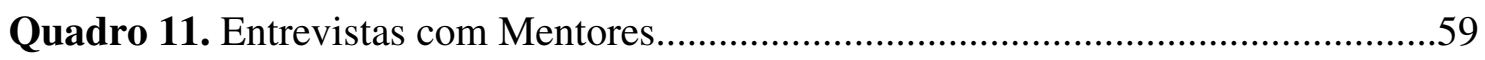

Quadro 12. Entrevistas com os Coordenadores dos programas...................................60

Quadro 13. Entrevistas com Monitores e Lideranças...................................................62

Quadro 14. Questionário de usuários respondidos.....................................................62

Quadro 15. Modelo de gestão e características das unidades selecionadas....................73

Quadro 16. Envolvimento com a Inclusão Digital - Mentores......................................76

Quadro 17. Definiçãa de Inclusão Digital - Mentores.................................................79

Quadro 18. Objetivos dos programas públicos de Inclusão Digital - Mentores.............81

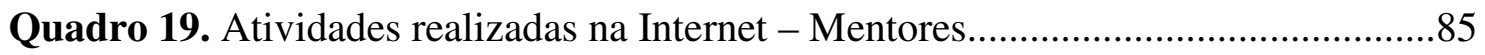

Quadro 20. Impacto da Internet no consumo e produção de informação - Mentores...88

Quadro 21. Contribuição dos programas de ID para o desenvolvimento social,

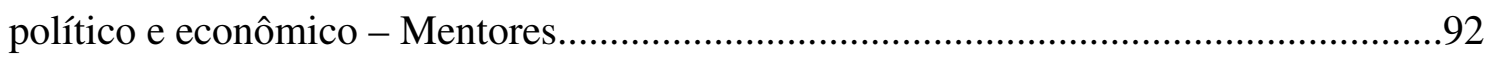

Quadro 22. Benefícios dos projetos de Inclusão Digital - Mentores.............................98

Quadro 23. Avaliação dos programas de Inclusão Digital - Mentores........................101

Quadro 24. Inclusão Digital como política pública - Mentores...................................103

Quadro 25. Desafios da Inclusão Digital - Mentores....................................................104

Quadro 26. Telefone celular como vetor para a Inclusão Digital - Mentores..............106

Quadro 27. Televisão digital como vetor para a Inclusão Digital - Mentores..............109

Quadro 28. Perfil do coordenador e envolvimento com a Inclusão Digital.................112

Quadro 29. Definição de Inclusão Digital - Coordenadores.......................................114

Quadro 30. Motivação para a criação do programa - Coordenadores.........................119

Quadro 31. Objetivos do programa - Coordenadores...............................................121 
Quadro 32. Capacitação do usuário e desenvolvimento de atividades locais - Coordenadores.

Quadro 33. Atividades realizadas na Internet - Coordenadores.

Quadro 34. Impacto da Internet no consumo e produção de informação -

Coordenadores

Quadro 35. Contribuição dos programas de ID para o desenvolvimento: oportunidade de geração de renda e emprego - Coord. 132

Quadro 36. Contribuição dos programas de ID para o desenvolvimento: oportunidades de educação, acesso à informação e cultura - Coord

Quadro 37. Contribuição dos programas de ID para o desenvolvimento:

conscientização social e participação política - Coordenadores.

Quadro 38. Benefícios dos programas de Inclusão Digital - Coordenadores.

Quadro 39. Desafios do programa - Coordenadores.

Quadro 40. Perfil Monitores 140

Quadro 41. Definição de Inclusão Digital - Monitores.

Quadro 42. Objetivos do programa - Monitores.

Quadro 43. Responsabilidades no programa - Monitores

Quadro 44. Atividades realizadas na Internet - Monitores.

Quadro 45. Impacto da Internet no consumo e produção de informação - Monitores 146

Quadro 46. Benefícios dos programas de Inclusão Digital - Monitores

Quadro 47. Contribuição dos programas de ID para o desenvolvimento social, político e econômico - Monitores

Quadro 48. Avaliação dos programas de Inclusão Digital - Monitores. 151

Quadro 49. Membro de partido político, associações de bairro, conselhos ou outras atividades comunitárias.

Quadro 50. Definição de Inclusão digital - Usuários.

Quadro 51. Significado do Centro Público de Acesso - Usuários.

Quadro 52. Impacto da Internet na vida do usuário e da comunidade - Usuários 


\section{LISTA DE FIGURAS}

Figura 1. Assinantes de telefonia móvel versus telefonia fixa......................................14

Figura 2. Computadores pessoais no mundo e crescimento mundial (1990-2004)........15

Figura 3. Usuários Internet Mundo e crescimento mundial (1990-2004).....................16

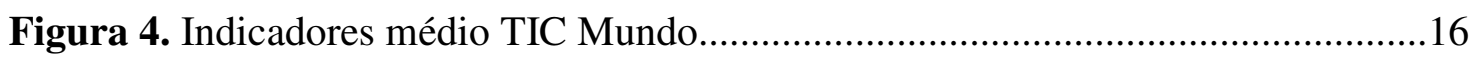

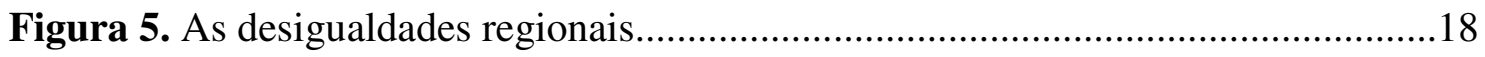

Figura 6. Esquema de Bardin : Desenvolvimento de uma anális.................................52

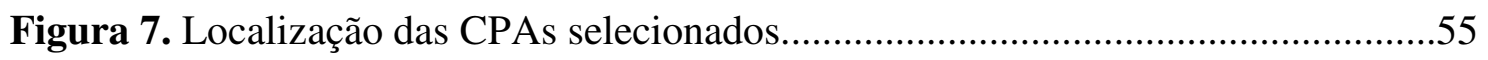

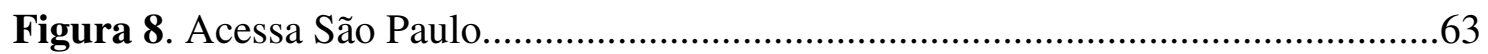

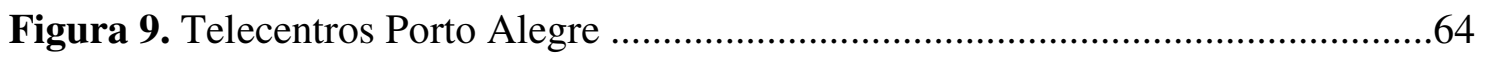

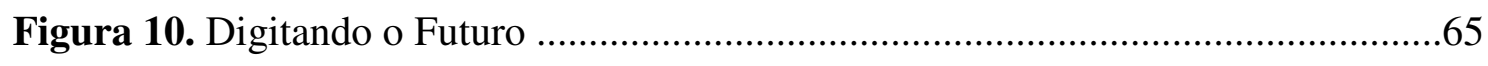

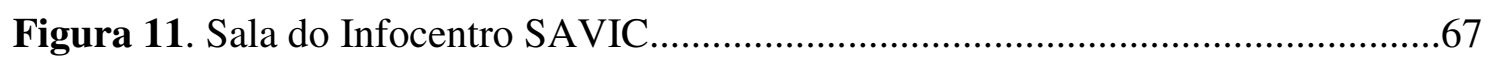

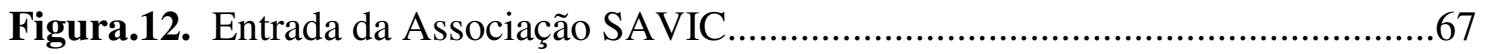

Figura 13. Sala do infocentro em Piracicaba................................................................69

Figura 14. Entrada da biblioteca municipal de Piracicaba...........................................69

Figura 15. Cadastramento dos usuários no telecentro Campo da Tuca..........................70

Figura 16. Sala do Telecentro Campo da Tuca, em Porto Alegre.................................71

Figura 17. Sala do Digitando o Futuro - Farol do Saber em Curitiba............................71 


\section{LISTA DE GRÁFICOS}

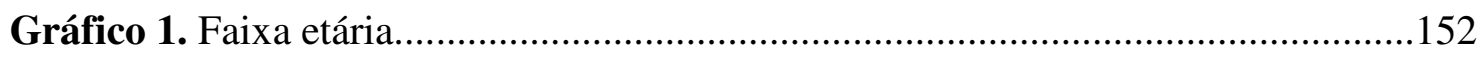

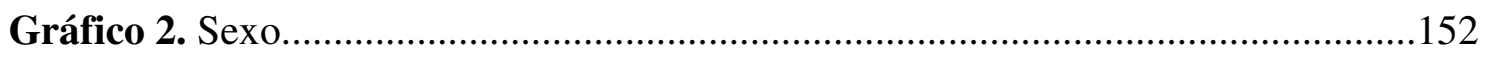

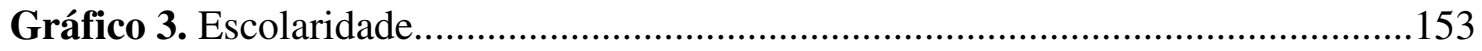

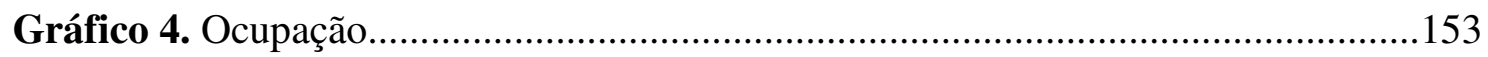

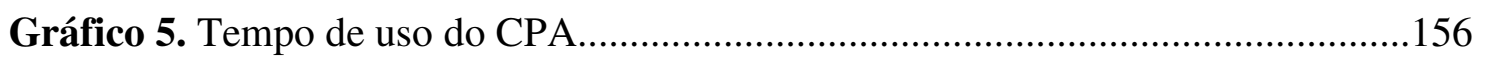

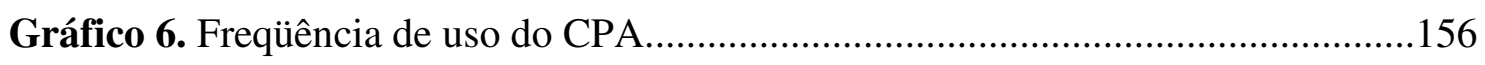

Gráfico 7. Atividades realizadas no computador, sem acesso à Internet.....................156

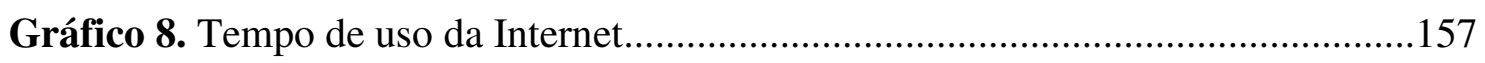

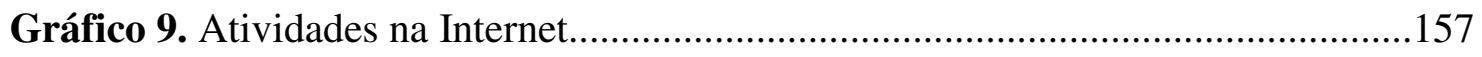

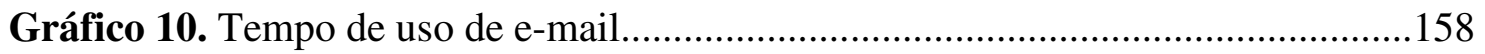

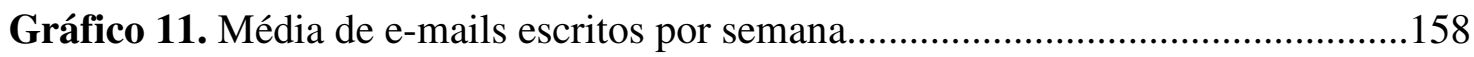

Gráfico 12. Média de e-mails recebidos por semana..............................................159

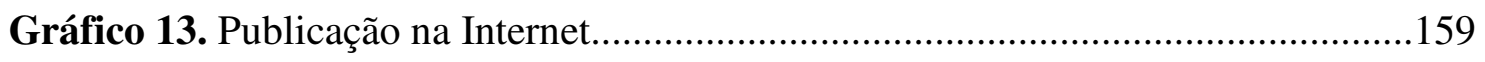

Gráfico 14. Tipo de publicação na Internet............................................................159

Gráfico 15. Tempo de publicação na Internet..........................................................160

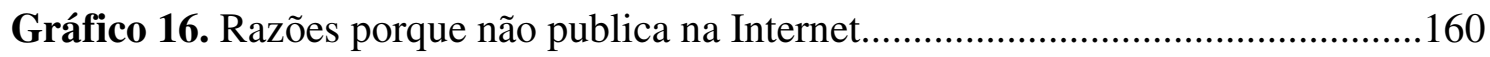

Gráfico 17. Existência de histórias da comunidade para contar...................................161

Gráfico 18. Intenção de publicar histórias sobre a comunidade..................................161

Gráfico 19. Existência de meio de comunicação produzido na comunidade................161

Gráfico 20. Tipo de meio de comunicação produzido na comunidade.........................162

Gráfico 21. Tempo de existência do meio de comunicação.........................................162

Gráfico 22. Participação na equipe de produção do meio de comunicação..................162

Gráfico 23. Assuntos divulgados no meio de comunicação......................................163

Gráfico 24. Assuntos não divulgados no meio de comunicação..................................163

Gráfico 25. Participação em espaços virtuais de discussão........................................163

Gráfico 26. Espaços virtuais de discussão freqüentados...........................................164

Gráfico 27. Período de tempo que freqüenta espaços virtuais de discussão.................164

Gráfico 28. Razões porque não participa de espaços virtuais de discussão..................164

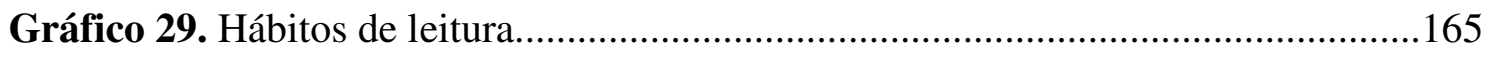

Gráfico 30. Hábitos de leitura antes de freqüentar o CPA..........................................165

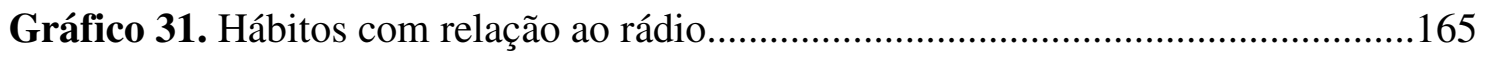

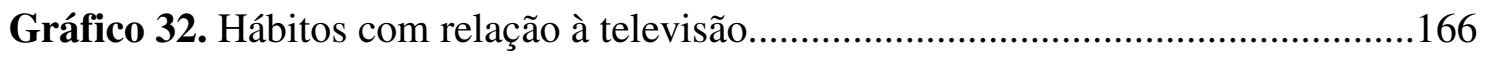


Gráfico 33. Relação da Internet com o "se sentir informado". 166

Gráfico 34. Impacto da Internet na vida do usuário.

Gráfico 35. Contribuição para o desempenho profissional 167

Gráfico 36. Contribuição para o aprendizado 167

Gráfico 37. Contribuição para o exercício da cidadania..............................................168

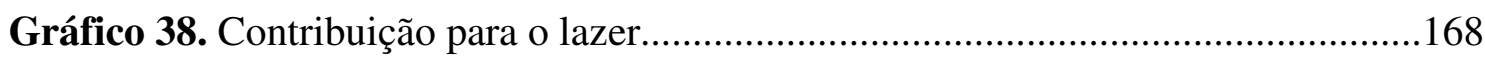

Gráfico 39. Contribuição para o relacionamento com amigos e família........................168

Gráfico 40. Intenção de aquisição de computador......................................................169

Gráfico 41. Atividades realizadas no CPA, sem computador e Internet.....................169

Gráfico 42. Impacto da Internet na comunidade..........................................................170

Gráfico 43. Contribuição para a situação econômica.................................................170

Gráfico 44. Contribuição para a articulação da comunidade.......................................170

Gráfico 45. Contribuição para o lazer da comunidade.................................................171

Gráfico 46. Avaliação dos programas de inclusão digital............................................171

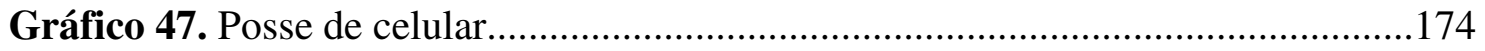

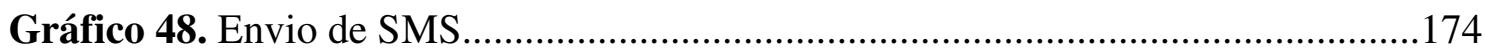

Gráfico 49. Freqüência de envio de SMS............................................................ 174

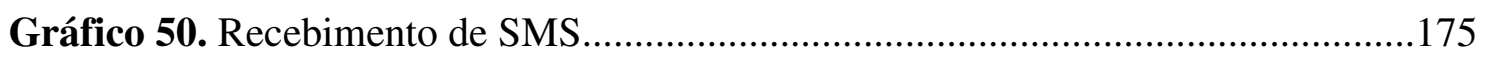

Gráfico 51. Freqüência de recebimento de SMS...................................................175

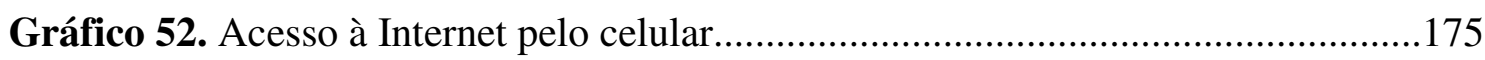

Gráfico 53. Freqüência do acesso à Internet pelo celular.........................................176

Gráfico 54. Atividades na Internet pelo celular..........................................................176 


\section{LISTA DE SIGLAS E ABREVIATURAS}

ALCA - Área de Livre Comércio entre as Américas

ANATEL - Agência Nacional de Telecomunicações

BBS - Bulletin Board System

CDI - Comitê para Democratização da Informática

CDHU - Companhia de Desenvolvimento Habitacional e Urbano do Estado de São Paulo

CEPAL - Comissão Econômica para a América Latina e Caribe

CGI.br - Comitê Gestor da Internet no Brasil

CJ - Centro de Juventude do SAVIC

CMSI - Cúpula Mundial sobre a Sociedade da Informação

CPA - Centro Público de Acesso

CUT - Central Única dos Trabalhadores

EIC - Escola de Informática e Cidadania

EJA - Educação de Jovens e Adultos

FUST - Fundo de Universalização dos Serviços de Telecomunicações

GESAC - Governo Eletrônico - Serviços de Atendimento ao Cidadão

GMD - Gestão de Mídias Digitais

HTML - HyperText Markup Language, Linguagem de Marcação de Hipertexto

IBASE - Instituto Brasileiro de Análises Sociais e Econômicas

ID - Inclusão digital

IDH - Índice de Desenvolvimento Humano

IBASE - Instituto Brasileiro de Análises Sociais e Econômicas

IBICT - Instituto Brasileiro de Informação em Ciência e Tecnologia

IBGE - Instituto Brasileiro de Geografia e Estatística

IBOPE - Instituto Brasileiro de Opinião Pública e Estatística

ICI - Instituto Curitiba de Informática

ICQ - Programa de troca de mensagens instantâneas

IDRC/IRDC - Centro de Pesquisa para o Desenvolvimento Internacional do Canadá

IPEA - Instituto de Pesquisa Econômica Aplicada

ITI - Instituto de Tecnologia da Informação

MDIC - Ministério do Desenvolvimento, Indústria e Comércio Exterior

MEC - Ministério da Educação

MINC - Ministério da Cultura

MP3 - MPEG Audio Layer-3, tipo de compactação de áudio

MPO - Ministério do Planejamento, Orçamento e Gestão 
MSN - Programa de troca de mensagens instantâneas

NAE - Núcleo de assuntos estratégicos

OECD - Organização para a Cooperação Econômica e o Desenvolvimento

ONG - Organização Não-Governamental

ONU - Organização das Nações Unidas

OSILAC - Observatório para a Sociedade da Informação na América Latina e Caribe

PC - Computador Pessoal

PFL - Partido da Frente Liberal

PPS - Partido Popular Socialista

PSDB - Partido da Social Democracia Brasileira

PIB - Produto Interno Bruto

PMSP - Prefeitura Municipal de São Paulo

PNAD - Pesquisa Nacional por Amostra de Domicílios

PNUD - Programa das Nações Unidas para o Desenvolvimento

PONLINE - Pesquisa On-line

POPAI - Posto Públicos de Acesso à Internet

POA - Porto Alegre

PROCEMP - Companhia de Processamento de Dados da Cidade de Porto Alegre

PT - Partido dos Trabalhadores

PUC - Pontifícia Universidade Católica

RENPAC - Rede Nacional de Pacotes

RITS - Rede de Informações para o Terceiro Setor

Sabesp - Companhia de Saneamento Básico do Estado de São Paulo

SAVIC - Sociedade Amigos da Vila Constança

SLTI - Secretaria de Logística e Tecnologia da Informação

SMDHSU - Secretaria Municipal de Direitos Humanos e Segurança Urbana de Porto Alegre

SME - Secretaria Municipal de Educação de Curitiba

SMS - Short Message Service, Serviço de Mensagens Curtas

TCU - Tribunal de Contas da União

TIC - Tecnologia da Informação e da Comunicação

TID - Todos pela Inclusão Digital

UIT - União Internacional de Telecomunicações

UNCTAD - United Nations Conference on Trade and Development

UOL - Universo On Line, provedor de acesso à Internet

USP - Universidade de São Paulo

WSIS - World Summit on the Information Society 


\section{INTRODUÇÃO}

A sociedade da informação ${ }^{1}$ é hoje uma realidade inquestionável para uma parcela significativa da população. Invadindo todas as esferas da vida cotidiana, as novas tecnologias da informação estão presentes nos escritórios, supermercados, escolas, nas ruas, nas casas. Mesmo sem perceber, nos deparamos com ela quando vamos ao banco, ao assistir televisão, falamos ao telefone e até mesmo quando escolhemos nas urnas nossos representantes políticos. Neste novo contexto global, a informação transformouse no produto mais importante para o desenvolvimento econômico, político e social de cada nação, de cada região, de cada indivíduo. Não só o acesso à informação é determinante para a participação ativa e democrática na sociedade, como a produção e distribuição do conhecimento podem contribuir muito para a construção da cidadania.

Entretanto, esta nova realidade está longe de ser idêntica entre as diversas regiões do mundo, de cada país, e menos ainda entre as diferentes camadas sociais da população. Enquanto os países desenvolvidos discutem a implementação de tecnologias móveis de última geração como o iPhone ${ }^{2}$, muitas nações em desenvolvimento não possuem sequer uma rede de telecomunicação capaz de garantir o acesso universal de sua população aos serviços de comunicação de base, muito menos à Internet. Segundo Information Economy Report da ONU, em $2006^{3}$, apenas 15,6\% da população mundial possuía acesso à Internet, pouco mais de 1 bilhão de pessoas, sendo que nos países ricos a taxa média de penetração é de $54,4 \%$, enquanto nas economias mais pobres não chega a $9 \%$. América do Norte e Europa são as regiões com o maior número de internautas - $66 \%$ da população tem acesso à rede, cerca de 425 milhões de pessoas. Já na América Latina e África as taxas de penetração da Internet são $15,5 \%$ e 3,6\%, respectivamente.

\footnotetext{
${ }^{1}$ Sociedade da informação é o termo usado normalmente para definir o novo contexto em que vivemos, no qual todas as atividades humanas estão cada vez mais dependentes das infra-estruturas eletrônicas da informação. (Castells, 1999).

${ }^{2}$ Segundo Ethevaldo Siqueira (2007), "trata-se de um celular sem teclado, com tela gigante, sensível ao toque dos dedos, câmera digital de 2 megapixels, memória para armazenar até 8 gigabytes de música, fotos ou vídeo, acesso à Internet, capacidade para enviar e receber e-mails e sistema operacional OSX, entre outros recursos".

${ }^{3}$ Disponível em Information Economy Report 2006, UNCTAD, em http://www.unctad.org/Templates/webflyer.asp?docid=7576\&intItemID=3991\&lang=1\&mode=download s/. Acesso em 15 de janeiro de 2007.
} 
Segundo pesquisa do Comitê Gestor da Internet no Brasil (CGI.br) ${ }^{4}$, em 2006 cerca de $67 \%$ da população - pouco mais de 100 milhões de brasileiros - nunca tinha acessado a Internet, sendo que entre as pessoas conectadas somente $15,5 \%$ são de classe D e $E^{5}$, percentual que representa 7,9 milhões de pessoas. Houve um crescimento em relação ao ano 2000, quando a taxa de acesso era de apenas 2,5\% (TAKAHASHI, 2000), mas continuamos com um número gigantesco de excluídos digitais ${ }^{6}$, pessoas que não têm acesso à Internet, e que por isso têm menos condições de participar ativamente na sociedade digital.

Visando reduzir este quadro, o avanço das Tecnologias da Informação e da Comunicação (TICs) no país tem sido acompanhado por políticas públicas e privadas ainda tímidas - voltadas à inclusão digital, em especial a universalização do acesso, com destaque para a instalação de centros públicos de acesso (CPA) à Internet em escolas, bibliotecas, telecentros e outros postos de atendimento à população (SCHWARTZ, 2002). Não existem estimativas oficiais, mas estima-se que já cheguem a 10 mil o número de CPAs instalados através de iniciativas públicas - em âmbito federal, estadual ou municipal -, de empresas ou de instituições do terceiro setor, oferecendo principalmente acesso gratuito à Internet e capacitação para o uso TICs à população. Entretanto, segundo o estudo do CGI.br somente 3,5\% dos internautas brasileiros acessam a Internet através de CPAs, o que mostra que o número de centros públicos instalados no país ainda é muito pequeno, ou que os programas públicos de inclusão digital em desenvolvimento não estão sendo capazes de estimular o acesso da população à rede.

O acesso à infra-estrutura de comunicação é importante, mas não é suficiente para lutarmos contra a exclusão digital. Em minha tese de mestrado tratei em profundidade da questão da importância do acesso à informação para o desenvolvimento, dando ênfase ao acesso à infra-estrutura de telecomunicações. Neste sentido, acompanhei todo o processo de privatização do Sistema Telebrás e foram sugeridas políticas públicas que

\footnotetext{
${ }^{4}$ Pesquisa Sobre o Uso das Tecnologias da Informação e Comunicação no Brasil 2006. Disponível em http://www.cetic.br/usuarios/tic/2006/index.htm. Acesso em 29 de janeiro de 2007.

${ }^{5} \mathrm{O}$ critério utilizado para classificação leva em consideração a educação do chefe de família e a posse de uma serie de utensílios domésticos, relacionando-os a um sistema de pontuação. A soma dos pontos alcançada por domicílio é associada a uma Classe Sócio-Econômica específica (A, B, C, D, E).

6 Segundo Macadar e Reinhard (2002), o termo "exclusão digital” (apartheid digital, digital gap, digital divide, brecha digital, etc) significa a não disponibilização do acesso às Tecnologias de Informação e da Comunicação (TICs), em especial à Internet.
} 
deveriam ser adotadas para garantir a universalização dos serviços de comunicação (BALBONI, 1999).

Se a exclusão por razões econômicas ainda é alarmante, hoje a discussão sobre a inclusão digital concentra-se na capacitação e apropriação destas novas tecnologias pelos usuários, assim como na utilização das mídias digitais para a geração de conhecimento e renda. É justamente este o foco desta tese: mais do que fornecer acesso a computadores conectados à Internet, o grande desafio atualmente é possibilitar que a população de baixa renda, ou com poucas oportunidades de acesso a estes recursos, utilize esta tecnologia e a informação que nela circula em seu benefício para transformar a sua realidade e a da comunidade onde vive. E mais importante ainda, é produzir e circular conteúdo útil para estimular a participação social desses indivíduos na rede. $\mathrm{O}$ simples acesso não garante que a informação seja processada, assimilada, e que se transforme em conhecimento.

Buscando refletir criticamente sobre a questão, esta tese apresenta também o histórico do desenvolvimento de programas públicos de universalização do acesso e de inclusão digital desde o governo de Fernando Henrique Cardoso até a atualidade, através da pesquisa de documentos e principalmente da opinião de mentores ${ }^{7}$, coordenadores, monitores e usuários de centros públicos de acesso entrevistados. Neste processo, os interesses políticos e econômicos relacionados à expansão das redes globalizadas de comunicação e aos processos produtivos estabelecidos através delas também emergiram, suscitando a necessidade da implementação de políticas públicas articuladas entre governo, empresas privadas e terceiro setor. Pela riqueza do material coletado durante as entrevistas, principalmente ao tecer o histórico e levantar os questionamentos atuais da inclusão digital no país, optei por apresentar o conteúdo das entrevistas em quadros e mantê-las no corpo da tese. Desta maneira, tanto a leitura de sua íntegra como dos resumos comparativos que as acompanham é possível.

A temática apresentada é ampla, complexa, e se caracteriza por um processo em constante evolução. A Internet representa uma nova estrutura de relações sociais,

\footnotetext{
${ }^{7}$ Personalidades que participaram da construção dos primeiros programas de acesso comunitário, coordenaram iniciativas-piloto de inclusão digital e/ou influenciam as políticas públicas em âmbito nacional.
} 
políticas e econômicas que envolve questionamentos multidisciplinares relacionados à educação, à sociologia, às ciências sociais e políticas, à ciência da computação, à comunicação, à economia, entre outros. Além disso, medir as transformações sociais trazidas pelas novas tecnologias é uma tarefa muito difícil, que vem sendo buscada ainda sem muito sucesso por diferentes áreas acadêmicas e organizações de desenvolvimento nacionais e internacionais. Ainda que se considere temas importantes à área, não serão abordadas aqui questões como propriedade intelectual, governança na Internet, produção de conteúdo em língua portuguesa e tecnologias avançadas de comunicação, assim como não serão tratados mais demoradamente aspectos relativos à democracia, exclusão social, limites de acesso relativos a deficiências físicas, políticas públicas e educação, por extrapolarem os objetivos propostos. Os dados colhidos através de nossas entrevistas também abrem um leque de temas - como gestão e sustentabilidade de centros públicos de acesso, formação de redes sociais e cidadania que poderão ser aboradado em pesquisas futuras, mas que fugiam ao escopo deste trabalho. A contribuição deste trabalho portanto se concentra na reflexão crítica e na historicização do desenvolvimento das iniciativas de inclusão digital no país, no registro do discurso e da opinião dos atores que elaboram e promovem esse processo, e principalmente na visão dos usuários desses programas, suas realizações e limitações, oferecendo pistas para a articulação de um plano nacional que envolva políticas públicas consistentes e que alavanquem a inclusão social e o desenvolvimento do país.

Esta tese está organizada em seis capítulos. O primeiro, que constitui o quadro teórico, apresenta uma visão geral sobre a importância das TICs - sobretudo da Internet - para a participação do cidadão na "sociedade da informação" e introduz a questão da desigualdade de acesso e da exclusão digital, destacando o cenário da exclusão no mundo - e sobretudo no Brasil. Em seguida, apresenta as definições de inclusão digital e o histórico do seu desenvolvimento no país; a importância do letramento e da apropriação tecnológica para a produção de conhecimento; e sugere enfoques colaborativos para a ampliação da participação social e da cidadania digital. O segundo capítulo introduz o questionamento sobre o potencial do acesso à Internet, por meio dos CPAs, para gerar mudanças no cotidiano de comunidades excluídas, especialmente sob os pontos de vista da produção e consumo de informação; do desenvolvimento social, político e econômico; e dos investimentos públicos e privados no setor. No terceiro capítulo é apresentada a metodologia de investigação utilizada, que se concentra em um 
estudo exploratório, prioritariamente qualitativo, baseado em análise de documentos, entrevistas em profundidade e na análise das mesmas. Também foram realizadas entrevistas fechadas com usuários de CPAs, através de um questionário on-line, e um breve estudo etnográfico. O quarto capítulo traz os resultados das observações referentes às visitas aos centros públicos de acesso investigados, assim como o discurso comparado de mentores, coordenadores, monitores e usuários de CPAs sobre a contribuição da Internet para a produção e consumo de informação, e para o desenvolvimento social, econômico e político, que serão analisados no capítulo seguinte. A discussão envolve também a identificação dos diferentes interesses principalmente políticos e econômicos - por trás da inclusão digital. Considerações finais sobre a contribuição das TICs para impulsionar a participação social de cidadãos de comunidades de baixa renda e os desafios da inclusão digital são apresentados no sexto e último capítulo. 


\section{QUADRO TEÓRICO}

Anderson tem 17 anos. Trabalha como office boy em uma empresa de telefonia no centro da cidade - distante uma hora e meia de ônibus de sua casa, quando não há muito trânsito - em um daqueles bairros empobrecidos e esquecidos da metrópole. Estuda à noite, está terminando o segundo colegial em uma escola pública da vizinhança, e antes de ir para a aula, quase todo os dias, passa encontrar a turma no centro de acesso público à Internet, que fica na associação comunitária do bairro. Aproveita para dar uma olhada no e-mail e atualizar a conversa no Orkut - e de passagem, dá uma olhada nas manchetes que encontra pelo caminho. Ele navega na Internet há alguns anos, antes mesmo de freqüentar o centro público, e hoje já não pode viver sem a rede. Pela Internet ele se comunica com amigos, desenvolve novas habilidades, e acima de tudo, se diverte. Ela é a "sua porta de entrada para o mundo".

Ele é o típico usuário dessas novas "instituições" que passaram a compor, nos últimos anos, a paisagem de áreas empobrecidas dos centros urbanos de todo o país. E faz parte de um pequeno universo de 3,5\% indivíduos que freqüentam centros públicos de acesso, segundo a TIC Domicílios 2006, pesquisa sobre o uso das tecnologias da informação no Brasil realizada pelo Comitê Gestor da Internet no Brasil ${ }^{8}$. O número é extremamente pequeno face os $67 \%$ da população - quase 100 milhões de brasileiros - que nunca acessaram a rede, mas é um início. Não existem dados oficiais, mas estima-se que desde o início dos anos 2000 tenham sido instalados mais de 10 mil centros públicos de acesso - frutos de iniciativas públicas, de empresas ou de instituições do terceiro setor dispersos por quase todo o país, oferecendo, na maior parte das vezes, acesso gratuito à Internet e capacitação para o uso das novas tecnologias da informação à população. Anderson é assim um privilegiado, foi resgatado da "exclusão digital" por um dos vários "programas de inclusão digital" responsáveis por estes centros públicos, e que vêm buscando melhorar as condições de acesso e participação da comunidade de baixa renda na chamada "sociedade da informação".

As iniciativas de inclusão digital são um fenômeno que vem sendo desenvolvido em todo o mundo, estimulado pelo processo de globalização da informação e do

\footnotetext{
${ }^{8}$ Disponível em http://www.cetic.br/usuarios/tic/2006/index.htm. Acesso em 29 de janeiro de 2007.
} 
conhecimento que, além dos benefícios trazidos para o cidadão, materializa diferentes motivações de mercado, políticas e sociais. No contexto da sociedade da informação, o acesso à Internet pode assim representar tanto oportunidades para o desenvolvimento do potencial humano - para o combate à desigualdade e exclusão, temas centrais desta tese - como o fortalecimento de interesses de grupos dominantes e hegemônicos. Nesta eterna luta de titãs, a melhor opção do indivíduo é se munir destas novas ferramentas para se articular e construir - coletivamente ou não - um cotidiano mais humano.

A história da "inclusão digital" no Brasil - e no mundo - pode ser considerada como um mosaico de casos bem sucedidos e de iniciativas que, mais ou menos exitosas, representam diferentes interesses - econômicos, políticos e sociais - que se materializam na atual sociedade da informação.

Além das dificuldades sócio-econômicas, limitações cognitivas - sobretudo educacionais - dificultam a participação ativa destas comunidades na rede, principalmente no que diz respeito ao seu potencial para a produção de conteúdos, e através dela melhoria das condições de vida e influência nas decisões políticas. Estes obstáculos, assim como os benéficos trazidos pela sociedade da informação serão abordados nesta tese.

\subsection{O paradigma da sociedade da informação}

A rápida evolução das tecnologias da informação ${ }^{9}$ - especialmente a convergência das telecomunicações e da informática - vem provocando mudanças profundas na estrutura da nossa sociedade, transformando a organização do modelo econômico, a participação política e a interação social. Este novo cenário, no qual todas as atividades humanas se encontram cada vez mais dependentes das infra-estruturas eletrônicas da informação, é também conhecido como "sociedade da informação". No início dos anos 70, Daniel Bell (1973) definiu a sociedade da informação como uma sociedade na qual a informação é

\footnotetext{
${ }^{9}$ Segundo Castells (1999, p. 49), as tecnologias da informação abrangem "o conjunto convergente de tecnologias em microeletrônica, computação (software e hardware), telecomunicações/radiodifusão, e optoeletrônica".
} 
tratada como uma mercadoria, que passa a ser produzida em maior quantidade do que os bens de consumo. Mais recentemente, Manuel Castells (1999) descreve o conceito como uma forma de organização social na qual a geração, processamento e transmissão de informação se transformam na principal fonte de produtividade e poder. Para ele:

\begin{abstract}
A revolução da tecnologia da informação e a reestruturação do capitalismo introduziram uma nova forma de sociedade, a sociedade em rede. Essa sociedade é caracterizada pela globalização das atividades econômicas decisivas do ponto de vista estratégico; por sua forma de organização em redes; pela flexibilidade e instabilidade de emprego e da individualização da mão-de-obra. Por uma cultura da virtualidade real construída a partir de um sistema de mídia onipresente, interligado e altamente diversificado. E pelas transformações das bases materiais da vida - o tempo e o espaço - mediante a criação de um espaço de fluxos e de um tempo atemporal como expressões das atividades e elites dominantes (CASTELLS, 2002, p. 17).
\end{abstract}

Amplamente estudada nos últimos $\operatorname{anos}^{10}$, a sociedade da informação é genericamente compreendida como uma "ágora" de conhecimento, onde a informação estaria universalmente disponível. Mais do que isso, uma estrutura dinâmica em cujas redes a informação flui, potencializando processo produtivos, a democracia direta e a diversidade cultural - uma perspectiva, entretanto, muito distante da maior parte da população mundial: pelo menos um terço das economias em desenvolvimento tem taxas de penetração de Internet menores de 5\% ${ }^{11}$. Dowbor (2001) resume o conceito como um conjunto de transformações que estão alterando a estrutura das instituições e das relações sociais, tendo a informação e o conhecimento como eixo articulador. Nesta linha, Eisenberg e Cepik (2002) descrevem a sociedade da informação por meio de três frentes gerais: uma economia baseada no conhecimento, um novo papel das finanças e sociabilidade em rede. Este novo padrão econômico de desenvolvimento, caracterizado pelo fluxo e troca intensa - quase instantânea - de informação e de capital, está remodelando a base material da sociedade, em ritmo acelerado, apresentando uma nova forma de relação entre a economia, o Estado e a sociedade.

\footnotetext{
${ }^{10}$ Alguns autores se preocupam mais com os aspectos econômicos deste novo cenário, como Castells (1999) e Hudson (1997a, 1997b). Outros, como Melody (1991) e Tehranian (1990), exprimem sua inquietude quanto às suas consequiências políticas, enquanto Woods (1993), Hanson (1990) e Mattelart (1995) se prendem às dimensões sociais dessa verdadeira revolução tecnológica, que vêm transformando a maneira como as pessoas trabalham, estudam, se divertem ou criam seus filhos.

${ }^{11}$ Disponível em Information Economy Report 2006, UNCTAD, em http://www.unctad.org/Templates/webflyer.asp?docid=7576\&intItemID=3991\&lang=1\&mode=download s/. Acesso em 15 de janeiro de 2007.
} 
Origens da discussão - Se a porta de entrada para a sociedade da informação é a Internet $^{12}$, a infra-estrutura de telecomunicações é o insumo básico para o seu funcionamento, e muitos governos vêm demonstrando, há décadas, sua preocupação com o seu desenvolvimento. O relatório Nora e Minc (1978), é um dos primeiros documentos que mostra a importância do acesso à informação, que se transformava então em um recurso econômico, político, social e cultural indispensável para a emancipação democrática. O documento exprimia assim uma grande inquietude em relação às consequiências que a revolução tecnológica da informática e das telecomunicações poderia trazer à sociedade contemporânea, ao redesenhar a estrutura social e o sistema político francês da época. Suas preocupações focavam mais especificamente o papel que o Estado deveria ocupar para garantir uma redistribuição igualitária do conhecimento e das tecnologias, garantindo a participação do país nesse processo:

O desenvolvimento das aplicações da informática é um fator de transformação da organização econômica e social, e do modo de vida: é necessário que nossa sociedade seja capaz de, ao mesmo tempo promovê-lo e compreendê-lo, de forma a colocá-lo a serviço da democracia e o desenvolvimento humano (Nora \& Minc, 1978, p. 3, tradução livre da autora).

Efetivamente, a falta de uma infra-estrutura de telecomunicações eficiente pode representar diferentes formas de exclusão: por um lado, pode se traduzir pela dificuldade de participação de um país no processo de desenvolvimento tecnológico (MATTELART, 1996; MELODY, 1990), de outro, corresponde à exclusão social e econômica dos indivíduos que não têm acesso a essa tecnologia (SAUNDERS ET AL., 1994; WELLENIUS \& STERN, 1994). De maneira geral, os diferentes níveis de acesso dos indivíduos e dos países ao poder da tecnologia é uma fonte de desigualdade em nossa sociedade. Castells ilustra essa preocupação ao afirmar que:

Sem dúvida, a habilidade ou inabilidade das sociedades dominarem a tecnologia e, em especial, aquelas tecnologias que são estrategicamente decisivas em cada período histórico, traça seu destino a ponto de podermos dizer que, embora não determine a evolução histórica e a transformação social, a tecnologia (ou a sua falta) incorpora a capacidade de transformação das sociedades, bem como os usos que as sociedades, sempre em um processo conflituoso, decidem dar aos seu potencial tecnológico (CASTELLS, 1999, p. 26).

\footnotetext{
${ }^{12}$ A Internet é um conglomerado de redes em escala mundial de milhões de computadores interligados que permite o acesso a informações e todo tipo de transferência de dados. Chamada também de "rede" ou "a rede das redes", a Internet é a principal das tecnologias de informação e comunicação (TICs).
} 


\subsubsection{Sociedade digital e globalização}

Uma das principais características do cenário inaugurado no final dos anos 80 com a hegemonia do neoliberalismo que sobreveio ao forte simbolismo da queda do muro de Berlim e a revitalização do capitalismo como forma de organização política e econômica - é a ausência de fronteiras nacionais (IANNI, 1996). O processo de globalização carrega consigo a interdependência entre nações, tanto na produção de bens materiais como culturais, podendo ao mesmo tempo ampliar mercados e o intercâmbio de conhecimento, como concentrar riquezas e aprofundar as desigualdades entre indivíduos, e entre países. Neste contexto, Silveira (2001) afirma que "o mais importante é perceber que a apropriação e os usos dessas tecnologias, bem como controle dos fluxos de informação, são novas questões políticas e sociais” ( p. 10).

Segundo Sacristan (2001), a globalização acelera e fortalece o processo de comunicação entre culturas, ao mesmo tempo que impõe idéias e comportamentos de forma desigual entre diferentes civilizações, acentuando confrontamentos e disparidades. Principalmente porque é muito pequena a parcela da população, em diferentes países, que tem acesso aos meios de informação digital e domina o processo de produção de conhecimento, podendo assim se beneficiar da cultura digitalizada disponível na rede. Desta maneira, surge a preocupação de que somente indivíduos "incluídos" na sociedade atual, com conta no banco, trabalho e educação formal, possam usufruir as facilidades trazidas por essas tecnologias. Aqueles à margem desta sociedade, desempregados ou analfabetos funcionais, possuem poucas chances de participar da rede, e dependem de políticas inclusivas de seus governantes que viabilizem essa interação. Corremos portanto o risco de transformar uma ferramenta potencialmente inclusiva e democrática em mais um indutor da pobreza e da miséria no mundo.

\subsection{Desigualdade e exclusão}

Mesmo sendo um entusiasta da sociedade da informação, Castells (1999) reconhece que parcelas significativas da população mundial não possuem condições materiais, cognitivas ou econômicas para se conectar à rede, devido principalmente à velocidade 
do processo de difusão tecnológica, que é seletiva tanto social como funcionalmente. $\mathrm{O}$ autor afirma assim que:

A centralidade da Internet em muitas áreas da atividade social, econômica e política equivale à marginalidade para aqueles que não têm acesso a ela, ou têm apenas um acesso limitado, bem como para os que são incapazes de usá-la eficazmente [...] A diferenciação entre os que têm e os que não têm Internet acrescenta uma divisão essencial às fontes já existentes de desigualdade e exclusão social, numa interação complexa que parece aumentar a disparidade entre a promessa da Era da Informação e sua sombria realidade para muitos em todo o mundo (CASTELLS, 2003, p. 203).

A exclusão é considerada uma categoria-chave na maior parte das ciências humanas e, em seu sentido geral, vem sendo discutido há muito tempo por inúmeros autores, mais recentemente por Santos B. S. (2002), Dowbor (1999), Barroso (1996), Gentili (2001), Almeida, 2005, entre outros. No entanto, são múltiplos, diversificados, fluidos e renováveis - no tempo e no espaço - os recortes teórico-conceituais que definem a exclusão (MARTINS, 1997 e 2002). Pensar essa categoria implica em definir fronteiras do "estar" e "não estar" inserido "em algum lugar", considerando ainda o ponto de vista de quem faz essas delimitações. Desta maneira, "estar ou não excluído" depende de quem, de onde e de quando se está falando - além do fato de que é pretensamente o "incluído" quem determina aquele que "está excluído". Além disso, o conceito de "incluído" carrega consigo uma dicotomia entre o "bom" e o "ruim", deixando transparecer que os "excluídos" levam uma vida desprivilegiada, menos articulada, "pior", o que nem sempre é verdade. Brito (2005) esclarece que o conceito de exclusão pode ter um sentido absoluto - privações definitivas - ou relativo:

\footnotetext{
Embora para o senso comum as noções de inclusão e exclusão pareçam razoavelmente claras como ações, é preciso compreendê-las também como estados. [...] coexistem ações de exclusão e estados de exclusão. Com exceção dos dicionários, onde a palavra exclusão tem sentido absoluto, na Filosofia e nas outras Ciências ela quase sempre tem sentido relativo (p. $33)$.
}

De forma geral, o excluído em nossa sociedade é determinado por aspectos principalmente econômicos e sociais. Ele se transforma assim no "excluído social", aquele que convive com "uma escassez crônica de oportunidades e de acesso a serviços básicos e de qualidade, mercados de trabalho e crédito, condições físicas e infraestrutura adequada, e acesso ao sistema judicial" (BID, 2004). A inclusão social entretanto não se refere apenas à partilha adequada de bens materiais e à participação na sociedade, mas à oportunidade do indivíduo de poder transformar a sua realidade. 


\subsubsection{Exclusão digital}

Em termos gerais, a exclusão digital diz respeito à distribuição desigual dos recursos relacionados à tecnologia da informação e da comunicação entre os países ou dentro de uma mesma região. Ela pode também ser vista como uma das muitas formas de manifestação da exclusão social, considerando que o acesso às TICs - especialmente à Internet - pode ao mesmo tempo reduzir ou ampliar a problemática social. Isso porque a exclusão digital é mais uma conseqüência das desigualdades sociais, econômicas e políticas que caracterizam a distribuição de poder e renda na sociedade. Por outro lado, o acesso à Internet pode evidenciar "a capacidade que têm as pessoas de transcender metas institucionais, superar barreiras burocráticas e subverter valores estabelecidos no processo de inaugurar um mundo novo" (CASTELLS, 2003, p. 13). Esse potencial faz com que a exclusão digital caracterize-se "não apenas pelo acesso físico a computadores e à conectividade, mas também a recursos adicionais, que permitem que as pessoas utilizem a tecnologia de modo satisfatório" (WARSCHAUER, 2006, p. 21). Principalmente no contexto atual, em que empresas e governos migram cada vez mais informações e serviços para os meios eletrônicos, o excluído digital passa a ter dificuldade para conhecer e exercer seus direitos de cidadão.

O excluído digital é portanto aquele indivíduo que não dispõe de recursos materiais e também de conhecimentos para acessar, interagir, se apropriar e produzir conteúdos através da rede. As limitações que definem o excluído digital não são apenas econômicas, mas podem ser sociais, como idade ou sexo, físicas, como deficiências e necessidades especiais, ou ainda culturais, como a religiosidade, entre outros. Neste trabalho, entretanto, serão investigados unicamente os indivíduos - ou comunidades que por dificuldades sócio-econômicas de acesso à rede estão impossibilitados de participar e interagir de forma autônoma e protagonista com os recursos oferecidos pela sociedade da informação. Desta maneira, o excluído digital em questão é definido como um indivíduo de baixa renda, que mora em comunidades que convivem com uma forte exclusão social, e que conseqüentemente teve, com poucas exceções, uma trajetória educacional deficitária e limitada. 


\subsubsection{O Cenário da exclusão no mundo}

Em setembro de 2000, a Organização das Nações Unidas (ONU) reuniu em Nova Iorque líderes de 191 países na Cúpula do Milênio, encontro considerado o mais relevante do século (PORCARO, 2005). Na agenda estavam os principais desafios da humanidade, entre eles a tutela dos direitos humanos e o compromisso com o combate à fome e à pobreza. Como resultado da discussão foi adotada a Declaração do Milênio ${ }^{13}$, que estabeleceu objetivos e metas concretas a serem atingidas pelas nações signatárias até 2015. As tecnologias da informação e da comunicação assumiram um papel preponderante na discussão, como ferramenta essencial para que os objetivos estabelecidos fossem atingidos. Em dezembro de 2003, em Genebra, foi realizada a Cúpula Mundial da Sociedade da Informação (fase 1) que, com base nas Metas do Milênio, definiu um Plano de Ações para melhorar a conectividade e o acesso às TICs em todo o mundo, estabelecendo os seguintes objetivos:

- conectar povoados com as TICs e estabelecer pontos comunitários de acesso;

- conectar universidades, escolas de ensino básico e fundamental com as TICs;

- conectar centros científicos e de pesquisa com as TICs;

- conectar bibliotecas públicas, centros culturais, museus e correios e com as TICs;

- conectar centros de saúde e hospitais com as TICs;

- conectar todos os órgãos de governo, central e local:

- adaptar o currículo das escolas de ensino básico e fundamental para atender os desafios da Sociedade da Informação, levando em consideração circunstâncias nacionais;

- garantir que todos tenham acesso a serviços de televisão e rádio;

- encorajar o desenvolvimento de conteúdo local na Internet; garantir que mais da metade da população mundial tenha acesso às TICs.

Dados do Information Economy Report 2005, relatório da ONU ${ }^{14}$ publicado na véspera da segunda fase da Cúpula da Sociedade da Informação, realizada em novembro de 2005, na Tunísia, mostrava que até o final de 2004 havia 875,6 milhões de usuários de Internet no mundo, mas que a sociedade da informação ainda estava - e continua longe de ser uma realidade global, diante das grandes disparidades entre os países ricos e pobres.

\footnotetext{
${ }^{13}$ Ver a Declaração do Milênio, Metas do Milênio, Declaração de Princípios e Plano de Ação em http://www.itu.int/dms_pub/itu-s/opb/pol/S-POL-WSIS.OD-4-2006-PDF-E.pdf. Acesso em 15 de janeiro de 2007.

${ }^{14}$ Ver http://www.unctad.org/Templates/WebFlyer.asp?intItemID=3591\&lang=1/. Acesso em 29 de abril 2006.
} 
A desigualdade na distribuição de renda é o primeiro grande problema: segundo o Relatório de Desenvolvimento Humano do PNUD ${ }^{15}$ (2005), o rendimento médio dos $20 \%$ da população mundial mais rica é cerca de 50 vezes superior ao rendimento médio dos $20 \%$ mais pobres, e equivale a três quartos do rendimento global. No outro extremo, os $40 \%$ mais pobres detêm somente $5 \%$ do rendimento mundial, e correspondem aproximadamente a 2 bilhões de pessoas que vivem com menos de 2 dólares por dia.

Telefonia - No que diz respeito às telecomunicações, segundo o World Telecommunication Development Report $2006^{16}$ da União Internacional de Telecomunicações (UIT), o número de assinantes de telefonia móvel supera os de telefonia fixa desde 2002 e hoje há 1,8 bilhão de telefones móveis no mundo, praticamente um para cada três pessoas, contra 1,2 bilhão de linhas fixas (ver figura 1). Entretanto, em 2005 o celular é uma realidade para apenas 17\% da população das economias pobres, contra 77,5\% nos países ricos. Com relação à rede de telefonia fixa, na Europa os serviços de telecomunicações atingem $41 \%$ da população, nas Américas, $34 \%$, e na África somente 3\% dos indivíduos.

\section{Figura 1. Assinantes de telefonia móvel versus telefonia fixa}

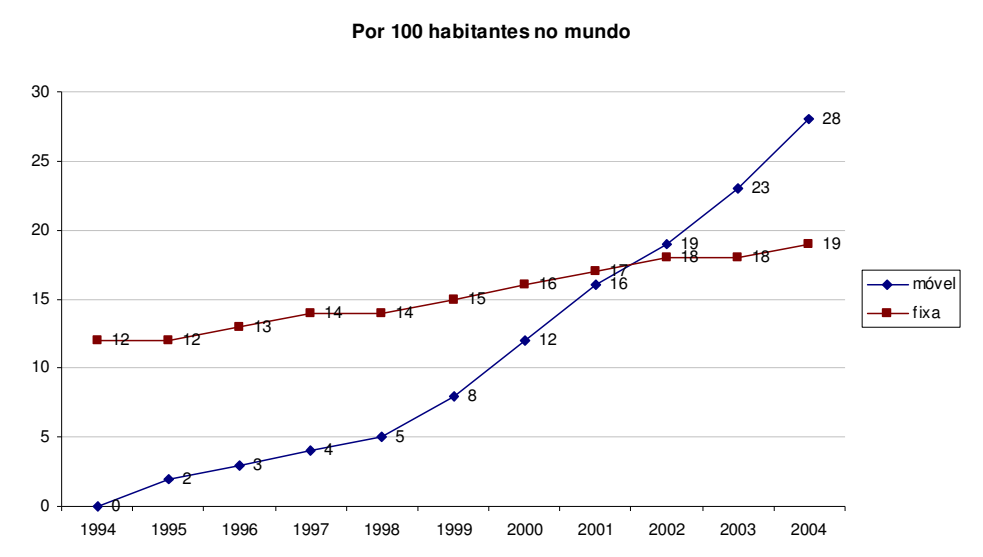

Fonte: ITU, World Telecommunication/ICT Development Report 2006

Acesso a computadores - O Information Economy Report 2005 aponta que o número de computadores no mundo também deixa clara a divisão entre ricos e pobres: em 2004, em toda a África havia 11,5 milhões de máquinas, contra 19 milhões no Brasil e 26 milhões na Coréia. Dos mais de 760 milhões de computadores existentes no mundo, 520

\footnotetext{
${ }^{15}$ Ver http://hdr.undp.org/reports/global/2004/pdf/hdr04_HDI.pdf/. Acesso em 29 de janeiro de 2007.

${ }^{16}$ World Telecommunication/ICT Development Report 2006, p.3
} 
milhões estão em países ricos. Na Suíça, 74\% da população tem computador. Na China e Índia, países conhecidos pela forte produção de equipamentos TIC para o mercado mundial, a penetração dos computadores é de apenas $2,7 \%$ e $0,7 \%$, respectivamente. A média mundial do número de PCs para cada 100 habitantes é de 12,89, sendo que na África esse total é de 1,73, enquanto na Oceania pode chegar a 50,86, pelos dados da UIT para 2005.

Figura 2. Computadores pessoais no mundo e crescimento mundial (1990-2004)

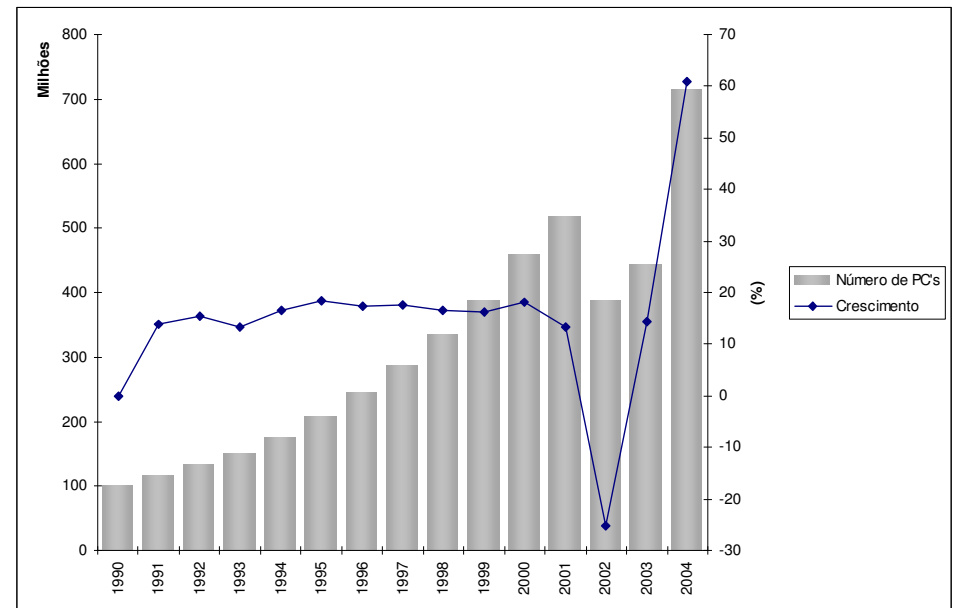

Fonte: ITU, World Telecommunication/ICT Development Report 2006

Acesso à Internet - Segundo o Information Economy Report 2005, a maior população de internautas fica nos Estados Unidos, com 185 milhões de pessoas conectadas. A China vem em segundo lugar, com 95 milhões de usuários. Na Europa, o país com o maior número de usuários é a Alemanha, com 41 milhões de pessoas conectadas. Já na América Latina, México e Brasil correspondem a $60 \%$ dos usuários. O relatório afirma ainda que os países em desenvolvimento estão fazendo um esforço importante para reduzir as diferenças tecnológicas em relação aos países ricos: em 2000, $73 \%$ das pessoas conectadas à Internet no mundo estavam nos países ricos, hoje são $57 \%$. Na China, por exemplo, apenas 7,2\% da população tem acesso à rede, embora em números absolutos o país seja o segundo do mundo. Na África, apenas 1,1\% da população está conectada, comparado à 55,7\% na América do Norte e 65\% na Coréia. 
Figura 3. Usuários Internet Mundo e crescimento mundial (1990-2004)

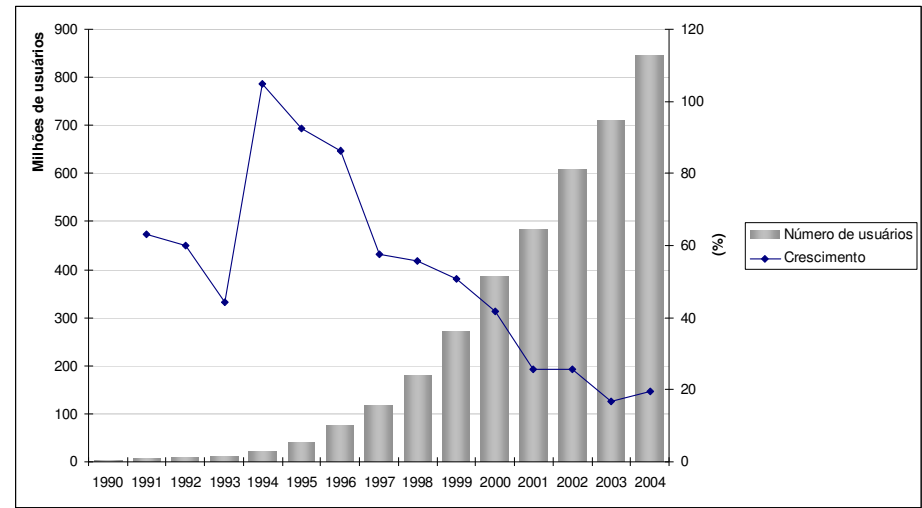

Fonte: ITU, World Telecommunication/ICT Development Report 2006

Figura 4. Indicadores médio TIC Mundo

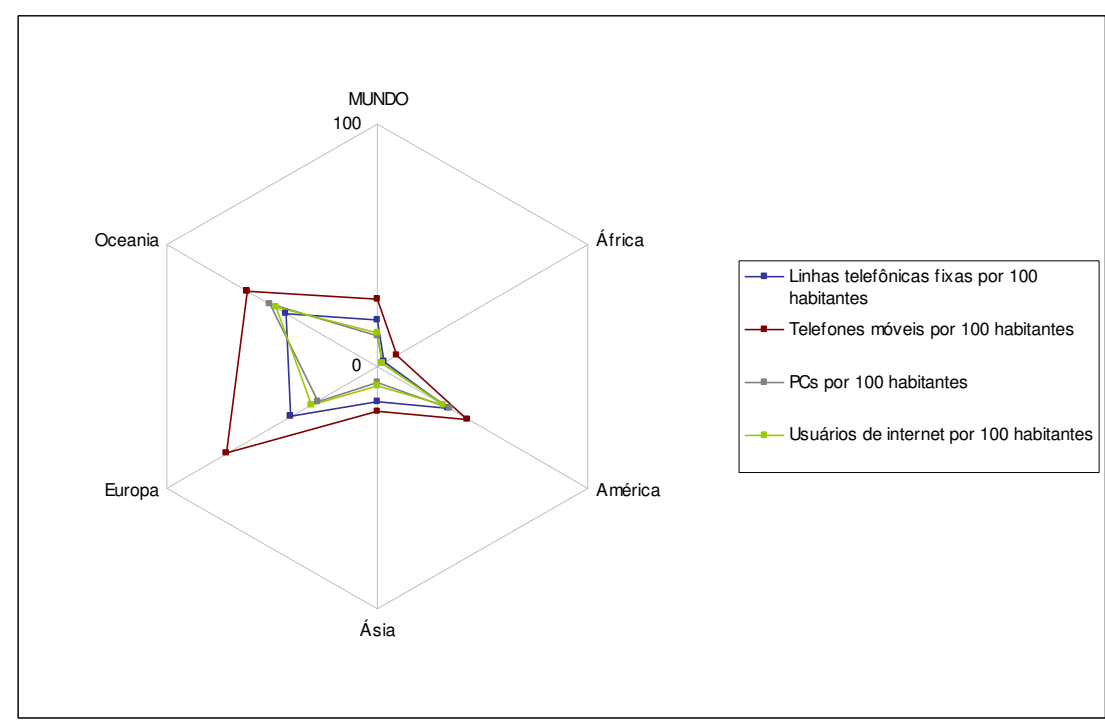

Fonte: ITU, World Telecommunication/ICT Development Report 2006

Banda larga - Outro fator importante para medir o acesso das populações às TICs é a disponibilidade de banda larga para a Internet nos países. Segundo o Information Economy Report 2005, entre 2003 e 2004, houve um crescimento de 88,2\% no número de usuários de banda larga no mundo, sendo o maior aumento se deu na África e América Latina. Mesmo assim, ainda vai levar anos para que esses países alcancem os níveis da Ásia, Europa ou América do Norte. De acordo com o documento, Coréia do Sul continua sendo o país líder no mundo em termos de penetração da banda larga: 24,6\% da população acessava a rede via conexão rápida em 2004. 


\subsubsection{O Cenário da exclusão no Brasil}

O Brasil é grande em tamanho e em contradições, e atualmente amarga a segunda pior distribuição de renda do mundo, ficando atrás apenas de Serra Leoa, segundo o estudo Radar Brasil 2005, produzido pelo Instituto de Pesquisa Econômica Aplicada do Ministério do Planejamento (IPEA, 2005, p. 60), que oferece um panorama dos principais problemas sociais do país no período de 2001 a 2003. Com uma organização social onde a classe média é muito pequena, o país está dividido em dois grupos econômicos distintos: os ricos e os pobres. O primeiro é constituído por $10 \%$ da população, que detêm $46 \%$ da riqueza do país, enquanto o segundo grupo, que representa $50 \%$ da população, detêm somente $13 \%$ da renda nacional. E a desigualdade vai além: os $10 \%$ mais pobres da população brasileira são responsáveis por apenas $0,7 \%$ do rendimento nacional, aponta o Relatório do Desenvolvimento Humano 2005 do Programa das Nações Unidas para o Desenvolvimento (PNUD).

\section{Quadro 1. Características socioeconômicas da população brasileira 2001/2005}

\begin{tabular}{|l|l|l|l|}
\hline Variável & Unidade & $\mathbf{2 0 0 1}$ & $\mathbf{2 0 0 5}$ \\
\hline População ( & milhões & $\mathbf{1 7 0 , 8}$ & $\mathbf{1 8 4 , 3}$ \\
\hline Urbana & milhões & 143,3 & 152,7 \\
\hline Rural & milhões & 27,4 & 31,6 \\
\hline Famílias & milhões & $\mathbf{5 0 , 8}$ & $\mathbf{5 3 , 4}$ \\
\hline Urbana & milhões & 43,4 & 48,5 \\
\hline Rural & milhões & 7,4 & 8,8 \\
\hline Distribuição de renda mensal familiar & & & \\
\hline Até 1 salário mínimo & $\%$ & 13 & 15 \\
\hline De 1 a 2 salários mínimos & $\%$ & 19 & 23 \\
\hline De 2 a 3 salários mínimos & $\%$ & 15 & 16 \\
\hline De 3 a 5 salários mínimos & $\%$ & 18 & 18 \\
\hline De 5 a 10 salários mínimos & $\%$ & 17 & 15 \\
\hline De 10 a 20 salários mínimos & $\%$ & 8 & 6 \\
\hline Mais de 20 salários mínimos & $\%$ & 4 & 3 \\
\hline Sem rendimento & $\%$ & 4 & 3 \\
\hline Sem declaração & $\%$ & 2 & 2 \\
\hline
\end{tabular}

Fonte: IBGE - Instituto Brasileiro de Geografia e Estatística

A pobreza atinge cerca de um terço $(31,7 \%)$ da população - 53,9 milhões de pessoas que vivem com uma renda per capita mensal de até meio salário mínimo ${ }^{17}$. E 12,9\%, ou 21,9 milhões de pessoas, são considerados indigentes, vivendo com renda domiciliar per capita de até um quarto de salário mínimo. O mais alarmante é que, diferentemente de outras nações, os elevados níveis de pobreza não estão relacionados a uma insuficiência

\footnotetext{
${ }^{17}$ Levantamento realizando em 2003, considerando que o valor nominal do salário mínimo entre abril de 2003 e abril de 2004 era de $\mathrm{R} \$ 240,00$.
} 
generalizada de recursos - o Brasil é uma das 10 maiores economias do mundo ${ }^{18}$ - mas justamente à extrema desigualdade em sua distribuição (ver quadro 1).

A desigualdade no país é preocupante, e ela se aprofunda quando consideradas as diferenças regionais e entre unidades da federação (ver figura 5). Considerando que a renda domiciliar média per capita no Brasil é de $\mathrm{R}$ \$ 360,50 (Radar Brasil, 2005, p.55), uma família no Distrito Federal conta com uma renda média mensal de $\mathrm{R} \$ 685,90$, enquanto no outro extremo, uma família maranhense vive no mesmo período com $\mathrm{R} \$$ 169,00. O levantamento mostra que as rendas mais elevadas estão nas famílias localizadas nas regiões Sudeste e Sul, com destaque para o estado de São Paulo, que apresenta uma renda domiciliar per capita média de quase dois salários mínimos, enquanto os estados do Nordeste detêm as menores médias, não ultrapassando um salário mínimo mensal por família.

\section{Figura 5. As desigualdades regionais}

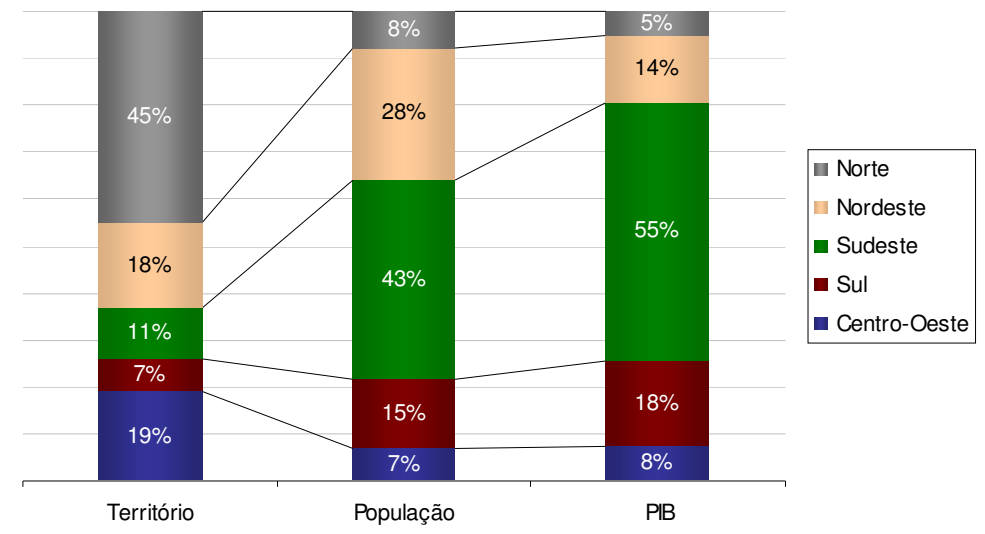

Fonte: IBGE 2005

Educação - Sobre a educação, o Radar Social 2005 aponta que 11,6\% da população é analfabeta $^{19}$, ou 14,6 milhões de pessoas com 15 anos ou mais, sendo que o índice chega

\footnotetext{
${ }^{18}$ Banco Mundial, 2006, disponível em: http://www.imf.org/external/pubs/ft/weo/2006/01/data/dbcoutm.cfm?SD=2005\&ED=2005\&R1=1\&R2=1 $\& \mathrm{CS}=3 \& \mathrm{SS}=2 \& \mathrm{OS}=\mathrm{C} \& \mathrm{DD}=0 \& \mathrm{OUT}=1 \& \mathrm{C}=223 \& \mathrm{~S}=\mathrm{NGDPD} \&$ Request Timeout $=120 \& \mathrm{CMP}=0 \& \mathrm{x}=109$ $\& y=12$. Acesso em 29 de janeiro de 2007.

${ }^{19}$ Vale ressaltar que o IBGE considera alfabetizada qualquer "pessoa capaz de ler e escrever pelo menos um bilhete simples no idioma que conhece", diferentemente da tendência atual internacional, que considera alfabetizadas somente as pessoas com 4 anos ou mais de estudos. Se a pesquisa brasileira seguisse essa tendência, o número poderia chegar a 30 milhões de analfabetos (cf. INEP, s.d., p. 9, disponível em http://www.inep.gov.br/download/estatisticas/analfabetismo2003/Analfabetismo.zip. Acesso em 29 de janeiro de 2007).
} 
a $26 \%$ entre indivíduos que moram nas regiões rurais. Assim como a desigualdade de renda, as maiores taxas de analfabetismo se encontram nas regiões Nordeste $-17,5 \%$ da população maranhense é analfabeta, enquanto a média nacional é de 5,7\%, e no Rio de Janeiro e Distrito Federal esse total é de cerca de 3\%. O estudo mostra ainda que as taxas de analfabetismo são muito maiores entre adultos com mais de 40 anos $(19,9 \%)$, e chega a 48,2\% entre idosos com mais de 75 anos, o que resulta do limitado acesso dessas gerações à educação formal no passado. A escolaridade média no país é de apenas 6,4 anos de estudo, abaixo do nível obrigatório de oito anos. Nas regiões urbanas metropolitanas, a média de estudo atinge o nível obrigatório, mas nas áreas rurais, o índice cai pela metade - lembrando que a população urbana no Brasil equivale a cinco vezes a população rural (ver quadro 1). De acordo com o IBGE, mais de $80 \%$ dos 180 milhões de brasileiros vivem em grandes cidades que se concentram na parte sul do país, sobretudo na região sudeste.

Exclusão digital no Brasil - A exclusão digital acompanha o cenário de exclusão social no país, fazendo com que a população de regiões mais ricas, próximas aos centros urbanos, com nível de escolaridade mais alta e mais jovem tenha mais acesso à infraestrutura de telecomunicações e aos serviços de Internet.

Mesmo chegando a quase todos os municípios e localidades do país ${ }^{20}$, a rede de telefonia fixa nacional está presente em apenas 48,1\% dos domicílios brasileiros (IBGE, 2005). Segundo dados da Agência Nacional de Telecomunicações (Anatel), o país apresentava em setembro de 2005 uma densidade telefônica de 28,72 linhas para cada 100 habitantes, número bem maior do que as 11,5 linhas por 100 habitantes registradas em 1997, um ano antes da privatização do Sistema Telebrás, ocorrida em 29 de julho de 1998, mas ainda muito aquém dos países desenvolvidos, onde os números estão próximos dos 40 telefones por 100 habitantes $^{21}$.

A rede de telefonia móvel está em franca expansão no país, e praticamente duplicou entre 2003 e 2005, chegando a 81,24 milhões de acessos instalados em 2.958 cidades brasileiras em setembro de 2005, segundo dados da Anatel. Entretanto, sua cobertura

\footnotetext{
${ }^{20}$ Ver Atlas Brasileiro de Telecomunicações 2006, Editora Teletime.

${ }^{21}$ World Telecommunication/ICT Development Report 2006.
} 
ainda deixa a desejar - existem 2.603 municípios sem serviços móveis, principalmente nas áreas rurais, sendo que somente $33 \%$ das cidades do Nordeste são atendidas por uma operadora móvel. De acordo com os dados do Atlas Brasileiro de Telecomunicações 2006, nas cidades atendidas concentram-se $88 \%$ da população brasileira, ou cerca de $93 \%$ da população urbana. Pelos dados do IBGE, 59,3\% dos domicílios brasileiros possuíam acesso a telefones móveis em 2005, sendo que o número de residências que contam somente com o celular passou de 7,8\% para $23,6 \%$ em quatro anos.

\section{Quadro 2. Percentual de municípios com serviço de telefonia móvel no Brasil

\begin{tabular}{|l|l|}
\hline & $\begin{array}{l}\text { Municipios cobertos por redes } \\
\text { celulares - 2005 }\end{array}$ \\
\hline Região do país & \\
\hline Norte & $45 \%$ \\
\hline Nordeste & $33 \%$ \\
\hline Sul & $64 \%$ \\
\hline Sudeste & $66 \%$ \\
\hline Centro-oeste & $65 \%$ \\
\hline Total Brasil & $\mathbf{5 3 \%}$ \\
\hline
\end{tabular} \\ Fonte: Atlas Brasileiro de Telecomunicações 2006}

No que diz respeito à infra-estrutura de banda larga, essencial para o acesso pleno à Internet no país, somente 1.606 municípios contam com algum tipo de acesso em alta velocidade à Internet - total considerado elevado, se considerarmos que em 2003 haviam apenas 251 cidades com esse serviço disponível ${ }^{22}$. A penetração de banda larga no país é de 6,7\%, ou seja, 3,32 milhões de assinantes para pouco mais de 50 milhões de domicílios - número extremamente baixo se comparado com a Coréia do Sul, onde o percentual chega a 25,58 .

Acesso ao computador e à Internet - A exclusão digital no Brasil é aguda. Segundo pesquisa do Comitê Gestor da Internet no Brasil2², em 2006 somente 19,6\% do total de domicílios possui computador e 14,5\% acesso à Internet ${ }^{24}$. Entretanto, a penetração dos equipamentos e serviço nas residências de classe $\mathrm{D}$ e E é de 2,8\% e 1,6\%, respectivamente, enquanto na classe $\mathrm{A}$, os percentuais saltam para $86 \%$ e $81,5 \%$, respectivamente (ver quadro 3). Ao mesmo tempo, 54,3\% da população nunca usou um computador e $66,7 \%$ nunca navegou na Internet (ver quadro 4). A maior barreira ao

\footnotetext{
${ }^{22}$ Segundo o Atlas Brasileiro de Telecomunicações 2006, p. 122.

${ }^{23}$ Pesquisa Sobre o Uso das Tecnologias da Informação e Comunicação no Brasil 2006. Disponível em http://www.cetic.br/usuarios/tic/2006/index.htm. Acesso em 29 de janeiro de 2007.

${ }^{24}$ Considerado somente o acesso à Internet via computador de mesa (desktop) ou computador portátil (laptop e notebook).
} 
acesso desses indivíduos à Internet se dá pela falta de computador, motivo apontado por $67,5 \%$ dos entrevistados, e $31,7 \%$ devido ao custo da conexão.

\section{Quadro 3. Penetração de computadores e Internet em domicílios}

Percentual sobre o total de domicílios

\begin{tabular}{|c|c|c|c|}
\hline \multicolumn{2}{|l|}{ Percentual (\%) } & Computador & Internet \\
\hline \multicolumn{2}{|l|}{ Total } & 19,63 & 14,49 \\
\hline \multirow{4}{*}{ Classe social } & A & 86,02 & 81,49 \\
\hline & $\mathrm{B}$ & 63,17 & 51,22 \\
\hline & $\mathrm{C}$ & 18,81 & 12,10 \\
\hline & $\mathrm{DE}$ & 2,83 & 1,61 \\
\hline \multirow{4}{*}{ Localização do Domicílio } & Localizado em uma favela & 9,06 & 7,29 \\
\hline & Conjunto Habitacional & 21,88 & 14,87 \\
\hline & Localizado próximo a uma favela & 17,34 & 13,09 \\
\hline & Não há favela próxima & 21,55 & 16,10 \\
\hline \multirow{5}{*}{ Regiões do país } & Sudeste & 24,19 & 81,00 \\
\hline & Nordeste & 8,50 & 94,37 \\
\hline & Sul & 24,63 & 83,07 \\
\hline & Norte & 10,39 & 93,79 \\
\hline & Centro-oeste & 18,88 & 86,88 \\
\hline
\end{tabular}

* Base: 10.510 domicílios entrevistados. Pesquisa realizada em julho/agosto 2006. Fonte: CGI.br

Pessoas da classe A que têm computador em casa têm 22,17 vezes mais chance de acessar a Internet do que as outras categorias; do outro lado estão as pessoas das classes $\mathrm{D}$ e $\mathrm{E}$, que mesmo possuindo computadores apresentam 6,25 menos chances do que as outras de ter acesso.

\section{Quadro 4. Penetração de computadores e Internet por indivíduos}

Percentual sobre o total da população*

\begin{tabular}{|c|c|c|c|}
\hline \multicolumn{2}{|l|}{ Percentual } & Computador & Internet \\
\hline \multicolumn{2}{|l|}{ Total } & 45,65 & 33,32 \\
\hline \multirow{5}{*}{ Regiões do país } & Sudeste & 49,22 & 36,89 \\
\hline & Nordeste & 34,06 & 22,41 \\
\hline & Sul & 48,53 & 36,19 \\
\hline & Norte & 41,79 & 25,54 \\
\hline & Centro-Oeste & 50,72 & 38,94 \\
\hline \multirow{2}{*}{ Sexo } & Masculino & 48,53 & 36,03 \\
\hline & Feminino & 43,06 & 30,88 \\
\hline \multirow{6}{*}{ Faixa etária } & De 10 a 15 anos & 72,00 & 46,47 \\
\hline & De 16 a 24 anos & 73,17 & 58,83 \\
\hline & De 25 a 34 anos & 56,68 & 42,88 \\
\hline & De 35 a 44 anos & 35,10 & 23,79 \\
\hline & De 45 a 59 anos & 18,67 & 12,50 \\
\hline & De 60 anos ou mais & 5,58 & 3,21 \\
\hline \multirow{4}{*}{ Grau de Instrução } & Analfabeto/ Educação infantil & 12,05 & 5,67 \\
\hline & Fundamental & 43,64 & 27,86 \\
\hline & Médio & 71,37 & 53,06 \\
\hline & Superior & 93,96 & 86,95 \\
\hline \multirow{4}{*}{ Classe social } & $\mathrm{A}$ & 96,57 & 95,08 \\
\hline & $\mathrm{B}$ & 81,12 & 72,29 \\
\hline & $\mathrm{C}$ & 54,04 & 38,85 \\
\hline & DE & 23,41 & 12,23 \\
\hline \multirow{4}{*}{ Localização do domicílio } & Localizado em uma favela & 34,10 & 20,12 \\
\hline & Conjunto Habitacional & 47,42 & 36,78 \\
\hline & Localizado próximo a uma favela & 44,94 & 33,11 \\
\hline & Não há favela próxima & 44,94 & 64,95 \\
\hline
\end{tabular}

* Base total: 10.510 entrevistados. Pesquisa realizada em julho/agosto 2006. Fonte: CGI.br 
Do total de usuários de Internet nos três meses anteriores à pesquisa, 40,04\% realizaram o acesso de casa, $24,40 \%$ do trabalho, $30,10 \%$ de lanhouses, e somente $3,49 \%$ utilizaram um centro público de acesso gratuito. No total de domicílios entrevistados, $36,03 \%$ dos homens declararam usar Internet, contra 30,88\% do sexo feminino. As principais atividades realizadas $^{25}$ (ver quadro 5) na Internet por esses usuários estão relacionadas à comunicação $(78,18 \%)$, busca de informações e serviços on-line $(75,36 \%)$, lazer $(70,84 \%)$ e educação $(64,39 \%)$, conforme está apresentado no quadro abaixo:

\section{Quadro 5. Atividades realizadas na Internet}

Percentual sobre o total de respondentes que utilizaram a Internet nos últimos 3 meses*

\begin{tabular}{|c|c|c|c|c|c|c|}
\hline \multicolumn{2}{|l|}{ Percentual } & Lazer & Comunicação & $\begin{array}{l}\text { Busca de } \\
\text { informações }\end{array}$ & Educação & $\begin{array}{l}\text { Serviços } \\
\text { financeiros }\end{array}$ \\
\hline \multicolumn{2}{|l|}{ Total } & 70,84 & 78,18 & 75,36 & 64,39 & 16,65 \\
\hline \multirow{2}{*}{ Sexo } & Masculino & 75,65 & 78,60 & 75,16 & 60,63 & 17,76 \\
\hline & Feminino & 65,72 & 77,74 & 75,57 & 68,39 & 15,46 \\
\hline \multirow{4}{*}{ Faixa etária } & De 10 a 15 anos & 84,89 & 71,97 & 56,80 & 74,03 & 1,94 \\
\hline & De 16 a 24 anos & 74,04 & 85,01 & 76,19 & 69,44 & 13,11 \\
\hline & De 45 a 59 anos & 57,75 & 75,93 & 78,53 & 45,96 & 25,55 \\
\hline & De 60 anos ou mais & 56,28 & 87,17 & 66,58 & 34,40 & 18,51 \\
\hline \multirow{3}{*}{$\begin{array}{l}\text { Grau de } \\
\text { instrução }\end{array}$} & Analfabeto/ Educação infantil & 78,81 & 66,63 & 57,34 & 59,33 & 3,19 \\
\hline & Fundamental & 76,62 & 71,80 & 62,12 & 61,56 & 5,95 \\
\hline & Médio & 68,74 & 77,02 & 77,01 & 60,07 & 15,44 \\
\hline Classe social & $\overline{\mathrm{DE}}$ & 68,56 & 70,95 & 65,72 & 63,79 & 6,89 \\
\hline \multirow{4}{*}{$\begin{array}{l}\text { Localização } \\
\text { do domicílio }\end{array}$} & Localizado em uma favela & 70,54 & 73,72 & 77,70 & 62,59 & 12,84 \\
\hline & Conjunto Habitacional & 66,90 & 78,69 & 73,43 & 65,16 & 16,35 \\
\hline & Localizado próximo a uma favela & 72,68 & 75,07 & 67,60 & 57,83 & 10,87 \\
\hline & Não há favela próxima & 71,13 & 78,99 & 77,32 & 65,78 & 18,28 \\
\hline
\end{tabular}

*Base: 2.924 entrevistados que utilizaram a Internet nos últimos três meses. Pesquisa realizada em julho/agosto 2006. Fonte: CGI.br.

\subsection{Inclusão digital}

O uso efetivo do computador, das demais ferramentas de tecnologia da informação e do acesso à Internet para incluir digitalmente as populações marginalizadas, de baixa renda, pode fazer toda a diferença neste início de século. Mas o que vem a ser inclusão digital? A preocupação em relação ao conceito se origina da discussão sobre o serviço universal, ou seja, basicamente o acesso às redes de comunicação, tratada amplamente

\footnotetext{
${ }^{25}$ http://www.nic.br/indicadores/usuarios/rel-int-09.htm. Acesso em 29 de janeiro de 2007.
} 
por autores como Hills (1993), Petrazzini (1995) e Hudson (1997). Segundo Garnham (1997), o conceito de serviço universal - também denominado acesso universal ou universalização do acesso - nasceu nos Estados Unidos, no início do século passado, cunhado por Theodore Vail, então presidente da AT\& $\mathrm{T}^{26}$, ao convencer o governo norte-americano na época que o monopólio seria mais eficiente para a expansão dos serviços de telecomunicações. Em outros países, sobretudo nos europeus, a definição de serviço universal não foi objeto de discussão até o início dos anos 80, com a chegada da liberalização no setor (OECD, 1991), dado que a rede de telecomunicações até então era controlada por empresas estatais, e a oferta do serviço de telefonia básica para a população - enquanto serviço público - era considerada uma obrigação do governo para com seus cidadãos, portanto prescindia de regulação pelos princípios do serviço universal.

Com o início das privatizações no setor de telecomunicações, a universalização do acesso passou a ser considerada uma garantia de que o mercado se responsabilizaria por estender os serviços básicos de telefonia para regiões afastadas e pessoas de baixa renda (PISCIOTTA, 1997; GARNHAM, 1997). Ao mesmo tempo, o paradigma da sociedade da informação, definido em meados dos anos 90, transformou a infra-estrutura de telecomunicações em principal distribuidora de bens e serviços, fazendo com que o valor econômico do acesso universal aumentasse na seguinte lógica: quanto maior o número de pessoas conectadas à rede, maior o mercado de consumo.

Com a evolução da temática, que migrou da questão do acesso à rede para o potencial da rede como ferramenta de desenvolvimento - processo no qual a capacitação e apropriação por parte do usuário se tornam imprescindíveis -, o conceito usado passou a ser o de "inclusão digital" (COMPAINE, 2001). O termo faz referência ao conceito de "digital divide", que em português poderia ser traduzido como "brecha digital", ou a defasagem (hiato) que existe entre aqueles que podem se beneficiar das tecnologias digitais e os que não podem ${ }^{27}$. Suas origens também remontam à teoria do "Knowledge Gap Hypothesis" (Hipótese da Lacuna de Conhecimento), formulada por Tichenor, Donohue e Olien, professores da Universidade de Minnesota, na década de 1970,

\footnotetext{
${ }^{26}$ American Telephone \& Telegraph Company, maior empresa de telecomunicações dos Estados Unidos.

${ }^{27}$ Ver http://www.itu.int/ITU-D/digitaldivide/
} 
conforme conta Ricardo Kobashi em sua coluna Cidadão Digital, publicada no Jornal “O Estado de São Paulo" de 3 de maio de 2005².

Segundo eles, a capacidade que uma pessoa tem de receber, compreender e assimilar conhecimento depende do seu conhecimento anterior, das redes sociais de que participa e do nível de exposição aos diferentes meios de comunicação. Pobres de informação tendem a ser cada vez mais pobres; e ricos em informação, cada vez mais ricos, gerando uma polarização crônica na sociedade. Vinte anos depois, a sociedade americana começou a notar que os moradores das regiões rurais do país tinham um nível de acesso às tecnologias da informação e comunicação (TICs) mais baixo que as populações dos centros urbanos. Estudos indicaram que essa diferença tinha reflexos na capacidade de geração de riqueza. A explicação estaria nas facilidades ou dificuldades encontradas para tirar proveito dos benefícios que a sociedade da informação ofereceria. Concluíram que essa diferença deveria ser tratada e a chamaram de 'digital divide' (brecha digital). Daí para reconhecer que também havia uma brecha digital entre os ricos e pobres do mundo, onde quer que eles estivessem, foi um pulo. Os primeiros projetos de inclusão digital foram lançados, e o mundo parecia estar de acordo que mais tecnologia é melhor do que menos (KOBASHI, 2005).

O conceito de inclusão digital parece se adaptar a diferentes cenários e a evoluir com o tempo, de acordo com os desafios que se apresentam à sociedade. Warschauer (2002), por exemplo, critica a divisão binária da sociedade entre aqueles que têm acesso à Internet e aqueles que não têm, ou a divisão entre os ricos em informações e os pobres em informação, definições muito comum para a brecha digital na literatura norteamericana e nos relatórios produzidos por agências de desenvolvimento internacional. Para ele o conceito é mais amplo, envolvendo o tema da inclusão social de populações excluídas mediante o uso das novas tecnologias digitais. Resnick (2001) também enfatiza que o acesso à informação não é suficiente, e defende a importância da fluência tecnológica para garantir que o aprendiz saiba como construir significados através do uso ferramentas digitais.

Amadeu (2003, p. 33) compreende a inclusão digital como a "universalização do acesso ao computador conectado à Internet, bem como, ao domínio da linguagem básica para manuseá-lo com autonomia”. E Delgadillo et al. (2002) completam, afirmando que inclusão digital envolve "a apropriação social das novas tecnologias digitais para atender às necessidades das comunidades, para promover a formulação de políticas públicas, a criação de conhecimentos, a elaboração de conteúdos apropriados e o fortalecimento das capacidades das pessoas" (p. 7). Nesse sentido também é significativo observar que o conceito de exclusão digital como decorrência da exclusão

\footnotetext{
${ }^{28}$ Ver artigo "Tecnologia a serviço da inclusão social - 2/5/2005 - Jornal OESP”. Disponível em http://www.link.estadao.com.br/index.cfm?id_conteudo=3568/ Acesso em 30 de junho de 2006.
} 
social $^{29}$ direciona a questão para a urgência de políticas compensatórias - que promovam maior acesso à educação formal e ampliem a distribuição de renda - e conseqüentemente para a compreensão da inclusão digital como um direito do cidadão, sujeita a políticas públicas específicas. Schwartz (2003 [s.p]) enfatiza assim que, “a construção de novas mídias, de um novo sistema de comunicação social no país, representa uma oportunidade única de redesenhar o pacto de solidariedade nacional em nome do interesse público, do desenvolvimento econômico e social de longo prazo e da defesa intransigente da democracia como valor universal".

\subsubsection{Centros públicos de acesso}

Em todo o mundo, a exclusão digital vem sendo combatida através da criação de centros público de acesso, também conhecidos no Brasil como telecentros e infocentros, que oferecem acesso a tecnologias da comunicação como telefonia, computadores e Internet (REINHARD e MACADAR, 2002). Não existe um consenso quanto à definição de telecentros. O Programa Sociedade da Informação da Comissão Econômica para América Latina e Caribe (CEPAL) adota o conceito de "facilidades de acesso a TIC comunitárias, governamentais ou subsidiadas que fornecem acesso a vários recursos de comunicação e serviços TIC" ${ }^{30}$. Para Macadar (2004, p. 31) a definição mais adequada é a de: "espaço físico que provê acesso público [e compartilhado] às TICs para pessoas que têm pouca ou nenhuma oportunidade de usar ou aprender a usar estas tecnologias".

Em sua grande maioria, os centros públicos que fornecem acesso gratuito à rede são resultado de políticas públicas do governo federal, estadual e municipal, muitas vezes em parceria com entidades do terceiro setor e empresas privadas. Eles podem ser implantados em escolas, centros culturais ou prédios públicos, organizações comunitários ou ONGs. Existem também centros públicos de acesso pago ou lanhouses, um modelo de negócio que se tornou muito comum em países da América Latina, e que nos últimos anos vêm se mostrando um fenômeno no Brasil.

\footnotetext{
${ }^{29}$ Vale lembrar que a exclusão é tratada nesta tese como produto direto da exclusão social, mas que essa exclusão digital pode ter outros vieses como a idade, as condições mentais, a religiosidade, etc.

${ }^{30}$ Ver http://www.eclac.cl/socinfo/osilac/
} 
Reinhard (2006, no prelo), estabelece três categorias de telecentros:

- o telecentro comunitário, implementado e coordenado normalmente pelo governo, operado por líderes comunitários, e instalado em centros comunitários, oferecendo principalmente acesso gratuito e cursos de letramento digital;

- o telecentro operado (unicamente) pelo governo, instalado em prédios públicos ou centros de serviço público, oferecendo serviços de governo eletrônico e email, principalmente para trabalhadores e adultos;

- e o telecentro de propósitos especiais, mantido pelo governo, entidades de terceiro setor e doadores privados, localizados em escolas, programas de desenvolvimento social, prisões, etc, cujo uso é referente aos propósitos da organização onde está instalado.

O foco deste estudo são os centros públicos de acesso (CPA) denominados por Reinhard como telecentros comunitários ou telecentros operados unicamente pelo governo, independente das denominações diferenciadas que os mesmos possuem localmente.

Segundo Delgadillo et al., (2002), os telecentros comunitários são iniciativas que se preocupam em utilizar as tecnologias digitais como instrumentos para o desenvolvimento humano em uma comunidade. "Sua ênfase é o uso social e a apropriação das ferramentas tecnológicas em função de um projeto de transformação social para melhorar as condições de vida das pessoas" (p. 8). Essa forma de aplicação das novas tecnologias caracteriza para Warschauer (2006) o conceito de informática comunitária, que vem a ser:

\footnotetext{
A perspectiva de que a TIC pode fornecer um conjunto de recursos e ferramentas que os indivíduos e as comunidades podem utilizar, inicialmente, para fornecer acesso à administração e ao processamento das informações, e, depois, para ajudar os indivíduos e as comunidades a perseguir objetivos relativos ao desenvolvimento local, a assuntos culturais, ativismo cívico e iniciativas baseadas na comunidade (p. 220).
}

Nestes espaços, portanto, a tecnologia e a conectividade são importantes, mas não suficientes. A formação de facilitadores ou "monitores" é fundamental não só para introduzir os aspectos técnicos aos usuários, mas para ajudar na identificação de problemas e oportunidades de usos estratégicos das tecnologias digitais para a mudança social. Os telecentros comunitários são considerados assim locais de encontros e intercâmbio, espaços de aprendizagem, no qual se é possível discutir os usos da 
tecnologia, para que os usuários possam tirar o melhor proveito dessas novas ferramentas.

O potencial e a viabilidade dos centros públicos de acesso é um tema complexo, que inclui aspectos de gestão, sustentabilidade, financiamento e informática comunitária, como é possível observar na trajetória das experiências de inclusão digital no Brasil.

\subsubsection{Histórico da inclusão digital no Brasil}

Desde o Governo Fernando Henrique Cardoso (FHC) a universalização do acesso às novas tecnologias da informação e da comunicação vem sendo apresentada como uma prioridade para o governo brasileiro, manifestada inicialmente através dos objetivos estabelecidos durante a privatização do Sistema Telebrás, na Lei Geral de Telecomunicações e em seu Plano de Metas de Universalização (BALBONI, 1999). Entretanto, nesse primeiro momento, a "inclusão digital" foi compreendida como o simples acesso aos serviços de telecomunicações, esforço que se efetivou através do crescimento do número de telefones fixos e posteriormente da explosão do número de celulares, mas não atendeu às necessidades de acesso à informação da população. Isso porque, mesmo nesta concepção simplista de inclusão digital, focada no acesso à infraestrutura, o custo do computador, da conexão Internet e até mesmo do pulso telefônico, eram - e continuam sendo - proibitivos para as comunidades de baixa renda. Nesse sentido é interessante observar que as classes menos privilegiadas têm encontrado diferentes estratégias para o uso econômico do celular, seja utilizando o equipamento apenas para receber chamadas ou estabelecendo um gasto fixo com o serviço, através dos pré-pagos. Estratégias difíceis de serem utilizadas no acesso à Internet, por exemplo.

Destaca-se nesse período a instituição do Fundo de Universalização dos Serviços de Telecomunicações (FUST), através da Lei No 9.998, de 17 de agosto de 2000, que recolhe $1 \%$ da receita operacional bruta das concessionárias de telefonia para aplicação em programas e atividades que relacionadas à universalização da infra-estrutura de telecomunicações brasileira. Entretanto estes recursos, que atualmente ultrapassam os 
R\$ 4 bilhões ${ }^{31}$, nunca foram utilizados e continuam no caixa do Tesouro Nacional. Muitas propostas para a utilização dos recursos foram apresentadas, mas limitações na Lei, falta de flexibilidade na aplicação dos recursos, impasses nos governos, problemas na formulação de editais e muitos debates inconclusos ainda não viabilizaram a aplicação dos mesmos (STANTON, 2002 ${ }^{32}$ e MIRANDA, 2003). Afonso (2004) chega a prever que "esse dinheiro possa ser simplesmente absorvido pelo orçamento geral da União para necessidades consideradas 'mais urgentes".

Em 15 de dezembro de 1999, o lançamento do Programa Sociedade da Informação (SocInfo) pelo Ministério da Ciência e Tecnologia (MCT) foi um marco na discussão da evolução da Internet e suas aplicações para o desenvolvimento do país. Mesmo que ainda centrado na questão da infra-estrutura e da universalização do acesso, o programa - constituído por um amplo conjunto de iniciativas em diversas áreas, e com ações integradas das diferentes esferas do poder público, da iniciativa privada e do terceiro setor - foi a primeira iniciativa de se estabelecer "um projeto estratégico, de amplitude nacional, para integrar e coordenar o desenvolvimento e a utilização de serviços avançados de computação, comunicação e informação e suas aplicações na sociedade" (TAKAHASHI, 2000). O SocInfo fazia parte do Plano Plurianual 2000-2004, com investimentos previstos de $\mathrm{R}$ \$ 3,4 bilhões, em quatro anos, para colocar o país em condições de operar a Internet com todos os requisitos técnicos já existentes nos países mais avançados, tanto no que diz respeito à velocidade de transmissão de dados, quanto a novos serviços e aplicações ${ }^{33}$, assim como democratizar o acesso da população às tecnologias da informação e contribuir para o incremento da competitividade do país no mercado global. Neste sentido, o lançamento do conhecido "Livro Verde", em outubro de 2000, representou a consolidação de um amplo debate reunindo mais de 150 especialistas que, ao longo de 13 meses, discutiram temas como: "Mercado, trabalho e oportunidades", "Universalização de serviços e formação para a cidadania", "Educação na sociedade da informação", "Conteúdos e identidade cultural”, "Governo ao alcance de todos", "Pesquisa e desenvolvimento, tecnologias-chave e aplicações", e "Infraestrutura avançada e novos serviços”. O programa foi responsável ainda pelo

\footnotetext{
${ }^{31}$ Ver http://www.oppi.org.br/apc-aainfoinclusao/infoinclusao/busca_results.shtml? $\mathrm{x}=1267$ \&slice_id=28c0788efe23f406d0fb3502b147f3e7/. Acesso em 5 de janeiro de 2007.

${ }^{32}$ Ver http://www.rnp.br/noticias/imprensa/2002/not-imp-020120.html/. Acesso em 5 de janeiro de 2007.

${ }^{33}$ Mais informações em http://ftp.mct.gov.br/temas/Socinfo/default.asp. Acesso em 15 de janeiro de 2007.
} 
lançamento do "Livro Branco", com o plano de ações e a explicitação de mecanismos de execução para um período de cinco anos. Com a mudança de governo em 2003, entretanto, o programa foi sendo esvaziado e hoje se encontra desativado.

Também se destaca neste período a implementação do Programa Nacional de Informática na Educação (PROINFO), iniciativa pioneira para a promoção do uso das TICs em escolas públicas de ensino médio e fundamental ${ }^{34}$. Criado em abril de 1997 pelo Ministério da Educação - e ainda em funcionamento -, o programa já foi responsável pela instalação de laboratórios de informática em mais de 52 mil escolas públicas. Cabe observar que em muitos casos os laboratórios permaneceram fechados por muitos anos devido à falta de capacitação adequada a professores e funcionários que cuidam dos equipamentos. Aqui é importante observar que as escolas que conseguem montar laboratórios de informática geralmente não têm pessoal nem verbas suficientes para manutenção, atualização e acompanhamento das atividades cotidianas.

Ainda durante o mandato de FHC, no início dos anos 2000, o Governo - em suas diferentes esferas -, passou a implementar um conjunto de iniciativas de inclusão digital, envolvendo a própria administração pública, a sociedade civil e o setor privado, com destaque para a disponibilização de serviços de governo eletrônico para a população. Orientado pelas metas do programa SocInfo, o governo federal lançou, em 3 de abril de 2000, o projeto interministerial de Governo Eletrônico Brasileiro ${ }^{35}$, gerido pelo Comitê Executivo do Governo Eletrônico (CEGE), com o objetivo de coordenar, estabelecer diretrizes e articular as ações de implementação destas novas formas eletrônicas de interação com o cidadão. Nesta época foram criados os primeiros programas públicos de inclusão digital ${ }^{36}$ - estaduais e municipais - com o objetivo de oferecer acesso gratuito à Internet no país: os telecentros comunitários do Digitando o Futuro, mantido pela prefeitura de Curitiba, os infocentros do Acessa São Paulo, iniciativa do governo do Estado de São Paulo, os Telecentros de Porto Alegre, e o Sampa.org, programa criado

\footnotetext{
${ }^{34}$ Mais informações em http://portal.mec.gov.br/seed/index.php?option=content\&task=view\&id=136\&Itemid=273/. Acesso em janeiro de 2007.

${ }_{35}$ Mais informações em http://www.governoeletronico.gov.br/.

${ }^{36}$ Não foram consideradas aqui as iniciativas do terceiro setor em parcerias com empresas como o Comitê para a Democratização da Informática (CDI), que iniciou suas atividades em 1995 oferecendo cursos de informática para a população de baixa renda, ou o Garagem Digital, iniciativa da HP Brasil em parceria com a Fundação Abrinq, da Cidade Escola Aprendiz e da Associação Meninos do Morumbi, que desde 1996 já atendeu mais de 4 mil através de atividades culturais e de cidadania.
} 
pelo Instituto de Políticas Públicas Florestan Fernandes, que inspirou o Telecentros São Paulo e posteriormente foi incorporado ao projeto da prefeitura.

A inclusão digital no Governo Lula - Desde o início do Governo Luis Inácio Lula da Silva, em 2003, a inclusão digital - termo que substituiu a universalização do acesso no discurso público nacional - passou a ser anunciada como uma dos principais insumos para o desenvolvimento do país, e ganhou destaque na mídia. A estratégia de inclusão digital adotada pelo governo federal reúne diversas iniciativas ministeriais e interministeriais que, com alguma articulação entre si, obtiveram resultados significativos, mas ainda inexpressivos diante do tamanho da exclusão digital brasileira. Tratarei a seguir de algumas destas iniciativas ${ }^{37}$, com o objetivo de desenhar o cenário atual das políticas públicas de inclusão digital no país - identificando a falta de um plano nacional de inclusão digital que integre esse conjunto de experiências, potencializando assim seus resultados e a inserção na comunidade.

Com novas concepções no campo social e nos avanços tecnológicos, o governo atual redefiniu a política de inclusão digital brasileira, que passou a ser vista como um importante vetor para a inclusão social. Neste contexto, foram elaboradas novas propostas em diferentes ministérios: das Comunicações, do Desenvolvimento Indústria e Comércio Exterior, da Ciência e Tecnologia, da Cultura e da Educação. Cada iniciativa se caracterizou pela atribuição institucional dos órgãos nos quais foram elaboradas $^{38}$ : o GESAC - Governo Eletrônico Serviço de Atendimento ao Cidadão, proporciona conexão via satélite à Internet a escolas, telecentros, ONGs, comunidades distantes e bases militares fronteiriças, e possui atualmente 3,3 mil pontos de presença em todo o país, incluindo iniciativas de outros ministérios (MC); os Telecentros de Informação e Negócios buscam inserir digitalmente a micro e a pequena empresa, e contam com mais de 1,6 mil unidades instaladas em 27 estados da nação (MDIC); os Pontos de Cultura fornecem equipamentos digitais e formação de agentes locais para o desenvolvimento de iniciativas culturais populares, e até junho de 2006 somavam 485 unidades instaladas (MinC); os Centros Vocacionais Tecnológicos, que oferecem

\footnotetext{
${ }^{37}$ Note-se que as informações referentes às iniciativas que serão descritas são provenientes essencialmente de buscas na Internet, de sites oficiais dos ministérios e dos portais dos programas de inclusão digital a eles vinculados e de notícias divulgadas em revistas e jornais especializados.

${ }^{38} \mathrm{O}$ detalhamento dos programas está disponível em http://www.inclusaodigital.gov.br/. Acesso em 29 de janeiro de 2007.
} 
capacitação tecnológica e formação profissional à população, e reúnem até o momento 153 unidades (MCT); entre outros programas.

De forma um pouco mais articulada, também foram implementadas iniciativas interministeriais que buscam ampliar o acesso da população às tecnologias da informação, entre as quais destacam-se: o Comitê Técnico de Inclusão Digital do Governo Eletrônico, com o Programa Inclusão Digital, que define a dotação orçamentária no Plano Plurianual 2004-2007 ${ }^{39}$ para diferentes ações relacionadas aos diversos projetos ministeriais e interministeriais do governo federal; o Programa Computador para Todos (PC Conectado), uma linha de financiamento para fomentar a venda de computador e acesso à Internet a preços subsidiados de até R \$1.400,00 para as classes B e C; o Projeto Computador para a Inclusão, que consiste na implantação de centrais de recondicionamento de computadores usados para serem destinados a telecentros, escolas e bibliotecas; o Programa Brasileiro de Inclusão Digital, que inclui parcerias com governos estaduais e municipais, organizações não-governamentais e outras entidades da sociedade civil, para a criação de pontos públicos de acesso; e o Projeto Casa Brasil, que pretende criar espaços de cidadania e cultura digital em regiões com índice de desenvolvimento humano baixo, disponibilizando não somente o acesso à Internet, mas laboratórios para a produção multimídia, rádios comunitárias, banco popular, base postal e núcleos de informação tecnológica para o desenvolvimento de projetos comunitários, culturais, profissionalizantes e educacionais (MARTINI, 2005), atualmente com 44 unidades em funcionamento.

Des-articulação do Governo - Ainda no início do Governo Lula, o Comitê Executivo do Governo Eletrônico (CEGE) - presidido pelo Chefe da Casa Civil e mantido pela Secretaria de Logística e de Tecnologia da Informação (SLTI), do Ministério do Planejamento, Orçamento e Gestão (MPO), ao qual foi atribuída a sua SecretariaExecutiva - criou oito Comitês Técnicos para coordenar as iniciativas de governo eletrônico em âmbito federal, assim como articular as iniciativas nas demais esferas de governo, entre eles o Comitê Técnico de Inclusão Digital (CTID), responsável - no conceito da nova administração - pela promoção da cidadania e da participação social,

\footnotetext{
${ }^{39}$ Ver Programação Plurianual para o período 2004-2007 em http://www.planobrasil.gov.br/. Acesso em 15 de janeiro de 2007.
} 
através da inclusão digital. É importante mencionar, que para o Governo Federal ${ }^{40}$, a inclusão digital é compreendida como um "direito de cidadania e, portanto, objeto de políticas públicas para sua promoção". Essas políticas têm como referência os direitos coletivos, incorporando a preocupação anterior de atender às necessidades individuais dos cidadãos, porém vinculada aos "princípios da universalidade, da igualdade perante a lei e da eqüidade na oferta de serviços e informações", incluindo a importância da utilização da tecnologia da informação pelas organizações da sociedade civil em suas interações com os governos.

Coordenado pela SLTI, o CTID estabeleceu uma série de metas e diretrizes, orientadas pelos seguintes preceitos (Oficinas de Planejamento Estratégico - Relatório Consolidado, 2004, pp. 12-4, apud PORCARO, 2005):

- Construir infra-estrutura de inclusão digital voltada para uso público e comunitário: Considera que a infra-estrutura de acesso deve promover a participação dos cidadãos e das organizações da sociedade civil em sua gestão. Enfatiza o modelo de Telecentros comunitários: uma estratégia que visa a promoção da inclusão digital não somente de indivíduos, mas também de organizações da sociedade civil.

- Pluralidade de modelos sob mesmas diretrizes: Considera que as ações de inclusão digital não estarão referenciadas a um modelo único de iniciativa, embora devam obedecer a princípios e diretrizes gerais, válidos para todas. Serão ações indutivas, normativas e financiadoras que deverão levar em conta especificidades de público e questões regionais, inclusive áreas rurais.

- Segmentação de públicos: Consideram as escolas e crianças os públicos prioritários e indispensáveis, mas não exclusivos. O público deve ser visto como sujeito do processo e não apenas destinatário de serviços.

- Construção de infra-estrutura a ser apropriada pela sociedade: Considera que os projetos de inclusão digital devam ser apropriados pela comunidade, especialmente pelo uso comunitário dos espaços e processos. Os projetos se constituirão de espaços multifuncionais geridos comunitariamente, visando uma cobertura territorial nacional.

- As iniciativas de inclusão digital devem ter comprometimento com o desenvolvimento local: Considera essencial o estimulo à produção e à sistematização de conteúdo e conhecimentos locais para a promoção da efetiva apropriação tecnológica pelas comunidades envolvidas. A sustentabilidade das iniciativas se dá pelo estímulo ao uso de TIC para o desenvolvimento local.

- Integração da inclusão digital a outras iniciativas e políticas: Considera que a inclusão digital deva se dar de maneira Integrada à promoção do Governo Eletrônico, e suas ações devam ser integradas no âmbito federal. A execução da política de inclusão digital deve ser compartilhada com outros níveis de governo, setor privado e sociedade civil. Deve considerar a integração das diversas demandas existentes, possibilitando a otimização dos recursos para sua implantação. $\mathrm{O}$ desenho das ações deve incorporar possibilidades de cooperação e articulação internacional.

- Avaliação: Considera que as ações de inclusão digital devam ser avaliadas permanentemente. A política de inclusão digital deve incluir a criação de sistema de avaliação das ações e indicadores de inclusão digital.

- Utilização de software livre: Considera que se deva privilegiar a utilização de software livre.

${ }^{40}$ Ver http://www.governoeletronico.gov.br/. Acesso em 15 de janeiro de 2007. 
Em documento divulgado no final de 2006 (SLTI, 2006, documento de circulação interna), o CTID, através da SLTI, apresenta os balanços e perspectivas da inclusão digital de janeiro de 2003 a agosto de 2006. Entre as conquistas apontadas estão a promoção de iniciativas dispersas de inclusão digital por todo o território nacional, fruto da interlocução entre os governos federal, estaduais e municipais, iniciativa privada, universidades e sociedade civil; os debates relativos à construção de uma política pública para a inclusão digital no país, com foco "na compreensão de que a promoção de acesso cotidiano às redes, equipamentos e ao domínio das habilidades relacionadas às tecnologias de informação e comunicação são elementos fundamentais de afirmação e garantia de direitos de cidadania, muito além da qualificação profissional ou da formação de consumidores" (2006, p. 1), assim como as discussões teóricas e trocas de experiências práticas entre diferentes iniciativas regionais e nacionais, consolidadas durante as quatro edições da Oficina Nacional para a Inclusão Digital, realizadas anualmente, desde 2003, com o apoio da $\mathrm{SLTI}^{41}$; e a criação do Observatório Nacional de Inclusão Digital (ONID), no início de 2005, com o objetivo de cadastrar telecentros e outros espaços não-comerciais de acesso coletivo e livre às tecnologias da comunicação e da informação para mensurar e acompanhar seu desenvolvimento, um passo importante para a instituição de mecanismos de acompanhamento e avaliação das iniciativas, através da construção de indicadores nacionais, ainda inexistentes. O ONID foi responsável também pela elaboração do site www.inclusaodigital.gov.br, que disponibiliza informações sobre todos os programas de inclusão digital do governo federal, notícias, referências a soluções tecnológicas, orientações para gestão, capacitação, promoção de projetos e acessibilidade para uso livre por responsáveis por telecentros e outras iniciativas de inclusão digital.

Desde 2004 o Governo Federal menciona - em declarações e discursos registrados pela mídia - uma tentativa de sistematização das diversas iniciativas em curso no país, que ficou conhecido como Programa Brasileiro de Inclusão Digital (PBID), entretanto não existe uma concepção oficial do que seja efetivamente o programa. Segundo Porcaro (2005, pg. 71), “em algumas declarações, o PBID é visto como o próprio Projeto Casa Brasil, por reunir várias ações de inclusão em diversas áreas, como educação, comunicação, cultura, serviços interativos e gestão pública, sendo, pois, grande a

\footnotetext{
${ }^{41}$ A $1^{\text {a }}$ Oficina para a Inclusão Digital aconteceu em 2001, também com o apoio da SLTI, durante o governo FHC.
} 
convergência de esforços de diversos órgãos federais para a inclusão digital [...]". Outras declarações, relata Porcaro (2005), relacionam o PBID a diferentes ações, como o Programa Computador Para Todos, o GESAC, o Serviço de Comunicação Digital (SCD) - que com verba do FUST, pretendia incluir digitalmente as instituições públicas do ensino básico, bibliotecas, hospitais, postos de saúde e redes ambulatoriais -, entre outros. Segundo Rogério Santanna dos Santos, Secretário de Logística e Tecnologia da Informação do MPO, e secretário executivo do CEGE:

O governo brasileiro está desenvolvendo o Programa Brasileiro de Inclusão Digital para estimular uma política pública de inclusão digital. A idéia é induzir e fomentar a implementação de espaços públicos de acesso comunitário por governos municipais, estaduais, iniciativa privada e sociedade civil, priorizando o uso de software livre para ampliar a proporção de cidadãos, sobretudo os de classe $\mathrm{C}, \mathrm{D}$ e $\mathrm{E}$, com acesso às tecnologias da informação e comunicação. São diferentes iniciativas que vão desde o oferecimento de linhas de financiamento específicas para subsidiar a venda de computadores, a reciclagem de computadores descartados para serem destinados a telecentros e escolas, entre outros, a instalação de telecentros voltados para diferentes segmentos da sociedade - zonas rurais, grandes centros urbanos, micro e pequenos empresários -, passando pelo levantamento das iniciativas de inclusão digital em curso no país. (SANTOS R. S., 2005) ${ }^{42}$.

O PBID, entretanto, parece ainda não ter se concretizado. Outro programa que ainda não saiu do papel, mas que merece atenção, é o Projeto Brasil 3 Tempos $^{43}$, elaborado pelo Núcleo de Assuntos Estratégicos da Presidência da República, organismo coordenado pela Secretaria de Comunicação de Governo e Gestão Estratégica (Secom). Com a perspectiva de estabelecer um projeto nacional estratégico de desenvolvimento para os próximos 15 anos, articulando governo e sociedade civil, e em sintonia com o cumprimento das Metas do Milênio estabelecidas pela ONU (ver seção 1.2.2), do qual o Brasil é signatário, o projeto estabeleceu como objetivos cruciais a melhora da qualidade do ensino e da educação básica, o combate à violência e a criminalidade, a diminuição da desigualdade social, e o aumento do nível de emprego, tendo na difusão do uso do tecnologias da informação e da comunicação, e na expansão do acesso em banda larga à Internet à população, as suas principais ferramentas. Entretanto, com a saída de Luiz Gushiken, articulador do projeto, do comando da Secom e do NAE, no final de $2006^{44}$, o futuro do mesmo permanece incerto.

\footnotetext{
${ }^{42}$ Ver Revista Inclusão Social http://www.ibict.br/revistainclusaosocial/viewarticle.php?id=1\&layout=html/. Acesso em 29 de janeiro de 2007.

${ }^{43}$ Mais informações em http://www.nae.gov.br/01brasil3t/01brasil3t.pdf/. Acesso em 5 de janeiro de 2007.

${ }^{44}$ Mais informações em http://www1.folha.uol.com.br/folha/brasil/ult96u86646.shtml/. Acesso em 5 de janeiro de 2007.
} 


\subsection{Informação, educação e conteúdo}

No contexto da sociedade digital, ouve-se muito falar em informação e conhecimento como insumos básicos para o desenvolvimento e participação social, sem que se faça uma distinção clara entre os dois conceitos, que materializam as relações estabelecidas através das novas tecnologias em discussão.

Para Setzer (1999), existe uma confusão muito grande entre informação e conhecimento. Preocupado em estabelecer uma clara distinção entre os termos, define informação como uma abstração informal que representa algo significativo para alguém através de textos, imagens, sons ou animação, enquanto conhecimento é uma abstração pessoal, associada ao processo de interação social. Ou seja, a informação possuiu semântica, enquanto o conhecimento está associado à pragmática - relaciona-se com alguma coisa existente no mundo real da qual temos uma experiência direta - e é subjetivo. Dowbor (2001, p. 33) propõe uma definição baseada em uma relação hierárquica: "elementos fragmentados constituem dados, os dados organizados constituem informação, a informação elaborada pelo sujeito que a utiliza, na interação com a realidade, se transforma em conhecimento". Já Cohn (2000) esclarece que o termo informação possui no mundo contemporâneo uma dimensão mais ampla do que o conceito de acesso a conhecimento sobre objetos e eventos, pois se aplica ao formato da sociedade. Para ele, a informação é a seleção dos elementos que darão a forma do objeto e lhe conferem valor como ente dotado de significado. Na nova concepção de informação, ela se encontra no cerne das atividades produtivas, caracterizando a etapa atual do capitalismo.

Pode-se sugerir assim que a informação seja a matéria-prima para a produção de sentido, entretanto este último só se torna efetivo através da interação do indivíduo com a sua realidade. Sorj e Guedes (2005) apontam que "o valor efetivo da informação depende da capacidade dos usuários de interpretá-la. Informação só existe na forma de conhecimento, e conhecimento depende de um longo processo de socialização e de práticas que criam a capacidade analítica que transforma bits em conhecimento. Portanto, confrontar a exclusão digital supõe enfrentar a exclusão escolar". 
Para os processos de inclusão digital não basta propiciar ao cidadão de baixa renda o acesso à informação, mas paralelamente ampliar seu um nível de letramento ${ }^{45}$, e desta maneira, oferecer condições para que ele possa refletir sobre estas informações, contextualizando-as em seu processo pessoal. Warschauer (2006) defende o letramento informacional como recurso básico para a interação com a rede mundial de computadores. Criado no início da década de 1980, o conceito de 'letramento por meio do computador' suscitou muitas críticas por parte de educadores, pois se referia apenas às formas básicas de operação com um computador. Para o autor, entretanto, é apropriado se considerado como um conjunto de práticas sociais que envolvem acesso a diversos recursos, entre eles estão "artefatos físicos (livros, revistas, jornais, computadores); conteúdo relevante transmitido por meio desses artefatos; habilidades, conhecimentos e atitudes adequadas dos usuários; e os tipos certos de comunidade e apoio social" (2006, p. 71).

O letramento digital exige portanto uma série de habilidades que independem da tecnologia, como análise e avaliação de fontes de informação, e a assimilação de uma série de novas habilidades relacionadas ao uso do computador - não apenas a capacidade de operar um teclado e um mouse, mas a capacidade de se articular na forma de uma narrativa hipermidiática e interativa, de se comunicar de forma síncrona por meio de salas de bate-papo e mensagens instantâneas, de dialogar em fóruns e blogs, e de exprimir suas idéias em sites de relacionamento ou áreas de trabalho colaborativo.

Ao mesmo tempo, a Internet, com sua interatividade e estimulo visual, representa um ambiente sedutor para o aprendizado e a comunicação, e conseqüentemente para o produção e consumo de informações. Esse encontro com textos e imagens se dá inicialmente pela exploração do hipertexto, num percurso pessoal através de links de manchetes e fotos, caracterizado por Lemos ([s.d.]) como uma condição de "ciberflaneur", no qual se estabelece o estado de "atenção-navegação-interação", que não é

\footnotetext{
${ }^{45}$ Traduzido do termo "literacy", em inglês, letramento é uma terminologia não dicionarizada que, nos meios acadêmicos, vem sendo utilizada com diferentes sentidos. Nesta tese foi adotado o conceito apresentado por (PEIXOTO et al. ?), de que "letramento é um fenômeno de cunho social, e salienta as características sócio-históricas ao se adquirir um sistema de escrita por um grupo social. Ele é o resultado da ação de ensinar e/ou de aprender a ler e escrever, e denota estado ou condição em que um indivíduo ou sociedade obtém como resultado de ter-se ‘apoderado' de um sistema de grafia”.
} 
uma leitura propriamente dita, mas uma exploração do ciberespaço ${ }^{46}$ que vai além da “consumação passiva”. Esta forma de interação com a rede predomina entre usuários de centros públicos de acesso, segundo Becker:

Em síntese, pode-se dizer que a relação do morador da periferia com a notícia on-line ocorre, primeiramente, sob a influência de um deslumbramento com as possibilidades abertas pela Internet: por meio da inclusão digital, torna-se possível não apenas o acesso a outro tipo de material jornalístico que não o da chamada imprensa popular, mas, em especial, o acesso a uma tecnologia que lhe permite, entre outros fatores: a) o controle do tempo de apropriação da informação, diferentemente da TV e rádio, únicos veículos aos quais se tinha acesso antes; b) o contato com conteúdos gerados por fontes primárias; c) a criação de uma esfera própria de informação (e-mail, bate-papo); d) o exercício do direito de expressão. ([s.d.] p. 14).

Neste contexto, a chegada iminente da TV Digital ${ }^{47}$ - equipamento que deverá agregar qualidade de sinal digital, recursos computacionais e interatividade à TV analógica - se apresenta como um vetor em potencial da inclusão digital, segundo Afonso e Soares (2005, p. 29):

\begin{abstract}
A possibilidade de transmissão de dados, além do áudio e vídeo principal que compõem um programa de TV, aumenta ainda mais a importância do sistema como um meio de difusão de informações. A inclusão de um canal de retorno permitirá a interação do usuário telespectador, a navegação nos dados difundidos pela emissora e, no caso de um canal bidirecional, o acesso a informações particulares oferecidas por qualquer provedor de conteúdo na rede de retorno (por exemplo, na Internet). No caso de um canal de retorno bidirecional de banda larga, pode-se até pensar em um outro patamar de inclusão social, permitindo ao cidadão telespectador não apenas ter acesso a informações, como também prover conteúdo audiovisual que retrate sua produção cultural e realidade.
\end{abstract}

Entretanto, a definição do padrão tecnológico e modelo de negócios a ser adotado é imprescindível para que se possa viabilizar a aquisição dos equipamentos de acesso pelas classes que se quer incluir: o setup box - que permitirá a conversão do sinal analógico para o digital, aproveitando a base instalada de televisores no país, presente em 97\% dos domicílios de acordo com a TIC Domicílios $2006^{48}$ - ou terminais de acesso mais poderosos. Sem mencionar as questões que envolvem a distribuição de canais os incentivos para a produção de conteúdo, temas ainda em debate, mas de vital importância em termos de oportunidades e inclusão.

\footnotetext{
${ }^{46}$ Segundo Pierre Lévy (2000) o ciberespaço é a interconexão mundial de computadores na forma de uma grande rede "universal sem totalidade", promovendo a interconexão generalizada, ao mesmo tempo que comporta a diversidade de sentidos, dissolvendo a totalidade.

${ }^{47}$ O padrão tecnológico e o modelo de negócios para a TV Digital brasileira estão atualmente em discussão no governo e em diferentes segmentos da sociedade.

${ }^{48}$ Pesquisa sobre o uso das tecnologias da informação e da comunicação no Brasil, realizada pelo CGI.br, disponível em: http://www.cetic.br/
} 


\subsubsection{Produção de conhecimento e apropriação tecnológica}

Em um mundo mediado pelas tecnologias digitais e caracterizado pela interdependência universal das nações (CASTELLS, 2002), tanto na produção econômica como cultural, existe uma grande tendência à concentração de poder pelos produtores de informação e à ampliação de desigualdades sociais. Se os grandes grupos de mídia historicamente controlam o comportamento da sociedade, no atual contexto a sua dominação pode ser ainda maior. Desta forma, ao invés de contribuir para a democratização do conhecimento, as TICs estão reafirmando o poder das grandes corporações, sejam elas empresas de mídia ou grandes indústrias do setor (CORRÊA, 2003). Para que esse cenário de controle não se fortaleça na sociedade digital, é imprescindível que o indivíduo não seja apenas um consumidor, mas que possa se apropriar de maneira crítica das informações à que tem acesso, articulando de forma protagonista novas formas de conhecimento, e produzindo conteúdos que o ajudem a interagir e a compreender melhor o universo ao seu redor. Mais do que isso, "se a inclusão "pelo digital' se der com o objetivo de incluir cada indivíduo 'no conhecimento', esse indivíduo estará capacitado a produzir valor e, participando do processo de inovações tecnológicas, possivelmente participar também da valorização das competências associadas ao trabalho em rede, com exercício de habilidades comunicacionais". (SCHWARTZ, 2003).

Neste contexto, a produção de conteúdo informativo, seja através de websites, blogs, boletins digitais e até mesmo e-mails, deve ser estimulada e incentivada nos grupos excluídos da população. Sorj e Guedes (2005, p. 20) apontam, portanto, que "a promoção de sites com conteúdos específicos para as populações de baixa renda, e em línguas nativas, pode ter um papel importante para compensar as dificuldades de acesso a conteúdos produzidos para públicos de classe média ou com conhecimento de outras línguas”. De acordo com Lévy (2002), é a linguagem que nos distingue dos demais animais e que possibilita a nossa evolução cultural, pois nos permite praticar uma forma de inteligência coletiva baseada no diálogo, no questionamento e na narrativa. $O$ questionamento nos faz perceber os nossos próprios limites - e é justamente porque percebemos nossos próprios limites que somos ilimitados -, a interpretação narrativa nos permite organizar nosso pensamento com relação ao tempo - vivemos na significação porque criamos um senso -, e com o diálogo nós participamos da 
interioridade dos outros. Esses três pontos são o motor de criação do universo humano, da significação.

\subsubsection{Construção colaborativa}

A colaboração intelectual humana e a construção coletiva do saber através das novas tecnologias da informação vêm sendo estudadas por Pierre Lévy (1993) desde o início da década de 90. Com a explosão da Internet nos últimos 15 anos, as práticas de inteligência coletiva - ou seja, a construção de novos saberes em rede - vêm crescendo e sendo assimiladas pelos mais diversos grupos: não apenas na comunidade científica, mas também no mundo dos negócios, da política, e da economia, mais e mais pessoas se organizam por intermédio da Internet para trocar conhecimento visando à cooperação intelectual (LÉVY, 2000). Esta nova forma de diálogo é considerada por ele como uma ferramenta importantíssima para o aprimoramento do processo de aprendizagem e de democratização do saber.

Lévy defende assim o desenvolvimento de uma ciência da inteligência coletiva que leve em consideração o ecossistema de todos os conhecimentos, de todas as idéias e de todas as práticas humanas, para que cheguemos a uma transformação cultural que beneficie um grupo cada vez maior de pessoas. A participação de cada indivíduo na construção destas comunidades virtuais seria portanto muito importante para a produção e circulação de informações úteis para o desenvolvimento efetivo da cidadania. Em resumo, o processo de circulação de informação e de cooperação intelectual no ciberespaço caminha no sentido da inclusão digital, no que diz respeito à construção de conhecimento útil para comunidades locais que podem ser partilhados globalmente. Nesse sentido, o autor situa a aprendizagem no contexto de uma "ecologia cognitiva", repleta de valores e significados simbólicos, que nutre psíquica e culturalmente a sociedade contemporânea.

Percebe-se assim que um novo campo de intervenção social vem se firmando na interface entre comunicação e educação, voltado para a construção de ecossistemas comunicacionais em espaços educativos, onde o ambiente mediado por tecnologias contribui na produção de sentidos (MORIN, 2002a). Trata-se, na verdade, de uma 
perspectiva de análise e de articulação em permanente construção, levando-se em conta o contínuo processo de mudanças sociais e de avanços tecnológicos pelos quais passa o mundo contemporâneo. Complementarmente, a educação não formal, defendida por Lévy (1993, 2000) e Morin (2002a e 2002b), que se faz por influência dos meios de comunicação e pela Internet, tem um papel de destaque na formação e no processo educativo contemporâneo.

Muitas experiências de educação à distância e de treinamento mediado pela Internet vêm sendo desenvolvidas no país e internacionalmente. Não pretendo tratar dessas experiências nesta tese, mas gostaria de ilustrar a importância desse processo para a inclusão digital, mencionando o programa Gestão de Mídias Digitais ${ }^{49}$ (GMD), uma experiência de capacitação de cerca de 200 profissionais que atuam em centros públicos de acesso à Internet na cidade de São Paulo, realizada entre julho de 2002 e agosto de 2003, que tive a oportunidade coordenar. O programa foi desenvolvido pela Cidade do Conhecimento $^{50}$, projeto que nasceu no Instituto de Estudos Avançados da USP, buscando a formação de redes de colaboração entre a comunidade acadêmica e a sociedade, assim como novas formas de comunicação e organização social baseadas nas novas tecnologias da informação (SCHWARTZ, 2002).

O GMD teve como objetivo contribuir para a formação de profissionais capazes de articular demandas sociais e possibilidades oferecidas pelas tecnologias de informação e comunicação (TICs) para fins comunitários e colaborativos, por meio de projetos que se apropriam da infra-estrutura tecnológica disponível em postos públicos de acesso à Internet, sobretudo em benefício de comunidades desfavorecidas (BALBONI e SCHWARTZ, 2005). Durante 12 meses, o programam reuniu de maneira inovadora monitores e lideranças de Infocentros do Acessa São Paulo, coordenadores dos Telecentros São Paulo, educadores do Comitê de Democratização da Informática e outros profissionais que atuam em pontos públicos de acesso à Internet na USP trocando conhecimento e experiências para buscar na tecnologia soluções para desafios cotidianos associados às premências de comunidades em áreas de risco social. Nesse período, foram desenvolvidos projetos de inserção cultural, social e econômica alavancados pelo processo de digitalização da sociedade, do qual até muito pouco

\footnotetext{
49 Mais informações em http://www.cidade.usp.br/gmd .

${ }^{50}$ Mais informações em http://www.cidade.usp.br
} 
tempo se encontravam excluídos. Além das capacitações em si, desenvolveu-se uma comunidade cuja solidariedade resultou na criação coletiva de um espaço público e um movimento social de discussão, pesquisa, colaboração e construção coletiva de conteúdos e textos reflexivos, permitindo que a voz desses grupos ecoasse pela rede ainda durante vários meses após o término do programa. Nesse sentido, o $\mathrm{GMD}^{51}$ propôs um novo marco para as práticas pedagógicas em áreas de risco social, práticas pautadas pela interatividade e pela construção social do conhecimento através da realidade das comunidades, como defende Paulo Freire (1980, 1991, 2003), mediada pela tecnologia digital. Posteriormente, os projetos elaborados durante o programa, com base na articulação e nas demandas já existentes na comunidade - e principalmente as habilidades para a elaboração dos mesmos - foram retomados na Rede de Projetos, atividade em andamento no programa Acessa São Paulo que estimula seus usuários a utilizarem o infocentro e a Internet para o desenvolvimento de iniciativas locais.

\subsubsection{Em busca da cidadania digital}

O fortalecimento da cidadania é um dos grandes desafios da inclusão digital, cada vez mais se transforma em sinônimo de apropriação social, de renda, de educação, de saúde, enfim, de todos os direitos de cidadania (DIAS, 2003). Um movimento nacional, ainda silencioso, começa a surgir pelas mãos de organizações comunitárias e de tímidas políticas públicas, arranhando a armadura da exclusão social. Um número crescente de serviços de governo eletrônico vêm sendo colocados à disposição do cidadão por diferentes esferas de governo - principalmente federal e estadual -, e novos canais de comunicação se abrem entre o cidadão e o poder público. Como lembra Martini (2005), governos democráticos e participativos encontram nas tecnologias da informação e da comunicação ferramentas fundamentais para a desburocratização dos processos de trabalho, para a melhoria da gestão e da qualidade dos serviços prestados, para a democratização do acesso e para o efetivo controle social das ações governamentais. Santos R. S. (2005) faz referência ainda à importante contribuição da Internet para a transparência do Estado, a prestação de contas do Governo à sociedade e a consulta à comunidade sobre as decisões que serão tomadas na gestão dos bens públicos. Cada vez

\footnotetext{
${ }^{51}$ Ver relatório final do programa Gestão de Mídias Digitais 2003 em http://www.cidade.usp.br/hotsitemagna/relatoriogmd.pdf
} 
mais o acesso à comunicação através das redes de informação passa a ser considerado um direito e um pressuposto básico da democracia na sociedade pós-moderna (AMADEU, 2001).

É consenso o potencial que a Internet tem de fortalecer a interação entre indivíduos e governos, reforçar a sociedade civil e caminhar rumo a processos democráticos mais participativos. Entretanto, este não parece ser o cenário que vem se estabelecendo, mesmo em governos democráticos e preocupados com os direitos de sua população. De forma geral, foram encontrados na rede um número muito maior de informações sobre obrigações e deveres que o cidadão tem em relação ao Estado, do que de seus direitos e possibilidades. As transações interativas disponíveis na maior das vezes facilitam a entrega do imposto de renda e o pagamento de taxas, mas continuam obrigando o cidadão a enfrentar filas para realizar seu cadastramento na previdência social ou fazer a segunda via de um documento.

Para Castells (2003) o potencial da Internet como um instrumento de promoção da democracia ainda não foi atingido.

Esperava-se que a Internet fosse um instrumento ideal para promover a democracia - e
ainda se espera. Como dá fácil acesso a informação política, permite aos cidadãos ser quase
tão bem informados quanto seus líderes. Com boa vontade do governo, todos os registros
públicos, bem como um amplo espectro de informação não sigilosa, poderia ser
disponibilizada on-line. A interatividade torna possível aos cidadãos solicitar informação,
expressar opiniões e pedir respostas pessoais a seus representantes. Em vez de o governo
vigiar as pessoas, as pessoas poderiam estar vigiando o seu governo - o que é de fato um
direito delas, já que teoricamente o povo é soberano. Entretanto, a maioria dos estudos e
relatórios descreve um quadro melancólico - com a possível exceção das democracias
escandinavas (p. 128).

É na articulação de movimentos sociais que usam a Internet para organizar suas ações e fortalecer sua rede que a cidadania digital vem se manifestando com sucesso. $\mathrm{O}$ surgimento da rede fortaleceu a sociedade civil, transformando a maneira com que a população ao redor do mundo reage a seus problemas: as reivindicações sociais não levam mais em consideração as fronteiras. Elas não têm mais o caráter local ou regional, mas são globais (MARTIN-BARBERO, 2003). No contexto da participação pública na sociedade da informação, Guzzi afirma que: 
[...] os meios de comunicação interativos, as comunidades virtuais sem território e a imensa possibilidade de expressão permitida pela Internet abrem um novo espaço para a comunicação transparente, tanto no nível local quanto global, levando, potencialmente, a profundas renovações das condições da vida pública no sentido de maior liberdade e responsabilidade de um indivíduo enquanto cidadão (2003, p. 7).

Atenta à heterogeneidade das redes que se formam, Starobinas (2005) observa que as diferenças individuais e os contextos de inserção devem ser levados em consideração quando se trata de estratégias de disseminação dos recursos tecnológicos, para que se promova uma inclusão com mais compreensão sobre a estrutura destes novos meios, e portanto menos resistência ou ingenuidades em relação às máquinas, reconhecendo também que a interação social continua a existir em paralelo à vida na rede.

A apropriação social dos recursos digitais é uma oportunidade de grande importância para aproximações e parcerias, para acesso à informação de forma mais ágil, para a conquista de espaços de autoria e circulação da expressão humana, com enorme potencial de mobilização e transformação. É este o norte a ser perseguido, o que busca a adesão a estes valores e combate a multiplicação de posturas excludentes, racistas e homofóbicas, à invasão de privacidade, ao roubo, às redes de contravenção e ao terrorismo (STAROBINAS, 2005). 


\section{PROBLEMÁTICA}

Frente ao contexto apresentado, este estudo concentra-se na discussão da inclusão digital pelo prisma do potencial de transformação que o consumo e produção de informação, através das mídias digitais, pode trazer para comunidades excluídas ${ }^{52}$. Conforme apresentando no quadro teórico, o uso de aparatos tecnológicos para o acesso à informação - e a possibilidade de transformar o conteúdo disponível na Internet em novas formas de conhecimento - são considerados de grande importância para garantir o desenvolvimento socioeconômico e a participação ativa e democrática do indivíduo na sociedade (CASTELLS, 2003, WARSCHAUER, 2006, LÈVY, 2002). E neste processo, a implementação de centros públicos de acesso (CPAs) tem sido vista como a melhor estratégia para permitir a interação de grupos excluídos com a rede (DELGADILLO et al., 2003)

Entretanto, este levantamento de dados indica que, ainda que venha sendo bastante alardeada, a criação desses CPAs ainda não mostrou resultados significativos no que diz respeito ao aporte informativo ou a mudanças nas condições de vida de comunidades “incluídas digitalmente" no Brasil. Com exceção de histórias ${ }^{53}$ pessoais ou coletivas de sucesso, limitações cognitivas e desigualdades sócio-econômicas parecem se colocar no caminho de programas de inclusão digital, dificultando a apropriação das TICs, seu uso, e até mesmo a compreensão de seu potencial, por indivíduos excluídos (WARSCHAUER, 2003).

Além disso, os dados também indicam que a implementação de projetos públicos de inclusão digital no país é freqüentemente motivada e guiada por interesses políticos e econômicos que se justificam pela causa social. Assim, a abertura de um novo CPA em determinada região, e não em outra, parece se confundir muitas vezes com interesses partidários e eleitorais. Nicolau Reinhard (2006, comunicação pessoal), crítico com

\footnotetext{
${ }^{52}$ Neste trabalho, como apresentado anteriormente, serão consideras comunidades - e indivíduos excluídos aqueles que por dificuldades sócio-econômicas de acesso à rede estão impossibilitados de participar e interagir de forma autônoma e protagonista com os recursos oferecidos pela sociedade da informação.

${ }^{53} \mathrm{Em}$ todas as entrevistas realizadas foram relatados casos exitosos de indivíduos que, através da apropriação e o uso Internet, conseguiram ampliar seu desenvolvimento pessoal, seja com a volta aos estudos, a conquista de um emprego, ganhos de auto-estima, a organização de atividades na comunidade, entre outros.
} 
relação aos resultados trazidos por programas de inclusão digital que vem investigando nos últimos anos, resume: "A inauguração de cada novo telecentro é como um evento político". Neste cenário, a motivação de grandes empresas de software e hardware também parece transcender a responsabilidade social, aflorando a grande preocupação em conquistar novos consumidores e abrir novos mercados. Schwartz (2003) alerta que: "Até hoje as chamadas políticas de 'inclusão digital' refletiram sobretudo o interesse de fabricantes de hardware e software interessados na ampliação do seu mercado, ou seja, na "inclusão" de mais indivíduos na categoria de "usuários"”.

Ao historicizar o desenvolvimento de políticas de inclusão no país e identificar a contribuição das tecnologias da informação e da comunicação - principalmente a Internet - para o consumo e produção de informação em comunidades excluídas, este trabalho poderá oferecer subsídios para a reflexão sobre o potencial das mídias digitais como indutor de transformação, social e econômica, evidenciando resultados e interesses envolvidos.

Os objetivos gerais para esta tese portanto são: a) Conhecer e analisar o impacto da Internet no consumo e produção de informação em centros públicos de acesso no Brasil, por meio de amostragem e, em paralelo, b) identificar os interesses e motivações que permeiam as ações junto aos CPAs e a outras iniciativas de inclusão digital no país.

Esses objetivos traduzem-se na seguinte questão de pesquisa:

A presença da Internet - por meio de Centros Públicos de Acesso - tem potencial de gerar mudanças no cotidiano de comunidades excluídas, especialmente sob os pontos de vista da produção e consumo de informação; do desenvolvimento social, político e econômico; e dos investimentos públicos e privados no setor?

Essa questão envolve uma análise sobre os CPAs, que será verificada sob três aspectos:

1. As mudanças que o acesso público à Internet provoca (ou não) no padrão de consumo e produção de informação (nas comunidades servidas por estes CPAs); 
2. Os benefícios trazidos (ou não) para o desenvolvimento político, econômico e social dessas comunidades excluídas;

3. A motivação dos investimentos públicos e privados nessas iniciativas de inclusão digital.

De forma mais abrangente, e objetivando contribuição para novas pesquisas, este trabalho também pretende:

1. Desenhar o panorama recente da inclusão digital no país;

2. Refletir sobre o potencial das mídias digitais para a da construção e divulgação do conhecimento;

3. Discorrer sobre a importância das tecnologias da informação e da comunicação para o desenvolvimento político, social e econômico;

4. Identificar as expectativas, conquistas e desafios dos programas públicos de acesso à Internet no cenário atual.

Para aferir os pressupostos apresentados foi realizado um estudo exploratório, prioritariamente qualitativo, baseado em análise de documentos, entrevistas e análise de conteúdo das mesmas. 


\section{METODOLOGIA}

A revolução digital transformou a maneira como nos comunicamos, não é novidade. $\mathrm{O}$ desenvolvimento acelerado dos novos meios com os quais criamos, reproduzimos e transmitimos informação colocou a comunicação no centro de todos os setores da sociedade contemporânea, fazendo com que esta responda pelas lógicas internas de funcionamento do sistema social. Mais do que isso, evidenciou o papel da comunicação como área de conhecimento (SANTAELLA, 2001).

Entretanto, o crescimento acelerado dessa área de conhecimento notadamente multidisciplinar e recente - a preocupação com o fenômeno da comunicação data de meados do século XX -, pode transparecer uma certa fragilidade metodológica (MELO, 2005), dado que as técnicas de pesquisa aplicadas na área ainda não oferecem todas as ferramentas necessárias para explorar a complexidade do campo comunicacional. Ressaltando a importância da construção do modelo metodológico para a prática da pesquisa em comunicação, Lopes (2004) aponta como principais obstáculos encontrados hoje no campo a ausência de reflexão epistemológica, a fraqueza teórica, a falta de visão metodológica integrada, a deficiência na combinação entre estratégia metodológica e o marco teórico, e a dicotomia entre pesquisa descritiva e interpretativa, e entre pesquisa quantitativa e qualitativa.

Cientes das dificuldades de nossa tarefa, foi adotado um método científico de pesquisa de campo que buscou responder apropriadamente às questões e problemática que foram identificadas em nossa pesquisa. Entretanto, como o objeto de estudo, a inclusão digital, é um tema relativamente recente e ainda pouco explorado cientificamente - mesmo que o "termo" esteja na "moda" e seja freqüentemente citado na mídia e em programas políticos -, não se buscará aqui criar ou verificar hipóteses de maneira exata e precisa. Mesmo porque, a multiplicidade de depoimentos e opiniões colhidas neste estudo refletem a visão individual e subjetiva dos membros das comunidades pesquisadas.

Será realizado assim um estudo exploratório (SELLTIZ et al., 1975), prioritariamente qualitativo, baseado em análise de documentos, entrevistas em profundidade e análise de conteúdo, com o objetivo de ampliar nossa compreensão sobre a temática da inclusão 
digital, identificar interesses (ocultos) ainda não debatidos, discutir proposições para a mudança de cenário, vislumbrar perspectivas e contribuir para a formulação de melhores práticas. Por tratar do "impacto da Internet no consumo e produção de informações em populações excluídas", nossa pesquisa se caracteriza também como um trabalho que mostra a importância da comunicação para o desenvolvimento sócioeconômico, político e cultural destas comunidades.

\section{Estratégia de pesquisa}

Como estratégia de pesquisa optou-se então por investigar três programas públicos de inclusão digital com uma sólida atuação na comunidade ${ }^{54}$, no Estado de São Paulo, e nos municípios de Curitiba e Porto Alegre. Foram entrevistados os coordenadores dos programas e selecionada uma unidade de cada programa para a realização de uma pesquisa de campo etnográfico, e das entrevistas com os monitores que trabalham em contato direto com o público. Foram realizadas também entrevistas com os mentores ${ }^{55}$ da inclusão digital, e uma ampla análise de documentos, imprescindível para a elaboração dos questionários aplicados e para a construção do cenário da temática em questão. Por último, através da análise de conteúdo, buscou-se comparar as respostas obtidas, inferindo sobre possíveis mudanças no padrão de consumo e produção de informação nas comunidades excluídas, sobre o potencial do acesso à Internet para o fortalecimento do desenvolvimento político e sócio-econômico nessas comunidades, e também identificando os interesses políticos e econômicos que motivam o desenvolvimento de programas públicos de inclusão digital.

Desta maneira, através da estratégia a ser detalhada neste capítulo, se buscarei responder a questão de pesquisa apresentada, conforme explicitado no capítulo 2, apresentando no capítulo de análise:

\footnotetext{
${ }^{54}$ Optou-se pelos programas de inclusão digital pioneiros, com uma rede de centros de acesso em funcionamento desde 2001, oferecendo acesso gratuito à Internet para a comunidade em geral. Mais informações sobre os programas selecionados no capítulo 5.

${ }^{55}$ Personalidades que participaram da construção dos primeiros programas de acesso comunitário, coordenaram iniciativas-piloto de inclusão digital e/ou influenciam as políticas públicas em âmbito nacional.
} 
a) a descrição dos programas de inclusão digital selecionados e as observações específicas das unidades visitadas, através da análise de documentos, depoimentos de coordenadores, monitores e usuários;

b) e a análise das categorias temáticas levantadas (ver quadro 7), através da identificação e análise do discurso dos quatro grupos de atores entrevistados com o as reflexões levantadas no quadro teórico.

\subsection{Técnicas de pesquisa}

Para este estudo exploratório foram utilizados prioritariamente procedimentos qualitativos $^{56}$. As técnicas de pesquisa utilizadas foram: análise de documentos, entrevistas em profundidade semi-abertas, trabalho de campo etnográfico, entrevistas em profundidade fechadas (que apesar de serem instrumento quantitativo, foram elaboradas dentro de critérios qualitativos, inclusive no processo empírico de definição da amostragem), e análise de conteúdo.

a) análise de documentos - a análise de documentos é um dos principais recursos metodológicos qualitativos utilizados em nossa pesquisa, tanto para a construção do quadro teórico como para a elaboração dos questionários e do cenário da inclusão digital no país. Conforme explica Moreira (2005), a análise documental compreende a identificação, a verificação e apreciação de documentos de referência que complementam outras formas de obtenção de dados, como a entrevista e o questionário. Freqüentemente as fontes da análise documental são de origem secundária, pois constituem conhecimento, dados ou informação já reunidos ou organizados, como relatórios técnicos, a mídia impressa e eletrônica, entre outros.

Dada a contemporaneidade da temática investigada, foram utilizados com freqüência artigos e periódicos disponíveis na Internet, além dos existentes em formato impresso

\footnotetext{
${ }^{56} \mathrm{Na}$ pesquisa qualitativa os dados coletados são predominantemente descritivos, obtidos no contato direto do pesquisador com a situação estudada, o processo é mais enfatizado que o produto e a maior preocupação é retratar a perspectiva dos participantes (LUDKE et al, 1986).
} 
tradicional. É importante mencionar a riqueza da Internet como fonte de informação (YAMAKODA, 2005), lembrando que o crescimento acelerado da rede e do volume de informações ali disponível exige grande discernimento na recuperação de material de referência, na garantia de sua qualidade e confiabilidade. O levantamento de dados secundários incluiu:

- pesquisas existentes sobre penetração e uso da Internet no país, como os poucos dados disponibilizados pelo Instituto Brasileiro de Geografia e Estatística (IBGE) e os indicadores de penetração e uso da Internet divulgados Comitê Gestor da Internet no Brasil (CGI.br), em 2006;

- duas pesquisas ${ }^{57}$ sobre o uso e impacto de centros públicos de acesso na vida cotidiana de comunidades de baixa renda na periferia da cidade de São Paulo realizadas em 2004: uma sobre o programa Telecentros São Paulo, realizada pela Rede de Informações para o Terceiro Setor (RITS), e a outra sobre o programa Acessa São Paulo, realizada pela Escola do Futuro da USP;

- documentos sobre as iniciativas do governo federal com relação à inclusão digital, entre eles o "Plano Brasil para Todos" 58 , do e o "Projeto Brasil 3 Tempos: 2007, 2015 e 2022”, do Núcleo de Assuntos Estratégicos da Presidência da República (NAE) ${ }^{59}$;

- informações disponíveis na mídia impressa - e principalmente digital - sobre o histórico e evolução dos programas de inclusão digital no Brasil;

- website dos programas de inclusão digital selecionados.

b) Entrevista em profundidade - muito útil em estudos do tipo exploratório, a entrevista em profundidade é uma "técnica qualitativa que explora um assunto a partir da busca de informações, percepções e experiências de informantes para analisá-las e apresentá-las de forma estruturada”, explica Duarte (2005, p. 62). Esse recurso metodológico permite que o informante defina os termos da resposta e que o investigador recolha as informações a partir da experiência subjetiva da fonte. A abordagem possibilita o mapeamento de uma situação ou campo de análise através de relatos da interpretação e experiências. Exige, entretanto, elaboração e explicitação de

\footnotetext{
${ }^{57}$ As pesquisas mencionadas serviram de base para a elaboração de nosso questionário on-line para usuários de centros públicos de acesso.

${ }^{58}$ Ver http://www.planobrasil.gov.br/

${ }^{59}$ Ver http://www.nae.gov.br/
} 
procedimentos metodológicos específicos: o estabelecimento de um marco conceitual, de critérios de seleção de fontes e de procedimentos para sua realização, o uso adequado das informações e a explicitação das limitações dos resultados. Normalmente realizadas individualmente, as entrevistas são classificadas como aberta, semi-abertas e fechadas. Veja quadro 6 abaixo:

\section{Quadro 6. Tipos de entrevista}

\begin{tabular}{|c|c|c|c|c|c|}
\hline \multirow{2}{*}{ Pesquisa } & Questões & Entrevistas & Modelo & Abordagem & Respostas \\
\hline \multirow{3}{*}{ Qualitativa } & Não-estruturadas & Aberta & $\begin{array}{c}\text { Questão } \\
\text { Central }\end{array}$ & $\begin{array}{c}\text { Em } \\
\text { profundidade }\end{array}$ & Indeterminadas \\
\cline { 2 - 6 } & $\begin{array}{c}\text { Semi- } \\
\text { estruturadas }\end{array}$ & Semi-aberta & Roteiro & Linear & Previstas \\
\hline \multicolumn{2}{|c|}{ Quantitativa } & Estruturadas & Fechadas & Questionário &
\end{tabular}

As entrevistas em profundidade podem ser abertas ou semi-abertas, sendo que as primeiras são realizadas através de um tema central, sem itinerário, e as segundas seguem um roteiro-base. Esses dois tipos de entrevista se caracterizam pela flexibilidade e por explorar ao máximo o tema investigado. As entrevistas fechadas, realizadas através de questionários estruturados, são utilizadas quando se deseja obter informações representativas de um conjunto de uma população (DUARTE, 2005).

Como mencionado anteriormente, neste estudo exploratório foram realizadas:

- entrevistas semi-dirigidas com os mentores da inclusão digital no país,

- entrevistas semi-dirigidas com os coordenadores e os monitores dos programas de inclusão digital selecionados,

- entrevistas fechadas com os usuários dos centros públicos de acesso, aplicadas pela Internet por meio de um questionário on-line estruturado.

c) Análise de conteúdo: A análise de conteúdo é um método de pesquisa que tem demonstrado grande capacidade de adaptação aos desafios emergentes da comunicação, inclusive pesquisas sobre novas tecnologias (FONSECA JUNIOR, 2005). De maneira, geral, a técnica é tributária do positivismo, corrente de pensamento que valoriza as ciências exatas como paradigma de cientificidade. Segundo a definição de Bardin (1988, apud FONSECA JUNIOR, 2005), trata-se de um método de pesquisa empírico e exploratório usado para a descrição sistemática do conteúdo manifesto da comunicação. 
Sua característica básica é a inferência, ou dedução de maneira lógica, operação usada para extrair conhecimentos através do tratamento das mensagens, como por exemplo adivinhar as intenções por detrás do discurso ou pôr em evidência as avaliações de um indivíduo, a partir de seus enunciados, processo ilustrado na figura abaixo:

Figura 6. Esquema de Bardin: Desenvolvimento de uma análise

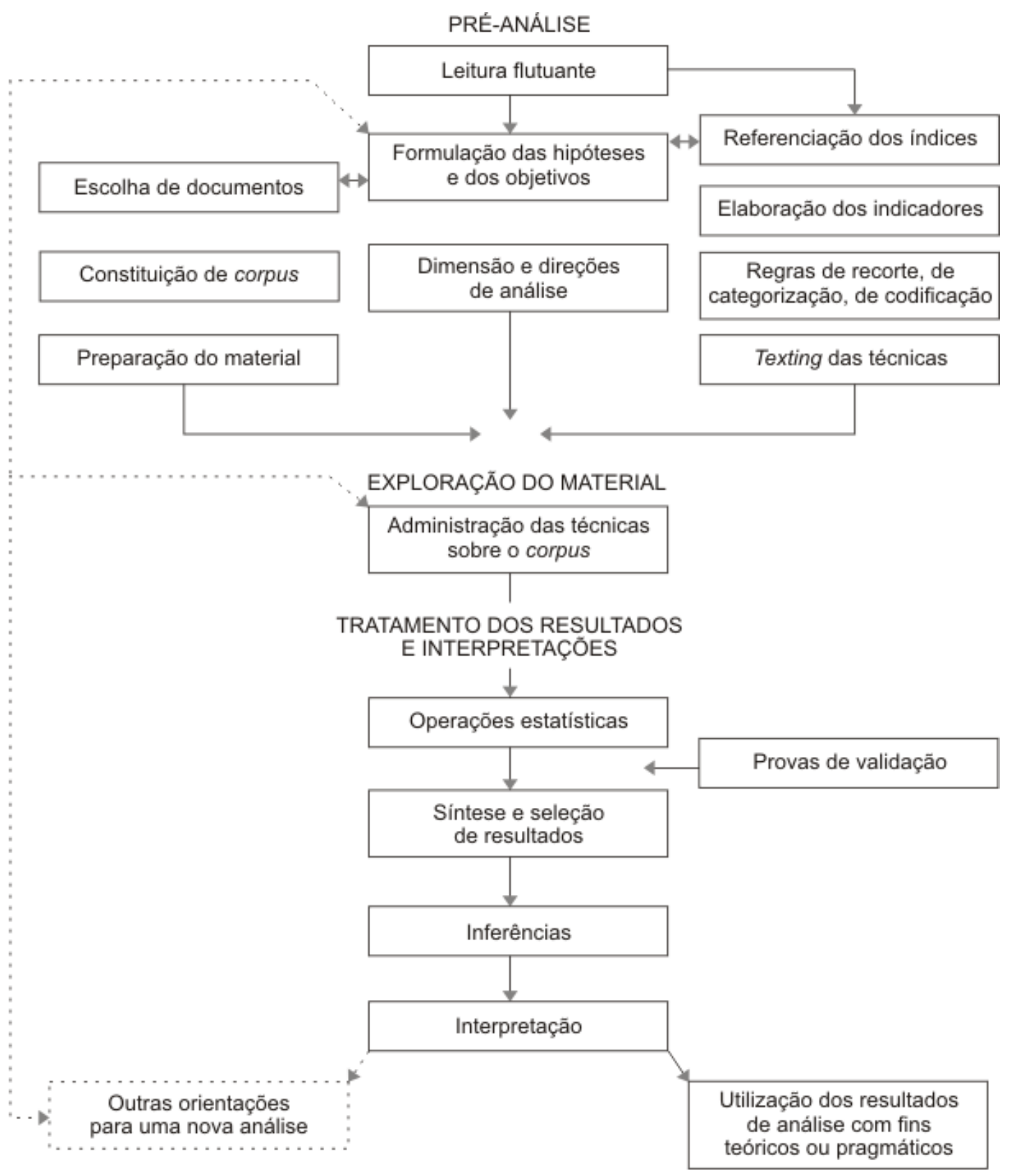

Fonte: Bardin, 1998, apud FONSECA JUNIOR, 2005

Por ser uma técnica que reúne o formalismo estatístico e a análise qualitativa, a metodologia se adequa perfeitamente a nossa pesquisa, que é prioritariamente 
qualitativa, mas que se utiliza também de amostragem não probabilística e de um questionário fechado, no caso das entrevistas com os usuários dos centros públicos de acesso, que será detalhado no capítulo 4. Assim, os recursos quantitativos estatísticos foram utilizados na categorização dos dados, através da classificação e reagrupamento das unidades de registro em um número reduzido de categorias (ver quadro 7), estruturas analíticas que reúnem e organizam o conjunto de informações obtidas a partir do fracionamento e da classificação em temas autônomos, mas inter-relacionados (DUARTE, 2005).

Quadro 7. Principais categorias de análise
\begin{tabular}{|l|l|}
\hline & Categorias \\
\hline 1 & Definição de Inclusão Digital \\
\hline 2 & Objetivos dos Programas de ID \\
\hline 3 & Principais atividades realizadas \\
\hline 4 & Impacto da Internet no consumo de informação pelo indivíduo \\
\hline 5 & Impacto da Internet na produção de informação pelo indivíduo \\
\hline 6 & $\begin{array}{l}\text { Contribuição dos programas de ID para o desenvolvimento sócio-econômico do individuo (real e esperado). } \\
\text { Sub categorias: oportunidade de geração de renda e emprego e oportunidades }\end{array}$ \\
\hline 7 & $\begin{array}{l}\text { Contribuição dos programas de ID para o desenvolvimento intelectual do individuo (real e esperado). Sub } \\
\text { categorias: oportunidades de educação, acesso à informação e cultura }\end{array}$ \\
\hline 8 & $\begin{array}{l}\text { Contribuição dos programas de ID para o desenvolvimento da cidadania (real e esperado). Sub categorias: } \\
\text { conscientização social e participação política }\end{array}$ \\
\hline 9 & Benefícios dos programas de ID para a comunidade (real e esperado) \\
\hline 10 & Desafios da ID \\
\hline
\end{tabular}

d) Estudo etnográfico - por último, ao visitarmos as unidades dos programas de inclusão digital selecionados (ver Figura 2) para a realização das entrevistas semidirigidas, foi utilizada complementarmente a técnica de etnografia (TRAVANCAS, 2005), observando seu funcionamento, infra-estrutura disponível e seu entorno, de forma a descrever e interpretar o contexto que está sendo estudado. 


\subsection{Coleta dos dados}

Nesta etapa da pesquisa serão apresentados os procedimentos relacionados à seleção dos programas de inclusão digital que fazem parte da pesquisa, assim como a construção de nossa amostra de entrevistados.

\subsubsection{Seleção dos programas}

A seleção dos programas de inclusão digital que fazem parte deste estudo teve início em 2003, quando passei a acompanhar o crescente - ainda que quase exclusivo a grandes capitais - desenvolvimento de iniciativas públicas referentes ao tema. Inicialmente foram identificados um conjunto de experiências, levando em consideração critérios como a região em que se localiza, a natureza da iniciativa (pública, terceiro setor, privada) e o público atendido. Foram pesquisados programas consistentes em todo o território nacional, buscando abranger os diferentes procedimentos metodológicos e experiências existentes (ver anexos 1 e 2). Foram selecionados em seguida os programas públicos com uma sólida atuação na comunidade, com mais anos de funcionamento, e que oferecessem acesso gratuito à Internet (quadro 8).

Quadro 8. Programas selecionados ${ }^{60}$

\begin{tabular}{|l|l|l|l|l|}
\hline & Programa & $N^{\circ}$ de Unidades & Data de criação & Atendimento \\
\hline 1 & Acessa São Paulo & 178 & Julho 2000 & 4 mil/mês \\
\hline 2 & Digitando o Futuro & 48 & Junho 2000 & 1,5 milhão de cadastros \\
\hline 3 & Telecentros Porto Alegre & 58 & 7 julho 2001 & $1,2 \mathrm{mil} / \mathrm{mês}$ \\
\hline
\end{tabular}

Obs.: Informações colhidas em outubro de 2005.

Por motivos históricos e sócio-econômicos, as primeiras iniciativas públicas de inclusão digital foram implementadas nas regiões sul e sudeste do país (ver figura 2). Após selecionados os programas, foi escolhida apenas uma unidade - ou centro público de acesso - de cada experiência para a realização das entrevistas com monitores e usuários. $\mathrm{O}$ recorte de amostragem qualitativo, apontado pelo coordenador de cada um dos programas, buscou atingir o CPA com maior movimento, para obter maior adesão nas respostas.

${ }^{60}$ Criado em junho de 2001, o programa Telecentros São Paulo - na época do levantamento com 117 unidades instaladas no município - também havia sido selecionado. Entretanto, devido a trocas de gestão e dificuldades de comunicação com a nova coordenação, não foi possível a realização das entrevistas. 


\section{Figura 7. Localização das CPAs selecionados}

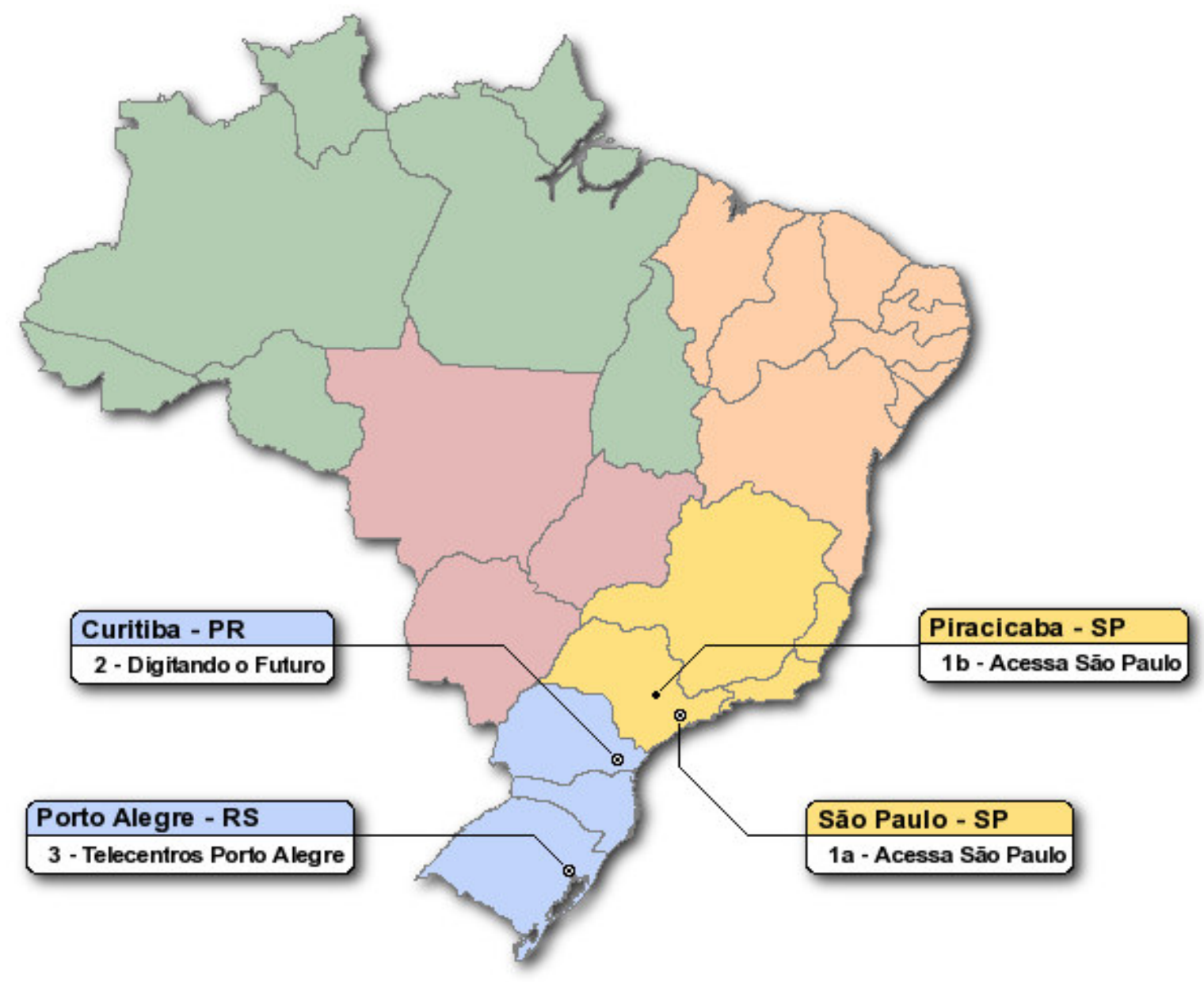

\subsubsection{Seleção dos entrevistados e amostragem}

A seleção das fontes é uma etapa essencial para que as entrevistas realizadas ajudem a responder o problema proposto. Em estudos qualitativos, como é o caso desta pesquisa, a seleção dos entrevistados tende a ser não probabilística. Segundo Duarte (2005), existem dois tipos básicos de amostras não probabilísticas: por conveniência ou intencional. A primeira é baseada na viabilidade, e ocorre quando as fontes são selecionadas por proximidade ou disponibilidade. No segundo caso o pesquisador seleciona o informante segundo o conhecimento específico que este possui em relação ao assunto tratado.

Neste estudo, as entrevistas semi-dirigidas foram definidas de forma empírica e intencional: 
a) os mentores da inclusão digital no país, personalidades relacionadas à concepção e desenvolvimento de programas de inclusão digital no Brasil, que coordenaram iniciativas-piloto ou influenciam as políticas públicas em âmbito nacional, foram selecionados a partir do acompanhamento do tema ao longo dos anos, e de minha experiência pessoal e de trabalho. Veja quadro abaixo:

\section{Quadro 9. Mentores selecionados}

\begin{tabular}{|c|c|c|}
\hline Nome & Função atual & Outras funções \\
\hline $\begin{array}{l}\text { Rogério Santanna } \\
\text { - entrevista piloto }\end{array}$ & $\begin{array}{l}\text { Secretário de Logística e Tecnologia da } \\
\text { Informação do MPO, membro do } \\
\text { CGI.br }\end{array}$ & $\begin{array}{l}\text { Idealizador do programa Telecentros de } \\
\text { Porto Alegre }\end{array}$ \\
\hline $\begin{array}{l}\text { Rodrigo } \\
\text { Assumpção }\end{array}$ & $\begin{array}{l}\text { Coordenador do Comitê de Inclusão } \\
\text { Digital do Governo Eletrônico }\end{array}$ & $\begin{array}{l}\text { Fundador e coordenador do Sampa.org, } \\
\text { ONG responsável pela primeira rede } \\
\text { pública do país }\end{array}$ \\
\hline Sérgio Amadeu & Pesquisador, professor universitário & $\begin{array}{l}\text { Idealizador do programa Telecentros } \\
\text { SP e Presidente do Inst. de Tecnologia } \\
\text { da Informação (ITI) }\end{array}$ \\
\hline Carlos Afonso & $\begin{array}{l}\text { Coordenador da RITS, membro do } \\
\text { CGI.br }\end{array}$ & Idealizador do Ibase/Alternex \\
\hline $\begin{array}{l}\text { Fernando } \\
\text { Guarnieri }\end{array}$ & Consultor & $\begin{array}{l}\text { Idealizador e coordenador do Programa } \\
\text { Acessa São Paulo }\end{array}$ \\
\hline Gilson Schwartz & $\begin{array}{l}\text { Professor universitário e coordenador } \\
\text { da Cidade do Conhecimento }\end{array}$ & Articulista da Folha de São Paulo \\
\hline Beatriz Tibiriça & Coordenadora da ONG Coletivo Digital & $\begin{array}{l}\text { Coordenadora do Programa Telecentros } \\
\text { SP }\end{array}$ \\
\hline Rodrigo Baggio & Coordenador CDI & \\
\hline
\end{tabular}

b) os coordenadores e monitores entrevistados foram apontados respectivamente pelos programas de inclusão digital e pelas unidades selecionadas, conforme apresentado no quadro 10 .

c) as entrevistas fechadas com os usuários dos centros públicos ${ }^{61}$ de acesso foram baseadas na disponibilidade e interesse dos mesmos. Durante 15 dias os questionários foram divulgados em cada um dos três centros público visitados, e foram respondidos via Internet. Nossa amostra correspondeu ao total de questionários respondidos voluntariamente nesse período (ver item 3.2.3).

\footnotetext{
${ }^{61}$ Os usuários dos centros públicos de acesso investigados são o objeto principal para a identificação das contribuições das TICs no consumo e produção de informação. É importante ressaltar que foram entrevistados usuários de Internet em programas de ID, e não usuários Internet de baixa renda que possuem acesso em suas casas ou trabalho, e apresentam assim um desenvolvimento diferenciado em relação à ferramenta virtual em questão.
} 
Quadro 10. Unidades, Monitores selecionados e Lideranças

\begin{tabular}{|c|c|c|c|}
\hline $\begin{array}{l}\text { Nome do } \\
\text { Programa }\end{array}$ & Coordenador & $\begin{array}{l}\text { Unidade } \\
\text { selecionada }\end{array}$ & Monitores \\
\hline \multirow{5}{*}{$\begin{array}{l}\text { Acessa São } \\
\text { Paulo }\end{array}$} & \multirow{5}{*}{$\begin{array}{l}\text { Maria Amélia Kuhlman Fernandes, } \\
\text { coordenadora operacional (entrevista } \\
\text { piloto) }\end{array}$} & \multirow{3}{*}{$\begin{array}{l}\text { Infocentro } \\
\text { Comunitário } \\
\text { SAVIC }\end{array}$} & Kleber Cardoso \\
\hline & & & Rodrigo Nascimento \\
\hline & & & $\begin{array}{l}\text { Nivaldo Cardoso (líder } \\
\text { comuniátirio) }\end{array}$ \\
\hline & & \multirow{2}{*}{$\begin{array}{l}\text { Infocentro } \\
\text { Piracicaba }\end{array}$} & Paula Okuda \\
\hline & & & Junior Batista da Silva \\
\hline $\begin{array}{l}\text { Digitando o } \\
\text { Futuro }\end{array}$ & $\begin{array}{l}\text { Fabricio Zanini (ex-coordenador) } \\
\text { Rosane Carvalho Pólli, gerente dos } \\
\text { Faróis do Saber }\end{array}$ & $\begin{array}{l}\text { Farol Aristides } \\
\text { Vinholes }\end{array}$ & Eli Élcio \\
\hline \multirow[b]{2}{*}{$\begin{array}{l}\text { Telecentros } \\
\text { Porto Alegre }\end{array}$} & \multirow{2}{*}{$\begin{array}{l}\text { Leandro Silva, assessor da coordenação } \\
\text { Secretaria Municipal de Direitos } \\
\text { Humanos e Segurança Pública }\end{array}$} & \multirow{2}{*}{$\begin{array}{l}\text { Associação } \\
\text { Comunitária } \\
\text { Campo da } \\
\text { TUCA }\end{array}$} & Cinara da Costa Dias \\
\hline & & & $\begin{array}{l}\text { Antônio Inácio Matos da } \\
\text { Silva (líder comunitário) }\end{array}$ \\
\hline
\end{tabular}

\subsubsection{Aplicação dos questionários}

As entrevistas com mentores, coordenadores e monitores foram realizadas através de um roteiro de perguntas, construído de forma empírica, tendo como base no quadro teórico, a leitura constante de jornais e revistas, e nossa experiência pessoal e de trabalho (ver anexos 3, 4 e 5). No total, foram gravadas e transcritas 22,5 horas de depoimentos (ver quadros 11, 12 e 13).

Já o formulário eletrônico (ver anexo 6) elaborado para a aplicação do questionário estruturado dirigido aos usuários dos programas de inclusão digital, teve como modelo as duas pesquisas sobre uso da Internet, realizadas pela RITS para a Prefeitura de São Paulo, em 2004, e pela Escola do Futuro, para o Programa Acessa São Paulo, do Governo do Estado de São Paulo, em 2005 .

Projeto Piloto - Para a validação dos questionários foi realizado inicialmente um projeto piloto na unidade da capital do programa Acessa São Paulo ${ }^{62}$. Como o programa possui dois coordenadores, nesta etapa foram entrevistados Maria Amélia, coordenadora operacional, e os monitores do Infocentro Sociedade Amigos da Vila Constança SAVIC, localizado na zona norte do município de São Paulo, e indicado pela

\footnotetext{
${ }^{62}$ Para o estudo exploratório serão feitas entrevistas em uma unidade do Acessa São Paulo no interior do Estado, no Infocentro de Piracicaba.
} 
coordenação. A entrevista com a coordenadora Maria Amélia, realizada no dia 20 de janeiro 2006, teve a duração de uma hora e ocorreu sem incidentes, validando a estrutura do questionário.

A visita ao Infocentro SAVIC foi realizada no dia 7 de fevereiro de 2006, após alguns contatos iniciais com a coordenação do programa. Os monitores Kleber Cardoso e Rodrigo Nascimento, assim como o líder comunitário da associação de bairro que hospeda o infocentro, Nivaldo Cardoso, foram muito receptivos ao projeto, respondendo prontamente as questões e dúvidas apresentadas. Em seguida, expliquei detalhadamente como seria realizada a pesquisa pela Internet com os usuários. Sua colaboração foi muito importante para que os usuários entendessem os procedimentos adotados, o que garantiu o mais alto nível de respostas voluntárias nesses 15 dias. No processo foram identificados problemas técnicos para a aplicação dos mesmos, os formulários, escritos em php e javascript não abriam corretamente nos browser dos infocentros, que utilizam navegadores em Linux sem suporte ao Java. Tive assim que reescrever os formulários, evitando o uso da ferramenta, que por ocultar partes do questionário, deixava-o menor e mais fluido. Voltei ao infocentro 15 dias depois para inquirir sobre possíveis dificuldades e recolher observações dos usuários que responderam a pesquisa. Em geral, não houve dificuldade, apesar do questionário ter sido considerado um pouco longo. A única alteração realizada no questionário foi justamente relativa ao conceito de “inclusão digital”, que causou muitas dúvidas aos respondentes. Assim, substituímos a questão aberta que pergunta "o que a inclusão digital significa para você" por "o que a Internet significa para você”.

Também foi realizada uma entrevista-piloto com um representante do grupo dos mentores, no caso o Secretário de Logística e Tecnologia da Informação do Ministério do Planejamento, Orçamento e Gestão e conselheiro do Comitê Gestor da Internet no Brasil, Rogério Santanna, que foi o idealizador do programa telecentros de Porto Alegre quando era presidente da Procempa - Empresa de Tecnologia da Informação e Comunicação de Porto Alegre (ver quadro 9). 


\section{Mentores da inclusão digital no Brasil}

Os encontros com os oito mentores identificados foram presenciais, com exceção apenas da entrevista com Rodrigo Baggio, realizada por telefone, e tiveram a duração média de $1 \mathrm{~h} 30$, totalizando quase 12 horas de entrevista, conforme está apresentado no quadro 11 abaixo. Com estes depoimentos pretende-se compreender melhor o cenário da inclusão digital no país, seu surgimento e suas perspectivas futuras.

\section{Quadro 11. Entrevistas com Mentores}

\begin{tabular}{|l|c|c|}
\hline Nome & Data & Duração \\
\hline Rogério Santanna - entrevista piloto & 16 e $17 / 02 / 06$ & $1 \mathrm{~h} 20$ \\
\hline Rodrigo Assumpção & $23 / 02 / 06$ & $2 \mathrm{~h} 04$ \\
\hline Sérgio Amadeu & $21 / 03$ e $09 / 05 / 06$ & $1 \mathrm{~h} 46$ \\
\hline Carlos Afonso & $07 / 04 / 06$ & $1 \mathrm{~h} 10$ \\
\hline Fernando Guarnieri & $10 / 04 / 06$ & $1 \mathrm{~h} 30$ \\
\hline Gilson Schwartz & $11 / 05 / 06$ & $1 \mathrm{~h} 44$ \\
\hline Beatriz Tibiriça & $17 / 05 / 06$ & $45 \mathrm{~min}$ \\
\hline Rodrigo Baggio & $05 / 06 / 06$ & $1 \mathrm{~h} 20$ \\
\hline & & TOTAL - 11h39 \\
\hline
\end{tabular}

\section{Coordenadores dos programas}

Para a realização das entrevistas com coordenadores e monitores foram efetuadas três visitas de campo nos CPA apontados pela coordenação de cada um dos programas de inclusão digital selecionados. Cada visita, no Infocentro de Piracicaba, no interior de São Paulo, no Telecentro Turma da TUCA, em Porto Alegre, e no Farol do Saber Aristides Vinholes, em Curitiba, teve uma duração média de quatro horas, durante as quais foi realizada uma breve pesquisa etnográfica, além das entrevistas com coordenadores e monitores.

Os coordenadores (quadro 12) dos programas de inclusão digital selecionados foram convidados inicialmente, por e-mail, a participar do projeto. Na mensagem (ver anexo E) apresentei o projeto de pesquisa, pedi algumas informações sobre o programa e uma sugestão de unidade para a pesquisa de campo, além de solicitar uma formalização de aceitação do convite. 
Quadro 12. Entrevistas com os Coordenadores dos programas

\begin{tabular}{|l|l|l|l|l|}
\hline $\boldsymbol{N}^{\boldsymbol{o}}$ & Nome do Programa & Coordenador & Data & Duração \\
\hline 1 & Acessa São Paulo & $\begin{array}{l}\text { Maria Amélia Kuhlman Fernandes } \\
\text { (entrevista piloto) }\end{array}$ & $20 / 01 / 06$ & $1 \mathrm{~h}$ \\
\hline 2 & Digitando o Futuro & Fabricio Zanini (ex-coordenador) & $17 / 03 / 06$ & $25 \mathrm{~min}$ \\
\hline 2 & Digitando o Futuro & Rosane Carvalho Pólli, & $17 / 03 / 06$ & $34 \mathrm{~min}$ \\
\hline 1 & Acessa São Paulo & Ricardo Kobashi & $21 / 03 / 06$ & $2 \mathrm{~h} 49$ \\
\hline 1 & Acessa São Paulo & Drica Guzzi (Escola do Futuro & $29 / 03 / 06$ & $2 \mathrm{~h}$ \\
\hline 3 & Telecentros Porto Alegre & Leandro Silva & $19 / 04 / 06$ & $48 \mathrm{~min}$ \\
\hline & & & TOTAL & $\mathbf{7 h 3 6}$ \\
\hline
\end{tabular}

As respostas não foram obtidas todas do primeiro contato. Em alguns casos foram realizados vários chamados telefônicos até a obtenção de uma resposta positiva. $\mathrm{O}$ processo teve início de junho de 2005 e se estendeu até o início da coleta de campo, em janeiro de 2006. No período que compreende o início dos contatos com a coordenação dos programas até a conclusão da pesquisa de campo, em junho de 2006, mudanças organizacionais e na gestão dos programas dificultaram o trabalho: por exemplo, no Acessa São Paulo, Fernando Guarnieri saiu da coordenação e Ricardo Kobashi assumiu, em parceria com Maria Amélia, e no Digitando o Futuro, Fabrício Zanini se desligou do projeto, sendo substituído por Rosane Pólli apenas dois meses antes de nossa visita à Curitiba para o trabalho de campo.

É importante mencionar que o contato com os mentores foi bem mais fácil, dado que conheci a maior parte deles no período de 2002 a 2004, quando trabalhei diretamente com projetos de inclusão digital na Cidade do Conhecimento da USP. O agendamento das entrevistas foi breve, por e-mail. Entretanto, no período de junho a outubro, três deles mudaram de função no governo ou atuação em programas de inclusão digital: Sérgio Amadeu saiu da presidência do Instituto de Tecnologia da Informação, da Casa Civil da Presidência da República; Ricardo Kobashi, considerado inicialmente como mentor, assumiu a coordenação técnica do Acessa São Paulo, e Fernando Guarnieri, antigo coordenador do Acessa, mudou para o grupo dos mentores ${ }^{63}$.

Assim como no caso dos mentores, procurei com estas entrevistas pensar o conceito de inclusão digital através da definição conceitual e da experiência prática dos coordenadores, identificar os objetivos e desafios desses programas e discutir o papel

\footnotetext{
${ }^{63}$ Lembrando que forma considerados mentores as personalidades que participaram da construção dos primeiros programas de acesso comunitário, coordenaram iniciativas-piloto de inclusão digital e/ou influenciam as políticas públicas em âmbito nacional.
} 
das novas tecnologias da informação para a construção da cidadania no contexto da sociedade da informação. Busquei ainda investigar a existência ou não, nestes programas, de objetivos relativos ao consumo e produção de informação pelas comunidades excluídas, e se estes vem sendo atendidos.

As entrevistas com os coordenadores tiveram durações variadas, se estendendo de 30 minutos a 3 horas, dependendo do entrevistado (ver quadro 12), e totalizando cerca de 8 horas. Com os monitores passei de 10 minutos a quase uma hora, somando pouco mais de 3 horas de depoimentos. No Acessa São Paulo, além da entrevista com Maria Amélia realizada como piloto, conversei com Ricardo Kobashi, que assumiu a coordenação em julho de 2005, e com Drica Guzzi, que desde 2001 responde pela coordenação pedagógica do programa, através da Escola do Futuro. Em Curitiba, conversei com o ex-coordenador, Fabrício Zanini, e com a coordenadora que acabara de assumir, Rosane Pólli. E em Porto Alegre entrevistei Leandro Silva, assessor da Secretaria Municipal de Direitos Humanos e Segurança Urbana, órgão ao qual o programa Telecentros está ligado.

\section{Monitores dos programas de ID e aplicação do formulário on-line para usuários}

Como mencionado anteriormente, a seleção das unidades (quadro 10) ficou a critério do coordenador de cada programa, com a intenção de atingir o CPA com maior movimento, para obter maior adesão nas respostas. Entrevistei os monitores responsáveis pelas unidades selecionadas seguindo o roteiro desenvolvido (anexo C). Foram realizadas ainda duas entrevistas abertas, sem roteiro pré-estabelecido, com os líderes comunitários de duas unidades investigadas: Nivaldo Cardoso, da Associação Sociedade Amigos da Vila Constança, que mantém o Infocentro SAVIC, e Antônio Inácio Matos da Silva, da Associação Comunitária Campo da TUCA, em Porto Alegre. As duas entrevistas não estavam previstas, mas foram importantes para desenhar o histórico das unidades e sua relação com a coordenação dos mesmos. Veja quadro abaixo: 
Quadro 13. Entrevistas com Monitores e Lideranças

\begin{tabular}{|c|c|c|c|c|c|}
\hline$N^{o}$ & $\begin{array}{l}\text { Nome do } \\
\text { Programa }\end{array}$ & Unidade selecionada & Monitores & Data & Duração \\
\hline 1a & \multirow{4}{*}{$\begin{array}{l}\text { Acessa São } \\
\text { Paulo }\end{array}$} & \multirow{2}{*}{$\begin{array}{l}\text { Infocentro Comunitário } \\
\text { SAVIC }\end{array}$} & Kleber Cardoso & $06 / 02 / 06$ & $27 \mathrm{~min}$ \\
\hline $1 \mathrm{a}$ & & & Rodrigo Nascimento & $06 / 02 / 06$ & $24 \min$ \\
\hline $\mathbf{1 b}$ & & \multirow{2}{*}{ Infocentro Piracicaba } & Paula Okuda & $08 / 04 / 06$ & $55 \mathrm{~min}$ \\
\hline 1b & & & Junior Batista da Silva & $08 / 04 / 06$ & $12 \mathrm{~min}$ \\
\hline 2 & $\begin{array}{l}\text { Digitando o } \\
\text { Futuro }\end{array}$ & Farol Aristides Vinholes & Eli Élcio & $17 / 03 / 06$ & $9 \min$ \\
\hline \multirow[t]{5}{*}{3} & $\begin{array}{l}\text { Telecentros } \\
\text { Porto Alegre }\end{array}$ & $\begin{array}{l}\text { Associação Comunitária } \\
\text { Campo da TUCA }\end{array}$ & Cinara da Costa Dias & 20/04/06 & $10 \mathrm{~min}$ \\
\hline & & & Líder Comunitário & & \\
\hline & $\begin{array}{l}\text { Acessa São } \\
\text { Paulo }\end{array}$ & $\begin{array}{l}\text { Infocentro Comunitário } \\
\text { SAVIC }\end{array}$ & Nivaldo Cardoso & $06 / 02 / 06$ & $37 \mathrm{~min}$ \\
\hline & $\begin{array}{l}\text { Telecentros } \\
\text { Porto Alegre }\end{array}$ & $\begin{array}{l}\text { Associação Comunitária } \\
\text { Campo da TUCA }\end{array}$ & $\begin{array}{l}\text { Antônio Inácio Matos da } \\
\text { Silva }\end{array}$ & $20 / 04 / 06$ & $20 \min$ \\
\hline & & & & TOTAL & 3h14 \\
\hline
\end{tabular}

O questionário para os usuários dos programas (ver anexo D), aplicado através de um formulário eletrônico via Internet, ficou disponível no endereço eletrônico http://www.comunidades.org.br/pesquisa durante 15 dias, em cada CPA visitado. Os monitores foram instruídos a convidar os usuários a participar da pesquisa voluntariamente, informar o link da pesquisa e esclarecer dúvidas. O formulário foi desenvolvido utilizando ferramentas compatíveis com todos os sistemas operacionais. Mesmo assim apresentaram problemas de compatibilidade com o browser e/ou sistema operacional utilizado nos CPAS e parte das questões obtidas nos Telecentros de Porto Alegre acabaram não sendo respondidas. Das respostas obtidas, os questionários válidos totalizaram 84. Ver quadro abaixo:

Quadro 14. Questionário de usuários respondidos

\begin{tabular}{|c|l|l|l|}
\hline$N^{\boldsymbol{o}}$ & Nome do Programa & Unidade selecionada & Total de respostas \\
\hline 1a - piloto & Acessa São Paulo & Infocentro SAVIC & 32 \\
\hline 1b & Acessa São Paulo & Infocentro Piracicaba & 13 \\
\hline 2 & Digitando o Futuro & Farol Aristides Vinholes & 9 \\
\hline 3 & Telecentros Porto Alegre & Turma da TUCA & 30 \\
\hline
\end{tabular}




\section{APRESENTAÇÃO DOS DADOS}

Nesta etapa primeiramente será apresentada uma breve descrição dos programas de inclusão digital e das unidades selecionadas, assim como o resultado das entrevistas realizadas com mentores da inclusão digital, coordenadores, monitores e usuários dos centros púbicos de acesso à Internet pesquisados.

\subsection{Descrição dos programas de inclusão digital selecionados}

\subsubsection{Acessa São Paulo}

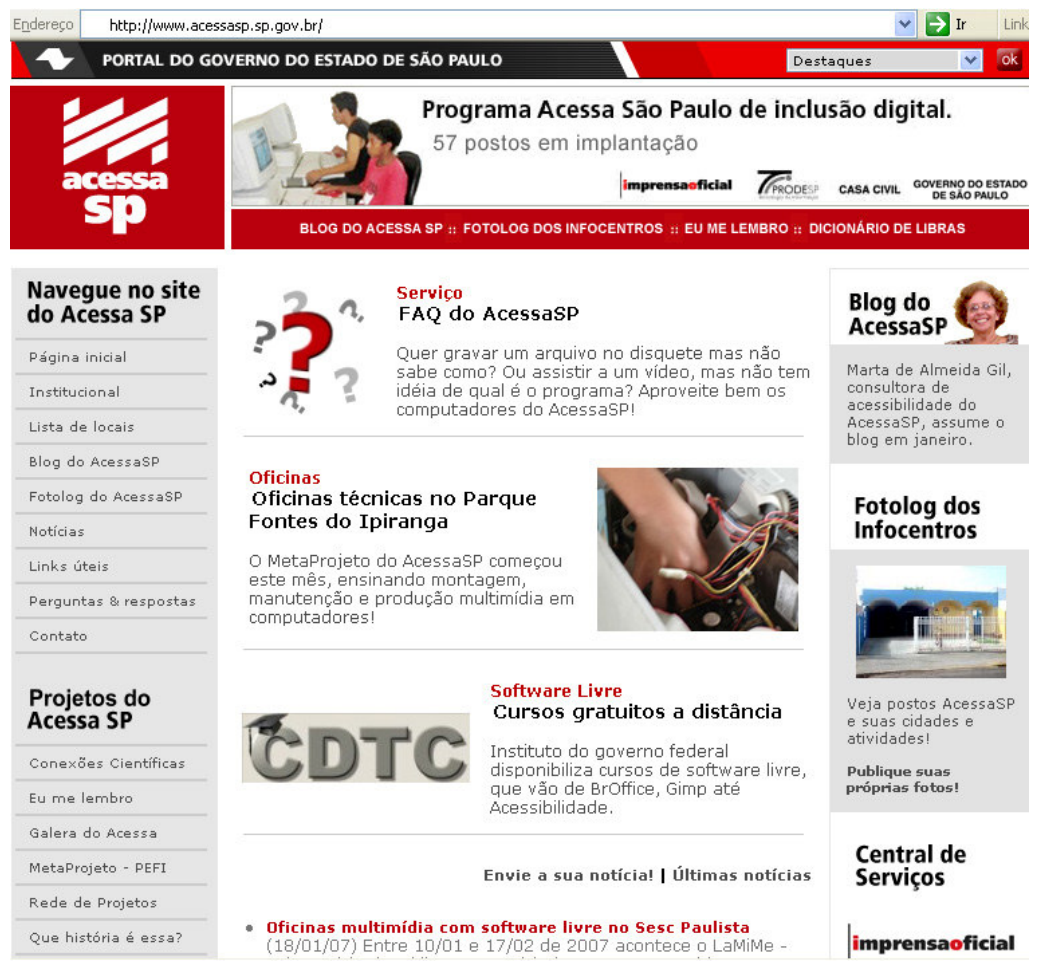

Figura 8. Acessa São Paulo (Acesso em janeiro de 2007)

O Programa Acessa São Paulo, criado em julho de 2000, é uma iniciativa do governo do Estado de São Paulo, com o objetivo de levar os recursos da Internet à população de baixa renda e estimular o desenvolvimento humano e social das comunidades. É a maior rede do país, e em outubro de 2005 contava com 178 infocentros em funcionamento, sendo 77 na capital e 101 em municípios do interior e do litoral. No final de 2006 já eram 400 unidades em todo o estado, e mais de 1 milhão de usuários cadastrados. 
Existem três tipos de infocentros: os comunitários, em parceria com associações de bairros e outras entidades comunitárias; os municipais, em parcerias com prefeituras; e os postos públicos de acesso à Internet (POPAI), em parceria com órgãos do próprio governo estadual. No Infocentro Comunitário, o Governo do Estado fornece os equipamentos, suporte técnico e suprimentos, assim como o salário e a capacitação dos monitores; a entidade com a qual é realizada a parceria se responsabiliza pela manutenção da sala e pelas despesas cotidianas, como energia elétrica e limpeza. $\mathrm{O}$ Infocentro Municipal é uma parceria do Estado com as prefeituras, que se encarregam da manutenção da sala, despesas cotidianas, suprimentos, suporte técnico e salário dos funcionários; o Estado entra com os equipamentos e a capacitação dos monitores. Nos POPAIs todas as responsabilidades são do governo estadual: instalações, funcionários, equipamentos e manutenção. A capacitação dos monitores e produção de conteúdo focado no exercício da cidadania para o programa é realizada pela Escola do Futuro, da Universidade de São Paulo. Nas salas com 10 computadores e acesso em banda larga (onde é possível), os usuários têm garantido o acesso livre e a possibilidade de desenvolver projetos comunitários. A coordenação e financiamento do projeto estão a cargo da Imprensa Oficial do Governo de São Paulo.

\subsubsection{Telecentros Porto Alegre}

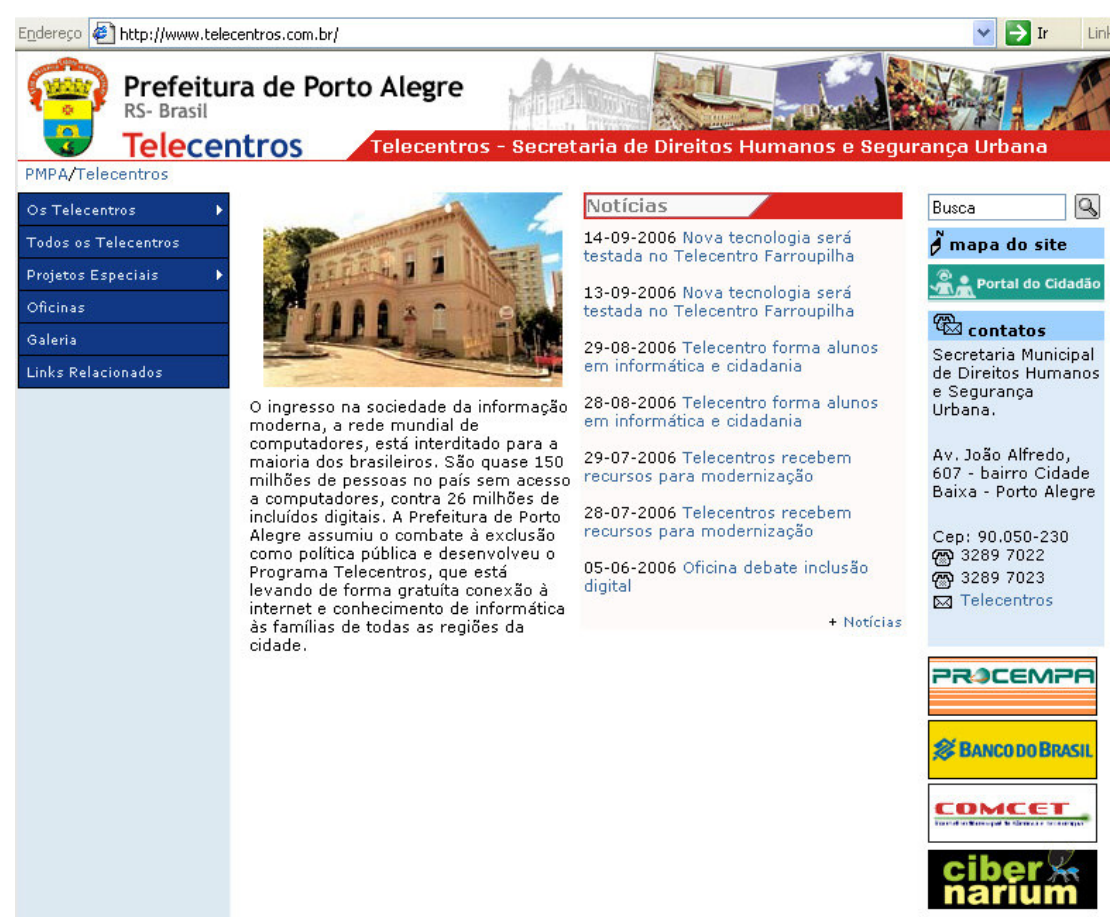

Figura 9. Telecentros Porto Alegre (Acesso em janeiro de 2007) 
O primeiro telecentro de Porto Alegre foi inaugurado em 7 de julho de 2001, num bairro carente da capital, no Parque Chico Mendes. Coordenado pela PROCEMPA (Companhia de Processamento de Dados do Município de Porto Alegre) e pela Secretaria Municipal de Direitos Humanos e Segurança Urbana, o projeto conta com a parceria de associações de bairro, de ONGs e da iniciativa privada. Cada unidade possui um conselho gestor e decide localmente as atividades que serão realizadas no telecentro, em geral cursos básicos de informática, além do acesso gratuito à Internet, com tecnologia ADSL, para a comunidade do entorno. Os equipamentos são fornecidos pela Prefeitura, que através de convênio realiza um repasse de verbas para o pagamento do salário dos monitores e despesas de manutenção. Em outubro de 2005 havia 58 telecentros em funcionamento no município, sendo que a escolha do local para a instalação de cada um deles foi feita pela comunidade, via associações de moradores do bairro. Além do uso dos computadores, são desenvolvidas atividades culturais e alfabetização de adultos nos pontos de acesso (DIAS, 2003). Atualmente 25 unidades estão em atividade, devido à reestruturação do programa, ocorrida após a mudança da administração municipal, tema que será futuramente tratado neste capítulo.

\subsubsection{Digitando o Futuro}

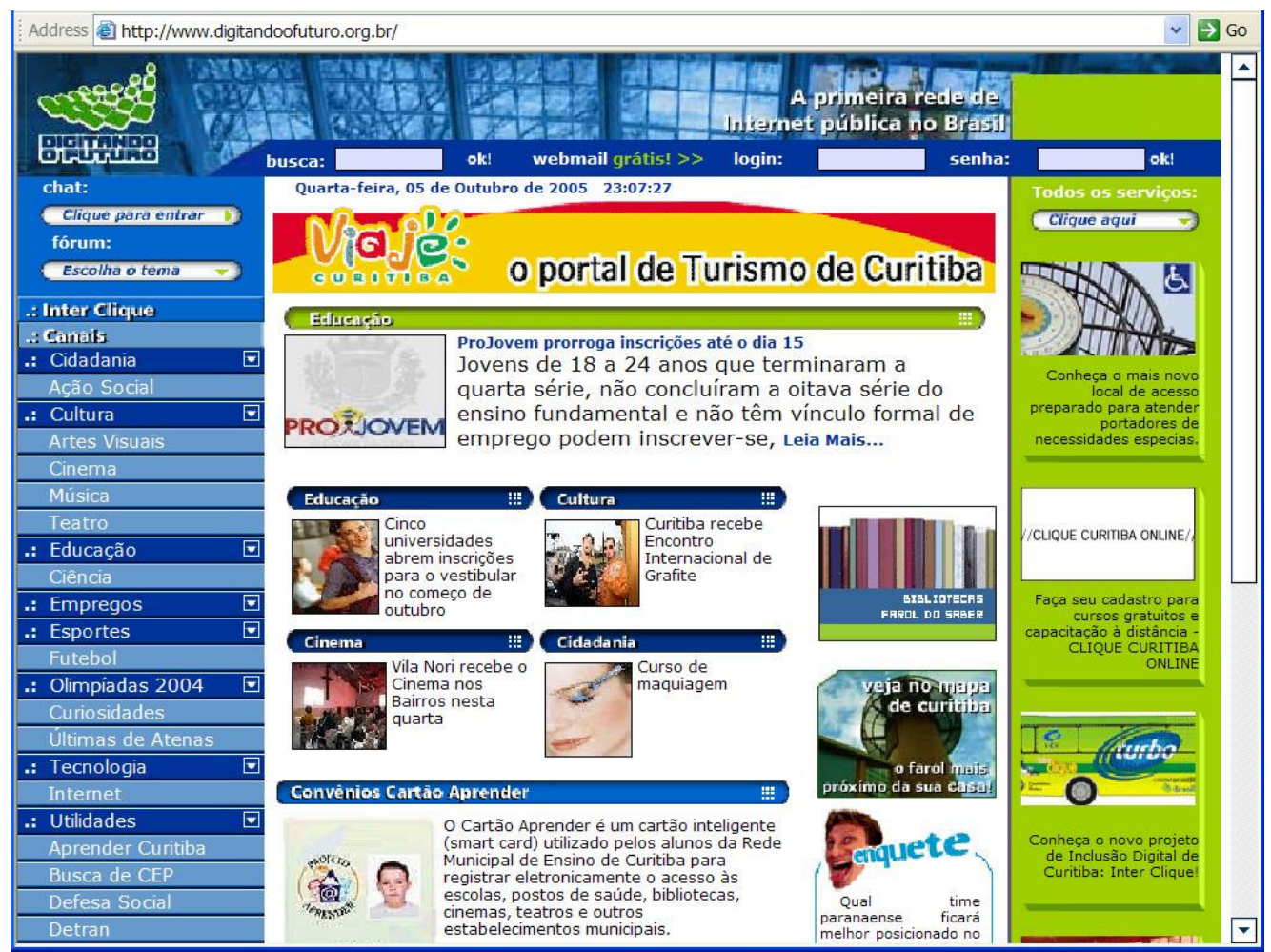

Figura 10. Digitando o Futuro (Acesso em março de 2006) 
Elaborado pela prefeitura de Curitiba, no Paraná, o Digitando o Futuro foi o primeiro projeto de inclusão digital público implantado no país, em julho de 2000. Para levar a Internet à população carente, a Secretaria Municipal de Educação (SME), em parceria com o Instituto Curitiba de Informática (ICI), transformou bibliotecas comunitárias, conhecidas como Faróis do Saber, em pontos públicos de acesso. Em outubro de 2006 havia 48 unidades em funcionamento, todas equipadas com nove micros, impressora e scanner, garantindo acesso gratuito em banda larga para pessoas de baixa renda. Apenas três pontos de acesso não estão dentro dos Faróis do Saber, um na Rua 24 Horas, que fica permanentemente à disposição da população, e outros dois nas Ruas da Cidadania e do Boqueirão. Os monitores, estudantes de $2^{\circ}$ e $3^{\circ}$ graus, eram treinados pelo ICI até o final de 2006, quando o Instituto foi desligado do programa, que passou a se chamar Cidade do Conhecimento, ficando totalmente sob a coordenação da SME.

\subsection{Descrição das unidades selecionadas}

Para as entrevistas com monitores e aplicação do questionário de usuários foram visitadas as unidades indicadas pelos coordenadores de cada projeto. Na oportunidade, foi realizado um estudo etnográfico identificando as características do local onde as unidades se encontram, seu entorno e funcionamento (veja comparativo no quadro 15, p. 68). As lideranças das duas unidades que se encontram em associações comunitárias também foram ouvidas, Nivaldo Cardoso, da Associação Comunitária Vila Constança, na zona norte de São Paulo, e Antônio Inácio Matos da Silva, da Associação de Bairro Campo da Tuca, em Porto Alegre.

\subsubsection{Infocentro SAVIC}

Instalado na Associação Comunitária Sociedade Amigos de Vila Constança (SAVIC), em um bairro periférico da Zona Norte da cidade de São Paulo - o maior centro urbano da América Latina, com $1.509 \mathrm{~km}^{2}$ de extensão e aproximadamente 11 milhões de 


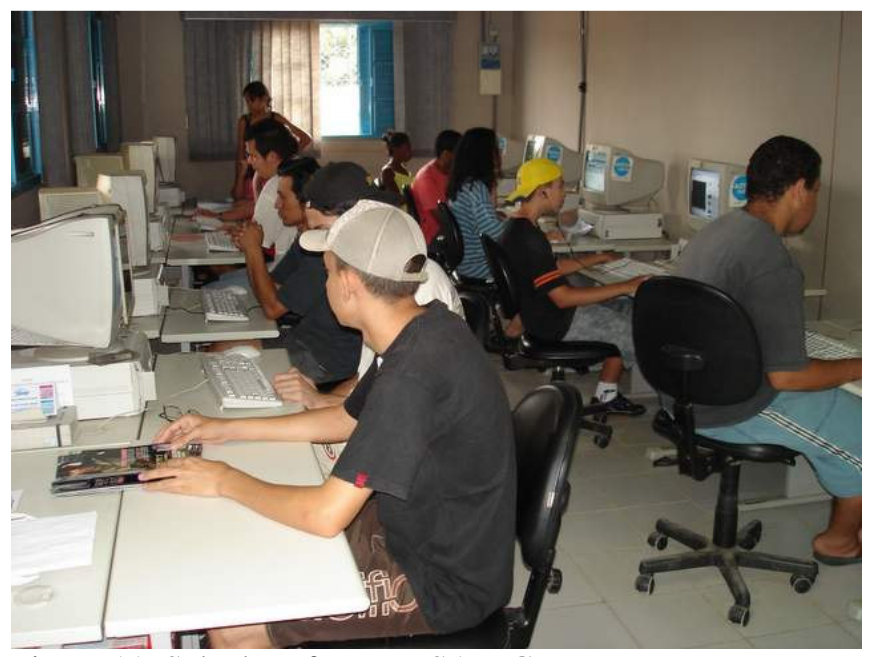

Figura 11. Sala do Infocentro SAVIC

habitantes ${ }^{64}$, entre eles $4,9 \%$ de analfabetos e $12,6 \%$ de desempregados ${ }^{65}-$, o Infocentro SAVIC foi uma das primeiras unidades do programa Acessa São Paulo a entrar em funcionamento, em julho de 2000. Desde sua inauguração, já contabilizou mais de 100 mil atendimentos - em média 180 por dia, a maior freqüência entre os CPAs estudados. A sala com 10 computadores ligados a um servidor rodando em Linux é simples, mal iluminada e ligeiramente apertada.

Mas a infra-estrutura da associação é considerada boa, e os usuários podem aguardar pela utilização dos computadores sentados em um banco de madeira, em frente ao campo de futebol da entidade. O prédio abriga um grande salão e quatro salas comunitárias de ensino básico e fundamental: "Fomos obrigados a colocar essas salas

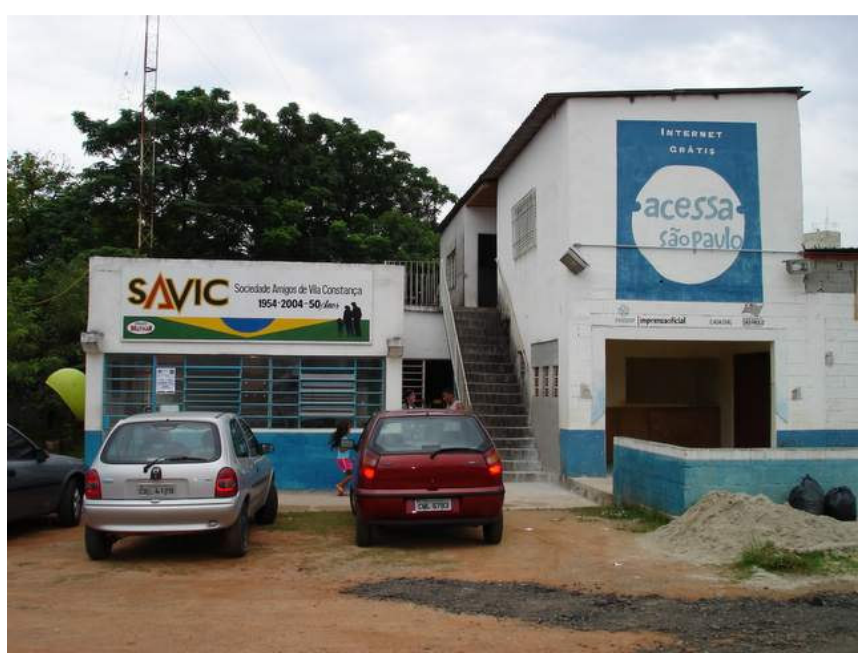

Figura 12. Entrada da Associação SAVIC por falta de escolas para educação infantil na região”, explica Nivaldo Cardoso, 47 anos, presidente da SAVIC. Criada em 1954, além do infocentro, a entidade oferece uma série de atividades e programas educacionais e de lazer para a comunidade, incluindo uma creche e seis salas de MOVA - Movimento de Alfabetização de Jovens e Adultos. A SAVIC participa ainda de programas de distribuição de cestas básicas e leite para as famílias pobres, e atua fortemente na luta pela melhoria das condições de vida na região.

\footnotetext{
${ }^{64}$ Segundo estimativa da PNAD 2005 (IBGE).

${ }^{65}$ Segundo levantamento da Fundação SEADE de novembro de 2006.
} 
O programa Acessa São Paulo não oferece cursos. No entanto, o infocentro é utilizado pela SAVIC para o ensino de crianças e idosos, através da Rede de Projetos. Cada usuário pode utilizar o infocentro por 30 minutos, o equivalente a um atendimento. Os iniciantes recebem ajuda dos monitores. Eleito em 1997, Nivaldo está no segundo mandato e atua na área assistencial há 15 anos. Profissional da área de vendas, chegou a cursar uma faculdade de administração de empresas, mas não concluiu.

\begin{abstract}
A Savic começou por conta de problemas sociais de uma região bastante complicada. Segundo a Fundação Seade, 8\% dos internos da Febem são aqui do Jardim Brasil, esse bairro vizinho que é separado pelo Córrego da Paciência. Então a violência entre jovens é muito grande. O Governo atua muito pouco aqui, só através da Polícia mesmo, o que não resolve nenhum problema, se não for uma coisa preventiva... Então nós nos propusemos a entrar nessa briga, conta.
\end{abstract}

Mesmo com vários convênios públicos com o governo estadual e municipal, é a comunidade quem oferece o suporte direto à entidade. "Infelizmente o Governo pensa nos projetos, mas não nas dificuldades da entidade", lamenta. Segundo Nivaldo, o Acessa SP é um projeto que agrega muito valor para a instituição, mas tem um custo operacional de energia, água e manutenção muito grande, que ainda não foi resolvido. "A gente sabe da importância da inclusão digital, enfim, por esse lado ele é excepcional. A Imprensa Oficial contrata os meninos, que estão gerenciando os projetos, mas o problema da energia todos os infocentros têm", explica.

Pelo modelo do Acessa São Paulo, a entidade comunitária fornece a sala e se encarrega da sua manutenção, o governo estadual provê os computadores, a assistência técnica, os suprimentos de tinta e papel, e o salário de dois monitores. A Escola do Futuro da USP realiza as capacitações técnicas e pedagógicas, provendo suporte direto aos monitores.

Nivaldo não tem nenhuma preocupação de que o infocentro feche. "Aqui na SAVIC ele não acaba nunca mais, a comunidade é muito unida", garante, mesmo no caso de uma eventual mudança de administração do Estado nas futuras eleições.

A questão política dentro da SAVIC bate forte. Aqui na região praticamente não se faz política sem passar por aqui. Pra você ter uma idéia, politicamente, na eleição de prefeito, no ano passado, teve o Maluf aqui, o Serra, a Marta ficou de vir, acabou não aparecendo, pela nossa cara aqui de... porque nós não ficamos em cima do muro aqui não, nós atuamos na eleição em política partidária pública", conta, sugerindo que para garantir ainda mais a estabilidade do programa seria interessante que ele fosse "uma Lei Estadual mesmo. 


\subsubsection{Infocentro Piracicaba}

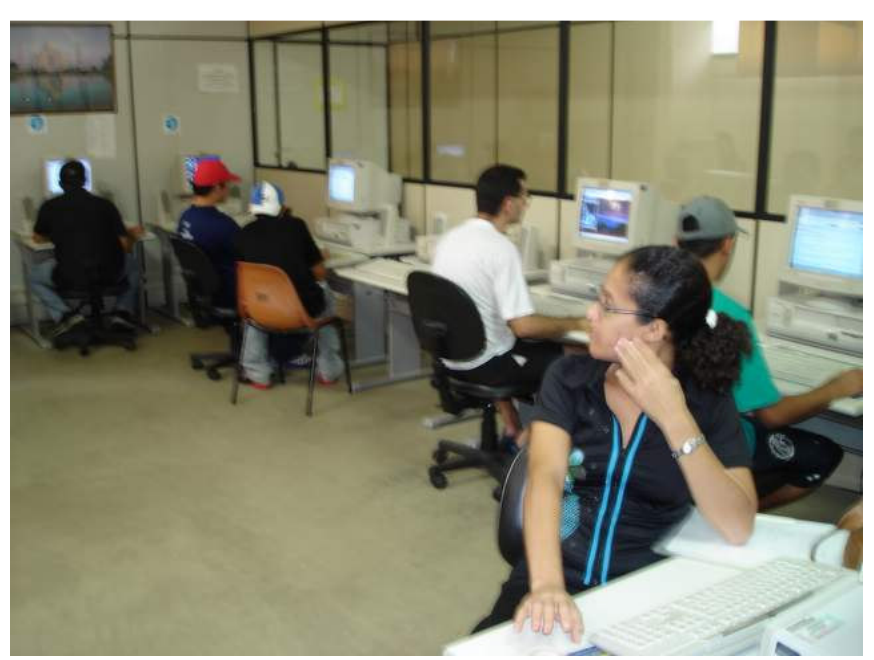

Figura 13. Sala do infocentro em Piracicaba

O segundo infocentro do programa Acessa São Paulo pesquisado fica no segundo andar da Biblioteca Municipal, no centro de Piracicaba, cidade de médio porte do interior do estado, com pouco mais de 360 mil habitantes e uma taxa de analfabetismo de $95 \%{ }^{66}$, situada em uma das regiões mais produtivas do país - onde a

pobreza não é tão aparente, e se esconde na zona rural.

Inaugurado na mesma época, julho de 2000, atende cerca de 800 pessoas por semana. Embora não possua acesso para deficientes físicos, a infraestrutura do prédio é muito boa. A sala do infocentro, com nove computadores e um servidor com Windows, é ampla e iluminada. Ao lado, a sala de espera tem até televisão, único caso em que

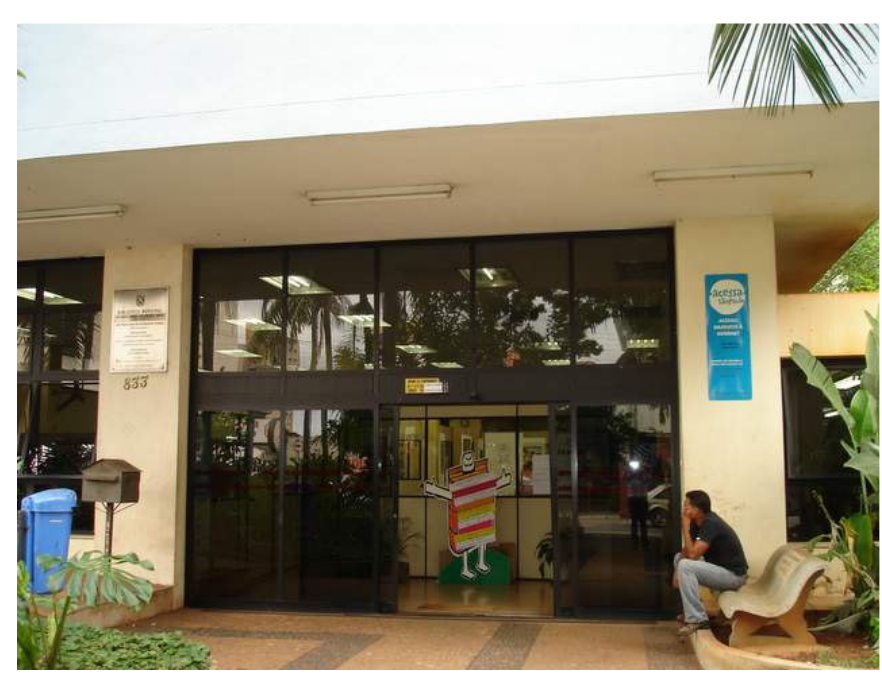

Figura 14. Entrada da biblioteca municipal de Piracicaba tanto conforto é oferecido aos usuários entre os CPAs estudados.

O tempo individual de uso dos computadores é de uma hora, e aqueles que não sabem navegar pela Internet ou utilizar o computador podem contar com o auxílio do monitor. Não há atividades comunitárias desenvolvidas no local. Já houve um curso rápido de como acessar a Internet, mas ele foi descontinuado "porque os alunos faltavam muito", explica Paula Okuda, coordenadora do infocentro.

${ }^{66}$ Segundo estimativa da PNAD 2005(IBGE). 


\subsubsection{Telecentros Porto Alegre - Campo da Tuca}

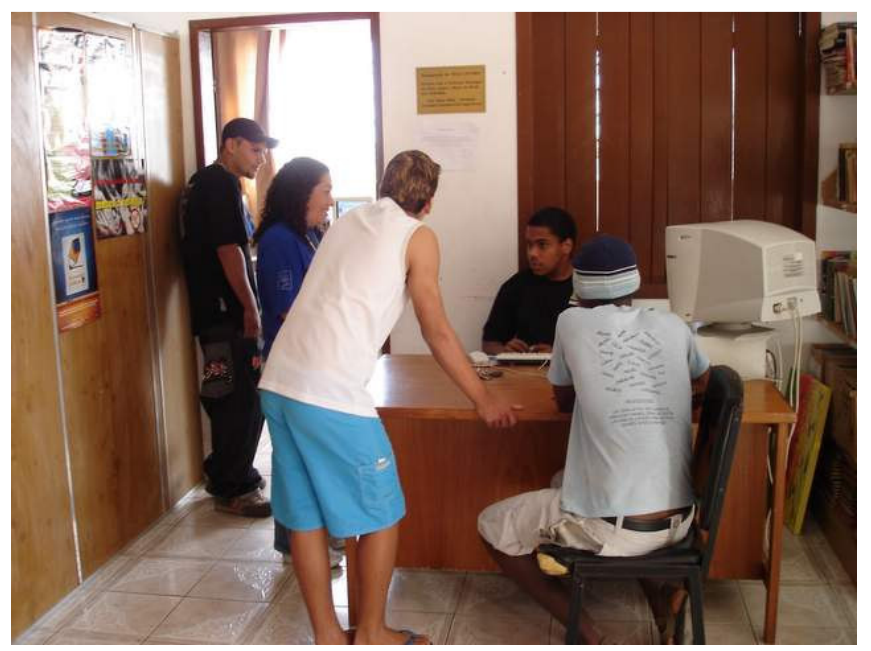

Figura 15. Cadastramento dos usuários no telecentro Campo da Tuca

A unidade do programa Telecentros de Porto Alegre visitada fica na Associação Comunitária Campo da Tuca, no bairro Partenon, na capital gaúcha, cidade com $476 \mathrm{~km}^{2}$, 1,44 milhão de habitantes ${ }^{67}$, taxa de alfabetização de $96,7 \%$, e reconhecida por sua sociedade civil organizada e pelo envolvimento de seus cidadãos na gestão municipal através do Orçamento Participativo. Foi inaugurado em junho de 2004 e atende uma média de 50 usuários por dia. O programa é o que apresenta maior flexibilidade de uso das instalações - cada usuário tem direito em média a 30 minutos de acesso, mas o tempo pode ser estendido de acordo com a necessidade -, e cada unidade decide quais atividades pedagógicas quer realizar: no Campo da Tuca cada novo usuário deve passar por um curso básico de inclusão digital, oferecido em parceria com a Fundação Pensamento Digital.

Desde a sua abertura, o telecentro foi integrado nos projetos em desenvolvimento na entidade, e os usuários iniciantes discutem cidadania e a importância da tecnologia e do acesso à Internet antes de sentar no computador: "Então a gente fica dois dias na teoria, usando retroprojetor. Quando vai pra máquina, para o computador, ele já vai com muitas noções construídas. Se ele não souber da importância da inclusão digital e a dimensão que dá pra vida dele, da transformação dele...ele não sai daquela coisa simples, que aquilo é pra brincadeira", comenta Antônio Inácio Matos da Silva, 54 anos, coordenador do Telecentro na entidade. Ele conta que trazer o programa para a comunidade foi resultado de um trabalho de articulação coletivo.

É o seguinte: nós não vivemos sozinhos. A gente se relaciona com as outras comunidades, nas 400 vilas e favelas em Porto Alegre, e nós estamos trocando. Tem as reuniões das associações de moradores de Porto Alegre, tem o conselho popular nas regiões, então a gente não faz uma ação isolada. Então, tem uma demanda geral para a cidade, a cidade quer discutir o Orçamento Participativo, né?, explica.

${ }^{67}$ Segundo estimativa da PNAD 2005 (IBGE). 
Antônio relata que a proposta do programa de inclusão digital foi construída junto com o Governo Municipal, e que as discussões com a comunidade são um processo contínuo. "Essa é uma necessidade para o momento atual, enfim, para essa transformação social que está acontecendo, para o crescimento de consciência", conta.

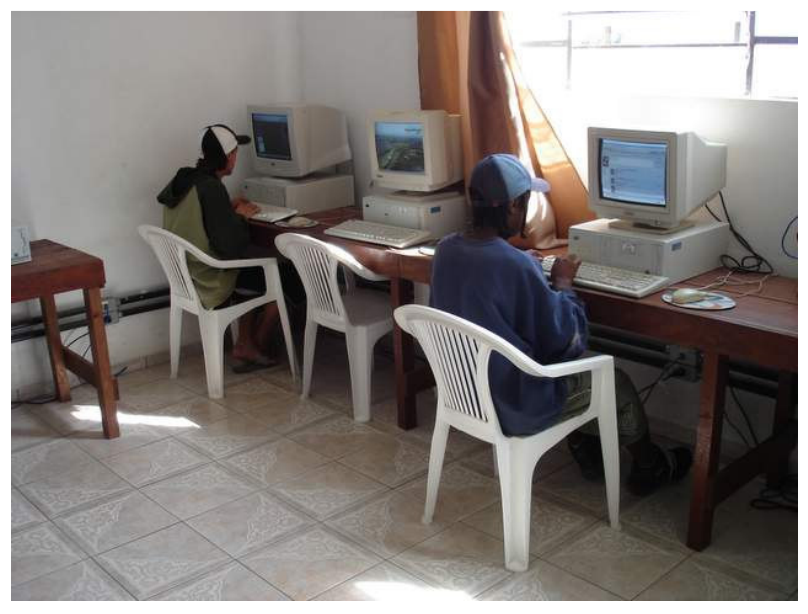

Figura 16. Sala do Telecentro Campo da Tuca, em Porto Alegre
A associação, que realiza diversas atividades culturais, sociais, esportivas e educacionais em conjunto com a Prefeitura e o Governo do Estado, tem também um Ponto de Cultura ${ }^{68}$ equipado com uma ilha de edição no local. A infraestrutura da sala - com 10 computadores rodando em Linux parece um pouco improvisada, com mesas e cadeiras inadequadas para o

uso do computador, no segundo andar da entidade.

\subsubsection{Digitando o Futuro - Farol do Saber Aristides Vinholes}

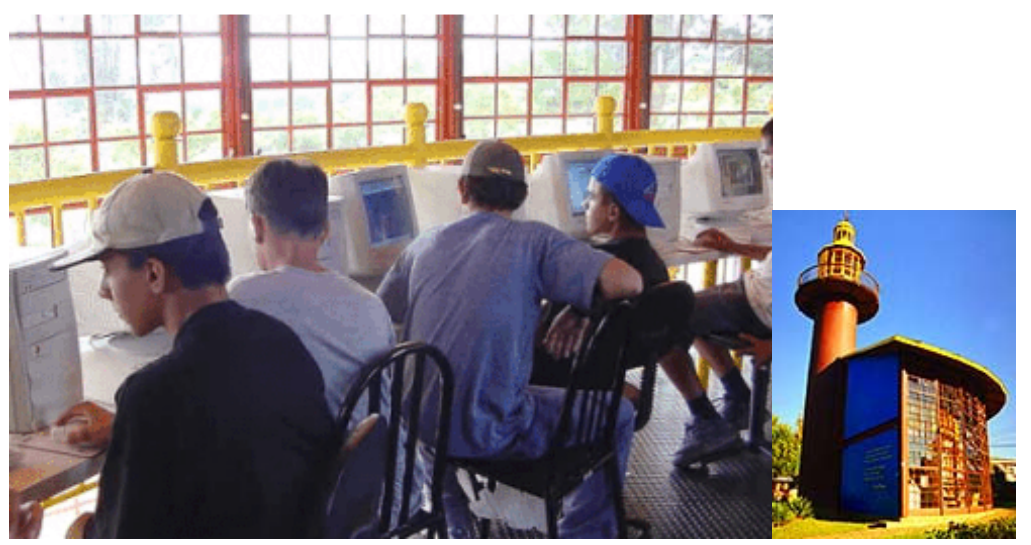

Figura 17. Sala do Digitando o Futuro - Farol do Saber em Curitiba
Inaugurado em junho de 2000, o Farol do Saber69 Aristides Vinholes está localizado ao lado de uma praça, na região sul de Curitiba, município que cultivou a imagem de

\footnotetext{
${ }^{68}$ O Ponto de Cultura é uma ação do Programa Cultura Viva, do Ministério da Cultura, que visa alavancar um novo processo social articulado nas comunidades através da produção cultural local.

${ }^{69}$ O programa Digitando o Futuro acontece dentro das unidades do Farol do Saber, prédios públicos que já abrigavam bibliotecas, mantidos pela Secretaria Municipal de Educação de Curitiba em diversas regiões da cidade.
} 
“cidade modelo", com 430,9 km² de extensão, uma população estimada de perto de 1,8 milhão de habitantes e índice de alfabetização de $96,6 \%{ }^{70}$. A sala do programa Digitando o Futuro fica no segundo andar do prédio, e conta com oito máquinas equipadas com Linux.

Os usuários podem acessar a Internet durante uma hora, via agendamento. Não é permitido o uso de programas como o MSN, tampouco acessar o Orkut ou entrar em salas de bate-papo que não façam parte do próprio programa. Assim como acontece com as outras iniciativas estudadas, não é permitido acessar conteúdo pornográfico. O Digitando o Futuro oferece cursos básicos para os usuários, com carga horária de até 20 horas

Municipal x Comunitário - As unidades investigadas se localizam em regiões periféricas, com exceção de Piracicaba. As instalações e a infra-estrutura dos prédios variam segundo o modelo de gestão do CPA: as unidades resultantes da parceria entre o poder público e entidades comunitárias, como o Telecentro Turma da Tuca, e o Infocentro SAVIC e, as instalações são um pouco mais improvisadas e têm as características do espaço que as abriga, nem sempre as mais adequadas; e no caso das unidades totalmente financiadas pelo poder público, seja unicamente municipal, Digitando o Futuro, ou parcerias entre o Estado e o Município, no caso do Infocentro de Piracicaba, a infra-estrutura segue o padrão de prédios públicos. No que diz respeito a equipamentos e infra-estrutura de acesso, todas as unidades tem em média 10 computadores com Internet, mas a qualidade desse acesso varia muito de acordo com a infra-estrutura de rede disponível no local. Entre as CPAs investigados a velocidade de acesso era satisfatória, com exceção do programa Digitando o Saber, que proíbe o uso de aplicativos de comunicação e multimídia por "tornar a rede lenta", o que mostra a fragilidade da rede e limita as atividades dos usuários. Em todas as unidades os computadores ficam voltados para a parede. O tempo de uso individual do computador nos CPAs varia entre 30 minutos e 1 hora. Em Porto Alegre, esse período pode ser estendido, enquanto em Curitiba é preciso agendar um horário com antecedência. A única restrição unânime para o acesso é a pornografia, proibida em todos os programas.

${ }^{70}$ Segundo estimativa da PNAD 2005 (IBGE). 


\begin{tabular}{|c|c|c|c|c|}
\hline Categoria & $\begin{array}{l}\text { Infocentro } \\
\text { Vila Constança-SAVIC }\end{array}$ & $\begin{array}{l}\text { Infocentro } \\
\text { Piracicaba }\end{array}$ & $\begin{array}{l}\text { Telecentro } \\
\text { Porto Alegre }\end{array}$ & $\begin{array}{l}\text { Digitando o Futuro } \\
\text { Farol do Saber Aristides Vinholes }\end{array}$ \\
\hline Município/ Estado & São Paulo/ SP & Piracicaba/ SP & Porto Alegre/ RGS & Curitiba/ Paraná \\
\hline Inauguração & Julho de 2000 & Julho de 2000 & 24 de junho de 2004 & Junho de 2000 \\
\hline Localidade & $\begin{array}{l}\text { Associação de bairro na zona norte. } \\
\text { Av. Jardim Japão, } 1.587 \text { - Jd. Brasil - 02221- } \\
\text { 001. Tel.: 6949-9612 }\end{array}$ & $\begin{array}{l}\text { Biblioteca Municipal, na região } \\
\text { central, ao lado da matriz. Rua do } \\
\text { Rosário, } 833 \text { - } 2 \text { andar } \\
\text { Tel.: (19) 3432-9099 / 3434-9032 } \\
\end{array}$ & $\begin{array}{l}\text { Na Associação de Bairro Campo da Tuca - } \\
\text { Telecentro Campo da Tuca. Rua D, No } 200 \\
\text { - Bairro Partenon. Tel: } 513384-6118 \text { r. } 22\end{array}$ & $\begin{array}{l}\text { Farol do Saber Aristides Vinholes, anexo à Praça } \\
\text { Nelson Monteiro } \\
\text { Rua Primeiro de Maio, } 1206 \text { - Xaxim - 81820-340. } \\
\text { Tel.: (41) 3346-9464 }\end{array}$ \\
\hline $\begin{array}{l}\text { Horário de } \\
\text { Funcionamento }\end{array}$ & $\begin{array}{l}\text { Seg. a sexta: } 8 \mathrm{~h} \text { às } 19 \mathrm{~h} \\
\text { Sáb.: } 8 \mathrm{~h} \text { às } 12 \mathrm{~h}\end{array}$ & $\begin{array}{l}\text { Seg. a sexta: } 8 \mathrm{~h} \text { às } 18 \mathrm{~h} \\
\text { Sáb.: } 8 \mathrm{~h} \text { às } 12 \mathrm{~h}\end{array}$ & $\begin{array}{l}\text { Seg. a sexta: } 9 \mathrm{~h} \text { às } 18 \mathrm{~h} \text {. As unidades têm } \\
\text { flexibilidade no horário para abrir e fechar. }\end{array}$ & $\begin{array}{l}\text { Seg. a sexta: } 9 \mathrm{~h} \text { às } 21 \mathrm{~h} \\
\text { Sáb.: } 9 \mathrm{~h} \text { às } 13 \mathrm{~h}\end{array}$ \\
\hline Perfil administrativo & Associação Comunitária & Municipal & $\begin{array}{l}\text { Associação Comunitária / em parceria com } \\
\text { o município }\end{array}$ & Municipal \\
\hline Homepage & $\begin{array}{l}\text { http://savicemnoticias.vilabol. } \\
\text { uol.com.br/infocentro.html }\end{array}$ & & $\begin{array}{l}\text { http://www.telecentros.com.br/ } \\
\text { default.php?reg=8\&p_secao=5 }\end{array}$ & \\
\hline Contatos & $\begin{array}{l}\text { Liderança comunitária: Nivaldo Cardoso, } 47 \\
\text { anos } \\
\text { Monitores: Kleber Palma N. Cardoso, } 22 \text { anos } \\
\text { e Rodrigo Ferreira Nascimento, } 22 \text { anos }\end{array}$ & $\begin{array}{l}\text { Funcionária da prefeitura: Paula } \\
\text { Okuda de Araújo, } 29 \text { anos, e } \\
\text { estagiário Junior Batista da Silva } \\
\text { Domingues, } 19 \text { anos }\end{array}$ & $\begin{array}{l}\text { Assessor da Coordenação do Programa } \\
\text { Telecentros: Leandro Augusto da Silva, } 27 \\
\text { anos. Coordenador da associação: Antonio } \\
\text { Inácio da Silva, } 54 \text { anos (8428-0766) e } \\
\text { Cínara da Costa Ortiz, } 27 \text { anos, monitora }\end{array}$ & $\begin{array}{l}\text { Gerente dos Faróis: Rosane Carvalho Polli } \\
\text { Estagiário: Eliélcio Skrock Antunes (17 anos) }\end{array}$ \\
\hline Data da visita & 18 de fevereiro de 2006 & 8 de abril de 2006 & 20 de abril de 2006 & 17 de março de 2006 \\
\hline Localização & $\begin{array}{l}\text { Associação de bairro bem estruturada, com } \\
\text { forte participação em diferentes projetos } \\
\text { sociais, culturais e esportivos da prefeitura e } \\
\text { do governo do Estado.Bairro periférico. }\end{array}$ & $\begin{array}{l}\text { Segundo andar do prédio da } \\
\text { biblioteca municipal. Região } \\
\text { Central. }\end{array}$ & $\begin{array}{l}\text { Associação comunitária bem estruturada, } \\
\text { com forte participação em diferentes } \\
\text { projetos sociais, culturais e esportivos da } \\
\text { prefeitura e do governo do Estado. Bairro } \\
\text { Periférico. Fica no segundo andar. }\end{array}$ & $\begin{array}{l}\text { Os Faróis do Saber são prédios públicos para acesso } \\
\text { à Internet. Este Farol se localiza na região periférica } \\
\text { sul de Curitiba, anexo a uma praça. Bairro } \\
\text { periférico. }\end{array}$ \\
\hline $\begin{array}{l}\text { Acesso } \\
\text { (ônibus/metrô/etc.) }\end{array}$ & $\begin{array}{l}\text { Fácil acesso de ônibus. Metro Tucuruvi a } 4 \\
\text { quilômetros. }\end{array}$ & Fácil acesso a pé e de ônibus & $\begin{array}{l}\text { Difícil acesso. É necessário caminhar } \\
\text { vários blocos até o ponto de ônibus. }\end{array}$ & Acesso a pé ou de ônibus. \\
\hline $\begin{array}{l}\text { Entorno (sinalização, } \\
\text { iluminação, etc) }\end{array}$ & $\begin{array}{l}\text { Não há sinalização na rua, mas na área da } \\
\text { associação é bem indicado. Rua iluminada, } \\
\text { com grande circulação de automóveis e } \\
\text { pedestres }\end{array}$ & $\begin{array}{l}\text { Sinalização no prédio. Entorno } \\
\text { agradável. A biblioteca fica no } \\
\text { meio de uma praça }\end{array}$ & $\begin{array}{l}\text { O entorno é simples. A associação fica } \\
\text { numa rua residencial de periferia. Não há } \\
\text { sinalização. }\end{array}$ & $\begin{array}{l}\text { O entorno é quase agradável, ao lado de uma praça. } \\
\text { Bem sinalizado. }\end{array}$ \\
\hline $\begin{array}{l}\text { Infra-estrutura do } \\
\text { prédio }\end{array}$ & $\begin{array}{l}\text { Boa. Tem sala de espera com um banco de } \\
\text { madeira ao lado da sala com os computadores. } \\
\text { Essa área está ao lado do campo de futebol, } \\
\text { com bebedouro e acesso para deficientes. Tem } \\
\text { banheiro. }\end{array}$ & $\begin{array}{l}\text { Boa. Possui sala de espera com } 12 \\
\text { lugares, com ventilador, televisão e } \\
\text { bebedouro. Não tem acesso para } \\
\text { deficientes. Tem banheiro. }\end{array}$ & $\begin{array}{l}\text { Não tem acesso para deficientes. Tem sala } \\
\text { de espera e banheiro. }\end{array}$ & $\begin{array}{l}\text { Possuiu uma biblioteca no andar térreo e uma sala } \\
\text { pouco iluminada, mesmo com janelas, no segundo } \\
\text { andar. Não tem acesso para deficientes. Não há sala } \\
\text { de espera nem banheiro. }\end{array}$ \\
\hline Infra-estrutura da sala & $\begin{array}{l}\text { Sala simples, com duas janelas. Máquinas } \\
\text { voltadas para a parede. Pouca iluminação na } \\
\text { sala. }\end{array}$ & $\begin{array}{l}\text { Sala bem estruturada, bem } \\
\text { iluminada, Máquinas voltadas para } \\
\text { a parede. }\end{array}$ & $\begin{array}{l}\text { Sala improvisada, com janelas, mas sem } \\
\text { mesas e cadeiras adequadas }\end{array}$ & $\begin{array}{l}\text { Muito pouca iluminação na sala. As máquinas são } \\
\text { voltadas para a janela. Há uma mesa para trabalhos. }\end{array}$ \\
\hline $\mathrm{N}^{\circ}$ de computadores & Possui 10 máquinas com Linux, um servidor & $\begin{array}{l}\text { Possui } 9 \text { máquinas e um servidor } \\
\text { rodando Windows }\end{array}$ & Possui 10 computadores rodando Linux & Possui 8 máquinas rodando Linux. \\
\hline Periféricos & Impressora & Impressora e caixas de som & Tem scanner e impressora & Impressora \\
\hline
\end{tabular}




\begin{tabular}{|c|c|c|c|c|}
\hline Categoria & $\begin{array}{l}\text { Infocentro } \\
\text { Vila Constança-SAVIC }\end{array}$ & $\begin{array}{l}\text { Infocentro } \\
\text { Piracicaba }\end{array}$ & $\begin{array}{l}\text { Telecentro } \\
\text { Porto Alegre }\end{array}$ & $\begin{array}{l}\text { Digitando o Futuro } \\
\text { Farol do Saber Aristides Vinholes }\end{array}$ \\
\hline Idade mínima & 11 anos & 11 anos & $\begin{array}{l}\text { Até } 14 \text { anos deve estar acompanhado. } \\
\text { Idade mínima é } 11 \text { anos, com flexibilidade. }\end{array}$ & Não tem limite de idade. \\
\hline Público & $\begin{array}{l}50 \%-14 \text { a } 17 \text { anos, } 20 \%-18 \text { a } 30 \text { anos, } 15 \%- \\
31 \text { a } 50 \text { anos, } 10 \%-11 \text { a } 14 \text { anos, } 5 \%-50 \text { out }\end{array}$ & Maioria são jovens & A maioria são jovens de 16 a 24 anos. & $60 \%$ de 11 a 17 anos \\
\hline $\begin{array}{l}\text { Tempo individual de } \\
\text { uso }\end{array}$ & 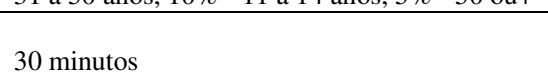 & 1 hora & $\begin{array}{l}\text { Flexível. Normalmente } 30 \text { minutos, mas se } \\
\text { houver necessidade, é permitida extensão. }\end{array}$ & 1 hora, com agendamento. \\
\hline $\begin{array}{l}\text { Média de } \\
\text { atendimentos }\end{array}$ & $\begin{array}{l}180 \text { atendimento diário em média. } 2624 \\
\text { usuários cadastrados. } 104983 \text { atendimentos }\end{array}$ & $\begin{array}{l}\text { Até } 130 \text { atendimentos diários. } \\
\text { Cerca de } 800 \text { por semana. }\end{array}$ & 50 atendimentos por dia & ---- \\
\hline $\begin{array}{l}\text { Tipo de atividade } \\
\text { desenvolvida no } \\
\text { prédio }\end{array}$ & $\begin{array}{l}\text { A associação desenvolve inúmeras atividades } \\
\text { culturais, educacionais, sociais e esportivas } \\
\text { para crianças, jovens, adultos e idosos. }\end{array}$ & $\begin{array}{l}\text { Salas de leitura e atividades da } \\
\text { biblioteca. } \\
\text { Não tem atividades comunitárias }\end{array}$ & $\begin{array}{l}\text { A associação desenvolve inúmeras } \\
\text { atividades culturais, educacionais, sociais e } \\
\text { esportivas. Abriga também um Ponto de } \\
\text { Cultura, com ilha de edição. }\end{array}$ & Funciona em conjunto com os Faróis do Saber. \\
\hline $\begin{array}{l}\text { Tipo de atividade } \\
\text { desenvolvida na } \\
\text { Internet }\end{array}$ & $\begin{array}{l}\text { Orkut, chat, MSN, e-mail e ferramentas de } \\
\text { buscas, sites de empregos }\end{array}$ & $\begin{array}{l}\text { Sala de bate-papo, Orkut, procura } \\
\text { de emprego, pesquisa, pesquisa de } \\
\text { música, receita culinária. Funciona } \\
\text { como um "poupatempo" }\end{array}$ & $\begin{array}{l}\text { Pesquisas escolares, currículos, Orkut, } \\
\text { fotlog, MSN. }\end{array}$ & $\begin{array}{l}\text { Pesquisas escolares. Sites de comunidades, música e } \\
\text { esportes. }\end{array}$ \\
\hline $\begin{array}{l}\text { Tipo de atividades } \\
\text { pedagógicas }\end{array}$ & $\begin{array}{l}\text { O programa não oferece cursos. A associação } \\
\text { tem aulas nos computadores para crianças e } \\
\text { idosos. São } 4 \text { salas comunitárias de EMEI } \\
\text { (Educação Infantil, pois faltam escolas na } \\
\text { região) e } 6 \text { salas de MOVA. O monitor faz a } \\
\text { introdução à Internet para o iniciante }\end{array}$ & $\begin{array}{l}\text { O programa não oferece cursos. } \\
\text { Houve cursos rápidos de como } \\
\text { acessar a Internet por } 8 \text { meses. Foi } \\
\text { descontinuado por excesso de } \\
\text { faltas. O monitor faz a introdução } \\
\text { ao computador e à Internet. }\end{array}$ & $\begin{array}{l}\text { Há curso básico de inclusão digital } \\
\text { obrigatório. Há uma parceria com a } \\
\text { Fundação Pensamento Digital } \\
\text { (http://www.pensamentodigital.org.br/) } \\
\text { As unidades estão livres para ampliar a } \\
\text { grade de oficinas. }\end{array}$ & $\begin{array}{l}\text { Inicialmente não havia cursos, Hoje tem cursos } \\
\text { básicos para os usuários, com grande procura. } \\
\text { Dependendo do módulo, a carga horária é de } 10 \text { a } 20 \\
\text { horas, com apostilas e ferramenta de e-learning. }\end{array}$ \\
\hline Sustentabilidade & $\begin{array}{l}\text { A associação é responsável pela manutenção } \\
\text { da sala, pagamento de luz, etc. } \\
\text { A Imprensa Oficial do Governo do Estado } \\
\text { fornece os equipamentos, suporte técnico, } \\
\text { papel ( } 500 \text { folhas por mês) e tinta para a } \\
\text { impressora ( } 1 \text { cartucho colorido e } 1 \text { preto por } \\
\text { mês). Também paga o salário e capacita os } \\
\text { monitores }\end{array}$ & $\begin{array}{l}\text { A Prefeitura é responsável pela } \\
\text { manutenção da sala, pagamento de } \\
\text { luz, etc, pelo suporte técnico, papel } \\
\text { e tinta para a impressora. Também } \\
\text { paga o salário dos monitores. } \\
\text { A Imprensa Oficial do Governo do } \\
\text { Estado fornece os equipamentos e } \\
\text { capacita os monitores }\end{array}$ & $\begin{array}{l}\text { Prefeitura, através da SMDHSU e a } \\
\text { entidade comunitária estabelecem } \\
\text { convênio. A Prefeitura pode pagar o } \\
\text { equipamento, mas a preferência é dada } \\
\text { para entidades que sustentem os próprios } \\
\text { gastos. Nesta unidade, a associação arca } \\
\text { com os gatos e a prefeitura fornece } \mathrm{R} \$ 900 \\
\text { para pagar o salário dos monitores }\end{array}$ & $\begin{array}{l}\text { Inteiramente mantido pela Secretaria Municipal de } \\
\text { Educação }\end{array}$ \\
\hline Restrições de uso & $\begin{array}{l}\text { O acesso não pode ser cobrado, nem a } \\
\text { impressão de arquivos. Não há restrição de uso } \\
\text { de programas de comunicação. Somente sites } \\
\text { de pornografia são proibidos. Jogos são } \\
\text { permitido comente às sextas e sábados. }\end{array}$ & $\begin{array}{l}\text { A impressão de arquivos pessoais é } \\
\text { cobrada, de serviços públicos é } \\
\text { gratuita. Não pode se usar os } \\
\text { computadores para a digitação de } \\
\text { trabalhos. Não permite jogo e sites } \\
\text { de pornografia. }\end{array}$ & $\begin{array}{l}\text { Pornografia. Algumas unidades permitem } \\
\text { MSN e Orkut, outras não. As unidades } \\
\text { podem cobrar pelos opcionais. }\end{array}$ & $\begin{array}{l}\text { Não permite MSN, Orkut e salas de bate-papo que } \\
\text { não sejam do próprio Digitando. Também não } \\
\text { permite pornografia. }\end{array}$ \\
\hline
\end{tabular}




\subsection{Discurso dos mentores}

As entrevistas realizadas com os mentores da inclusão digital no Brasil tiveram como objetivo identificar o discurso dos mesmos sobre: o conceito de inclusão digital; o seu envolvimento com programas de inclusão digital; os principais objetivos dos programas; as principais atividades realizadas pelos usuários na Internet; o impacto da Internet no consumo e produção de informação; os benefícios do programa para o usuário, assim como sua contribuição para o desenvolvimento social, político e econômico da comunidade; a avaliação dos programas públicos de inclusão digital no país; a discussão sobre ser ou não transformada em política pública; os desafios dos programas para o futuro; e o potencial do telefone celular e da TV Digital para impulsionar a inclusão digital no país. Os resultados desses encontros serão relatados a seguir.

Ao relatar o seu envolvimento com a inclusão digital (quadro 16), os mentores tecem a própria história da inclusão digital no Brasil. Ainda que haja diversidade em suas origens profissionais, todas as narrativas se cruzam e convergem, criticamente ou não, para o poder público, reforçando com isso a idéia de que a inclusão digital necessita de políticas públicas para poder abarcar todo o universo dos excluídos. Fernando Guarnieri e Rogério Santanna foram os responsáveis pela criação dos programas Acessa São Paulo e Telecentros Porto Alegre, respectivamente. Rodrigo Assumpção e Sérgio Amadeu estão diretamente ligados à elaboração e à implementação do Telecentros São Paulo, que passou a ser coordenado por Beatriz Tibiriçá (Beá), quando este último assumiu a presidência do Instituto de Tecnologia da Informação da Casa Civil, no início do primeiro governo de Lula. Carlos Afonso, com amplo currículo em movimentos de democratização da informação, também teve forte atuação no Telecentros São Paulo durante a gestão de Marta Suplicy, através da RITS, responsável pelo gerenciamento dos recursos humanos, pela capacitação dos monitores e pela articulação em rede do projeto. Gilson Schwartz se envolveu com a capacitação e articulação de monitores do programa Acessa SP e Telecentros SP, através do projeto Cidade do Conhecimento, dirigido por ele no Instituto de Estudos Avançados da USP. E Rodrigo Baggio foi o responsável pela criação do Comitê pela Democratização da Informação (CDI), ONG pioneira na área de inclusão digital. 


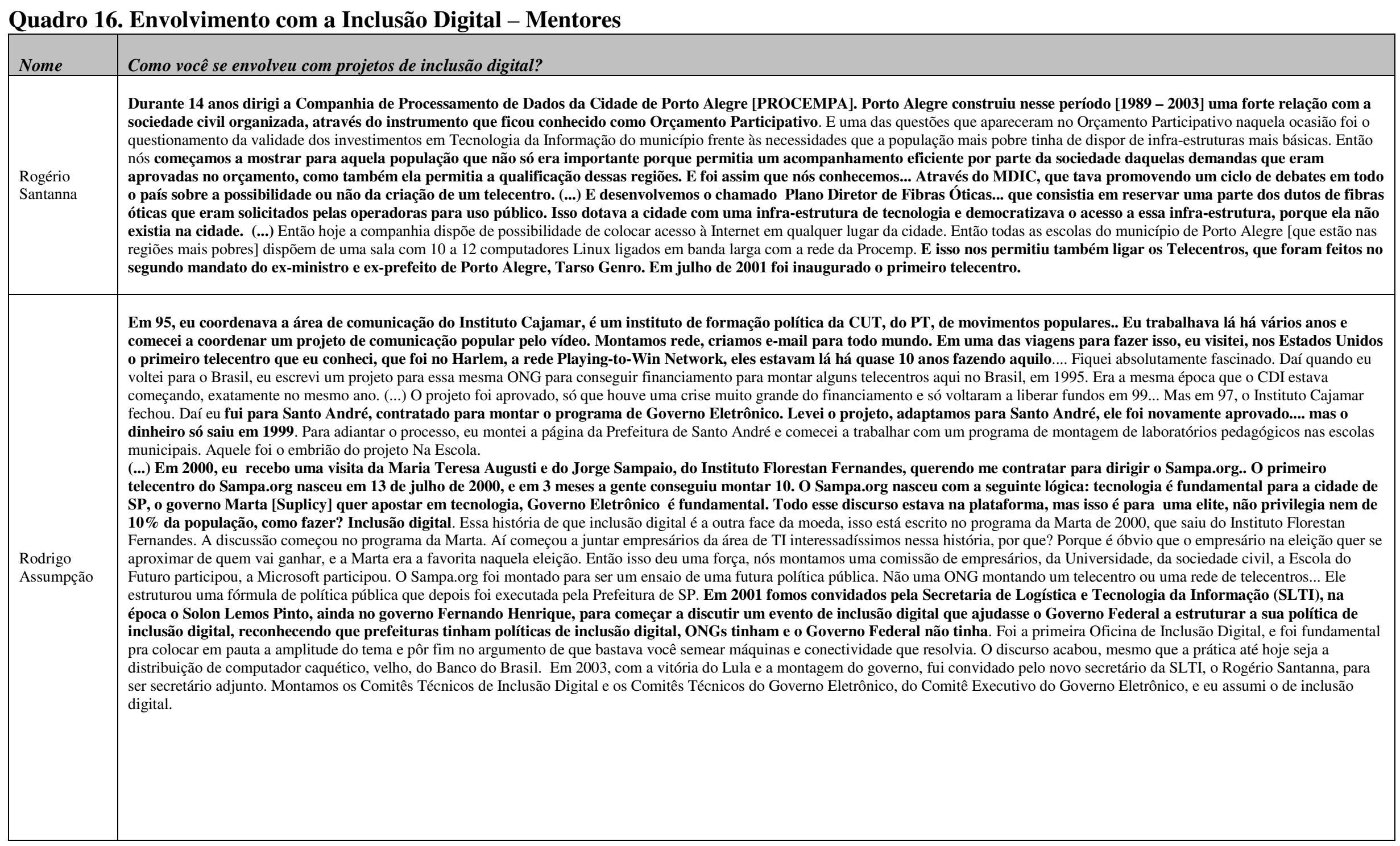




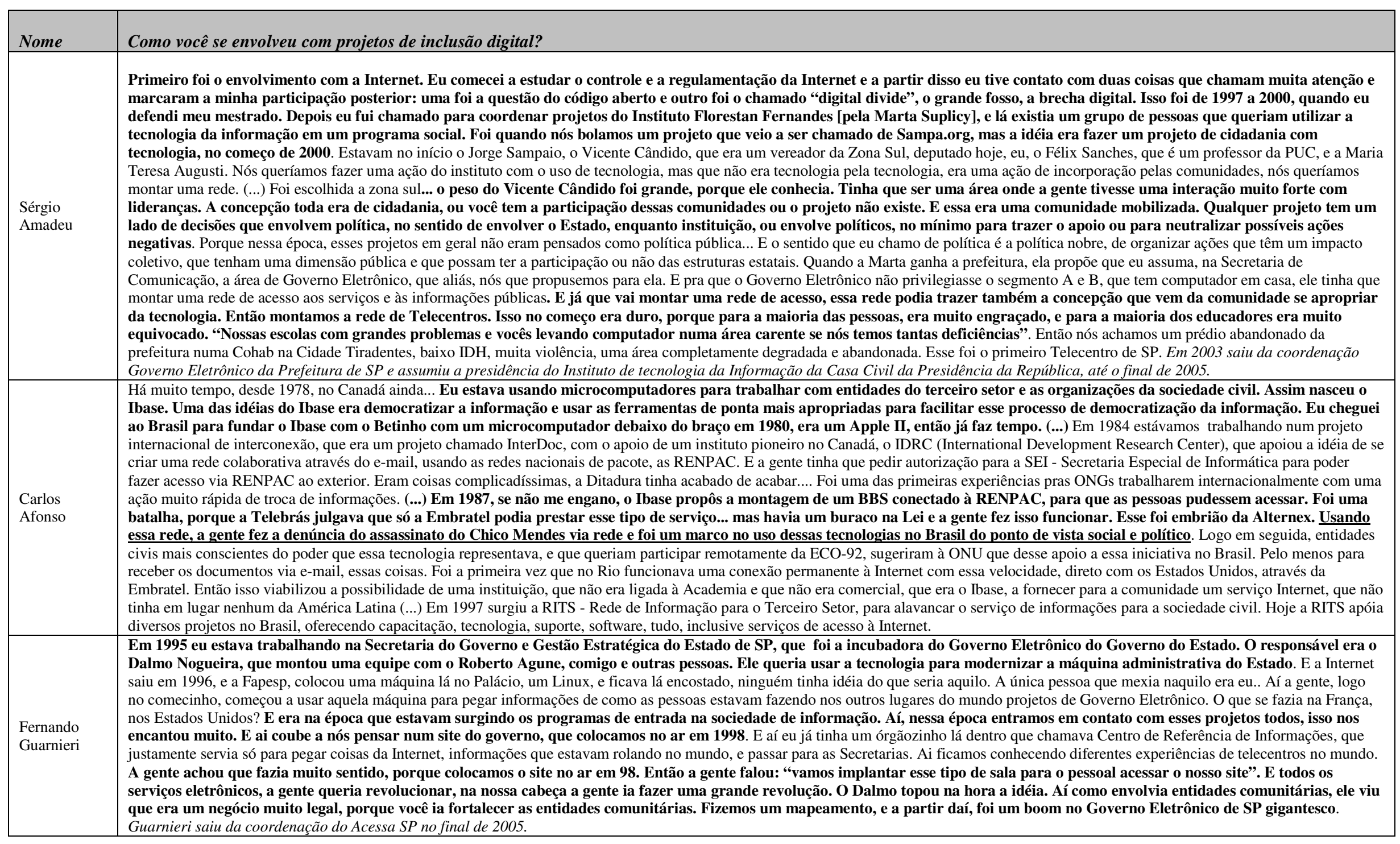




\begin{tabular}{|c|c|}
\hline Nome & Como você se envolveu com projetos de inclusão digital? \\
\hline $\begin{array}{l}\text { Gilson } \\
\text { Schwartz }\end{array}$ & $\begin{array}{l}\text { No final dos anos 90, a partir de um trabalho com professores e alunos do ensino médio, discutindo perspectivas de profissionalização, educação, emprego, mercado de trabalho, chamado } \\
\text { "Que Fazer”. Era um boletim sobre geografia e política internacional editado pelo Demétrio Magnoli. A partir daí veio a idéia de um trabalho com o Ensino Médio discutindo tecnologia e inserção } \\
\text { no mercado de trabalho. Comecei discutindo como a tecnologia afeta a empregabilidade dos jovens, (...) que é, de forma mais ampla, uma questão de inclusão sócio-econômica, não inclusão } \\
\text { "digital”. Antes disso, em 1996, atuei na criaçãa do primeiro portal brasileiro de economia, em parceria com o Núcleo de Pesquisa e Relações Internacionais da USP e a Câmara } \\
\text { Americana de Comércio de SP. Eu era economista-chefe do Bank Boston e saí do banco para fazer um projeto de inclusão digital do empresariado. Em } 1999 \text { houve um concurso no } \\
\text { Instituto de Estudos Avançados da USP e eu apresentei a idéia da Cidade do Conhecimento. Em } 2000 \text { ainda foi um período de pesquisa, discussão, mobilização, sensibilização, em } 2001 \\
\text { houve a criação da Cidade do Conhecimento. Em setembro de } 2003 \text { monta um telecentro comunitário experimental na praia de Pipa, no Rio Grande do Norte. }\end{array}$ \\
\hline $\begin{array}{l}\text { Beatriz } \\
\text { Tibiriçá } \\
\text { (Beá) }\end{array}$ & $\begin{array}{l}\text { Eu comecei a mexer com a questão da Internet em 1999. Eu e mais um grupo de pessoas começamos a montar projetos de inclusão digital com a idéia da democratização do acesso, } \\
\text { porque não tem sentido você discutir conceitos de Internet cidadã se você não tiver o acesso multiplicado para a população de baixa renda. Durante o período da campanha da Marta } \\
\text { [Suplicy], algumas experiências foram feitas com o Sampa.org, que depois vieram a dar na rede pública de telecentros da cidade de SP. E coordenei o projeto de } 2002 \text { até o final da gestão, [em } \\
\text { 2004]. Quando a gente saiu do Governo Eletrônico, uma boa parte da equipe, que tinha participado da instrumentação, da conceituaçãa, da ampliação do projeto na Prefeitura de SP, se } \\
\text { juntou em torno de uma ONG, no final de 2004, que chama Coletivo Digital e que trabalha com três pilares: inclusão digital, software livre e Internet cidadã, a Internet que abre espaço } \\
\text { como instrumento de fiscalização e participação, que interage com o cidadão e não só que divulga a informação. Temos parceria com a Fundação Perseu Abramo, a gente vai entregar o portal, tem } \\
\text { parceria com a RITS no portal TID, que é o Telecentros pela Inclusão Digital Trabalhamos na área de telecentros com capacitação também e estamos implantando, em convênio com a prefeitura, o } \\
\text { projeto de telecentros na cidade de Osasco. }\end{array}$ \\
\hline $\begin{array}{l}\text { Rodrigo } \\
\text { Baggio }\end{array}$ & 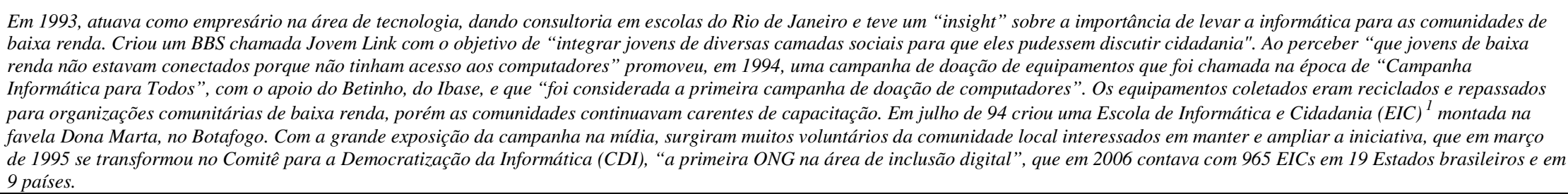 \\
\hline
\end{tabular}




\begin{tabular}{|c|c|}
\hline Nome & Como você define inclusão digital? \\
\hline $\begin{array}{l}\text { Rogério } \\
\text { Santanna }\end{array}$ & $\begin{array}{l}\text { É talvez a face mais dura da questão da exclusão social, porque ela é também uma exclusão do conhecimento, da } \\
\text { possibilidade de acesso ao conhecimento, portanto a possibilidade de melhorar, de reforçar a sua vida. É a filha } \\
\text { tecnológica e moderna da exclusão social. }\end{array}$ \\
\hline $\begin{array}{l}\text { Rodrigo } \\
\text { Assumpção }\end{array}$ & $\begin{array}{l}\text { É o processo de uma sociedade proporcionar àqueles que ainda não têm, acesso aos equipamentos, às linguagens, } \\
\text { às tecnologias, às capacidades necessárias para usufruir das TIC. É o reconhecimento de uma sociedade de } \\
\text { que existe uma situação de exclusão digital e que essa situação tem que ser combatida com um processo de ID. } \\
\text { (...) E quando eu falo em linguagem, não falo só de um aplicativo, mas da própria cultura dentro da rede, desde as } \\
\text { coisas básicas como não mandar spam, até como fazer uma pesquisa eficaz, como acessar serviços, conhecimento da } \\
\text { língua para poder digitar. Conhecimentos básicos mínimos para poder usufruir de um processo. (..) Tem muita } \\
\text { coisa da inclusão digital que não está nas máquinas nem na relação com as máquinas, e sim no processo global } \\
\text { de inclusão social. }\end{array}$ \\
\hline $\begin{array}{l}\text { Sérgio } \\
\text { Amadeu }\end{array}$ & $\begin{array}{l}\text { É um processo de capacitação da sociedade para ter acesso ao processamento, armazenamento e transmissão } \\
\text { de informações, através do uso das tecnologias mais avançadas disponíveis atualmente. É mais do que acesso à } \\
\text { infra-estrutura, é capacitar as pessoas para que possam processar e avaliar informações. (...) A ID não é também só } \\
\text { ensinar algumas ferramentas básicas visando a profissionalização. É um processo mais amplo de capacitar o } \\
\text { cidadão para a sociedade da informação, possibilitando a comunicação e a expressão de idéias. (...) }\end{array}$ \\
\hline $\begin{array}{l}\text { Carlos } \\
\text { Afonso }\end{array}$ & $\begin{array}{l}\text { O Demi [Getschko] diz que fui eu quem trouxe esse termo ao Brasil. Não é verdade, mas hoje existem algumas } \\
\text { correntes que não gostam do termo, que acham ele muito limitado, tecnicista, etc. Mas eu continuo gostando. Eu } \\
\text { acho que ID é você trazer pessoas de comunidades para os benefícios das novas TICs (...) Hoje, esses benefícios } \\
\text { são essenciais, e se você não tiver a possibilidade de usar estes serviços, você estará excluído socialmente. É a } \\
\text { pessoa ter acesso a essas tecnologias, se apoderar delas, se apropriar delas para o seu próprio benefício, tanto } \\
\text { como comunidade quanto como indivíduo. }\end{array}$ \\
\hline $\begin{array}{l}\text { Fernando } \\
\text { Guarnieri }\end{array}$ & $\begin{array}{l}\text { ID é um termo muito infeliz, uma tradução mal feita do Digital Divide. Então eu acho que a inclusão digital } \\
\text { reúne vários conceitos diferentes, desde a questão do acesso à tecnologia em si, quer dizer, você conseguir } \\
\text { dispor para cada cidadão um micro na casa do cidadão até cursos de alfabetização digital (...).No início do } \\
\text { Acessa }[S P] \text {, a questão da inclusão digital era o acesso à informação, ao conteúdo que crescia na Internet e que só } \\
\text { estava disponível para as pessoas de classes A e B. Então a questão era aproximar o conteúdo das demais pessoas, } \\
\text { através do uso da tecnologia, isso era o forte daquele conceito de ID. Na época [início de } 2000] \text { a gente nem falava } \\
\text { em ID. Com essa história de ID, o processo ficou engessado, porque começou a se conceituar a coisa. Então } \\
\text { hoje ID é o acesso à tecnologia e a capacitação para o uso dessa tecnologia, e você tem esses espaços todos } \\
\text { oferecendo cursos de informática, mas se descuidou um pouco do conteúdo. }\end{array}$ \\
\hline $\begin{array}{l}\text { Gilson } \\
\text { Schwartz }\end{array}$ & $\begin{array}{l}\text { Sou contra o conceito de inclusão digital. Para mim, ID é um slogan da indústria, para colocar as pessoas na } \\
\text { dependência dessa infra-estrutura. Embora a palavra inclusão faça uma referência, em última análise, à inclusão } \\
\text { social e econômica, a ID tem sido praticada como a conexão das pessoas a essa infra-estrutura, a subordinação das } \\
\text { pessoas a essa infra-estrutura. Então ID já foi uma boa intenção, hoje ela está a serviço das corporações. }\end{array}$ \\
\hline $\begin{array}{l}\text { Beatriz } \\
\text { Tibiriçá } \\
\text { (Beá) }\end{array}$ & $\begin{array}{l}\text { ID tem que ser entendida dentro do escopo da inclusão social. Deve ser tratada como política pública, como } \\
\text { um direito do cidadão, e só tem sentido na medida em que você tiver envolvimento com a comunidade que recebe o } \\
\text { equipamento que vai proporcionar tecnologia para a inclusão digital. }\end{array}$ \\
\hline $\begin{array}{l}\text { Rodrigo } \\
\text { Baggio }\end{array}$ & $\begin{array}{l}\text { É mais do que dar acesso aos computadores e à Internet. É formar cidadãos que possam exercer sua } \\
\text { cidadania de forma ativa e empreendedora, produzindo conteúdos e conhecimentos. }\end{array}$ \\
\hline
\end{tabular}

Para os mentores, a definição de inclusão digital (quadro 17) abrange bem mais do que o simples acesso ao equipamento, a capacitação do usuário, a profissionalização ou até mesmo a possibilidade de se apropriar de um computador e da Internet para articular projetos comunitários e produzir conteúdo local. Ela deve ser compreendida dentro do escopo da inclusão social, ao possibilitar a participação protagonista do indivíduo no processo produtivo estabelecido pela sociedade da informação. Rogério explica a amplitude do conceito pelo seu oposto, ao afirmar que exclusão digital "é talvez a face mais dura da questão da exclusão social, porque ela é também uma exclusão do conhecimento, da possibilidade de acesso ao conhecimento, portanto a possibilidade de melhorar, de reforçar a sua vida. É a filha tecnológica e moderna da exclusão social".

Na realidade, existe uma polêmica discussão em torno do termo "inclusão digital". Para Guarnieri o conceito parece reduzir o amplo processo de apropriação tecnológica e 
produção de sentido "à questão do acesso à tecnologia e à capacitação". Carlos Afonso comenta a rejeição ao termo, "por ser muito limitado e tecnicista", mas defende seu uso para definir o processo de apropriação da tecnologia pelo indivíduo em seu benefício e de sua comunidade. Já Gilson defende que "inclusão digital" se transformou em um slogan da indústria para colocar as pessoas na dependência da Internet. "Embora a palavra inclusão faça uma referência, em última análise, à inclusão social e econômica, a inclusão digital tem sido praticada como a conexão das pessoas a essa infra-estrutura, a subordinação das pessoas a essa infra-estrutura. Então inclusão digital já foi uma boa intenção, hoje ela está a serviço das corporações”, afirma. 


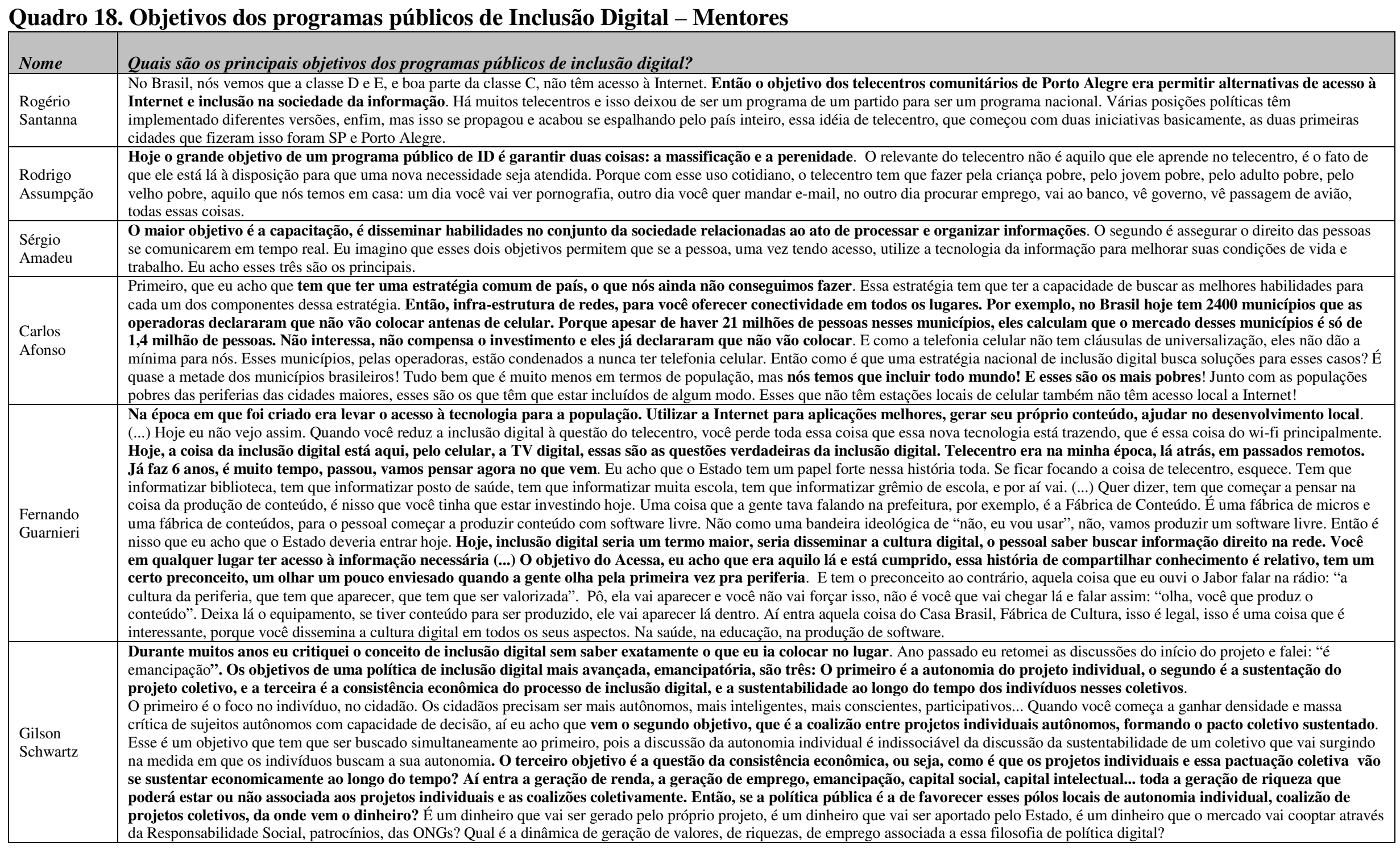




\begin{tabular}{|c|c|}
\hline Nome & s dos programas públicos de inclusão digital? \\
\hline $\begin{array}{l}\text { Beatriz } \\
\text { Tibiriça }\end{array}$ & $\begin{array}{l}\text { É ser uma política pública. E o terceiro setor tem sido importante nesse sentido inclusive: de impulsionar as prefeituras, o Poder Municipal, o Poder Federal e o Estadual a cada vez mais } \\
\text { se engajar na luta contra a exclusão digital.(...) E é pela credibilidade, pela amplitude que o projeto na cidade de SP acabou tendo que você consegue firmar o conceito de telecentros, que tem que } \\
\text { ter conexão Internet, acesso gratuito, [ser] tratado como política pública. É um conceito que passou a ser firmado no governo da Marta [Suplicy] e que hoje é reivindicação, é ponto pacífico a } \\
\text { necessidade da ampliação do número de telecentros e da democratização de acessos no Brasil. }\end{array}$ \\
\hline $\begin{array}{l}\text { Rodrigo } \\
\text { Baggio }\end{array}$ & $\begin{array}{l}\text { A formação de cidadãos que exerçam a sua cidadania de forma ativa e empreendedora, sendo também produtores de conhecimento e conteúdo. As EICs são a nossa bandeira de inclusão } \\
\text { digital sustentável, para a gente é muito importante que as EICs sejam auto-geridas E então pessoas da própria comunidade são os coordenadores, os educadores de informática e cidadania. Nós } \\
\text { procuramos um parceiro na comunidade e ele gerencia todo o processo. Quer dizer, a EIC é vista pela comunidade como um projeto da comunidade, e isso é muito importante para a apropriação total } \\
\text { do projeto ali na comunidade. O CDI capacita pessoas da comunidade para serem os gestores e os educadores de informática e cidadania. Através de uma auto-gestão e de uma mensalidade } \\
\text { simbólica, que varia em torno da realidade daquela comunidade, a pessoa de baixa renda contribui para o desenvolvimento da EIC. A gente tem algumas escolas que são gratuitas, mas a } \\
\text { partir desse processo de criação, é negociada toda uma estratégia com a organização parceira para viabilizar a qualidade e a continuidade da escola. (...) O acesso à Internet é desejável, } \\
\text { mas não é necessário. } 42 \% \text { das EICs têm acesso à Internet em banda larga. As outras ou têm acesso com linha discada, ou não têm acesso. E isso acontece porque nós estamos atuando em zonas } \\
\text { rurais, em zonas remotas, como aldeias indígenas, comunidades ribeirinhas, em que a alternativa seria a conexão à Internet via satélite, que é muito cara. (...) como a gente sabe, não é prioridade para } \\
\text { empresas de telecomunicação cabear comunidades de baixa renda ou zonas menos favorecidas da nossa sociedade, então a gente tem esse desafio. Para a gente, não é condição de um trabalho de } \\
\text { inclusão digital o acesso à Internet. É desejável, é muito importante, mas não é condição. Porque dentro do processo histórico de aprendizado da rede CDI, mesmo computadores } \\
\text { desconectados da Internet têm um trabalho muito importante e de alto resultado qualitativo nessas comunidades de baixa renda. }\end{array}$ \\
\hline
\end{tabular}


Para os mentores, os principais objetivos dos programas de inclusão digital (quadro 18), são conceitos complementares que de alguma maneira evoluíram com o tempo, desde a implementação das primeiras iniciativas, no final dos anos 1990. Inicialmente a preocupação era oferecer "alternativas de acesso à Internet e inclusão na sociedade da informação" e "levar a tecnologia à população" através dos centros públicos de acesso. Paralelamente, o objetivo era - e continua sendo - "a formação de cidadãos que exerçam a sua cidadania de forma ativa e empreendedora, sendo também produtores de conhecimento e conteúdo", centro da questão para Baggio. Entretanto, a idéia de preparação para o mercado de trabalho foi substituída pela capacitação através da disseminação de "habilidades no conjunto da sociedade relacionadas ao ato de processar e organizar informações", sustenta Sérgio, levantando ainda a importância de se "assegurar o direito das pessoas se comunicarem em tempo real", para que a as mesmas possam utilizar "a tecnologia da informação para melhorar suas condições de vida e trabalho".

Neste sentido Assumpção afirma que "hoje o grande objetivo de um programa público de inclusão digital é garantir duas coisas: a massificação e a perenidade”. E para que isso aconteça, segundo Beá, a inclusão digital tem que ser tratada como uma política pública. "É ponto pacífico a necessidade da ampliação do número de telecentros e a democratização de acessos no Brasil”, resume. Para Carlos Afonso essa política pública representa "uma estratégia comum de país, o que nós ainda não conseguimos fazer". Essa estratégia deve reunir diversos componentes, e o principal deles é a infraestrutura de rede, para que seja possível se oferecer conectividade em todos os lugares:

Por exemplo, no Brasil tem hoje 2400 municípios onde as operadoras declararam que não vão colocar antenas de celular. Porque apesar de haver 21 milhões de pessoas nesses municípios, eles calculam que o mercado desses municípios é só de 1,4 milhão de pessoas. Não interessa, não compensa o investimento e eles já declararam que não vão colocar. E como a telefonia celular não tem cláusulas de universalização, eles não dão a mínima para nós. Esses municípios, pelas operadoras, estão condenados a nunca ter telefonia celular. Então como é que uma estratégia nacional de inclusão digital busca soluções para esses casos? É quase a metade dos municípios brasileiros! Tudo bem que é muito menos em termos de população, mas nós temos que incluir todo mundo! E esses são os mais pobres! Junto com as populações pobres das periferias das cidades maiores, esses são os que têm que estar incluídos de algum modo. Esses que não têm estações locais de celular também não têm acesso local a Internet!, sustenta.

Guarnieri reflete que a questão da inclusão digital foi reduzida ao telecentro, e neste processo estão se perdendo as possibilidades que dispositivos como o celular, a TV 
digital, e principalmente tecnologias como o wi-fi, podem trazer para o processo. "Essas são as questões verdadeiras da inclusão digital", defende. Para ele, o acesso à Internet deve estar em qualquer lugar e por isso o Estado tem um papel importante na informatização de bibliotecas, escolas, etc, mas não na manutenção de telecentros. Pelo menos não no modelo atual. Para Guarnieri, inclusão digital hoje é um termo maior, "seria disseminar a cultura digital, o pessoal saber buscar informação direito na rede, você em qualquer lugar ter acesso à informação necessária".

$\mathrm{Na}$ opinião de Gilson, um conceito mais apropriado para a realidade atual é o de “emancipação digital", e os seus três principais objetivos são: "o primeiro é a autonomia do projeto individual, o segundo é a sustentação do projeto coletivo, e o terceiro é a consistência econômica do processo de inclusão digital, e a sustentabilidade ao longo do tempo, dos indivíduos nesses coletivos”. Pois só depois de "ganhar densidade e massa crítica" o sujeito ganha autonomia e "capacidade de decisão" para transformar projetos individuais em um "pacto coletivo sustentado". E essa coalizão entre diferentes projetos individuais precisa se sustentar economicamente ao longo do tempo. "Aí entra a geração de renda, a geração de emprego, emancipação, capital social, capital intelectual... toda a geração de riqueza que poderá estar ou não associada aos projetos individuais e às coalizões coletivamente.” Mas para ele, a grande questão é saber de onde virão os recursos para sustentar esse pacto coletivo. " $E$ um dinheiro que vai ser gerado pelo próprio projeto, é um dinheiro que vai ser aportado pelo Estado, é um dinheiro que o mercado vai cooptar através da responsabilidade social, patrocínios, das ONGs? Qual é a dinâmica de geração de valores, de riquezas, de emprego associada a essa filosofia de política digital?”, questiona. 


\section{Quadro 19. Atividades realizadas na Internet - Mentores}

\begin{tabular}{|c|c|c|}
\hline Nome & $\begin{array}{l}\text { Pela sua experiência, quais são as principais atividades das comunidades de baixa } \\
\text { renda na Internet? }\end{array}$ & Existe diferença entre o uso que se faz da Internet no centro público e em casa? \\
\hline $\begin{array}{l}\text { Rogério } \\
\text { Santanna }\end{array}$ & $\begin{array}{l}\text { Bom, o programa mais usado na Internet acaba sendo a declaração de isento do imposto de } \\
\text { renda. Na época em que precisa declarar o IR, é um programa bastante utilizado nos telecentros. } \\
\text { Mas aí depende do perfil da comunidade e dos usuários. Por exemplo, no caso de Porto Alegre, } \\
\text { cada telecentro é diferente do outro. Tem telecentros em que a prioridade são alunos, então acaba } \\
\text { sendo um laboratório que reforça o laboratório da escola, porque o da escola é mais restrito. Então } \\
\text { as crianças vão lá, fazem pesquisa na Internet. O e-mail, que todo mundo usa, é comum a todas as } \\
\text { faixas etárias de usuários do telecentro. }\end{array}$ & $\begin{array}{l}\text { Eu não conheço nenhum caso de pessoas das classes } \mathrm{D} \text { e E, pelo menos na cidade em que eu } \\
\text { vivi, que dispusessem de acesso à Internet antes... No telecentro, tem uma comunidade para } \\
\text { resolver as dúvidas. Tem um monitor para ajudar, então isso agrega mais valor a ele. } \\
\text { Porque sozinho ele não consegue resolver todas as suas dúvidas. Há mais suporte, sobretudo } \\
\text { porque são comunidades que têm como característica o baixo grau de instrução. Âs vezes, uma } \\
\text { das funções do processo é começar: os semi-alfabetizados começarem a se interessar pela } \\
\text { alfabetização, pela leitura, pela escrita, já que o e-mail força isso. }\end{array}$ \\
\hline $\begin{array}{l}\text { Rodrigo } \\
\text { Assumpção }\end{array}$ & $\begin{array}{l}\text { Eu acompanhava isso mais de perto na época do Sampa.org, então estou um pouco defasado... Mas } \\
\text { o que eu via muito era Chat, e-mail, matéria de fofoca, de famosos, a novela, o Big Brother, } \\
\text { futebol, uma coisa de atualidades e diversão. E daí coisas mais concretas, tipo trabalho escolar, } \\
\text { procurar informações, contatar outras pessoas, as necessidades de comunicação. Agora, o } \\
\text { interessante é que essas coisas vão se expandindo na medida em que o uso é cotidiano e } \\
\text { permanente. Tem pessoas ajudando a encontrar novos usos, os animadores, os monitores têm que } \\
\text { ter essa tarefa. }\end{array}$ & $\begin{array}{l}\text { Eu acho que o uso do equipamento próprio é muito mais intenso porque está à sua disposição. } \\
\text { As limitações são econômicas, de custo de conexão. Mas não vejo um uso tão diferente não. } \\
\text { Eu acho que isso aí é um mito. Eu acho que a diferença positiva para um telecentro é que a } \\
\text { gente deve apostar nesse uso coletivo comunitário, é a possibilidade de desenvolver } \\
\text { projetos conjuntos, é a possibilidade de ter relacionamentos estruturados a partir daquilo, } \\
\text { mais do que a solidão do uso individual. }\end{array}$ \\
\hline $\begin{array}{l}\text { Sérgio } \\
\text { Amadeu }\end{array}$ & $\begin{array}{l}\text { As principais atividades que eu tenho notado são: primeiro, o uso da Internet para e-mail, } \\
\text { comunicação em geral; segundo, pra obter informações sobre empregos, postos de trabalho, } \\
\text { envio de currículos, eu chamaria de informações profissionais ou sobre emprego. E um } \\
\text { terceiro é entretenimento, as várias formas de entretenimento. Por exemplo, as pessoas mais } \\
\text { velhas, as donas de casa usam muito sites que são referenciados à televisão, programas de televisão, } \\
\text { basicamente isso. Não necessariamente nesta ordem. E tem uma quarta coisa que está começando a } \\
\text { acontecer, muito eventual, que é: em momentos de recadastramento de CFP exigido pela Receita } \\
\text { Federal, tenho visto e ouvido uma generalização de uso. Então tem acontecido o uso de um serviço } \\
\text { público, mas esse é eventual e é, sem dúvida, o maior uso de serviço público. }\end{array}$ & $\begin{array}{l}\text { Eu não posso dizer, acredito que a gente não tenha condições de responder isso sem aferir } \\
\text { mesmo. Uma pista, talvez, é que muitos jovens de periferia usam o telecentro para } \\
\text { entretenimento, para sites de jogos e uso do mensageiro instantâneo, essas coisas, tal como } \\
\text { o jovem de classe média, que tem computador em casa. Agora, se isso significará que ambos } \\
\text { terão o mesmo uso, ou seja, que o fator classe social efetivamente não interfira, eu não tenho } \\
\text { como dizer, porque aí eu acho que requer uma pesquisa de campo. }\end{array}$ \\
\hline $\begin{array}{l}\text { Carlos } \\
\text { Afonso }\end{array}$ & $\begin{array}{l}\text { O Rodrigo Assumpção pode ter dado boas respostas para isso, porque o Sampa.org, de certo } \\
\text { modo, foi a semente do projeto de SP. No Sampa.org a gente viu isso acontecer, as coisas } \\
\text { nasceram lá a nível cultural, a nível de expressão cultural das comunidades, de produção de } \\
\text { conteúdo, foi fantástica essa experiência do Sampa.org. }\end{array}$ & $\begin{array}{l}\text { Provavelmente, porque tem a questão do tempo, a questão de estar ou não mais a vontade } \\
\text { na sua casa ou nesse local. Eu imagino que ao navegar e buscar informações, ele pode ter } \\
\text { comportamentos diferentes em um lugar público e em um lugar privado. Mas também não é } \\
\text { bem certo falar isso porque tem alguns usos que são essenciais, por exemplo, ver o seu e-mail. } \\
\text { Ele faria a mesma coisa em casa ou lá. Porque não se conseguiu ainda uma arquitetura de } \\
\text { telecentro que priorize a privacidade da pessoa que está navegando. Você já viu que todos } \\
\text { os monitores são virados para o público em todas as instalaçôes? Porque é mais barato fazer } \\
\text { assim. }\end{array}$ \\
\hline $\begin{array}{l}\text { Fernando } \\
\text { Guarnieri }\end{array}$ & No Acessa, em primeiro lugar era o e-mail, depois navegação, procurar emprego, Chat... & \\
\hline
\end{tabular}




\begin{tabular}{|c|c|c|}
\hline Nome & $\begin{array}{l}\text { Pela sua experiência, quais são as principais atividades das comunidades de baixa } \\
\text { renda na Internet? }\end{array}$ & Existe diferença entre o uso que se faz da Internet no centro público e em casa? \\
\hline $\begin{array}{l}\text { Gilson } \\
\text { Schwartz }\end{array}$ & $\begin{array}{l}\text { É difícil qualificar só o de baixa renda. Tem que cruzar baixa renda com a idade do cara, a questão } \\
\text { do gênero, varia muito. Se você pegar baixa renda, os meninos fazem uma coisa, as meninas fazem } \\
\text { outra. Os mais jovens fazem uma coisa, os mais velhos fazem outra. É difíicil. Mas pela experiência } \\
\text { que eu tive nesses anos, nem sei se é uma questão de baixa renda, quer dizer, ser ou não de baixa } \\
\text { renda. (...) Tudo bem, a gente que já trabalhou com essa turma no GMD , a gente vê que, primeiro, } \\
\text { é a fome de conteúdo. Para que serve a Internet? Para saber o que está acontecendo no mundo, } \\
\text { as pessoas querem conteúdo. O segundo ponto é a sexualidade. Por trás de todo esse } \\
\text { movimento da Internet, das redes, sei lá, } 30 \%, 40 \% \text { do que acontece tem sexo envolvido, num } \\
\text { sentido bem amplo. É fortíssimo e até me surpreende, acho que tem que se discutir muito mais } \\
\text { isso, porque é muito presente essa nova forma de aproximação. E o terceiro, disputando com a } \\
\text { questão cultural, é o entretenimento e o jogo. Não só os games e jogos eletrônicos, mas } \\
\text { também apostas, esquemas de enriquecimento, pirâmides.... Se a gente pensar no grupo } \\
\text { sexualidade e jogo, acho que tem 90\% do que as pessoas estão procurando, inclusive pelo que } \\
\text { eu tenho observado nas comunidades de baixa renda. Quer dizer, até tem educação... }\end{array}$ & $\begin{array}{l}\text { Eu acho que não. Não têm dados e pesquisas sobre o assunto. Mas pela vivência, pra mim, o } \\
\text { que o menino de classe média que tem um computador em casa procura é muito parecido } \\
\text { com o que o de baixa renda vai buscar no telecentro: cultura, conteúdo, sexualidade e o } \\
\text { jogo. E a comunicação entra nessa sexualidade, a informação de briefing. }\end{array}$ \\
\hline $\begin{array}{l}\text { Beatriz } \\
\text { Tibiriçá } \\
\text { (Beá) }\end{array}$ & $\begin{array}{l}\text { O principal público é o público jovem. Você tem também uma grande parcela do público de terceira } \\
\text { idade que vai para as unidades de acesso dos telecentros levados pelo seu neto, sobrinho, pelos } \\
\text { jovens. Aí você tem uma grande parte do acesso na Internet que a gente chama de } \\
\text { "entretenimento" - sala de bate-papo, e-mail, tal. E você tem uma procura muito grande na } \\
\text { relação emprego e mercado de trabalho: desde enviar currículo até procurar alternativas, isso } \\
\text { é uma coisa que é muito procurada. E tem uma faixa que usa para complementação de } \\
\text { escolaridade mesmo, desde trabalho escolar até cursos on-line, e uma área pouco explorada } \\
\text { inclusive, que é usar a Internet para programas de reforço escolar em parceria com as escolas. }\end{array}$ & $\begin{array}{l}\text { Tem toda uma polêmica que as próprias comunidades puxam. Quando a gente instalou os } \\
\text { telecentros, uma grande discussão que tinha era se era permitido ou não usar sala de bate-papo, } \\
\text { ficar lendo o jornal... Havia uma série de conselhos gestores da comunidade que, num } \\
\text { primeiro ímpeto, achavam que isso tinha que ser proibido. Jogo e bate-papo, isso não } \\
\text { podia. E aí tinha que ter toda uma discussão de "porque o filho de classe média que tem } \\
\text { computador em casa pode se familiarizar com a tecnologia usando aquilo que o atrai no } \\
\text { computador, que é jogar e se comunicar com o resto do mundo, entrar em redes de } \\
\text { relacionamento, redes de música, enfim.” Mas isso é um trabalho de convencimento quando } \\
\text { você chega nas comunidades de baixa renda, principalmente porque a idéia é: “aqui é um } \\
\text { equipamento público, então a gente deve usar para coisas que são importantes, então vamos } \\
\text { tratar da questão só do desemprego". A idéia da Internet chapa-branca, onde você só pode } \\
\text { freqüentar os sites governamentais. Que é importante para a articulação do cidadão na } \\
\text { sua cidade, em busca dos seus direitos, é, mas se você limitar o acesso que ele tem a só esse } \\
\text { tipo de navegação, você está impedindo que ele estabeleça uma relação com o mundo, } \\
\text { limitando as possibilidades desse cidadão. }\end{array}$ \\
\hline $\begin{array}{l}\text { Rodrigo } \\
\text { Baggio }\end{array}$ & $\begin{array}{l}\text { Fazer currículo, fazer trabalhos de escola, digitação de textos, serviços - até mesmo banco de } \\
\text { dados que ajudem a controlar o estoque da padaria ou de tal comércio da própria } \\
\text { comunidade, da própria favela. O uso da Internet é amplo, vai desde a pessoa que quer } \\
\text { pesquisar alguma coisa para o seu trabalho, aquele pequeno empreendedor que vai criar um } \\
\text { site para o seu pequeno empreendimento a pessoas que estão participando de chats, conversas } \\
\text { com outras pessoas através da Internet. É desestimulado o uso para questões que não são } \\
\text { educativas ou de geração de renda. Vamos dizer claramente: acesso a sites pornográficos ou coisa } \\
\text { do gênero, através de um processo pedagógico. Entretenimento, ok, jogos, chat e coisas do gênero. }\end{array}$ & \\
\hline
\end{tabular}


Segundo os entrevistados, as principais atividades realizadas na Internet (quadro 19), pelos usuários em CPAs, são a comunicação e o entretenimento, incluindo e-mail, sala de bate-papo, e a busca de informações sobre temas cotidianos e triviais como televisão, fofoca, famosos e futebol. Em seguida as atividades relacionadas à geração de renda, como a busca de ofertas de trabalho, envio de currículo ou a criação de um website para um pequeno empreendimento, e a complementação escolar, seja pesquisa ou procura por cursos on-line. Por último está o uso de serviços de governo eletrônico, como o recadastramento de $\mathrm{CPF}$ e o envio de imposto de renda de isento. Beá lembra que a faixa etária do usuário é importante para determinar o tipo de atividade, sendo que o público jovem é o mais presente, e Assumpção pontua que "o interessante é que essas coisas [atividades] vão se expandindo na medida em que o uso é cotidiano e permanente". Para Gilson a questão da renda não é fator determinante das atividades realizadas na Internet, "é difícil qualificar só o de baixa renda. Tem que cruzar baixa renda com a idade do cara, a questão do gênero, varia muito. (...) nem sei se é uma questão de ser ou não de baixa renda", mas o que ele vê é a "fome de conteúdo" e a "sexualidade": "Por trás de todo esse movimento da Internet, das redes, sei lá, 30\%, $40 \%$ do que acontece tem sexo envolvido". Em terceiro lugar fica o jogo e a questão cultural, segundo ele.

Para os mentores o uso da Internet em um centro público ou em casa também parece não ser muito diferente, desconsiderando o fato de que em casa esse uso é mais freqüente e a privacidade é maior. Rogério aponta o fato de que nos CPAs há mais suporte, pois o monitor está presente, e o uso tem uma vocação coletiva, para projetos da comunidade. "Mas não vejo um uso tão diferente não. Eu acho que isso aí é um mito. Eu acho que a diferença positiva para um telecentro é que a gente deve apostar nesse uso coletivo comunitário, é a possibilidade de desenvolver projetos conjuntos, é a possibilidade de ter relacionamentos estruturados a partir daquilo, mais do que a solidão do uso individual”, completa Assumpção. Para Beá, as próprias comunidades impõem um uso "chapa-branca" da Internet, considerando que "equipamento público" deve priorizar o acesso a "coisas que são importantes", como a questão do emprego e o acesso a sites governamentais, mas que a coordenação do Telecentros SP, quando sob sua gestão, buscava mostrar que "se você limitar o acesso que ele tem a só esse tipo de navegação, você está impedindo que ele estabeleça uma relação com o mundo, limitando as possibilidades desse cidadão". 


\section{Quadro 20. Impacto da Internet no consumo e produção de informação - Mentores}

\begin{tabular}{|c|c|c|}
\hline Nome & $\begin{array}{l}\text { Na sua opinião, houve alguma mudança nos hábitos de consumo de informação desses } \\
\text { indivíduos antes e depois da Internet? }\end{array}$ & $\begin{array}{l}\text { E nos hábitos de produção de informação? Caso a resposta seja afirmativa, } \\
\text { como você descreve essas mudanças? }\end{array}$ \\
\hline $\begin{array}{l}\text { Rogério } \\
\text { Santanna }\end{array}$ & $\begin{array}{l}\text { Uma pesquisa que a Cisco fez recentemente, diz que nas comunidades de baixa renda, três coisas } \\
\text { motivam o sujeito que acessa a Internet. Primeiro, o acesso à educação, às informações sobre educação, } \\
\text { para os seus trabalhos escolares, são bastante importantes. Acesso à saúde e acesso ao emprego, são } \\
\text { as coisas que as pessoas querem muito. Se preocupam em mandar currículo, fazer currículo, } \\
\text { procurar vagas de emprego, então são as três coisas que agregam valor para essas comunidades. }\end{array}$ & $\begin{array}{l}\text { Acho que sim, em alguns casos, inclusive com a geração de jovens interessados em } \\
\text { produzir filmes, processos multimídia, documentar a sua comunidade, então } \\
\text { começou a surgir muitas iniciativas correlacionadas. É claro que no caso de Porto } \\
\text { Alegre é um plano que está integrado a outros programas estruturais, mas a junção } \\
\text { dessas tecnologias... Por exemplo, na Restinga surgiu um grupo de jovens que produzia } \\
\text { filmes, documentários da sua comunidade sob o seu ponto de vista. Chegou a se } \\
\text { investir inclusive em tecnologia de câmeras e de materiais para que eles pudessem } \\
\text { gerar esses documentários, produzir as rádios comunitárias, que começaram a } \\
\text { melhorar. Com a Internet eles começaram a trocar programas com outras rádios } \\
\text { comunitárias que existem pelo Brasil, trocar de informação. }\end{array}$ \\
\hline $\begin{array}{l}\text { Rodrigo } \\
\text { Assumpção }\end{array}$ & $\begin{array}{l}\text { Certamente. Eu acho que ele passou a se ver como consumidor de informação. Não necessariamente } \\
\text { a informaçãa que eu julgue adequada, mas isso não importa. Qual é a informação que ele consumia } \\
\text { antes, além do boca-a-boca...? Concretamente, não há jornal, não há revista. É escola para aqueles que ali } \\
\text { estão, e a rua. Essas serão as duas fontes, e obviamente, a onipresente televisão. Então na hora que você } \\
\text { coloca o computador, seja para ler a respeito do Big Brother em vez de assistir, já é outra relação com } \\
\text { aquele processo. }\end{array}$ & $\begin{array}{l}\text { Os que se metem nesse caminho são os que se dão, de longe, melhor. Só que eles } \\
\text { são um percentual muito pequeno do grupo total. Mas aqueles que entram nessa } \\
\text { estrada, esses são os que dão certo, essas são as grandes histórias de sucesso, os que } \\
\text { perceberam que podem ser produtores. Esses estão aí hoje como ativistas políticos, } \\
\text { gente que está trabalhando em ONG, que está desenvolvendo projeto, que assumiu } \\
\text { cargos interessantes dentro da sua comunidade. Esses são os que fizeram a diferença. }\end{array}$ \\
\hline $\begin{array}{l}\text { Sérgio } \\
\text { Amadeu }\end{array}$ & $\begin{array}{l}\text { Eu acho que está havendo, nesses segmentos onde foram instalados equipamentos de acesso coletivo. } \\
\text { Essa é uma hipótese que fundamenta, no fundo, todos os programas de inclusão digital, mas elas carecem } \\
\text { de confirmação prática, de pesquisas empíricas. Porque os programas hoje se preocupam muito, os } \\
\text { gestores, em instalar equipamentos, mas nós ainda não estamos com uma massa tão grande de } \\
\text { equipamentos instalados que nos permita se preocupar com a outra fase. }\end{array}$ & $\begin{array}{l}\text { Tem vários grupos que já produziam atividades culturais diversas, começaram a } \\
\text { produzir informação... Porque a disseminação de informações, de imagens, de } \\
\text { textos pela Internet é muito mais barata do que com as velhas tecnologias } \\
\text { impressas. Então existe sim uma proliferação grande. Agora, ela é, insisto nisso, ela } \\
\text { gira em torno de dois aspectos: o fenômeno individual, ou seja, indivííduos ativos que } \\
\text { antes não podiam exercer essa sua potência porque não tinham instrumentos baratos, } \\
\text { então vocêe tem o fenômeno de blogs... e um fenômeno coletivo, que é onde existe a a } \\
\text { mobilização, trabahos coletivos diversos, é onde tem mais divulgação. A comunidade } \\
\text { já existia como ativa, só que aí ela ganha computador, um telecentro, capacitação, } \\
\text { quer dizer, ela vai exercer a capacidade comunicativa dela com esses novos meios. } \\
\text { Isso está acontecendo, assim, em um monte de lugar. (...) Eu sei que há outro } \\
\text { fenômeno, nos sites de relacionamentos isso acontece. As pessoas escrevem, antes elas } \\
\text { não escreviam. Bom, aí você vai falar: “e daí que as pessoas estão escrevendo?". Por } \\
\text { enquanto nada, é uma mera constatação, eu não estou dizendo que isso é bom ou isso é } \\
\text { ruim. Vou dizer mais: é melhor do que ficar só passivamente diante de uma televisão. } \\
\text { Mas eu não sei te dizer, além disso, é um terreno inicial que os institutos de pesquisa, } \\
\text { os pesquisadores estão começando a analisar, então é muito insipiente. }\end{array}$ \\
\hline Carlos Afonso & $\begin{array}{l}\text { Claro. Em qualquer escala social, em qualquer lugar. Isso é um fenômeno que aconteceu obviamente } \\
\text { com a web e com o crescimento espantoso da oferta de informação, tanto comentada como noticiada. } \\
\text { Se você fala tupi-guarani, você está numa situação difícil na Internet. Você tem muito pouca informação. } \\
\text { Mas se você fala português, você é uma das comunidades mais privilegiadas que existem. . ...) Você pode } \\
\text { dizer que em volume talvez não seja tanto, mas em qualidade, nós temos muita informação. No Brasil, não } \\
\text { colou vender a informação, porque muitos jornais são abertos. E hoje, quem tem acesso a Internet em casa } \\
\text { jamais vai se contentar em ler um jornal só. Vai ver vários, sempre. E quem tem acesso a um telecentro, } \\
\text { ele vai ver essas informações, com certeza. Ele provavelmente é uma pessoa que nunca assinou jornal } \\
\text { na vida e agora tem acesso a noticias na hora. }\end{array}$ & $\begin{array}{l}\text { Muitas pessoas que nunca escreveram nada, exceto no período, muitas vezes } \\
\text { curto, em que ficava na escola, passaram a escrever e a ler na Internet. Esse é um } \\
\text { fator muito importante, isso a gente nota nos telecentros. A pessoa tem que mandar um } \\
\text { e-mail, ela tem que escrever alguma coisa, isso é impressionante, é um novo } \\
\text { mundo.(...) As pessoas escrevem e-mail, elas não escreviam cartas, mas elas escrevem } \\
\text { e-mail. É informação. Esses dados estão na Internet, eles são informação. }\end{array}$ \\
\hline
\end{tabular}




\begin{tabular}{|c|c|}
\hline Nome & $\begin{array}{l}\text { Na sua opinião, houve alguma mudança nos hábitos de consumo de informação desses } \\
\text { indivíduos antes e depois da Internet? }\end{array}$ \\
\hline $\begin{array}{l}\text { Fernando } \\
\text { Guarnieri }\end{array}$ & $\begin{array}{l}\text { Não sei se as pessoas estão melhor informadas, não, mas mudou o jeito que a pessoa se informa. Está muito } \\
\text { diferente. Tem essa coisa do abrir a página por que está na frente dela, e ela vai se aprofundar em algumas } \\
\text { coisas. E também vai reproduzir: "olha, você viu isso aqui, tal". Então tem essa coisa de você estar sendo } \\
\text { bombardeado por muito mais informação do que você tava antes, e também você estar repassando } \\
\text { informação, você estar dando a sua opinião, você estar mobilizando, ta rolando. }\end{array}$ \\
\hline $\begin{array}{l}\text { Gilson } \\
\text { Schwartz }\end{array}$ & $\begin{array}{l}\text { Aparentemente você tem alguns indicadores de que mudou e aumentou o acesso, o uso de } \\
\text { informações, o volume de transações que envolvem troca de informações com o uso do computador. } \\
\text { Você pode ter um efeito de substituição, mas não ter um efeito de aumento da informação, quer dizer, } \\
\text { simplesmente o que você pode estar fazendo é: para um conjunto de setores sociais que tinha um nível "x" } \\
\text { de informação sem o computador, eles agora têm um volume de informação que aumentou muito pela } \\
\text { mídia digital, mas diminuiu pelo outro, portanto no agregado permanecia o mesmo. Por exemplo: } \\
\text { aumentou o número de pessoas que lêem notícias pela Internet. Sim, mas caiu o número de pessoas que } \\
\text { lêem o jornal. Portanto, no agregado, o nível de informação das pessoas pode continuar o mesmo ou até } \\
\text { pode diminuir, se a gente considerar que um jornal talvez seja um objeto de informação mais complexo e } \\
\text { mais rico do que a navegação individual, não-linear, por tópicos... O negócio é que na comunidade de baixa } \\
\text { renda pode haver menos televisão e mais Internet. Eu não sei se o efeito de substituição entre mídias é o } \\
\text { que predomina ou não. Pode ser que agora ele passe duas horas por semana num telecentro, LAN house ou } \\
\text { coisa assim, mas ele está tendo exatamente o mesmo nível de informação que tinha antes. Ele substituiu a } \\
\text { mídia, mas ele não necessariamente aumentou a qualidade ou a quantidade de informação que ele é é } \\
\text { capaz de buscar ou é capaz de absorver. }\end{array}$ \\
\hline $\begin{array}{l}\text { Beatriz } \\
\text { Tibiriçá } \\
\text { (Beá) }\end{array}$ & $\begin{array}{l}\text { Na periferia, onde as pessoas não tinham nenhum tipo de acesso, o primeiro contato delas na Internet } \\
\text { é buscar os sucessos da temporada... E aí você vai redirecionando com a própria discussão com os } \\
\text { usuários o que eles podem buscar de informação... Porque você [não pode] jogar uma pessoa na rede, com } \\
\text { o excesso de informações existe. Você tem que orientar o acesso, não no sentido de dizer "isso pode, isso } \\
\text { não pode", mas no sentido de como você vai aproveitar essa informação, pra que você vai usar isso, seja } \\
\text { pro entretenimento, seja para fazer o trabalho. (...) O que muda muito é a relação dessas comunidades } \\
\text { com o mundo em geral. Então você tem, por exemplo, comunidades indígenas do Peru que passaram } \\
\text { a ter contato com comunidades indígenas do Canadá para trocar experiências desde como defender } \\
\text { os seus direitos... até para fazer troca comercial de produto. Tem outro na Colômbia que se articulou } \\
\text { em torno da caminhada contra a ALCA, e o telecentro serviu para fazer a transmissão on-line da } \\
\text { caminhada. Tinha centro de capacitação para repórter comunitário... Então essa dimensão do "eu não estou } \\
\text { sozinho no mundo e eu posso usar a Internet para me relacionar com outras comunidades que têm os } \\
\text { mesmos problemas ou têm outras soluções, que eu posso trocar", é a grande mudança de cabeça que ocorre } \\
\text { em quem freqüenta um telecentro. Eu estou partindo do pressuposto de que telecentro não são cinco } \\
\text { máquinas para o cara ir lá acessar e-mail e ir embora. É um lugar que tem monitor, que tem espaço } \\
\text { de convivência, que tem uma vida própria. }\end{array}$ \\
\hline $\begin{array}{l}\text { Rodrigo } \\
\text { Baggio }\end{array}$ & $\begin{array}{l}\text { Eu não tenho, dados para quantificar... Mas com certeza o impacto é muito grande na medida em } \\
\text { que aprendendo a utilizar novas tecnologias, você tem uma diversidade maior na busca e no trato } \\
\text { com informações. E na verdade é assim, a televisão brasileira fala muito da Internet. Você vê no final do } \\
\text { noticiário “www.jornalnacional.com.br”, no final de programas... Então esse público de baixa renda é } \\
\text { muito motivado pelos meios de comunicação para o uso da Internet. Revistas, jornais, outdoor na rua, a } \\
\text { tecnologia é algo muito sedutor, muito novo. Quando a gente dá a oportunidade (...) aumenta muito essas } \\
\text { possibilidades de trabalho com a informação. }\end{array}$ \\
\hline
\end{tabular}

E nos hábitos de produção de informação? Caso a resposta seja afirmativa, como você descreve essas mudanças?

Então, produção de informação eu acho que rola muito em blog e nessas coisas assim. Embora isso não role tanto, acho que nem todo mundo gosta de texto. Agora, uma coisa que não está acontecendo ainda, mas que tende a rolar mais, isso quando baratear, é foto, som . É o pessoal começar a criar, é criação, uma pequena parte de todo mundo.

\section{Eu acho que por enquanto... os projetos de inclusão digital buscam essa}

capacitação para a produção de informação. Se você considerar que ter um e-mail e mandar um e-mail ou entrar no UOL é produzir mais informação, com certeza essa pessoas estão produzindo mais bits. Agora, se for por um ponto de vista mai emancipatório, no que diz respeito a produzir conteúdo, conhecimento, que corresponda a um projeto individual e dê sustentabilidade a um coletivo e amplie as perspectivas de produção social, aí eu tenho dúvida. Agora se for uma medida mais básica, mais elementar, considerar que produzir informação é mandar SMS para dizer quem vai para o paredão, quem vai ser eliminado no Big Brother Brasil, então com certeza está aumentando. Antes as pessoas não votavam em nada e agora num dia de paredão do jogo no Brasil você tem 10,12 milhões de pessoas clicando no celular. Bom, clicar no celular é produzir informação.

Aí eu acho que tem toda essa expectativa de produzir o jornal do seu bairro, o site da sua comunidade, o boletim da igreja... Eu acho que eles produzem com o que les sabem fazer, com o que eles sabem observar.

Elas vão se interessando pelo aprendizado de saber ler e escrever. Tinha gente que participava de fanzine que não sabia sequer ler! E aí aprendia a fazer as coisas de imagem. A partir daí, essas pessoas, se integrando no grupo, no jornal comunitário, resolveram que iam estudar, que iam aprender a ler. Porque senão ela não sabia o que estava sendo publicado com a imagem que ela tinha trabalhado, que ela tinha aprendido a trabalhar mais ou menos mecanicamente. E é óbvio que você tem que respeitar a identidade cultural que se constrói nesses espaços através desses mecanismos de comunicação. (...) Houve a criação de site e o jornalismo comunitário. Tanto eles participavam, por exemplo, das coberturas que o Governo Eletrônico. Toda a parcina Lancontro Latino-Americano foi feita pelos reporteres comunitarios que tinham sido criados nessas oficinas.(...) Então eles faziam a cobertura com o olhar deles, com a linguagem
deles, direto na rede. deles, direto na rede.

Um dos eixos da nossa proposta político-pedagógica é mergulhar na comunidade. (...) Isso pressupõe todo um trabalho de pesquisa em que os alunos da EIC vão à comunidade para coletar dados e informações que retratem, que ajudem a ampliar o seu conhecimento sobre a ela. Então a própria proposta políticopedagógica do CDI estimula fortemente esse tipo de levantamento de informação, de trabalho com a informação. 
De acordo com os mentores, no que diz respeito ao impacto da Internet no consumo e produção de informação (quadro 20), não existem dados que possam quantificar o aumento no consumo de informação, mas pode-se dizer que, com a Internet, o acesso ao conteúdo ficou mais fácil, que mudou a maneira como o usuário de baixa renda se informa. Já a qualidade desse conteúdo ainda é duvidosa, o que faz com que não se possa afirmar se esse internauta está realmente melhor informado.

Eu acho que ele passou a se ver como consumidor de informação. Não necessariamente a informação que eu julgue adequada, mas isso não importa. Qual é a informação que ele consumia antes, além do boca-a-boca...? Concretamente, não há jornal, não há revista. É escola para aqueles que ali estão, e a rua. Essas serão as duas fontes, e obviamente, a onipresente televisão. Então na hora que você coloca o computador, seja para ler a respeito do Big Brother em vez de assistir, já é outra relação com aquele processo, explica Assumpção.

Baggio lembra ainda que a televisão estimula muito o uso da Internet. "Você vê no final do noticiário 'www.jornalnacional.com.br', no final de programas... Então esse público de baixa renda é muito motivado pelos meios de comunicação para o uso da Internet”. Para Beá, esse novo contato com a informação se traduz em uma mudança na relação dessas comunidades com o mundo: "Então essa dimensão do 'eu não estou sozinho no mundo e eu posso usar a Internet para me relacionar com outras comunidades que têm os mesmos problemas ou têm outras soluções, que eu posso trocar', é a grande mudança de cabeça que ocorre em quem freqüenta um telecentro".

No que diz respeito à produção de informação, o consenso é de que houve sim um aumento na produção de conteúdo, mas principalmente textos básicos como e-mails e envio de mensagens de texto, o que Carlos Afonso já considera "um fenômeno muito importante" para esse universo de pessoas que não têm o hábito de ler ou escrever. Gilson, de forma crítica, coloca em questão essa produção:

Se você considerar que ter um e-mail e mandar um e-mail ou entrar no UOL é produzir mais informação, com certeza essas pessoas estão produzindo mais bits. Agora, se for por um ponto de vista mais emancipatório, no que diz respeito a produzir conteúdo, conhecimento, que corresponda a um projeto individual e dê sustentabilidade a um coletivo e amplie as perspectivas de produção social, aí eu tenho dúvida.

Mas é fato que a produção de conteúdo local tende a aparecer - ainda que em casos pontuais - através de fanzines, blogs ou websites. Para Rogério, esse processo se mostra mais completo quando integrado a outros programas estruturais em desenvolvimento no 
CPA. "Por exemplo, na Restinga surgiu um grupo de jovens que produzia filmes, documentários da sua comunidade sob o seu ponto de vista", conta, lembrando a experiência dos Telecentros POA. E Assumpção destaca que os usuários que se motivam a produzir conteúdos são de longe os que se dão melhor, mas são um percentual muito pequeno do grupo total: "essas são as grandes histórias de sucesso, os que perceberam que podem ser produtores. Esses estão aí hoje como ativistas políticos, gente que está trabalhando em ONG, que está desenvolvendo projeto. Esses são os que fizeram a diferença".

Em geral, os mentores também argumentam que não existem indicadores que meçam objetivamente a contribuição dos programas de inclusão digital para o desenvolvimento social, político e econômico (quadro 21), o que existem novamente são histórias ou casos pessoais de sucesso. Mas a tecnologia não faz milagres. Como diz Assumpção, "não é assim, 'eu consumo computador e a gata borralheira vira princesa', né? A tecnologia não tem magia nenhuma”. Além disso, Gilson lembra que medir impacto social é muito complicado e demanda grandes intervalos de tempo: “Esse é um processo de longo prazo porque os efeitos demoram, porque como ele é reflexivo, na medida em que ele vai avançando, a percepção e a consciência que os agentes têm do que está acontecendo com isso também vai mudando, vai exigindo outros indicadores. É um processo que não é trivial, não é linear”.

Independente do impacto, para Beá o grande potencial do CPA é se transformar num centro de relacionamento, de atividade, de programação: "Nem tudo o que se faz dentro de um telecentro ou na maioria deles tem a ver com a tecnologia propriamente dita, mas tem a ver com grupos de comunidades, com projetos locais, com o debate do desenvolvimento local. Então essas atividades passam a acontecer em torno do computador e em torno do telecentro", diz. 
Quadro 21. Contribuição dos programas de ID para o desenvolvimento social, político e econômico - Mentores

\begin{tabular}{|c|c|c|c|}
\hline \multirow[b]{2}{*}{ Nome } & \multicolumn{3}{|c|}{ Qual o impacto dos programas públicos de acesso à Internet no desenvolvimento dos indivíduos que vivem em comunidades de baixa renda? } \\
\hline & Oportunidade de geração de renda e emprego & $\begin{array}{l}\text { Oportunidades de educação, acesso à informação e } \\
\text { cultura }\end{array}$ & Conscientização social e participação política \\
\hline $\begin{array}{l}\text { Rogério } \\
\text { Santanna }\end{array}$ & & $\begin{array}{l}\text { [Existem histórias de pessoas] que retomaram os estudos, } \\
\text { sim. Eu citava o caso da Isabel, por exemplo, que era uma } \\
\text { catadora de latinha, depois foi fazer vestibular e tal, começou a } \\
\text { se interessar em estudar }\end{array}$ & $\begin{array}{l}\text { Eu acho que um pouco de cada coisa, mas sem muitas ilusões, } \\
\text { dizendo que vai interferir fortemente. No caso da cidade de Porto } \\
\text { Alegre houve um benefício adicional porque toda a prestação de } \\
\text { contas, todo o ciclo do orçamento participativo da cidade se dá } \\
\text { pela Internet. Então as comunidades conseguem acompanhar a } \\
\text { demanda, o andamento do orçamento as futuras execuções, se as } \\
\text { obras estão atrasados ou não estão, sugerir melhorias... Facilita a } \\
\text { relação com a prefeitura. (...) O programa sozinho não faz } \\
\text { nada, mas a Internet permite que as comunidades com } \\
\text { problemas similares troquem informaçôes entre si. }\end{array}$ \\
\hline $\begin{array}{l}\text { Rodrigo } \\
\text { Assumpção }\end{array}$ & $\begin{array}{l}\text { Eu já tenho dezenas de exemplos de histórias que eu me } \\
\text { envolvi diretamente de gente cuja vida mudou } \\
\text { completamente a partir desse processo. Agora, não é assim, } \\
\text { "eu consumo computador e a gata borralheira vira princesa", né? } \\
\text { A tecnologia não tem magia nenhuma, o que existe é um } \\
\text { espaço comunitário atraente, onde novas perspectivas de } \\
\text { vida são aprendidas. (...) Você aprender que para você escapar } \\
\text { do ciclo de pobreza, você precisa não ter filho aos } 16 \text { anos e você } \\
\text { precisa estudar. É muito mais uma coisa de estruturar o projeto } \\
\text { de vida, que passa pelo acesso, consumo e a capacidade de } \\
\text { produção de informação. Esse é o padrão moderno da } \\
\text { sociedade, de acúmulo de riqueza, de estratificação social. É } \\
\text { você conseguir se enxergar dentro desse padrão moderno que } \\
\text { é o fundamental. Então não é uma relação direta, "eu terei } \\
\text { emprego porque sei datilografar nessa maquininha", não. É "eu } \\
\text { terei emprego porque eu percebi que eu sendo uma pessoa que } \\
\text { lida com informação e sabe a importância e o papel da } \\
\text { informação na nossa sociedade, eu vou conseguir estar inserido } \\
\text { na nossa sociedade num papel com chance maior de não ser } \\
\text { submisso, não ser subordinado". }\end{array}$ & $\begin{array}{l}\text { Certamente [amplia as opções de lazer, de cultura], sobretudo } \\
\text { na periferia, onde o lazer mais efetivo pra muitos adolescentes } \\
\text { é engravidar... Mais isso não é o mais relevante: o lazer, o } \\
\text { ocupar, tirar das ruas. Tudo isso eu acho uma visão bastante } \\
\text { pobre e minimalista do negócio. A questão é começar a ver que } \\
\text { tem coisas a serem feitas, que você pode ingressar. (...) Os } \\
\text { projetos existentes têm uma falha ainda grande de conteúdo. } \\
\text { Agora, o fato de instalar a Internet lá, de permitir que um } \\
\text { jovem entre em um site, mesmo que seja no Orkut, esse } \\
\text { jovem vai uma hora entrar em contato com a comunidade } \\
\text { "Eu apóio X, eu odeio Y”, ele vai começar a ter um acesso } \\
\text { que ele não tinha antes, argumentos que não faziam parte } \\
\text { do seu cotidiano ou conhecer pessoas que ele jamais teria } \\
\text { condição de fazer dada a situação dele. Então a base da } \\
\text { cidadania está sendo montada. Agora, sobre a base, é } \\
\text { necessário construir edifício, e aí os projetos são muito } \\
\text { insipientes, todos eles. }\end{array}$ & $\begin{array}{l}\text { Profundamente, em todos os sentidos. Desde o componente } \\
\text { educacional, até aquela coisa de identidade, de auto- } \\
\text { conhecimento. Desde coisas bem informacionais ( } s i c \text {, "quais são } \\
\text { os meus direitos, quem eu sou, o que eu posso e o que eu não } \\
\text { posso", até de novo como você se enxerga e se coloca dentro do } \\
\text { mundo, dentro da sociedade. A chance dele ser um cidadão é } \\
\text { participar disso, senão ele está fora. A chance de uma criança } \\
\text { ser um cidadão hoje, sem inclusão digital, é zero. Não dá } \\
\text { para ser cidadão sem máquina hoje, principalmente nas } \\
\text { classes excluídas. }\end{array}$ \\
\hline $\begin{array}{l}\text { Sérgio } \\
\text { Amadeu }\end{array}$ & $\begin{array}{l}\text { O segundo é que começam a existir exemplos de superação } \\
\text { de condições de pobreza com o uso de tecnologia, mas ainda } \\
\text { são exemplos. }\end{array}$ & $\begin{array}{l}\text { Na maior parte das vezes, os programas da inclusão digital } \\
\text { estão desprovidos de um conteúdo que permita um ganho, } \\
\text { uma absorção tecnológica maior pelas comunidades. Você } \\
\text { não faz isso simplesmente pela tecnologia, você faz para } \\
\text { trabalhar conteúdos que elas vejam utilidade, que passem então } \\
\text { a se apropriar das tecnologias por causa desses conteúdos, mas } \\
\text { eu vejo pouco isso ainda. Então os efeitos estão por vir... }\end{array}$ & $\begin{array}{l}\text { Um primeiro fator, que é muito difícil de aferir no curto } \\
\text { prazo que têm esses projetos, é o fator da cidadania. Ele passa } \\
\text { a ter um acesso que ele não tinha antes a um conjunto de } \\
\text { informações que ele nunca teve à sua disposição. Então antes ele } \\
\text { participava da esfera pública com informações principalmente do } \\
\text { rádio e da televisão. Hoje, ele tem instrumentos que são muito } \\
\text { distintos. Isso não quer dizer que eles o utilizem, mas tem } \\
\text { cada vez mais a utilização sendo feita. }\end{array}$ \\
\hline
\end{tabular}




\begin{tabular}{|c|c|c|c|}
\hline \multirow[b]{2}{*}{ Nome } & \multicolumn{3}{|c|}{ Qual o impacto dos programas públicos de acesso à Internet no desenvolvimento dos indivíduos que vivem em comunidades de baixa renda? } \\
\hline & Oportunidade de geração de renda e emprego & $\begin{array}{l}\text { Oportunidades de educação, acesso à informação e } \\
\text { cultura }\end{array}$ & Conscientização social e participação política \\
\hline $\begin{array}{l}\text { Carlos } \\
\text { Afonso }\end{array}$ & $\begin{array}{l}\text { É difícil de avaliar quantitativamente. Ainda não tem essas } \\
\text { estatísticas para o Brasil. Existem algumas estatísticas, a gente } \\
\text { fez uma pesquisa inclusive de amostragem, que mostra que } \\
\text { muitas coisas melhoraram: performance na escola, essas coisas. } \\
\text { Mas fica difícil avaliar, por exemplo, em que isso alavancou o } \\
\text { empreendedorismo. Eu sei que alavancou, eu tenho certeza } \\
\text { que alavancou, mas eu não sei quanto. Eu não sei como, em } \\
\text { que escala. A gente tem histórias, ouve histórias, sabe que elas } \\
\text { são verdadeiras, mas em que medida? Isso ainda precisa ser } \\
\text { avaliado. }\end{array}$ & $\begin{array}{l}\text { A resposta é fácil, podem ou não contribuir, depende. Se você } \\
\text { faz a coisa enraizada na comunidade, com essa consciência de } \\
\text { que eles têm que se apropriar do instrumento para outra coisa } \\
\text { que não seja só usar o instrumento em si, é claro que vai fazer } \\
\text { uma diferença.(...) A gente fez [uma experiência] em } \\
\text { Brasília, uma escola em que um grupo ficou tendo acesso e } \\
\text { outro não. A diferença quantitativa e qualitativa da } \\
\text { produção dessas pessoas, de desempenho na escola foi } \\
\text { gritante, então é claro que faz diferença, não há dúvida. } \\
\text { Então contribui tanto para o desenvolvimento individual como } \\
\text { para a sua percepção do seu papel nessa sociedade, porque eles } \\
\text { estão interagindo. De repente, o garotão que vivia na rua } \\
\text { jogando bola agora é um instrutor de webdesign num } \\
\text { telecentro. }\end{array}$ & $\begin{array}{l}\text { O que eu sei é que mudanças sociais existem, eu sempre cito o } \\
\text { exemplo de uma comunidade próxima de Quito que tinha um } \\
\text { telecentro instalado pela Chasquinet }{ }^{72} \text {. Era uma comunidade } \\
\text { totalmente patriarcal e o telecentro passou a ser uma } \\
\text { oportunidade para as mulheres de se reunir. Elas iam para lá } \\
\text { para aprender a usar a Internet e, pela primeira vez, } \\
\text { conversar entre si. E descobriram que tinham algumas coisas } \\
\text { em comum, entre elas apanhar do marido. Aí começaram a } \\
\text { se organizar e se articular, [alterando a relação entre homens e } \\
\text { mulheres naquela comunidade]. Então esses impactos, essas } \\
\text { histórias existem, mas quantificar isso, dizer que isso é um } \\
\text { perfil que vai acontecer em todas é muito difícil. }\end{array}$ \\
\hline $\begin{array}{l}\text { Fernando } \\
\text { Guarnieri }\end{array}$ & $\begin{array}{l}\text { Se você pegar a Ponline, você tem essa pergunta para os } \\
\text { usuários, qual é o impacto na vida deles... Uma boa parte acha } \\
\text { que realmente aumenta a empregabilidade, que vai ter uma } \\
\text { oportunidade de emprego. Mas a gente não tem idéia, não } \\
\text { tem nenhum indicador, é muito difícil medir isso. A gente não } \\
\text { sabe se ele mudou a realidade dele por causa do infocentro, ou } \\
\text { porque a escola melhorou, ou porque entrou uma empresa lá... É } \\
\text { muito complicado, não temos como controlar as variáveis... }\end{array}$ & $\begin{array}{l}\text { Então, qual é o impacto disso no aprendizado? Você teria que } \\
\text { pegar todos os alunos de uma classe, talvez de uma escola, e } \\
\text { colocar nos telecentros. Pegar todos os alunos de uma outra } \\
\text { escola e não deixar eles acessarem. Aí depois de três anos, } \\
\text { você vê qual foi o impacto. Porque a gente não sabe se o cara } \\
\text { que vai para o telecentro é um cara mais esforçado, menos } \\
\text { esforçado, se é realmente o gazeteiro que vai lá só pra ficar no } \\
\text { chat, não dá pra saber, não dá pra ter esse controle, entendeu? } \\
\text { (...) Tem os cases... e o case é uma coisa muito da imprensa, } \\
\text { pra repórter ver. }\end{array}$ & $\begin{array}{l}\text { Toda a idéia do Acessa era fazer isso, porque a Internet é um } \\
\text { ótimo instrumento pra isso. Você pode mandar um e-mail } \\
\text { sugerindo uma melhoria na rua, você pode fiscalizar as contas do } \\
\text { governo. Então, quer dizer, todo o ferramental(sic) está dado, } \\
\text { você tem que correr atrás. Então, quer dizer, a partir do momento } \\
\text { que você coloca o telecentro, esse telecentro tá lá para isso. E aí } \\
\text { é essa coisa de você criar essa cultura, essa participação. De } \\
\text { repente, o Acessa podia fazer isso, né? Tenta fazer, mas eu } \\
\text { não sei se dá.... }\end{array}$ \\
\hline $\begin{array}{l}\text { Gilson } \\
\text { Schwartz }\end{array}$ & \multicolumn{3}{|c|}{$\begin{array}{l}\text { Não há indicadores ou pesquisas suficientes sobre isso. Emprego e renda por enquanto são chavões sem números para fundamentar uma análise séria. Pelo menos até agora eu não consegui } \\
\text { ver indicadores sustentáveis. Eu acho que não só porque falta uma pesquisa, mas porque as políticas são tão diversas, sobre bases tão diferentes em todos os seus aspectos... Não existe uma } \\
\text { política de inclusão digital, é tudo muito diferenciado. Uns são mais voltados para a educação, outros não, como é que você vai comparar coisas que são diferentes? (...) E eu acho também que existe } \\
\text { uma diversidade muito grande, mesmo dentro do Governo Federal. Na última vez que eu contei, tinha nove tipos diferentes de programas de inclusão digital. Cada ministério quer ter o seu, cada } \\
\text { liderança quer fazer a sua rede de atuação. O MDIC quer ter um telecentro de cidadania, o MINC tem o Ponto de Cultura., o Casa Brasil já é outra coisa. O MEC vai ter uma outra política. Quer dizer, } \\
\text { o FUST nunca foi para o cara... Eu acho que tem muitas políticas que mais ou menos têm a ver com esse universo da inclusão digital, mas não são articuladas, não compartilham as mesmas } \\
\text { ideologias, portanto é difícil encontrar indicadores comparáveis. Como é que eu vou comparar o impacto de um telecentro do MDIC com um impacto de um ponto pequenininho? Tudo é diferente, } \\
\text { o intuito é diferente, a metodologia é diferente. A única coisa que tem em comum é que eu sei que os dois estão colocando equipamentos nos locais de acesso público. Por isso que eu digo que } \\
\text { no final das contas, o que é comum acaba sendo a disponibilização de uma infra-estrutura. Agora, a parte de metodologia, indicadores, avaliação de resultados, isso não surgiu, e para mim } \\
\text { continua a dúvida: será que realmente tá ajudando, tá gerando emprego? A minha conclusão é a seguinte: é muito complicado, é muito demorado, realmente a gente está na pré-história desse processo. } \\
\text { (...) E esse é um processo de longo prazo porque os efeitos demoram, porque como ele é reflexivo, na medida em que ele vai avançando, a percepção e a consciência que os agentes têm do } \\
\text { que está acontecendo com isso também vai mudando, vai exigindo outros indicadores. É um processo que não é trivial, não é linear. }\end{array}$} \\
\hline
\end{tabular}

${ }^{72}$ Fundação latino-americana que tem como objetivo promover os usos estratégicos das TIC nos setores empobrecidos, em nível local e regional, incidindo em políticas econômicas e sociais para o desenvolvimento humano e sustentável. Ver http://www.chasquinet.org/ 


\begin{tabular}{|c|c|c|c|}
\hline \multirow[b]{2}{*}{ Nome } & \multicolumn{3}{|c|}{ Qual o impacto dos programas públicos de acesso à Internet no desenvolvimento dos indivíduos que vivem em comunidades de baixa renda? } \\
\hline & Oportunidade de geração de renda e emprego & $\begin{array}{l}\text { Oportunidades de educação, acesso à informaçãa e } \\
\text { cultura }\end{array}$ & Conscientização social e participação política \\
\hline $\begin{array}{l}\text { Beatriz } \\
\text { Tibiriçá } \\
\text { (Beá) }\end{array}$ & $\begin{array}{l}\text { Todo mundo vai para o telecentro procurar, num primeiro } \\
\text { ímpeto, qualificação para o mercado de trabalho. Paralelo a } \\
\text { isso, o cara vai por causa da escola, e a partir daí ele } \\
\text { diversifica a sua atividade dentro do telecentro. Aí você tem o } \\
\text { encontro tanto dos projetos que já existiam na comunidade e } \\
\text { que passam a usar a tecnologia para melhorar o que estavam } \\
\text { fazendo: cooperativa de compra, quiosque de venda que se } \\
\text { articula até em volta de telecentro... E também surgem, a partir } \\
\text { do telecentro, iniciativas que acontecem por causa do uso que os } \\
\text { usuários aprenderam. Então o fanzine proliferou nas unidades do } \\
\text { telecentro porque o cara adora o fato de virar repórter } \\
\text { comunitário, de botar no computador e já sair impresso. Ele } \\
\text { organiza melhor os projetos que estão na própria comunidade e } \\
\text { também apresenta novos projetos para essa comunidade. }\end{array}$ & $\begin{array}{l}\text { A questão de organizar as informações e divulgar para a } \\
\text { sua comunidade acaba aparecendo com muita força depois } \\
\text { do momento em que você atende a primeira demanda que } \\
\text { aprendeu a lidar com a máquina. A partir daí, você precisa } \\
\text { pôr as oficinas que, em geral são as mais solicitadas: } \\
\text { construção de website, comunicação comunitária. Então o cara } \\
\text { quer construir o site da sua igreja, quer fazer o fanzine pro seu } \\
\text { pessoal do bairro. (...) } \\
\text { Primeiro você tem um impacto porque acaba se transformando } \\
\text { num centro de relacionamento, de atividade, de programação, } \\
\text { pelas possibilidades que ele abre. Nem tudo o que se faz } \\
\text { dentro de um telecentro ou na maioria deles tem a ver com } \\
\text { a tecnologia propriamente dita, mas tem a ver com grupos } \\
\text { de comunidades, com projetos locais, com o debate do } \\
\text { desenvolvimento local. Então essas atividades passam a } \\
\text { acontecer em torno do computador e em torno do } \\
\text { telecentro. }\end{array}$ & $\begin{array}{l}\text { A possibilidade que você tem, tendo uma rede pública de } \\
\text { acessio, é que eles virem ponto de referência inclusive do } \\
\text { Poder Executivo nessas comunidades. Como que isso } \\
\text { acontece? O cara precisa da segunda via do IPTU, precisa buscar } \\
\text { coisas na sua relação de cidadão com o Poder Executivo, ele não } \\
\text { precisa mais se deslocar. Agora isso é muito pouco usado } \\
\text { quando você fala em transparência, fiscalização e } \\
\text { participação. (...) E eu acho que é pouco usada inclusive porque } \\
\text { os governos ainda têm um conceito que não é o conceito amplo } \\
\text { de Internet cidadã. Eu acho que em, administrações democráticas } \\
\text { populares que têm iniciativas tipo Orçamento Participativo, você } \\
\text { não tem um instrumento que permita que esse Orçamento } \\
\text { Participativo possa ser visualizado e interferido via Internet. Ou } \\
\text { seja, que o usuário possa acompanhar a emenda que ele } \\
\text { apresentou na plenária, e possa votar na plenária via Internet. }\end{array}$ \\
\hline $\begin{array}{l}\text { Rodrigo } \\
\text { Baggio }\end{array}$ & $\begin{array}{l}\text { Como nós medimos este impacto, é muito claro e rápido ver que } \\
\text { o conhecimento básico de informática e cidadania possibilita a } \\
\text { esse jovem uma perspectiva de mudança de vida. E essa } \\
\text { perspectiva acontece na empregabilidade desse jovem, a } \\
\text { gente percebe claramente o aumento da preparação desse } \\
\text { jovem para competir por uma vaga no emprego. (...) A gente } \\
\text { tem também exemplos muito importantes de geração de } \\
\text { renda, de criação de cooperativas de serviços da informática, } \\
\text { ou até mesmo informalmente, dois ou três alunos se } \\
\text { organizam e vão gerar alguma renda através do que eles } \\
\text { aprenderam. }\end{array}$ & $\begin{array}{l}\text { A gente percebe também impactos importantes no que } \\
\text { consiste no encaminhamento, a volta para a escola pública. } \\
\text { Nós temos uma série de exemplos, principalmente em grandes } \\
\text { centros urbanos, de pessoas que estavam na criminalidade, no } \\
\text { tráfico de drogas e procuram a EIC com uma postura de } \\
\text { conversão, de (...) buscar uma vida mais produtiva. (...) Um } \\
\text { outro fato também mais de auto-estima é ter o seu tempo } \\
\text { ocupado de uma forma produtiva. Isso eu diria em geral, } \\
\text { porque se a gente for entrar no impacto em aldeias } \\
\text { indígenas, portadores de necessidade especial, } \\
\text { penitenciárias, a gente tem uma série de outros fatores } \\
\text { relevantes também para considerar. }\end{array}$ & $\begin{array}{l}\text { A nossa proposta pedagógica é completamente integrada a essa } \\
\text { forma de refletir e discutir sobre a realidade da comunidade } \\
\text { gerando uma ação de transformação. Quer dizer, a proposta } \\
\text { político-pedagógica objetiva (...) a formação de agentes de } \\
\text { mudança. Essa visão de fomentar o empoderamento }(s i c) \text {, essa } \\
\text { visão de que a pessoa de baixa renda deve sim fazer alguma } \\
\text { coisa para a transformação da realidade que ela vive. }\end{array}$ \\
\hline
\end{tabular}


No que diz respeito à oportunidade de geração de renda e emprego, foram lembrados alguns exemplos de "superação de condições de pobreza com o uso de tecnologia" mas, como diz Sérgio, esses "são apenas exemplos". O senso comum é de que, intuitivamente, percebe-se que o uso da Internet ou mesmo a existência do CPA alavancou as chances de inserção no mercado de trabalho, a qualificação, o empreendedorismo. Pelo menos é essa percepção que os usuários transmitem para a coordenação dos programas, como relata Guarnieri, pela sua experiência no Acessa SP:

Se você pegar a Ponline ${ }^{73}$, você tem essa pergunta para os usuários, qual é o impacto na vida deles... Uma boa parte acha que realmente aumenta a empregabilidade, que vai ter uma oportunidade de emprego. Mas a gente não tem idéia, não tem nenhum indicador, é muito difícil medir isso. A gente não sabe se ele mudou a realidade dele por causa do infocentro, ou porque a escola melhorou, ou porque entrou uma empresa lá... É muito complicado, não temos como controlar as variáveis....

Beá argumenta que "todo mundo vai para o telecentro procurar, num primeiro ímpeto, qualificação para o mercado de trabalho. Paralelo a isso, o cara vai por causa da escola, e a partir daí ele diversifica a sua atividade dentro do telecentro". E é nesse contexto que ela percebe o impacto, quando "o cidadão passa a usar a tecnologia para melhorar o que já estavam fazendo". Para Baggio é mais fácil identificar a contribuição da tecnologia para o desenvolvimento do indivíduo: "é muito claro e rápido ver que o conhecimento básico de informática e cidadania possibilita a esse jovem uma perspectiva de mudança de vida. E essa perspectiva acontece na empregabilidade desse jovem, a gente percebe claramente o aumento da preparação desse jovem para competir por uma vaga no emprego". Já para Assumpção a questão é bem mais complexa:

\begin{abstract}
É muito mais uma coisa de estruturar o projeto de vida, que passa pelo acesso, consumo e a capacidade de produção de informação. Esse é o padrão moderno da sociedade, de acúmulo de riqueza, de estratificação social. É você conseguir se enxergar dentro desse padrão moderno que é o fundamental. Então não é uma relação direta, 'eu terei emprego porque sei datilografar nessa maquininha', não. É 'eu terei emprego porque eu percebi que eu sendo uma pessoa que lida com informação e sabe a importância e o papel da informação na nossa sociedade, eu vou conseguir estar inserido na nossa sociedade num papel com chance maior de não ser submisso, não ser subordinado.
\end{abstract}

Quanto às oportunidades de educação, acesso à informação e cultura, foram identificadas novamente histórias de pessoas que retomaram os estudos, de ganho de

\footnotetext{
${ }^{73}$ Pesquisa on-line anual realizada pela coordenação do programa Acessa SP com seus usuários.
} 
auto-estima, e de forma geral, todos concordam que a Internet amplia as opções de lazer e de cultura, "sobretudo na periferia, onde o lazer mais efetivo pra muitos adolescentes é engravidar...”, comenta Assumpção. Mas para ele isso não é o mais relevante, "tudo isso eu acho uma visão bastante pobre e minimalista do negócio. A questão é começar a ver que tem coisas a serem feitas, que você pode ingressar", sustenta.

Sérgio aponta uma falha grande de conteúdo: "Na maior parte das vezes, os programas da inclusão digital estão desprovidos de um conteúdo que permita um ganho, uma absorção tecnológica maior pelas comunidades". Beá, por outro lado, esclarece que após ensinar o usuário a "lidar com a máquina", a demanda pela divulgação de informação acaba aparecendo, e nesse momento é necessário orientar, abrir oficinas e disponibilizar meios para "o cara que quer construir o site da sua igreja, fazer o fanzine pro pessoal do seu bairro".

Carlos Afonso relata uma experiência concreta de impacto da Internet na educação realizada pela RITS em Brasília, quando se acompanhou, em uma escola, o desenvolvimento de um grupo de alunos com acesso e outro sem: "A diferença quantitativa e qualitativa da produção dessas pessoas, de desempenho na escola, foi gritante, então é claro que faz diferença, não há dúvida. Então contribui tanto para o desenvolvimento individual como para a sua percepção do seu papel nessa sociedade, porque eles estão interagindo”, conclui.

Quanto à conscientização social e a participação política, são valorizadas algumas possibilidades abertas com a Internet, como o acesso e a troca de informações, a elaboração e encaminhamento de petições, mas dentro de certos limites. Rogério comenta, por exemplo, a experiência positiva de Porto Alegre - comunidade historicamente bem organizada - onde a Internet contribuiu amplamente no processo do orçamento participativo, pois: "as comunidades conseguem acompanhar a demanda, $o$ andamento do orçamento, as futuras execuções, se as obras estão atrasados ou não estão, sugerir melhorias... Facilita a relação com a prefeitura", conta. "O programa sozinho não faz nada, mas a Internet permite que as comunidades com problemas similares troquem informações entre si”, complementa. 
Para Assumpção, é a chance do indivíduo conhecer os seus direitos, de exercer a sua cidadania, "senão ele está fora. Não dá para ser cidadão sem máquina hoje, principalmente nas classes excluídas", defende, ao lembrar ao mesmo tempo que a Internet e o computador sozinhos não são capazes de articular uma comunidade:

as lutas, os processos, o desenvolvimento, tudo isso já está naquela comunidade, já pertence àquela comunidade ou já pertence àqueles indivíduos. As máquinas não são capazes de mobilizar isso por si só. O que elas fazem é colocar esses processos comunitários, organização, educação popular, estruturação da democracia, de participação política, no ritmo da sociedade atual, sustenta (ver citação no quadro 22).

Carlos Afonso resume de forma simples: "o que eu sei é que mudanças sociais existem", e cita o exemplo de uma comunidade próxima de Quito onde um telecentro instalado pela Chasquinet ${ }^{74}$ alterou a relação entre homens e mulheres: "Era uma comunidade totalmente patriarcal e o telecentro passou a ser uma oportunidade para as mulheres de se reunir. Elas iam para lá para aprender a usar a Internet e, pela primeira vez, conversar entre si. E descobriram que tinham algumas coisas em comum, entre elas apanhar do marido. Aí começaram a se organizar e se articular".

\footnotetext{
${ }^{74}$ Ver nota de pé de página do quadro 21.
} 


\section{Quadro 22. Benefícios dos projetos de Inclusão Digital - Mentores}

\begin{tabular}{|c|c|}
\hline Nome & a você, qual o maior benefício que o projeto trouxe para o usuário? E para a comunidade? \\
\hline $\begin{array}{l}\text { Rogério } \\
\text { Santanna }\end{array}$ & $\begin{array}{l}\text { Eu acho que no caso das comunidades, uma grande preocupação é o combate à violência e, sobretudo, não ter uma atividade para um conjunto de jovens que não estão na escola, ficam soltos } \\
\text { pela vila e são mais facilmente cooptados pelo narcotráfico, pela criminalidade, que geralmente é alta nesses lugares. Então o fato de gerar para eles um sentido da atividade faz com que a gente } \\
\text { discuta esse jovem com o traficante. Porque o jovem não tem o sonho de ser um pintor de parede como o pai, ou um pedreiro, mas de ser um webdesigner, ser um músico, ser alguém } \\
\text { reconhecido. É uma possibilidade de progresso. E eles também sabem que as suas chances, seus melhores empregos estão com quem sabe usar a Internet, a informática... Mesmo as } \\
\text { profissões mais básicas, mais tradicionais, precisam de apoio, de suporte de informática. E se fez outras ações. No Telecentro Chico Mendes tinha um programa junto com uma ONG que fazia a } \\
\text { regularização de documentos. Tinha um menino de } 21 \text { anos que não tinha nenhum registro, não era um cidadão. Então conseguiu tirar certidão de nascimento, CPF, ajudar a regularizar socialmente } \\
\text { o indivíduo, que formalmente era um sujeito inexistente. }\end{array}$ \\
\hline $\begin{array}{l}\text { Rodrigo } \\
\text { Assumpção }\end{array}$ & $\begin{array}{l}\text { Quando eu estava montando o Sampa.org, em 2000, eu fui conversar com várias comunidades, e uma das coisas que elas estavam preocupadas era com a nossa intervenção, da ONG do centro indo } \\
\text { lá na Zona Sul. Eu falei: Eu não estou aqui pra ensinar vocês a ser a Associação Comunitária do Jardim Ângela, isso só vocês sabem. O que eu estou aqui é pra oferecer para vocês meios de vocês } \\
\text { fazerem melhor e mais rápido aquilo que vocês já fazem. Então é um pouco essa a história. As lutas, os processos, o desenvolvimento, tudo isso já está naquela comunidade, já pertence àquela } \\
\text { comunidade ou já pertence àqueles indivíduos. As máquinas não são capazes de mobilizar isso por si só. O que elas fazem é colocar esses processos comunitários, organização, educação } \\
\text { popular, estruturação da democracia, de participação política, no ritmo da sociedade atual. (...) As comunidades que vão se dar bem nesse processo não serão necessariamente aquelas que } \\
\text { terão maior domínio tecnológico, serão aquelas que entenderem como usar aquelas ferramentas para o seu processo. Quem se deu bem nas lutas pela moradia não se deu bem porque sabia rodar o } \\
\text { mimeógrafo, se deu bem porque conseguiu mobilizar lideranças. Agora, uma liderança talentosa com máquina é muito mais poderosa que uma liderança talentosa sem máquina. }\end{array}$ \\
\hline $\begin{array}{l}\text { Sérgio } \\
\text { Amadeu }\end{array}$ & $\begin{array}{l}\text { O maior benefício é o da cidadania, ele abre horizontes, ele é um pequeno espaço dentro de um grande muro onde ele pode tentar passar e adquirir contato com muitas formas de } \\
\text { conhecimento. Ele está bloqueado, ele tem um muro da desigualdade ali forte, então ele tem uma brecha. Agora, a segunda coisa é do ponto de vista, dele conseguir assimilar essas tecnologias da } \\
\text { informação para benefício dele e da sua comunidade. Aí é um outro passo, que ele pode não chegar. Mas o elemento cidadania pra mim é o derradeiro, base dos outros, inclusive da } \\
\text { profissionalização e tal. }\end{array}$ \\
\hline Carlos Afonso & $\begin{array}{l}\text { Inseri-los na chamada Sociedade da Informação. Potencialmente, a possibilidade de ter acesso a esse recurso para a sua vida profissional, pessoal, etc. Num país como o Brasil, que tem um } \\
\text { e-governo desenvolvido a nível federal, isso é muito importante. Um país como o Brasil tem muita informação fornecida por provedores de conteúdo em português, é muito importante também. }\end{array}$ \\
\hline $\begin{array}{l}\text { Fernando } \\
\text { Guarnieri }\end{array}$ & 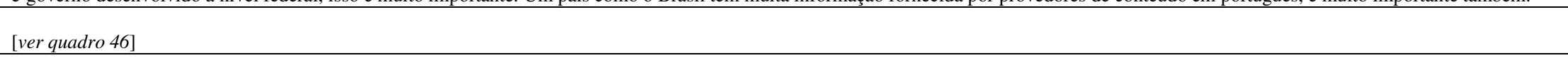 \\
\hline $\begin{array}{l}\text { Gilson } \\
\text { Schwartz } \\
\end{array}$ & t termos genéricos não se pode ainda falar de benefícios. Faltam dados e fiscalização. O próprio TCU indicou isso no programa GESAC, que atravessou os governos FHC e Lula. \\
\hline $\begin{array}{l}\text { Beatriz } \\
\text { Tibiriçá } \\
\text { (Beá) }\end{array}$ & $\begin{array}{l}\text { Eu acho que o maior benefício que traz é a relação com o mundo mesmo e a colocação de instrumentos na mão dessas comunidades, que diferenciam a forma como ela pode enfrentar as } \\
\text { exclusões que ela é submetida. (...) A tecnologia não é um meio, "não dá pra você tratar como cortador de grama". Essa tecnologia tem que ser apropriada pela comunidade e tem que ser usada no } \\
\text { sentido da participação e da democracia. (...) É um local onde as pessoas podem exercer cidadania, ter lazer e entretenimento, informação, formação, é uma cesta de produtos muito grande pra você } \\
\text { poder dar essa amplitude de inclusão social ao que é ID. }\end{array}$ \\
\hline $\begin{array}{l}\text { Rodrigo } \\
\text { Baggio }\end{array}$ & $\begin{array}{l}\text { No mínimo, o que a gente percebe é que o ensino básico da tecnologia através dessas reflexões sobre a realidade possibilitam a formação de um indivíduo que sabe utilizar a tecnologia de } \\
\text { uma forma crítica e empreendedora. (...) A partir daí, ele tem um objetivo muito claro e muito palpável para buscar um emprego, um trabaho... O benefício mais impactante está nessa } \\
\text { capacitação do uso da tecnologia, mesmo que básico, junto com uma reflexão sobre a vida, sobre o entorno, sobre a comunidade, os direitos e deveres deles. }\end{array}$ \\
\hline
\end{tabular}


De maneira geral, segundo os mentores, o maior benefício dos projetos de inclusão digital (quadro 22) para o indivíduo é a possibilidade de se relacionar com o mundo e enfrentar de forma mais preparada as exclusões a que está submetido. E para a comunidade é a possibilidade de usar esses instrumentos para fortalecer suas lutas e organizações. Há também um consenso de que a tecnologia por si só nada resolve, mas a abertura de horizontes promovida por ela, potencializa as ações e reflexões já presentes em grupos articulados, como explica Beá:

\begin{abstract}
A tecnologia não é um meio, 'não dá pra você tratar como cortador de grama'. Essa tecnologia tem que ser apropriada pela comunidade e tem que ser usada no sentido da participação e da democracia. (...) É um local onde as pessoas podem exercer cidadania, ter lazer e entretenimento, informação, formação, é uma cesta de produtos muito grande pra você poder dar essa amplitude de inclusão social ao que é inclusão digital.
\end{abstract}

Rogério lembra ainda que as tecnologias da informação permitem que o poder público estabeleça um novo diálogo com o jovem que está fora da escola e vive muito próximo da criminalidade, oferecendo a ele uma nova perspectiva de vida. "Porque o jovem não tem o sonho de ser um pintor de parede como o pai, mas de ser um webdesigner, um músico, ser alguém reconhecido. É uma possibilidade de progresso. E eles também sabem que as suas chances, seus melhores empregos estão com quem sabe usar a Internet, a informática...”, argumenta.

Quanto à avaliação dos programas de Inclusão Digital (quadro 23), na opinião dos mentores as iniciativas existentes aumentam o acesso, mas existe uma grande variação de qualidade entre elas. São apontadas experiências exitosas, mas em geral é consenso o argumento de que os programas públicos deixam muito a desejar porque "o governo ainda não entendeu que os infocentros são uma necessidade tão grande quanto bibliotecas públicas ou escolas", como explica Assunção. Os programas com mais sucesso parecem ser aqueles em que o "envolvimento da comunidade é maior", ou que a "administração pública mostrou maior comprometimento" com a sua sustentabilidade e manutenção, como aponta Rogério: "em muitos dos casos há uma visão política pequena de que a obra foi feita pelo governo anterior, e que é um aparelho político do A ou do B. Então são descontinuados esses telecentros, eles começam a receber menos recursos por parte da prefeitura...”. Para Guarnieri, o problema está no modelo dos programas atuais, que custam uma fortuna para o governo e ainda não atendem nem $3 \%$ do seu público-alvo: "os telecentros se tornaram um modelo inviável. Para atender toda as classes $D$ e E seriam necessários investimentos da ordem de 1 bilhão, no modelo dos 
telecentros da PMSP e dos Infocentros do Estado. Além disso, no ritmo atual, demoraríamos mais de uma década para construir todas as salas necessárias".

A solução apontada é a mesma: é necessário um programa nacional de inclusão digital que articule os diferentes níveis de governo - municipal, estadual e federal -, a sociedade civil organizada e as empresas, garantindo que interesses públicos ou econômicos não dominem o processo. Guarnieri vai além, sugere que as parcerias atuais sejam ampliadas, "com o Estado dando incentivos para cyber-cafés privados, que têm sido muito eficazes no provimento de acesso na periferia". Gilson, sempre crítico, acha que o modelo atual é uma tragédia, e sustenta que os "programas governamentais têm sido usados como cabide de emprego para cabos eleitorais e redutos de grupos partidários".

É consenso a visão de que inclusão Digital deva ser vista como uma política pública (quadro 24), e também de que toda a sociedade precisa se envolver, numa ampla parceria entre o Estado, a iniciativa privada, o terceiro setor e o governo. "A inclusão digital deve ser entendida como direito do cidadão", sustenta Beá, "porque as TICs para o desenvolvimento humano já são um bem essencial, um serviço essencial, tal como saúde pública, educação, etc...", completa Carlos Afonso. A grande questão é como deve ser elaborada esta política pública, para que ela não "amarre" as iniciativas e propicie essa ampla participação de todos os setores.

De forma geral, o Estado é visto como o "indutor da cultura digital" e o financiador dos programas, mas não necessariamente como o gestor, devido à sua ineficiência orgânica, ou simplesmente porque alguns níveis de governo estão muito longe da realidade da população. O financiamento também pode ser realizado pela empresas, que têm como investir e trabalhar em parceria com o Poder Público para aumentar a capacidade de atendimento. Assumpção lembra, entretanto, que muitas empresas ainda confundem responsabilidade social com marketing social, e gastam mais na divulgação da iniciativa do que na execução da mesma. O terceiro setor é visto como um bom gestor das iniciativas comunitárias, justamente por atuar ao lado da população. E as Universidades poderiam se envolver tanto na pesquisa como na produção de conhecimento. Educação é justamente uma grande preocupação dos mentores: "é o grande buraco negro da inclusão digital nesse país. Porque todo mundo que mexe com inclusão digital tenta ignorar, porque dá trabalho, e ninguém quer se meter no lamaçal que é a educação. Agora, sem resolver a educação, não sai de dentro do buraco nunca", sustenta Assumpção. 


\section{Quadro 23. Avaliação dos programas de Inclusão Digital - Mentores}

\begin{tabular}{|c|c|}
\hline Nome & $\begin{array}{l}\text { Na sua opinião, as experiências de inclusão digital em desenvolvimento no país, mantidas pelo governo, são eficientes para aumentar o acesso das comunidades de baixa } \\
\text { renda à informação? }\end{array}$ \\
\hline $\begin{array}{l}\text { Rogério } \\
\text { Santanna }\end{array}$ & $\begin{array}{l}\text { Olha, há muitas iniciativas e elas são muito variadas. Há casos muito bem sucedidos e há casos em que, numa determinada administração que aposta nisso, o projeto começa e vai bem. } \\
\text { Naqueles casos em que o envolvimento da comunidade não atinge um grau de adesão ao projeto, em que ela não se sinta dona do telecentro, há possibilidade dele sofrer um revés quando trocar de } \\
\text { administração. Porque em muitos dos casos há uma visão política pequena de que a obra foi feita pelo governo anterior, e que é um aparelho político do A ou do B. Então são } \\
\text { descontinuados esses telecentros, eles começam a receber menos recursos por parte da prefeitura, são criadas dificuldades burocráticas e administrativas que acabam desestimulando } \\
\text { essas comunidades que muito sofridamente chegaram até ali. }\end{array}$ \\
\hline $\begin{array}{l}\text { Rodrigo } \\
\text { Assumpção }\end{array}$ & 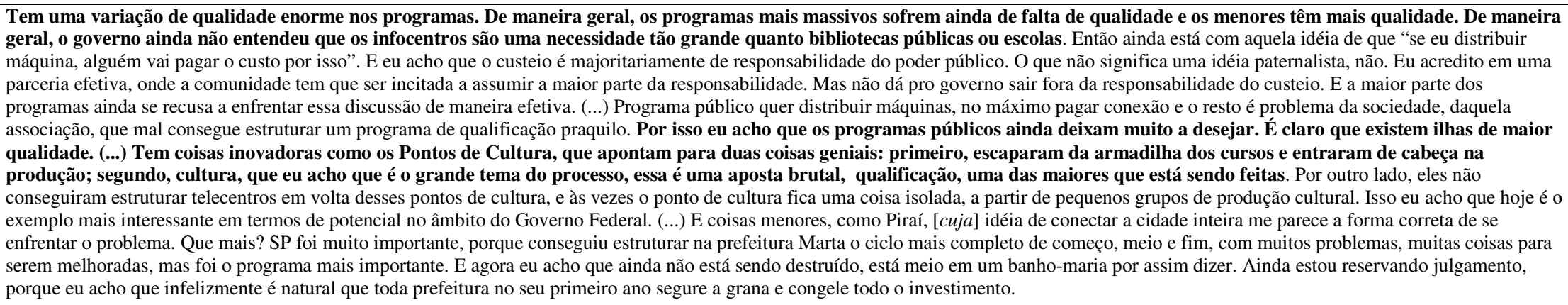 \\
\hline $\begin{array}{l}\text { Sérgio } \\
\text { Amadeu }\end{array}$ & $\begin{array}{l}\text { Depende de que governo. Eu acho que a organização de uma prefeitura como a de SP, de um programa de inclusão digital nas áreas de menor IDH, que tenham o objetivo de assegurar o } \\
\text { acesso em escala é fundamental e deveria ser feito por todas as prefeituras com recursos próprios. Agora como isso não é feito, e como nem toda prefeitura tem recurso para isso, entra o papel } \\
\text { do Estado e do Governo Federal. Acho que o que falta é um programa articulado de inclusão digital que seja nacional, que envolva União, Estados e municípios, assim como a gente tem } \\
\text { uma integração clara das escolas. Tem que ter um plano que envolva também a sociedade civil organizada. Não adianta montar com dinheiro público totens em cidades que não têm telecentro, } \\
\text { porque você não vai permitir que o estudante faça trabalho de escola, que as pessoas acessem. Agora, como fazer isso? Eu acho muito difícil ser um plano nacional que tenha valor vinculante, sabe } \\
\text { por quê? Porque vai virar um embate, vai ter a briga das empresas que têm... porque esse setor tem todos os interesses econômicos poderosos e tem o interesse público. Então pra que você } \\
\text { não fique refém de interesses poderosos econômicos privados, eu acho que precisa ter um grande encontro mesmo nacional, que envolva prefeituras, governos dos Estados, e que tire uma } \\
\text { diretriz. }\end{array}$ \\
\hline Carlos Afonso & $\begin{array}{l}\text { Aí varia muito, são abordagens diferentes. Tem uma abordagem que é burocrática, de cima para baixo: ele monta o telecentro, e é para isso, só pode usar para isso e acabou. E outras que são feitas } \\
\text { em conjunto com a comunidade. }\end{array}$ \\
\hline $\begin{array}{l}\text { Fernando } \\
\text { Guarnieri }\end{array}$ & $\begin{array}{l}\text { Eu acho que os telecentros se tornaram um modelo inviável, já que não atendem nem 3\% de seu público alvo. Para atender toda as classes D e E seriam necessários investimentos da } \\
\text { ordem de } 1 \text { bilhão, no modelo dos telecentros da PMSP e dos Infocentros do Estado. Além disso no atual ritmo que as coisas estão indo, demoraríamos mais de uma década para construir todas } \\
\text { as salas necessárias. Portanto, para conseguir atingir todo esse público devem ser feitas parcerias. Por um lado devem ser expandidas as experiências do Infocentros Municipais e dos chamados } \\
\text { "postos públicos" que são parcerias entre Estado, prefeitura e empresas públicas. Essas parcerias deveriam ser estendidas para a iniciativa privada, inclusive com o Estado dando incentivos para } \\
\text { cyber-cafés privados, que têm sido muito eficazes no provimento de acesso na periferia. (...) O telecentro em si não assume o caráter dele. Na biblioteca, você entra, você sente essa coisa } \\
\text { comunitária na biblioteca. O pessoal ainda sente aquela coisa coletiva. Num telecentro ou infocentro que você entra, você sente a coisa individual, você sente que cada um está lá consultando o seu. } \\
\text { A não ser que tenha uma atividade, uma oficina ou uma atividade específica para otimizar o uso. (...) Sabe quem achou uma forma de uso coletivo de mídias digitais em um espaço muito parecido? } \\
\text { A LAN house. Porque na LAN house você vai sentir o uso coletivo. Quando acaba o Counter Strike lá, que o seu time perdeu, você vai ver o último gritando, xingando. Porque está um jogando com } \\
\text { o outro. Dez, vinte caras jogando, dez contra dez lá dentro. Tá todo mundo envolvido um com o outro através do micro. Isso não rola num infocentro. }\end{array}$ \\
\hline
\end{tabular}




\begin{tabular}{|c|c|}
\hline Nome & $\begin{array}{l}\text { Na sua opinião, as experiências de inclusão digital em desenvolvimento no país, mantidas pelo governo, são eficientes para aumentar o acesso das comunidades de baixa } \\
\text { renda à informação? }\end{array}$ \\
\hline $\begin{array}{l}\text { Gilson } \\
\text { Schwartz }\end{array}$ & $\begin{array}{l}\text { São uma tragédia. Os programas governamentais têm sido usados, isso sim, como cabide de emprego para cabos eleitorais e redutos de grupos partidários. Ainda não foi contada a história } \\
\text { da saída do PT da PMSP, seguida por um "enxugamento" de telecentros, em tese porque havia muitos casos de sobreposição, às vezes na mesma rua, de telecentros e infocentros (gerenciados ou } \\
\text { patrocinados pelo governo estadual). Mais recentemente, a "máfia dos sanguessugas" foi flagrada em pleno Ministério da Ciência e Tecnologia desviando recursos de "inclusão digital". }\end{array}$ \\
\hline $\begin{array}{l}\text { Beatriz } \\
\text { Tibiriçá } \\
\text { (Beá) }\end{array}$ & $\begin{array}{l}\text { Eu acho que ainda não, eu acho que você teve um aumento da adesão ao combate da exclusão digital. Mas isso não repercutiu ainda em amplitude e universalização desses projetos. Então } \\
\text { você tem iniciativas em vários municípios, nos Governos dos Estados, também tem iniciativas do Governo Federal, mas que não conseguiram ainda atingir a população como um todo porque } \\
\text { não tiveram investimento suficiente em dinheiro, informação, mão-de-obra qualificada. Então você tem, na verdade, muitas iniciativas que não atendem a demanda que você tem hoje de ID. } \\
\text { (...) Você ainda tem uma visão que pára no colocar a máquina e não pensa no que, em torno da máquina, pode acontecer. Em torno da máquina há uma série de possibilidades que não são } \\
\text { exploradas porque não se pensa em informação, em capacitação. }\end{array}$ \\
\hline $\begin{array}{l}\text { Rodrigo } \\
\text { Baggio }\end{array}$ & $\begin{array}{l}\text { Essas iniciativas de políticas públicas de ID são muito importantes para dar escala aos trabalhos de ID. (...) mas os governantes sejam eles municipais, estaduais ou federais, têm uma } \\
\text { visão muito assistencialista da política pública, voltada para o curto prazo (...), que está nas próximas eleições. É feito um investimento grande de recursos financeiros numa área, cria-se um } \\
\text { projeto, na maioria das vezes de forma assistencialista, e quando muda o governo, ou você não tem a continuidade ou você tem uma mudança da marca em função da apropriação para a nova } \\
\text { campanha ou para o novo governante. Esse é um desafio muito grande das políticas públicas na área social como um todo. (...) Outro desafio está na co-gestão, quer dizer, uma forma de } \\
\text { controle muito importante dessas políticas públicas poderia ser feita a partir da co-gestão, através de alianças intersetoriais, através da sinergia entre os três setores da nossa sociedade. É } \\
\text { muito importante que na condução, planejamento e implementação de políticas públicas na área de ID, ONGs e empresas fossem convidadas, criando um fórum maior de criação, } \\
\text { planejamento e implementação dessas políticas. A participação mais eficiente do Poder Público poderia se dar através da parceria com uma iniciativa social que já está dando certo. Esse é um } \\
\text { grande desafio das nossas iniciativas de políticas públicas da área social, em especial, de ID. Nós vemos sempre projetos que são muito caros, acontecendo de forma "de cima para baixo", com } \\
\text { desafios muito fortes de continuidade e sustentabilidade. }\end{array}$ \\
\hline
\end{tabular}




\section{Quadro 24. Inclusão Digital como política pública - Mentores}

\begin{tabular}{|c|c|}
\hline Nome & 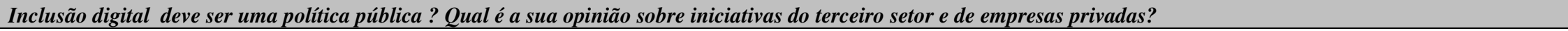 \\
\hline $\begin{array}{l}\text { Rogério } \\
\text { Santanna }\end{array}$ & $\begin{array}{l}\text { Acho que esse é um caso em que todos precisam se envolver. O Estado não é muito eficiente administrando isso diretamente, então é preciso um acordo que envolva a iniciativa privada, o } \\
\text { terceiro setor e o governo no sentido de criar as condições para que funcione. }\end{array}$ \\
\hline $\begin{array}{l}\text { Rodrigo } \\
\text { Assumpção }\end{array}$ & $\begin{array}{l}\text { De preferência deve ser uma política pública, mas pode não ser. O processo pode ser tocado por indivíduos, por empresas, por governos, por ONGs. Empresas privadas? Algumas coisas são } \\
\text { muito legais, muito interessantes, mas empresa privada ainda tem um discurso dúbio no que concerne à responsabilidade social, ainda não decidiu o quanto quer responsabilidade social e o } \\
\text { quanto quer marketing social. Então eu ainda vejo muita empresa gastando cinco vezes mais para fazer um livrinho que retrata a experiência porque é a experiência que está financiando. } \\
\text { Ele quer o lucro. É um crime, é um absurdo, então temos aí um problema sério. (...) As ONGs tiveram um papel fundamental na formulação, no desenho, do que era a política de inclusão digital no } \\
\text { país, desde de os tempos históricos do CDI, passando pelo Sampa.org, pela RITS. E eu acho que agora o papel delas não é tanto o de criar a inovação, mas de ajudar a consolidar, a massificar. O } \\
\text { terceiro setor mais da base, são os o parceiros preferenciais para os telecentros, e o terceiro setor mais "topo da pirâmide" tem o papel de assessoria, de estruturação, de qualificação de quadros. (...) E } \\
\text { um grande ausente, continua sendo toda a área de educação. As Universidades, que poderiam aprofundar brutalmente seu envolvimento com isso, tanto na parte da pesquisa, produção de } \\
\text { conhecimento, quanto na execução efetivamente, e as próprias escolas, que é o grande buraco negro da inclusão digital nesse país. Porque todo mundo que mexe com inclusão digital tenta } \\
\text { ignorar, porque dá trabalho, e ninguém quer se meter no lamaçal que é a educação. Agora, sem resolver a educação, não sai de dentro do buraco nunca. }\end{array}$ \\
\hline $\begin{array}{l}\text { Sérgio } \\
\text { Amadeu }\end{array}$ & $\begin{array}{l}\text { Sim. Tem que ter uma política pública nacional como a Educação e a Saúde. Mas o centro dessa política pública é capacitação. (...) E se não virar uma política pública, nós vamos caminhar } \\
\text { muito devagar. (...) Tem que fazer uma política de uso coletivo (...) Isso não quer dizer que seja o Estado que vai executar, pode ser as entidades, mas tem lugar que não tem entidade. Tem pequenos } \\
\text { municípios que você vai ter que envolver o poder local. Mas mesmo onde tenha entidades fortes, você tem que envolver o poder local, pois [o programa de ID] não é sustentável, o Estado tem } \\
\text { que pagar, tem que pagar porque a ONG tem duas formas de renda: ou é o Estado ou são empresas. E a terceira é cobrar. Se ela vai cobrar do cidadão, então uma empresa poderia montar um } \\
\text { cybercafé, não precisava ser uma ONG. (...) Acho fundamental [a participação das ONGs e das empresas], mas elas gerariam muito mais impacto se elas tivessem dentro de uma política pública, } \\
\text { que hoje está começando a surgir, mas numa fase muito inicial, que é desorganizada. }\end{array}$ \\
\hline $\begin{array}{l}\text { Carlos } \\
\text { Afonso }\end{array}$ & $\begin{array}{l}\text { Definitivamente, sim, porque as TICs para o desenvolvimento humano já são um bem essencial, um serviço essencial, tal como saúde pública, educação, etc. Então não tem como dissociar } \\
\text { isso do desenvolvimento humano. Agora qual política pública, qual o nível de envolvimento, deve ser definido em uma estratégia nacional de ID, na qual todos têm que participar, cada um no seu } \\
\text { papel. Por exemplo, os empresários têm muito a ensinar, não é um sociólogo que vai lá ensinar empreendedorismo para a comunidade. }\end{array}$ \\
\hline $\begin{array}{l}\text { Fernando } \\
\text { Guarnieri }\end{array}$ & $\begin{array}{l}\text { O Estado pode gerar incentivos para isso crescer, mas não faz sentido a questão do acesso ficar só por conta do Estado. A sociedade vai ter que assumir isso. Como eu disse antes, políticas de } \\
\text { inclusão digital têm que ser pensadas de uma maneira muito mais ampla do que essa. O Estado deve ser o indutor dessa cultura digital, utilizando a tecnologia para se aproximar mais do cidadão. } \\
\text { Disseminando informações, realizando consultas públicas, enquetes por meio eletrônico, dando força para o software livre, digitalizando e dispondo de seu conteúdo. Isso deve permear todas as } \\
\text { políticas públicas desde seu processo de formulação (utilizando a TI para criar um diálogo entre todas as partes interessadas) até sua implementação (utilizando a TI para que o cidadão possa fiscalizar } \\
\text { e avaliar). Se o Estado fizer isso ele estará dando mais um motivo para que o cidadão utilize a tecnologia quer seja em um telecentro público ou em um privado. (...) No interior, o Acessa SP está } \\
\text { certo, ele coloca o micro, treina o monitor para que ele faça o atendimento e oriente o usuário. A prefeitura dá a sala, os monitores e o custeio. Isso deveria ser feito por vários outros } \\
\text { parceiros. Não tem sentido mais a gente caminhar sozinho, muito menos no ritmo que está. }\end{array}$ \\
\hline $\begin{array}{lll}\text { Gilson } \\
\text { Schwartz }\end{array}$ & $\begin{array}{l}\text { Sem dúvida a promoção de acesso à informação é uma política pública e o uso de meios digitais para isso tem sido crescente. Mas há também iniciativas no setor privado e no chamado } \\
\text { terceiro setor. Não sabe, no entanto, qual a eficácia dessas ações, menos ainda se o resultado é melhor ou pior comparativamente. }\end{array}$ \\
\hline $\begin{array}{l}\text { Beatriz } \\
\text { Tibiriçá } \\
\text { (Beá) }\end{array}$ & $\begin{array}{l}\text { Sim, se não for uma política pública você não vai ter o acesso democratizado em um país como o nosso. [A ID] deve ser entendida como direito do cidadão. As famílias de baixa renda não } \\
\text { têm capacidade de financiar o uso de máquina com Internet, provedor, luz, o custo é muito alto. Então, se o Poder Público não tomar as iniciativas de alavancar os pontos de acesso para essa } \\
\text { população, ela nunca vai ser integrada à sociedade da informação e vai ter a pior exclusão, que é a exclusão do conhecimento e da informação. Vai agregar essa exclusão a outras que ela já tem que } \\
\text { enfrentar e lutar contra. (...) Eu acho que telecentro deve ser tratado como foi a escola. Pensando num público que não é mais o aluno, mas é toda a comunidade. Então, eu acho que tanto o terceiro } \\
\text { setor quanto a iniciativa privada têm um papel e uma participação na construção dessa política pública. A iniciativa privada tem como investir e pode trabalhar em parceria com o Poder } \\
\text { Público para aumentar a capacidade de atendimento. O terceiro setor trabalha tanto nos telecentros comunitários, que buscam projetos de auto-sustentabilidade, como provocando o Poder Público, } \\
\text { para que os programas tenham perenidade e continuidade. Na Prefeitura [de SP] o modelo era esse. Nós tínhamos uma parceria com o terceiro setor que ajudava na implementação do projeto e } \\
\text { tínhamos várias parcerias com a iniciativa privada que traziam novos investimentos para o projeto. }\end{array}$ \\
\hline $\begin{array}{l}\text { Rodrigo } \\
\text { Baggio }\end{array}$ & $\begin{array}{l}\text { Sim, uma política pública co-gerida através de uma agenda inter-setorial. E [as iniciativas de terceiro setor e as empresas privadas] seriam parceiros executores. (...) A articulação das } \\
\text { ONGs e das empresas é fundamental para alavancar, para inspirar ações que devem ser feitas pelo governo ou sem governo. (...) A visão que a gente tem para a nossa sociedade é uma visão de } \\
\text { empoderamento mesmo, uma visão de envolvimento da sociedade civil organizada, de criação e ampliação dos trabalhos sociais através das ONGs e, ao mesmo tempo, no setor privado, é uma visão } \\
\text { cada vez maior de responsabilidade social, de mudança do comportamento e da atitude dessas empresas. (...) }\end{array}$ \\
\hline
\end{tabular}




\section{Quadro 25. Desafios da Inclusão Digital - Mentores}

\begin{tabular}{|c|c|}
\hline Nome & uís hoje (questões políticas, econômicas, alfabetização)? \\
\hline $\begin{array}{l}\text { Rogério } \\
\text { Santanna }\end{array}$ & $\begin{array}{l}\text { O grande desafio da exclusão digital é conseguir aplicar esse dinheiro do FUST de forma eficiente. Ele já é conhecido como "frust", porque já fazem dois governos... tem uma legislação muito } \\
\text { restrita, se ele pudesse ser mais amplo, cada vez mais a gente poderia financiar projetos, não só hardware. Na minha avaliaçãa, o maior problema para a instalação de um telecentro, não são as } \\
\text { máquinas nem a conexão. Todo mundo acha que terminou quando comprou os computadores, ligou e inaugurou, mas o problema vem depois: como sustentá-lo, como financiá-lo, como } \\
\text { envolver as pessoas, como fazer com que eles se sintam donos, como não roubarem os computadores (...) A presença da Universidade também é muito importante, para criar uma } \\
\text { abordagem pedagógica. Porque não se pode chegar num telecentro desses e começar a ensinar sistema operacional e planilhas eletrônicas. Isso é uma atividade para quem está num escritório, mas } \\
\text { não é uma abordagem adequada para quem não sabe ler ou escrever. Tem que começar com atividades mais simples, lúdicas. E pensar em questões mais ligadas à realidade daquelas comunidades, a } \\
\text { lá Paulo Freire. }\end{array}$ \\
\hline $\begin{array}{l}\text { Rodrigo } \\
\text { Assumpção }\end{array}$ & $\begin{array}{l}\text { Eu acho que nós temos que aprender a descentralizar recursos, nós temos que aprender a contratar de forma descentralizada. Os governos têm que aprender a utilizar o potencial do } \\
\text { terceiro setor, da sociedade civil, como repassar e fiscalizar recursos pra isso. É isso que de fato vai permitir que a gente escape dessa idéia de que ficar inaugurando qualquer merda em vez de } \\
\text { efetivamente estimular processos importantes e transformadores. }\end{array}$ \\
\hline $\begin{array}{l}\text { Sérgio } \\
\text { Amadeu }\end{array}$ & $\begin{array}{l}\text { Eu acho que primeiro é mudar a política pública. É o problema da conscientização do poder público e dos agentes políticos de que inclusão digital requer uma política pública tanto } \\
\text { quanto a Saúde e a Educaçãa. E o centro dessa política pública é capacitação. Então eu acho que esse é o maior problema. O segundo é o problema de conexão. É preciso que você monte uma } \\
\text { rede de backbones que chegue e que cubra todo o território nacional. E o terceiro é usar as tecnologias avançadas e os modelos avançados de tecnologia, como o software livre e as redes virais. (...) } \\
\text { Agora, eu estou separando de escola, escola é outra página. Não tem nem sentido não liberar o dinheiro do FUST pra conectar todas as escolas do Brasil, não tenho nem dúvida disso. }\end{array}$ \\
\hline $\begin{array}{l}\text { Carlos } \\
\text { Afonso }\end{array}$ & $\begin{array}{l}\text { Questões políticas. Econômicas seria uma vergonha falar. Nós temos } R \$ 4 \text { bilhões parados por uma estratégia de superávit primário. Seria vergonhoso falar que a questão é econômica. Aliás, eu te } \\
\text { digo aqui: eu acho incrível que a gente tenha que buscar fundos no exterior, para poder alavancar um projeto de inclusão no Rio Tapajós, tendo todos esses recursos. Mas é essa a situação. } \\
\text { É uma decisão política não usar os recursos, a prioridade era outra. (...) A gente reconhece que }[o \text { FUST] tem dificuldades na estrutura da lei, na lógica daquilo, mas não houve nenhum esforço } \\
\text { também para que mudasse isso. A idéia de criar um fundo dessa importância, que não tem representação efetiva dos vários setores..., o fundo tem que ter uma representação pluralista, e ele não tem! } \\
\text { (...) E falta também um plano nacional de ID, esse é um grande desafio. O governo tem que trabalhar uma estratégia nacional de inclusão digital em parceria com os governos locais, que têm que } \\
\text { estar entendendo que isso vai alavancar a economia, o empreendedorismo na sua cidade, vai contribuir para a diminuição da exclusão social. Criamos o Comitê Nacional de Inclusão Digital, e não } \\
\text { adiantou nada. Fizemos as oficinas de inclusão digital e nada se consolidou. Por causa dos diferentes interesses e das prioridades também. Mas eu acho que ainda há espaço para se tentar } \\
\text { conseguir essa estratégia. }\end{array}$ \\
\hline $\begin{array}{l}\text { Fernando } \\
\text { Guarnieri }\end{array}$ & $\begin{array}{l}\text { Primeiro viria a ampliação do acesso das classes C, D e E. Esse acesso praticamente não mudou, não houve impacto nenhum quantitativo com as experiências feitas. É claro que isso não } \\
\text { passa só pelo Estado, cujo modelo de inclusão digital precisa ser revisto. Acho que o segundo desafio é essa coisa da produção, é você criar conteúdo que atraia um público mais diversificado, } \\
\text { desde o garoto que já acessa até o pessoal da terceira idade, mulheres, etc. É você pegar o molequinho lá da escola da periferia e ensinar programação, robótica, criação multimídia. Todo mundo, em } \\
\text { todas as aulas, deveria se utilizar das ferramentas de TI. Todos os professores deveriam estar preparados para utilizar a Internet como material didático. Então esse negócio tem que se disseminar, } \\
\text { essa coisa da cultura digital, mais colaborativa, mais descentralizada, mais democrática. }\end{array}$ \\
\hline $\begin{array}{l}\text { Gilson } \\
\text { Schwartz }\end{array}$ & $\begin{array}{l}\text { O desafio foi proposto no final do governo FHC e nunca mais foi retomado: formular uma política de longo prazo para promover o desenvolvimento da sociedade da informação no Brasil. Os } \\
\text { instrumentos foram criados naquela época também, sobretudo o FUST, até hoje congelado. Nosso desafio é encontrar gente responsável para governar o país. A questão é política. }\end{array}$ \\
\hline $\begin{array}{l}\text { Beatriz } \\
\text { Tibiriçá } \\
\text { (Beá) }\end{array}$ & $\begin{array}{l}\text { Eu acho que é ser tratado como política pública e plano de governo, e atingir a amplitude que a exclusão do nosso país exige. [O Governo Lula] não conseguiu ter uma política pública de ID, } \\
\text { isso é um fato. Você tem muitas iniciativas de ID, mas elas não existem enquanto um programa de governo voltado para a ID. O que está acontecendo no Governo Federal é isso, você tem o } \\
\text { PC Conectado, Casa Brasil, os telecentros de negócios do Furlan, os pontos de cultura que estão sendo implantados.. mas por que não são um projeto só? Aqui em SP, o programa de ID só teve } \\
\text { impacto porque chegou na rede que chegou, senão não teria impacto. Vira uma disputa entre ministérios. }\end{array}$ \\
\hline $\begin{array}{l}\text { Rodrigo } \\
\text { Baggio }\end{array}$ & $\begin{array}{l}\text { Hoje temos quatro desafios para a ID no Brasil. Primeiro é a capacitação massiva e qualitativa da população de baixa renda em tecnologia e cidadania. Segundo, não adianta ter pessoas } \\
\text { capacitadas se a gente não tem pontos de acesso público à tecnologia. Então a criação e disseminação de pontos de acesso público às novas TIC. Terceiro, criar infra-estrutura de acesso à } \\
\text { Internet no Brasil: dos cerca de } 5500 \text { municípios brasileiros, pouco mais de mil têm infra-estrutura local de acesso à Internet. Então nesses municípios que não têm essa infra-estrutura, a alternativa } \\
\text { é a conexão via satélite ou pagar interurbano, duas soluções que criam uma legião de excluídos tecnológicos. Quarto, a co-gestão de políticas públicas de inclusão digital através de alianças inter- } \\
\text { setoriais - Poder Público, empresas e o setor da cidadaia. Eu crio aí um imenso destaque para o FUST, que deveria ser o maior exemplo latino-americano de inclusão digital e hoje é um engodo. } \\
\text { Hoje no Brasil temos várias experiências excelentes de ID que, com recursos do FUST, poderiam ter escala e ampliar sua qualidade. }\end{array}$ \\
\hline
\end{tabular}


De forma geral, é consenso que os desafios da Inclusão Digital (quadro 25), para a ampliação do acesso às comunidades de baixa renda, passam pela revisão do modelo atual de parcerias e gestão dos programas em desenvolvimento, e pela adoção de uma estratégia nacional de inclusão digital, uma política pública financiada provavelmente com os recursos do FUST, que é a grande frustração do setor e que foi citado por quase todos os mentores, com exceção de Assumpção, Guarnieri e Beá. "É uma decisão política não usar os recursos [do FUST], a prioridade era outra. (...) A gente reconhece que tem dificuldades na estrutura da lei, na lógica daquilo, mas não houve nenhum esforço também para que mudasse isso", denuncia Carlos Afonso. "Criamos o Comitê Nacional de Inclusão Digital, e não adiantou nada. Fizemos as Oficinas de Inclusão Digital e nada se consolidou. Por causa dos diferentes interesses e das prioridades também. Mas eu acho que ainda há espaço para se tentar conseguir essa estratégia”, completa.

Já Assumpção argumenta que o grande problema é "aprender a descentralizar recursos, nós temos que aprender a contratar de forma descentralizada. Os governos têm que aprender a utilizar o potencial do terceiro setor, da sociedade civil, como repassar e fiscalizar recursos pra isso". Sérgio ordena os desafios na seguinte escala: "primeiro é mudar a política pública, e o centro dessa política pública é capacitação. O segundo é o problema de conexão, é preciso que você monte uma rede de backbones que chegue e que cubra todo o território nacional. E o terceiro é usar as tecnologias avançadas, como o software livre e as redes virais (...)". Gilson resume o cenário da seguinte forma:

O desafio foi proposto no final do governo FHC e nunca mais foi retomado: formular uma política de longo prazo para promover o desenvolvimento da sociedade da informação no Brasil. Os instrumentos foram criados naquela época também, sobretudo o FUST, até hoje congelado. Nosso desafio é encontrar gente responsável para governar o país. A questão é política. 


\section{Quadro 26. Telefone celular como vetor para a Inclusão Digital - Mentores}

\begin{tabular}{|c|c|}
\hline Nome & $\begin{array}{l}\text { Em março de } 2005 \text { um editorial da revista 'The Economist'afirmou que o grande vetor para a inclusão digital no mundo não é o computador nem a Internet, mas o telefone } \\
\text { celular. Qual é a sua opinião? }\end{array}$ \\
\hline $\begin{array}{l}\text { Rogério } \\
\text { Santanna }\end{array}$ & $\begin{array}{l}\text { Eu acho que o telefone celular é bastante importante no Brasil. (...) Em torno do telefone celular se criou um ecossistema, então existe produto para pobre, embora ele seja muito caro. Na } \\
\text { verdade, o telefone celular resolveu um problema. Mesmo aquele sujeito que fazia frete com a carrocinha, ele também tem um telefone celular, ele pode ser achado, seus potenciais clientes podem ser } \\
\text { achados. E pode controlar a conta, o quanto é que ele vai gastar com comunicação. Se ele não tem nada fica lá só recebendo, telefona de um telefone público, mas ele é localizado por alguém. }\end{array}$ \\
\hline $\begin{array}{l}\text { Rodrigo } \\
\text { Assumpção }\end{array}$ & $\begin{array}{l}\text { Eu não concordo muito com isso. Se você quiser dizer que a inclusão digital efetiva, no futuro, passará por um instrumento mais móvel e mais pessoal, eu estou de acordo. Mas daí a achar que isso é } \\
\text { necessariamente um celular, eu acho que essa distinção está perdendo o significado. Quando o celular cumprir as tarefas que um computador cumpre, ele deixará de ser celular e a questão é } \\
\text { irrelevante. Que os computadores vão ser capazes de telefonar e vão ser mais próximos do tamanho de um celular, eu to de acordo, agora eu não acho que é o celular que vai aprender a computar, } \\
\text { eu acho é que o computador que vai diminuir. }\end{array}$ \\
\hline $\begin{array}{l}\text { Sérgio } \\
\text { Amadeu }\end{array}$ & $\begin{array}{l}\text { Eu acho que é uma visão completamente diferenciada do que eu tenho dito do que é inclusão digital. Das duas, uma: ou ele está dizendo que basta a pessoa usar um microondas digital para ser } \\
\text { uma incluída digital... Isso é um equívoco enorme, porque a inclusão digital é a capacidade das pessoas utilizarem, armazenarem e transmitirem informações, então usar celular digital não } \\
\text { quer dizer que as pessoas estão incluídas digitalmente. Essa é a linha da indústria, que acha que vai transformar todos em meros consumidores dos seus produtos. Isso denuncia efetivamente } \\
\text { qual é o interesse do primeiro mundo quando faz programas de inclusão digital, que nada mais é do que tornar esse terceiro mundo consumidor de produtos. A segunda hipótese é: ou então, } \\
\text { o celular, como está acontecendo, está cada vez mais virando uma máquina de processamento como o computador, e aí nós estamos falando de um computador, de um similar que processa } \\
\text { informação, que permite o armazenamento, que permite o acesso à Internet, então nós estamos falando de outra coisa, estamos falando de máquinas de processar. Agora, as máquinas de processar } \\
\text { são caras, mais caras do que um computador. (...) eu não concordo mesmo na segunda hipótese, [porque] estamos falando de uma topologia centralizada, num desenho onde eu dependo de uma } \\
\text { infra-estrutura de telecomunicações. Eu estou dizendo que a tendência é a comunicação cada vez mais prescindir de uma infra-estrutura de telecomunicações. Então eu estou falando que, se o celular } \\
\text { for uma máquina de processar, nessa rede, ele vai rotear informações, servindo de ponte, de escala pra outros fluxos de informação. Eu estou dizendo isso, e é isso que muita gente não está } \\
\text { percebendo, eles não estão percebendo porque o negócio deles é vender produtos para os pobrezinhos aqui. }\end{array}$ \\
\hline $\begin{array}{l}\text { Carlos } \\
\text { Afonso }\end{array}$ & $\begin{array}{l}\text { Na época, um absurdo. Hoje eu digo: o telefone celular como a gente o conhece vai acabar desaparecendo. Acontece que os dispositivos de conexão com a Internet vão virando dispositivos } \\
\text { multimídia cada vez mais miniaturizados. Então tudo pode acontecer. Quer dizer, no paradigma do celular de hoje, claro que não, porque o custo é elevadíssimo. Quem pode pagar para baixar } \\
\text { dados da Internet em um celular? Mas na hora que ele mudar de qualidade, ou seja, daqui a pouco set-top-box, computador portátil, e celular é tudo a mesma caixinha que você pluga nos dispositivos } \\
\text { periféricos da maneira que você quiser, aí sim. }\end{array}$ \\
\hline $\begin{array}{l}\text { Fernando } \\
\text { Guarnieri }\end{array}$ & O celular sozinho não. O Palm é um pouquinho maior do que o celular, é móvel, é pequeno, é portátil, é pessoal e é conectado, então é por aí. Mas não é o celular mesmo. \\
\hline $\begin{array}{l}\text { Gilson } \\
\text { Schwartz }\end{array}$ & $\begin{array}{l}\text { Os números são eloqüentes quanto à penetração do celular em populações de baixa renda. No Brasil, entretanto, } 80 \% \text { são comprados no sistema pré-pago. Ou seja, } \\
\text { não há renda disponível para usar o celular além do banal recebimento de chamadas. (...) Além disso, a informação sobre os fluxos, sobre as transações dentro dessas redes é totalmente proprietária, } \\
\text { totalmente privada. Nem as agências de publicidade, que em princípio são aliadas das operadoras, têm. Ninguém tem a informação, ela é guardada a sete chaves. Houve uma privatização da infra- } \\
\text { estrutura de telecomunicações e com isso, o sigilo de propriedade privada de informações sobre o que esses coletivos estão fazendo. Como é que eu posso avaliar o impacto do telefone celular se } \\
\text { isso tem um valor comercial e não há despojo, não há publicidade dessas informações? Essas são informações importantes do ponto de vista comercial que o mercado não tem e as } \\
\text { operadoras têm. E a política pública está no escuro, a Anatel... Sinto muito, não há informação. }\end{array}$ \\
\hline $\begin{array}{l}\text { Beatriz } \\
\text { Tibiriçá } \\
\text { (Beá) }\end{array}$ & $\begin{array}{l}\text { Eu acho que existem experiências, Sem dúvidas você tem aí um binômio que tem que ser explorado, porque se você pensar que, no Brasil, a população de baixa renda, por exemplo, tem } \\
\text { muito mais telefone celular do que telefone fixo, isso é uma verdade. E eu acho que ainda são pouco explorados os instrumentos que você pode ter via celular. Desde fazer consulta pública por } \\
\text { telemensagem, que é uma possibilidade que existe, como a própria articulação em rede através de celular para movimentos. (...) Se você pegar os usos que isso tem tido no nosso país, é o Faustão, o } \\
\text { Big Brother, o PCC. Mas nos Estados Unidos tem uma ONG que chama "Res Publica" que está fazendo um grande projeto de pesquisa voltado para a exploração desse binômio, articulação em rede e } \\
\text { telefone celular. É muito interessante a pesquisa deles. }\end{array}$ \\
\hline $\begin{array}{l}\text { Rodrigo } \\
\text { Baggio }\end{array}$ & \\
\hline
\end{tabular}


O uso do telefone celular como vetor para a inclusão digital (quadro 26), ainda é uma perspectiva remota para os entrevistados, uma possibilidade vista com muitas ressalvas. De alguma forma é consenso que a massificação do acesso passará por um equipamento menor, mais "móvel e pessoal" - não necessariamente o celular - mas, se depender do contexto atual do mercado, essa ferramenta será muito dispendiosa para a transmissão de dados, como atualmente é o acesso à rede através do telefone móvel. De um lado, Beá pondera que "ainda são pouco explorados os instrumentos que você pode ter via celular" para a articulação em rede, mas comenta que algumas pesquisas já estão sendo realizadas neste sentido. Gilson denuncia a falta de informação sobre os usos realizados através desses equipamentos, já que as redes de celular são totalmente proprietárias, tornando impossível se avaliar o impacto do telefone celular para o desenvolvimento de políticas públicas. E Sérgio discorda completamente da possibilidade, argumentando que mesmo que o celular vire uma "máquina de processamento como o computador", ele continuará tendo uma topologia centralizada, "num desenho onde eu dependo de uma infra-estrutura de telecomunicações", que é o contrário da tendência descentralizada prevista por ele, na qual os equipamentos funcionarão como roteadores de fluxos de informação, prescindindo da infra-estrutura de rede no modelo atual. "Essa é a linha da indústria, que acha que vai transformar todos em meros consumidores dos seus produtos. Isso denuncia efetivamente qual é o interesse do primeiro mundo quando faz programas de inclusão digital, que nada mais é do que tornar esse terceiro mundo consumidor de produtos" defende enfático Sérgio.

Já o potencial da televisão digital como vetor de inclusão digital (quadro 27), parece ter se tornado um grande mistério. Primeiro, pela falta de informação sobre o que vem sendo debatido. Segundo pelo que parece estar sendo priorizado nessa discussão, ou seja, o padrão tecnológico em detrimento do modelo de negócio, da interatividade, e da democratização na produção de conteúdo. Terceiro, porque envolve interesses de grandes conglomerados que historicamente sempre controlaram o setor. E por último, porque exige o controle do espectro por parte do governo.

Existe a promessa de que a televisão digital permita novas abordagens e seja uma ferramenta mais acessível para que as comunidades de baixa renda usem a Internet, podendo também produzir e transmitir conteúdos em formato digital, como lembram 
parte dos entrevistados. "Estão prometendo um set-top-box tão barato... E como é menor o investimento, se isso puder realmente aproveitar a televisão atual, certamente vai ser uma coisa importantíssima...”. lembra Carlos Afonso. E também pode “disseminar a produção independente, a quantidade de produções independentes vai crescer. Hoje você pode gerar seu conteúdo na Internet e pode ver isso na tela do seu computador, se quiser", completa Guarnieri. Mas para que essa "democratização" aconteça é necessário um "marco regulatório mais flexível” e um modelo de negócio que estimule a interatividade.

Meu feeling é que está se discutindo muito o padrão tecnológico, que é o secundário. (...) E eu acho que o modelo de negócios tende a não ser alterado. $O$ que não quer dizer que a interatividade não virá, eu acho que virá. (...). O que eu não acho que vai acontecer é a mudança na relação entre produtores e consumidores. Porque obviamente limitam-se os encargos na interatividade, e a interatividade vira, 'interatividade pra comprar coisas da Rede Globo', observa Assumpção.

E Sérgio vai além, argumentando que, diferente do que se anda sugerindo, TV digital não é o equivalente a Internet:

Eu abro o site na hora que eu quiser. Eu não vou poder abrir um canal de televisão digital na hora que eu quiser. A TV digital tem um controle do espectro do governo, ela tem uma diferença brutal. Agora, por ela ser tão amplamente divulgada, por ela poder viabilizar uma conversão do sinal digital para o analógico, podendo aproveitar o parque de televisões que temos no Brasil, nós podíamos ter um grau de interatividade enorme e uma democratização no broadcasting, comportando no sinal digital um número muito maior de emissoras. Aí o que aconteceu? A tendência, pelo que eu tenho lido nos jornais é ruim. Nós estamos optando pelo modelo menos interativo, menos democrático.

Para Carlos Afonso ainda restam várias dúvidas, pois mesmo que haja essa interatividade, como será viabilizada a produção do conteúdo local?: "Que política vai ter para que a TV comunitária realmente tenha um espaço? Para que pequenos empreendedores em informação, de conteúdo, possam ter o seu espaço garantido(...) Porque só os grandes é que têm acesso a essas verbas. Então isso tudo são questões externas da tecnologia, na verdade", conclui. E Gilson resume, afirmando categoricamente que a TV digital não será um vetor para a inclusão digital nem para a democratização da informação:

Não muda nada, como a Internet não mudou, nem o celular. A massa é tratada, na melhor das hipóteses, como amorfa e apenas consumidora. Os oligopólios dominam o processo de produção e regulação do consumo e o governo apenas assiste, respondendo até hoje com ações tópicas, de pequena escala e irrelevantes do ponto de vista de criação de um novo modelo de desenvolvimento econômico. 


\section{Quadro 27. Televisão digital como vetor para a Inclusão Digital - Mentores}

\begin{tabular}{|c|c|}
\hline Nome & $\begin{array}{l}\text { Qual será o impacto da televisão digital nas comunidades brasileiras de baixa renda? Ela deverá favorecer ou desfavorecer a inclusão digital? Como? Você acha qu } \\
\text { televisão digital manterá o padrão de relação entre os produtores e os consumidores de informação (concentração de poder das grandes empresas de mídia)? }\end{array}$ \\
\hline $\begin{array}{l}\text { Rogério } \\
\text { Santanna }\end{array}$ & $\begin{array}{l}\text { A televisão digital vai nos permitir novas abordagens e eu acho que pode ser uma ferramenta muito importante para as comunidades de baixa renda acessarem a Internet, porque } \\
\text { dependendo do nível da escolha do setup box que nós fizermos pra adoção da TV digital, ele poderá ser também um meio de acesso à Internet. (...) O que vai popularizar e fazer com que } \\
\text { outros produtores de mídia ingressem no negócio não é necessariamente a TV digital separadamente, mas a convergência das mídias. Então nós vamos para a TVIP, com outras possibilidades, que } \\
\text { evidentemente aparecem também no ambiente da TV digital, mas que vão aparecer, por exemplo, no celular. (...) Se tiver um marco regulatório mais flexível, as companhias telefônicas vão concorrer } \\
\text { com as televisões abertas, e também serão contratadores de programas. Então os produtores de conteúdo vão ter mais clientes, vão poder disputar um mercado mais amplo, não vão precisar ficar } \\
\text { dependendo das redes de televisão e suas cadeias de transmissão, vão poder vir de fora para dentro. Como já está se vendo na Internet, com programas que começam na Internet e depois vão para a } \\
\text { mídia tradicional. É uma diminuição da concentração de certa forma. Se o marco regulatório, por exemplo, impedir esse tipo de ação, aí vai ser um grande dificultador. }\end{array}$ \\
\hline $\begin{array}{l}\text { Rodrigo } \\
\text { Assumpção }\end{array}$ & $\begin{array}{l}\text { Tudo depende. Depende se nós vamos usar essa oportunidade para mudar o modelo de negócio ou não. Depende se nós vamos conseguir efetivamente estimular a interatividade ou não. O } \\
\text { debate hoje tem possibilidade de qualquer uma dessas tendências, e tem possibilidade também de ser o exato oposto. (...) Meu feeling é que está se discutindo muito o padrão tecnológico, que é o } \\
\text { secundário, porque com qualquer um dos três da pra desenvolver, e está se discutindo pouquíssimo o modelo de negócio. E eu acho que o modelo de negócios tende a não ser alterado. Eu sou } \\
\text { mais pessimista que o otimista. O que não quer dizer que a interatividade não virá, eu acho que virá. A pergunta da interatividade, da inclusão digital, sim, vai favorecer. O que eu não acho que } \\
\text { vai acontecer é a mudança na relação entre produtores e consumidores. Porque obviamente limitam-se os encargos na interatividade, e a interatividade vira "interatividade pra comprar coisas da } \\
\text { Rede Globo". }\end{array}$ \\
\hline $\begin{array}{l}\text { Sérgio } \\
\text { Amadeu }\end{array}$ & $\begin{array}{l}\text { Eu acho que a TV digital terá, no mínimo, o mesmo impacto que a TV aberta tem nas comunidades de baixa renda. Agora, a TV digital, pelo caminho que está indo o modelo brasileiro, os } \\
\text { decisores desse processo estão optando por uma baixa interatividade, uma baixa democratização do espectro. Porque a TV digital nunca será a Internet, diferente do celular. Porque } \\
\text { andaram vendendo por aí que a TV digital é o equivalente à Internet, não tem nada a ver. Um exemplo que eu uso é muito claro: eu abro o site na hora que eu quiser. Eu não vou poder abrir um canal } \\
\text { de televisão digital na hora que eu quiser. A TV digital tem um controle do espectro do governo, ela tem uma diferença brutal. Agora, o que a gente discutia é: por ela ser tão amplamente divulgada, } \\
\text { por ela poder viabilizar uma conversão do sinal digital para o analógico, podendo aproveitar o parque de televisões que temos no Brasil, nós podíamos ter um grau de interatividade enorme e uma } \\
\text { democratização no broadcasting, comportando no sinal digital um número muito maior de emissoras. Aí o que aconteceu? A tendência, pelo que eu tenho lido nos jornais é ruim. Nós estamos } \\
\text { optando pelo modelo menos interativo, menos democrático. Então a discussão, você reparou, foi invertida: em vez da gente discutir antes modelo tal, a gente começa a discutir o padrão. }\end{array}$ \\
\hline $\begin{array}{l}\text { Carlos } \\
\text { Afonso }\end{array}$ & $\begin{array}{l}\text { Eu acho que a TV digital tal como ela está concebida hoje é transitória. Isso é o começo de uma convergência. Daqui a pouco essa TV digital é parte da Internet, que vai ser de outra natureza, } \\
\text { muito mais poderosa, com muito mais conectividade. (...) Na situação atual, acho que vai ter um impacto, porque estão prometendo um set-top-box tão barato... E como é menor o } \\
\text { investimento, se isso puder realmente aproveitar a televisão atual, certamente vai ser uma coisa importantíssima. Agora, a segunda parte é outra dúvida: como vão ser liberados esses canais? Que } \\
\text { política vai ter para que a TV comunitária realmente tenha um espaço? Para que pequenos empreendedores em informação, de conteúdo, possam ter o seu espaço garantido? Ou você vai ter que } \\
\text { implorar para que um grande provedor distribua sua informação? Para poder produzir informação? Porque só os grandes é que têm acesso a essas verbas. Então isso tudo são questões externas da } \\
\text { tecnologia, na verdade. }\end{array}$ \\
\hline $\begin{array}{l}\text { Fernando } \\
\text { Guarnieri }\end{array}$ & $\begin{array}{l}\text { A TV Digital vai concorrer... Eu vou fazer meu estudiozinho e vou concorrer com a Globo. Eu acho que vai disseminar a produção independente, a quantidade de produções independentes } \\
\text { vai crescer. Hoje você pode gerar seu conteúdo na Internet e pode ver isso na tela do seu computador, se quiser. Agora a inclusão digital... com certeza você vai baratear mais ainda o custo da } \\
\text { pessoa ter acesso à Internet. Você compra um aparelhinho bem mais barato que qualquer outro. Então é claro que vai favorecer a inclusão digital. Como a questão de criação de conteúdo, vai ser } \\
\text { igual ao que é no computador. É a coisa do telecentro. Se você quiser fazer... um negócio coletivo, tem que pintar da comunidade, não adianta a gente como programa falar para eles, fazer com que as } \\
\text { pessoas façam coletivamente. }\end{array}$ \\
\hline $\begin{array}{l}\text { Gilson } \\
\text { Schwartz }\end{array}$ & $\begin{array}{l}\text { Não muda nada, como a Internet não mudou, nem o celular. A massa é tratada, na melhor das hipóteses, como amorfa e apenas consumidora. Os oligopólios dominam } \\
\text { o processo de produção e regulação do consumo e o governo apenas assiste, respondendo até hoje com ações tópicas, de pequena escala e irrelevantes do ponto de vista de criação de um novo } \\
\text { modelo de desenvivimento econômico. }\end{array}$ \\
\hline $\begin{array}{l}\text { Beatriz } \\
\text { Tibiriçá } \\
\text { (Beá) }\end{array}$ & $\begin{array}{l}\text { A TV digital ainda é um grande mistério, e é uma discussão que é quase como você discutir o poder da Internet. As pessoas não sabem direito o que é. Elas têm uma certa noção de que isso } \\
\text { pode interferir na vida delas, mas essa discussão não está popularizada. Então o padrão da TV digital virou problema de técnico, quando o padrão da TV digital pode ou não alterar a produção de } \\
\text { conteúdo, a interatividade, a própria democratização da produção em televisão, e a mudança do modelo de negócio. Então essa discussão eu acho que ainda não aconteceu. (..) Inclusive de como as } \\
\text { comunidades articuladas e organizadas dentro dessa camada de população de baixa renda que uso ela pode fazer disso? E eu acho que as possibilidades são infinitas, mas vai depender, como } \\
\text { sempre, de uma decisão política, que por enquanto ninguém tomou, né? }\end{array}$ \\
\hline $\begin{array}{l}\text { Rodrigo } \\
\text { Baggio }\end{array}$ & \\
\hline
\end{tabular}




\subsection{Discurso dos coordenadores}

Nas entrevistas realizadas com coordenadores dos três programas de inclusão digital selecionados buscou-se identificar a opinião dos mesmos sobre: o conceito de inclusão digital; o envolvimento dos entrevistados com a inclusão digital; a principal motivação para a criação dos programas e seus principais objetivos; a capacitação dos usuários; as atividades realizadas pelos usuários na Internet; o impacto da Internet no consumo e produção de informação; os benefícios do programa para o usuário, assim como sua contribuição para o desenvolvimento social, político e econômico da comunidade; e os desafios dos programas para o futuro. Os resultados desses encontros serão relatados a seguir.

Perfil e envolvimento com a inclusão digital - Os coordenadores entrevistados se envolveram com projetos de inclusão digital após vivenciarem experiências diretas com projetos sociais, seja no serviço público, seja em empresas privadas (ver quadro 28). Maria Amélia Fernandes, coordenadora operacional do Acessa, e Rosane Pólli, gerente de Bibliotecas e Faróis do Saber da Secretaria Municipal de Educação (SME) de Curitiba, são da área de educação, sendo que a primeira tem ampla experiência no desenvolvimento de programas educacionais no Governo de São Paulo. Ricardo Kobashi $^{75}$, coordenador técnico do Acessa SP, foi diretor do CDI-SP por vários anos, e possui um vasto currículo na implantação de iniciativas de inclusão digital e na articulação da comunidade em torno da tecnologia. É o único que já possuía experiência com ID antes de assumir a gestão do programa. Drica Guzzi é coordenadora pedagógica do Acessa SP na Escola do Futuro da USP, não é funcionária do programa, mas está envolvida profissionalmente com o Acessa SP desde a sua criação. Fabrício Zanini, coordenador de projetos sociais da ONG Instituto de Informática de Curitiba (ICI), coordenou o Digitando o Futuro de 2000, quando o programa teve início, até dezembro de 2005, quando essa responsabilidade foi transferida para a gerência do programa Faróis do Saber. Leandro Silva, assistente social, é assessor da coordenação do

\footnotetext{
${ }^{75}$ É importante mencionar que Kobashi, mesmo pertencendo ao grupo de coordenadores - devido a sua atual função executiva -, deve ser considerado como um dos "mentores" da inclusão digital no país, devido a sua vasta experiência.
} 
programa desde março de 2005 na Secretaria Municipal dos Direitos Humanos e Segurança Urbana, órgão responsável pelos Telecentros Porto Alegre.

É interessante notar que cada uma das iniciativas se encontra em uma área diferente do governo, seja municipal ou estadual: o Acessa SP é responsabilidade da Imprensa Oficial da Casa Civil do Governo do Estado de São Paulo, o Digitando o Futuro está na Secretaria Municipal de Educação de Curitiba, e o Telecentros São Paulo é gerido pela Secretaria Municipal dos Direitos Humanos e Segurança Urbana. Os programas apresentam também estruturas distintas, como será visto ainda neste capítulo.

Interesses - De maneira geral, todos foram convidados a participar do programa, com exceção de Rosane, que "herdou” a gestão única do Digitando o Futuro, que a SME dividia com o ICI. Como são programas públicos, mudanças de administração trazem, de alguma forma, alteração na sua coordenação: o Digitando o Futuro, por exemplo, foi criado durante a gestão de Cássio Taniguchi (PFL), e com a entrada de Carlos Alberto Richa (PSDB), em 2004, o programa parece ter desacelerado. Em Porto Alegre, o programa de Telecentros foi desenvolvido em 2001, durante a administração do prefeito Tarso Genro (PT), e em 2003 chegou a ter 58 unidades. No ano de 2005, na época em que foram realizadas as visitas, já sob a gestão de José Fogaça (PPS), somente 17 unidades estavam ativas.

No discurso dos coordenadores e ex-coordenador dos programas destes dois municípios foi notado o impacto da mudança de gestão. Fabrício se mostra sempre preocupado em ressaltar as realizações obtidas com o programa durante sua coordenação, enquanto Rosane, que havia assumido o comando há três meses, demonstra grande desconhecimento com relação à dinâmica e até mesmo aos objetivos do Digitando o Futuro (que mudou inclusive de nome, e atualmente se chama Cidade do Conhecimento). Leandro, assessor da coordenação do Telecentros POA, demonstra conhecer o programa, mas grande parte de seu discurso são justificativas pelo fechamento de unidades e dificuldades burocráticas do processo, demonstrando que mesmo o caráter participativo da comunidade porto-alegrense e seu envolvimento com os telecentros não impediu que ocorresse um certo "desaparelhamento" dos mesmos. 


\begin{tabular}{|c|c|c|c|}
\hline CPA & Nome & Perfil do coordenador & Como você se envolveu com projetos de inclusão digital? \\
\hline \multirow{3}{*}{$\begin{array}{l}\text { Acessa São } \\
\text { Paulo }\end{array}$} & $\begin{array}{l}\text { Maria } \\
\text { Amélia }\end{array}$ & $\begin{array}{l}\text { Maria Amélia Kuhlmann } \\
\text { Fernandes, coordenadora } \\
\text { operacional do Acessa São Paulo, } \\
\text { desde } 1^{\circ} \text { de julho de } 2005 \text {. }\end{array}$ & $\begin{array}{l}\text { (...) desde } 1999 \text { [através do projeto] Parceiros do Futuro, que abriu em } 100 \text { escolas (...). Então você abria esse espaço nos finais de semana pra } \\
\text { que a comunidade pudesse usufruir de várias atividades ali dentro. Era um programa do governo, coordenado pela Secretaria da Educação e } \\
\text { fazia um pool de secretarias, fazendo ações pontuais dentro da escola. (...) E tinha um programa que chamava "De } 8 \text { a 80", que era de ID. } \\
\text { Tínhamos uma parceria com a Telefônica e essa parceria foi ampliando e chegamos a } 400 \text { em } 2003 \text {. A Fundação Telefônica fazia um programa de } \\
\text { ID nessas escolas, no sentido de pesquisar Internet e terminava com um jornalzinho comunitário, feito pelos próprios alunos. E eu já percebia } \\
\text { desde então a importância disso. Tinha muito mais procura do que oferta, muito, mas muito mais. Aí eu fui para a Secretaria da Cultura para } \\
\text { implantar o programa Fábricas de Cultura }{ }^{76} \text {, em } 2003 \text {. (...). Ao longo desse tempo, teve um processo pessoal mesmo de ID, porque eu sou do } \\
\text { tempo que "botão faz tec-tec", então levantava para mudar o canal, eu nasci em 1950, então você imagina.(...). O primeiro programa, Parceiros do } \\
\text { Futuro, era inclusão social. (...), um programa de cidadania. O Fábrica de Culturas é um programa de inclusão cultural e esse é um programa de } \\
\text { ID. Agora, veja: a ID vai proporcionar inclusão cultural e a inclusão social e vice-versa os outros, né? }\end{array}$ \\
\hline & $\begin{array}{l}\text { Ricardo } \\
\text { Kobashi }\end{array}$ & $\begin{array}{l}\text { Ricardo Kobashi, coordenador } \\
\text { técnico Acessa São Paulo, desde } 1^{\circ} \\
\text { de julho de 2005. É conselheiro } \\
\text { fiscal do CDI São Paulo. Participou } \\
\text { do Comitê Técnico do Sampa.org, } \\
\text { teve uma coluna sobre inclusão } \\
\text { digital no Estadão }\end{array}$ & $\begin{array}{l}\text { Eu tinha uma empresa de publicidade que, em 94/95, foi procurada pelo CDI em São Paulo para fazer o material de divulgação de uma } \\
\text { parceria com a Plug\&Use, referente a uma doação de descarte de computadores. Eu queria fazer algum trabalho dentro da área social... E esse } \\
\text { assunto eu conhecia. Eu acabei me oferecendo para fazer o planejamento estratégico do CDI SP. No ano seguinte a diretoria me convidou para } \\
\text { ser o presidente da entidade. (...) E aí eu comecei a me interessar pelo assunto, comecei a estudar, a conversar com as pessoas, a discutir, a dar } \\
\text { palestra, a viajar... e ai a ID acabou virando o assunto da minha vida. (...) Eu estabeleci vários convênios nessa época [2001/2] com a prefeitura, } \\
\text { com o governo, para implantar programas de ID... Entrei para o Ação da Cidadania... então você aprende duas coisas, na verdade quando } \\
\text { você começa a trabalhar numa ONG de ID, você tem que aprender sobre ID, e você tem que aprender sobre inclusão social, que no final é } \\
\text { um objetivo a parte. Mas é um dos objetivos da ID. }\end{array}$ \\
\hline & $\begin{array}{l}\text { Drica } \\
\text { Guzzi }\end{array}$ & $\begin{array}{l}\text { Drica Guzzi, coordenadora do } \\
\text { LIDEC - Laboratório de Inclusão } \\
\text { digital e Educação Comunitária da } \\
\text { Escola do Futuro, da USP. } \\
\text { Engenheira, estudou gerenciamento } \\
\text { de tecnologia e cinema digital nos } \\
\text { EUA. Coordena as atividades } \\
\text { pedagógicas e produção de } \\
\text { conteúdo do Acessa desde } 2001 .\end{array}$ & $\begin{array}{l}\text { Eu venho da iniciativa privada, trabalhei um tempo na área de logística e fui pra área de Recursos Humanos, que era onde eu tinha mais } \\
\text { afinidade. (...) A minha questão era sempre na relaçãa do modo de vida e educação. (...) Em } 2001 \text {, eu tinha visto um artigo do [Fredric] Litto } \\
\text { sobre "telecentros comunitários: uma resposta à exclusão digital", que foi um artigo que ele publicou no final dos anos } 2000 \text { (...) Conversei com o } \\
\text { pessoal lá do Aprendiz, e aí, a coincidência é que quando eu cheguei aqui para conversar com o Litto, na hora ele falou: "pô, você não quer } \\
\text { trabalhar com Universidade Corporativa?" (...) Em } 2001 \text {... a Escola do Futuro fecha um contrato anual [com o Acessa] de ciclos de } \\
\text { capacitação, desenvolvimento de estratégias para a participação comunitária, questão de produção de conteúdo, pesquisa. Aí sim você } \\
\text { começa a investir no programa sistematicamente. }\end{array}$ \\
\hline $\begin{array}{l}\text { Digitando o } \\
\text { Futuro }\end{array}$ & $\begin{array}{l}\text { Rosane } \\
\text { Pólli }\end{array}$ & $\begin{array}{l}\text { Rosane Carvalho Polli, } 42 \text { anos, } \\
\text { educadora e bibliotecária, gerente } \\
\text { de Bibliotecas e Faróis do Saber da } \\
\text { SME. Há } 2 \text { meses coordena o } \\
\text { Digitando o Futuro }\end{array}$ & $\begin{array}{l}\text { Eu vim para os Faróis em 98. Naquele tempo nós não tínhamos a ID, esse programa de informática grátis. Só tinha a biblioteca nos Faróis. Em } \\
2000 \text { foi incluída essa parte da Internet. No começo com bastante problemas, foi bastante difícil no início, mas agora ninguém fica sem. Se o } \\
\text { Farol tiver um problema de equipamento, às vezes dá problema da tinta, o pessoal reclama no 156, eles estão cobrando direto. [Que tipo de } \\
\text { problema vocês tiveram?] No começo, as pessoas queriam que o Farol desse cursos, a intenção deles era aprender a usar o micro. Queriam chegar } \\
\text { lá e que o estagiário pegasse individualmente e ensinasse como entrar na Internet... Aí eles foram entendendo que eles tinham que ter uma noção } \\
\text { para ir ao Farol usar o micro. E nós começamos a fazer programas de cursos para poder atender a essa demanda. Agora os Faróis vão abrir } \\
\text { também no final de semana, sábado a tarde e domingo o dia todo (...). Estagiários de curso superior serão treinados para dar cursos de } \\
\text { informática, porque é muito pedido. Eles telefonam, pedem pelo 156, querem até pôr vereadores telefonando, "o pessoal quer curso de informática } \\
\text { dentro do Farol". }\end{array}$ \\
\hline
\end{tabular}

${ }^{76}$ As Fábricas de Cultura são um projeto da Secretaria Estadual de Cultura de São Paulo, que inclui equipamentos, recursos humanos, orientação e capacitação para desenvolverem atividades artístico-culturais em diferentes áreas de expressão. 


\begin{tabular}{|c|c|c|c|}
\hline CPA & Nome & Perfil do coordenador & Como você se envolveu com projetos de inclusão digital? \\
\hline & $\begin{array}{l}\text { Fabrício } \\
\text { Zanini }\end{array}$ & $\begin{array}{l}\text { Fabrício Zanini, coordenador de } \\
\text { projetos sociais da organização sem } \\
\text { fins lucrativos, Instituto Curitiba de } \\
\text { Informática (ICI), que até } \\
\text { dezembro de } 2005 \text { coordenou o } \\
\text { programa Digitando o Futuro. }\end{array}$ & $\begin{array}{l}\text { Foi uma delegação da minha empresa colocar um gestor [de projetos sociais] e eu fui escolhido para trabalhar nessa área. Já participei de } \\
\text { vários eventos nacionais, fomos premiados inclusive por esse projeto, que foi na realidade o primeiro projeto do Brasil com relação a isso. A gente } \\
\text { começou com } 26 \text { pontos em } 2000 \text { e terminamos em } 2003 \text { com } 49 \text { pontos, sendo que em } 2004 \text { a gente criou até uma unidade móvel, que fazia esse } \\
\text { processo de ID também. Essas informações todas você consegue ter acesso no site. É um site que está sendo reformulado, provavelmente } \\
\text { muitas das coisas que estão ali vão ser retiradas, porque fazem parte de uma outra gestão da prefeitura, tem uma política por trás de tudo } \\
\text { isso. Então é importante que se queira resgatar, que se resgate o quanto antes porque não sei até quando vai continuar assim. E nesse processo de } \\
\text { ID a gente trabalhou não só (...) promovendo dentro da cidade muitos pontos de acesso, com alta velocidade, com cursos... a gente tentou } \\
\text { se preocupar com todos os aspectos relacionados com a questão da ID. A gente não colocava só o acesso ao computador, promovia cursos } \\
\text { com esse computador conectado à Internet. E além disso, se você percebeu, esses locais já eram frequientados pela comunidade, porque existia } \\
\text { uma biblioteca, então você potencializava todo esse processo de inclusão. }\end{array}$ \\
\hline $\begin{array}{l}\text { Telecentros } \\
\text { POA }\end{array}$ & $\begin{array}{l}\text { Leandro } \\
\text { Silva }\end{array}$ & $\begin{array}{l}\text { Leandro Augusto da Silva, } 27 \text { anos, } \\
\text { assessor da coordenação do } \\
\text { programa desde março de } 2005 \text { na } \\
\text { Secretaria Municipal dos Direitos } \\
\text { Humanos e Segurança Urbana } \\
\text { (SMDHSU), órgão responsável } \\
\text { pelo Telecentros Porto Alegre. }\end{array}$ & $\begin{array}{l}\text { Através de um convite, há bastante tempo. Já há } 5 \text { anos que eu lido com a questão social no município de Porto Alegre. Sou ex-conselheiro } \\
\text { tutelar, já fui gestor de ONG... Como eu já lidava aqui com as questões de direitos humanos na secretaria, eu fui agregado ao projeto. Devido a } \\
\text { essa visão de inclusão social mesmo, até por ser acadêmico da área de assistência social, realmente a gente tem uma maneira diferenciada } \\
\text { de lidar com essa questão. }\end{array}$ \\
\hline
\end{tabular}




\section{Quadro 29. Definição de Inclusão Digital - Coordenadores}

\begin{tabular}{|c|c|c|}
\hline CPA & Nome & Como você define inclusão digital? \\
\hline \multirow{3}{*}{$\begin{array}{l}\text { Acessa São } \\
\text { Paulo }\end{array}$} & $\begin{array}{l}\text { Maria } \\
\text { Amélia }\end{array}$ & $\begin{array}{l}\text { (...) eu vou te dar uma definição não-teórica, vou te dar uma definição prática. Eu acho que é você } \\
\text { dar à população acesso aos equipamentos, que por enquanto são muito caros. Então você tem que abrir } \\
\text { espaços onde a população pode usar o que há de mais moderno na tecnologia. É o que nós estamos } \\
\text { tentando fazer. Então eu defino ID como dar oportunidades, abrir espaços para que as pessoas } \\
\text { possam interagir com essas novas tecnologias. }\end{array}$ \\
\hline & $\begin{array}{l}\text { Ricardo } \\
\text { Kobashi }\end{array}$ & $\begin{array}{l}\text { Eu tenho uma definição que eu uso para leigo que eu acho ótima, que é: ID é quando você consegue } \\
\text { fazer com que a tecnologia jogue no seu time e não só no time do adversário. Na verdade, a gente } \\
\text { tem uma série de dificuldades em definir ID, e o maior problema dela é o tal do alvo móvel. O que é ID } \\
\text { hoje não é amanhã, e não é a mesma coisa que foi ontem, então esse é um problema básico. (...) Que a } \\
\text { tal da "cesta mínima" de tecnologia que uma pessoa precisa ter para estar incluída depende do } \\
\text { momento, (...) do estágio da tecnologia que o país está. E o que está dentro dessa cesta varia muito em } \\
\text { função do local, do tempo, da sociedade, da faixa de renda, o trabalho que a pessoa tem, o que ela faz } \\
\text { da vida, etc. Na verdade, essa definição depende de tantas variáveis (...) e as definições genéricas } \\
\text { raramente levam em conta a perspectiva do grupo ou da pessoa, quer dizer, “o que ela quer” e } \\
\text { não “o que eu acho que ela deveria ter”, então isso é uma coisa importante. É uma idéia de } \\
\text { percepção, isso depende muito da percepção que o indivíduo tem. }\end{array}$ \\
\hline & $\begin{array}{l}\text { Drica } \\
\text { Guzzi }\end{array}$ & $\begin{array}{l}\text { A gente já sabe que não tem uma definição só, né? Mas de qualquer maneira, eu gosto de uma } \\
\text { definição que eu acho que até o pessoal da Benton Foundation }{ }^{77} \text { usa, que é: a ID é uma definição } \\
\text { elástica, é um contínuo e vai desde uma exclusão digital total e completa, até uma oportunidade } \\
\text { digital. E aqui, oportunidade digital a gente entende como não só acesso, apropriação, mas a } \\
\text { partir daí você tem um impacto na sua vida, entendeu? (...) esse impacto pode se traduzir em } \\
\text { melhoria financeira, em melhoria educacional, cognitiva, tanto pessoal quanto comunitária, em } \\
\text { melhoria emocional pessoal e comunitária, melhoria política e cultural. Então é você tá } \\
\text { produzindo coisas e isso tá transformando a tua realidade. Então você vai do zero até cem, e você } \\
\text { vai encaixando aqui o nível de desenvolvimento, seja individual, seja no coletivo. Seja numa visão de } \\
\text { uma pessoa, seja um grupo, seja um país... }\end{array}$ \\
\hline \multirow{2}{*}{$\begin{array}{l}\text { Digitando } \\
\text { o Futuro }\end{array}$} & $\begin{array}{l}\text { Rosane } \\
\text { Pólli }\end{array}$ & $\begin{array}{l}\text { Pra mim, a ID é a expansão da informática para todas as pessoas: os de baixa renda, os que } \\
\text { podem ter computador em casa, e para aqueles também que não têm. Principalmente para os que } \\
\text { não tem. Nós temos Faróis que são muito retirados do centro da cidade e que tem pessoas que jamais } \\
\text { vão poder realmente ter um computador em casa e você precisa ver as crianças, a alegria deles quando } \\
\text { eles marcam horário e vão utilizar o computador. }\end{array}$ \\
\hline & $\begin{array}{l}\text { Fabrício } \\
\text { Zanini }\end{array}$ & $\begin{array}{l}\text { Como um processo importantíssimo na sociedade atual, porque a maioria dos meios de comunicação } \\
\text { e de interação entre o governo e a comunidade, entre a empresa e a comunidade como um todo, estão } \\
\text { cada vez mais atrelados ao processo da Internet. E esse processo só acontece com a população } \\
\text { tendo acesso ao computador e a essas formas de interação. Então esse processo não tem mais volta, } \\
\text { está cada vez mais amplo. E infelizmente o brasileiro não tem poder aquisitivo para ter esse acesso. }\end{array}$ \\
\hline $\begin{array}{l}\text { Telecentros } \\
\text { POA }\end{array}$ & $\begin{array}{l}\text { Leandro } \\
\text { Silva }\end{array}$ & $\begin{array}{l}\text { A inclusão depende de várias etapas: a parte pedagógica, a parte de aprendizado, a própria } \\
\text { questão do acesso e a questão de inclusão de fato desse indivíduo no mercado de trabalho, e } \\
\text { socialmente, nessas redes de comunicação. A gente pensa que não é somente o acesso, e sim a } \\
\text { permanência e evolução desses indivíduos numa escala progressiva. }\end{array}$ \\
\hline
\end{tabular}

Os coordenadores entrevistados apresentam uma visão complementar do conceito de inclusão digital (ver quadro 29), com diferentes graus de complexidade, mas em geral está presente a concepção de que ID não significa somente disponibilizar acesso à Internet, mas possibilitar a participação do indivíduo na atual dinâmica da sociedade e a transformação da sua própria realidade. Rosane e Fabrício, do Digitando o Futuro, e Maria Amélia, do Acessa SP, se preocupam principalmente com a primeira fase, ou seja, a promoção do acesso e de oportunidades de interação com a tecnologia àqueles que não têm condições econômicas de fazê-lo. Já Kobashi e Drica, também do Acessa SP, e Leandro, do Telecentros Porto Alegre, enfatizam a idéia de um processo em construção, um processo de apropriação que gradualmente pode levar a um impacto efetivo na vida do usuário, dependendo de suas características individuais e de suas

\footnotetext{
${ }^{77}$ Fundação norte-americana criada em 1981, com o objetivo de articular o interesse público na era digital e demonstrar o valor das comunicações para a resolução de problemas sociais. Ver http://www.benton.org/
} 
vontades. "Esse impacto pode se traduzir em melhoria financeira, em melhoria educacional, cognitiva - tanto pessoal quanto comunitária -, em melhoria emocional pessoal e comunitária, melhoria política e cultural", enumera Drica.

Além do fato comum, de que todas as iniciativas investigadas partiram do poder público, a motivação para a criação dos programas (quadro 30) se mostra diretamente ligada ao momento histórico - final dos anos 1990 - e aos interesses do Governo e do mercado de tecnologia, principalmente. Kobashi relata detalhadamente o macro cenário desse período, quando as administrações públicas - tanto em nível municipal, estadual como federal - passam a investir pesadamente na informatização da sua estrutura e a oferecer serviços de governo eletrônico para o cidadão:

\begin{abstract}
De um lado você tinha o governo, que precisava justificar os investimentos que estava fazendo em governo eletrônico. Quando ele começa a oferecer serviços de governo eletrônico, ele não pode oferecer serviços excludentes, ou seja, só para a população que tem acesso. Responsavelmente ele tem que começar a pensar em oferecer uma forma da população que não tem computador e acesso à Internet utilizar esse serviço. Então é óbvio que o governo como o do Estado de SP, que estava investindo pesadamente na informatização do Estado e na prestação de serviços através da Internet, tivesse a preocupação de ter um programa como o Acessa SP, senão seriam serviços excludentes.
\end{abstract}

De outro lado estavam as empresas de tecnologia, constantemente buscando expandir seus mercados, e que encontravam no discurso da inclusão digital um negócio extraordinário: podiam ao mesmo tempo formar novos usuários, capacitar mão-de-obra especializada e ainda "doar" equipamentos obsoletos, fortalecendo sua imagem cidadã através de ações de responsabilidade social.

\footnotetext{
Nesse contexto começam programas como o CDI [1994/95], de reciclagem de equipamento, de pegar equipamento velho e transformar em um equipamento que pudesse ser utilizado para algum fim. Que fim é esse? Inclusão digital. E aí nesse contexto, os programas como o CDI eram baseados na tentativa de melhora de empregabilidade. Então era pegar a máquina velha pra ensinar o pessoal a trabalhar pra preparar pra o mercado de trabalho. As empresas investiram nisso, era um ótimo negócio. Formavam mão-de-obra grátis, não tinha que pagar curso pra ninguém. Ele dava um computador velho, que não tinha mais uso, para os 'pobrinhos'. Os 'pobrinhos' usavam, aprendiam a usar pra depois trabalhar pra ele. Então era isso, ninguém arcava com esse negócio. Era 'pobrinho' dando aula pra 'pobrinho' usando lixo tecnológico, relata Kobashi.
}

Mais do que isso, podiam ainda vender mais equipamentos para os governos, agora para esses programas de inclusão digital. Como relata Kobashi, em 2000 os mercados de TIC no primeiro mundo começam a dar fortes sinais de saturação, os equipamentos - que 
antes tinham um ciclo de vida muito curto - agora com processadores geração Pentium deixam de ficar obsoletos tão rapidamente, e a estratégia expansionista das companhias se volta para mercados emergentes do terceiro mundo:

Nessa época (...), a Carly Fiorina, que era presidente da HP, dá a seguinte declaração: 'a gente precisa achar os próximos 2 bilhões de consumidores'. O que ela quer dizer com isso? Não vai ser mais o ciclo de obsolescência que vai fazer a gente vender. Quem tem dinheiro já tem computador. E esses 2 bilhões estão aonde? No Brasil, na Índia, na África... Então é nessa época que você começa a ter as grandes empresas investindo na inclusão digital no terceiro mundo. Nessa época que esse pensamento, que a gente acha que foi idéia nossa, chega no Brasil.... Então a indústria tem papel importantíssimo em vender a idéia de na inclusão digital, da necessidade de na inclusão digital. Não tinha uma reunião de na inclusão digital que não tinha um representante da Microsoft. Essas empresas estavam vendendo essa idéia, legitimamente.

Nesse cenário, Kobashi ainda cita a participação das organizações sociais, "que vêem na tecnologia uma forma de ação social", de fortalecer e levar benefício para as comunidades que estão atendendo, e da Universidade, que começa a pensar o impacto dessa tecnologia na inclusão social dos indivíduos.

Segundo os entrevistados, o contexto direto para a criação dos programas que investigo estava ligado a uma nova postura do Governo, de se aproximar do cidadão, através da oferta de informações e serviços via Internet. "Toda essa mudança de paradigma na questão pública implica, quase que naturalmente, em você ampliar os canais de relação com o cidadão. Uma das formas, é claro, é você utilizar as novas tecnologias. (...) Aí começou o programa [Acessa SP]", conta Drica. Seja para justificar gastos em TIC ou por perceber que o mercado sozinho não fará com que o cidadão tenha acesso aos benefícios de governo eletrônico, começam os investimentos públicos em inclusão digital: o primeiro programa mantido pelo poder público a entrar em operação foi o Digitando o Futuro, em junho de 2000. No mês seguinte foi a vez do Acessa SP e, um ano depois, do Telecentros $\mathrm{POA}^{78}$.

Inicialmente estas iniciativas tomaram como exemplo as experiências de entidades do terceiro setor, que desde 1995 já desenvolviam projetos de informática comunitária e de acesso à Internet, como o CDI e o Sampa.org, sempre desenvolvendo parcerias com a sociedade civil organizada - seja através de associações comunitárias ou ONGs -, com empresas e universidades. Já a expansão dos programas está diretamente ligada ao

\footnotetext{
${ }^{78}$ O programa Telecentros São Paulo iniciou suas atividades um mês antes, em 18 de junho de 2001.
} 
comprometimento dos gestores públicos em conseguir financiamento, destinação orçamentária ou estabelecer convênios para o seu desenvolvimento.

De maneira geral o primeiro objetivo do programa (quadro 31) é colocar a tecnologia à serviço do cidadão de baixa renda, que não dispõe de um computador ou de acesso à Internet em casa. E mais do que isso, ajudar o cidadão a perceber o que a tecnologia pode trazer para ele em termos de benefícios, de ampliação de horizontes, de relacionamentos e de oportunidades de inclusão social.

\begin{abstract}
A questão é como a gente faz pra tecnologia fazer parte do dia-a-dia dele. (...) Não é de apropriação em si da tecnologia, mas de entendimento. (...) Se as estruturas educacionais públicas soubessem lidar melhor com o uso da tecnologia dentro da educação, dentro dos processos educacionais, a missão dos infocentros ou telecentros seria bem reduzida. Seria bom dar o acesso... o resto já foi feito do lado de fora!, coloca Kobashi.
\end{abstract}

Ensinar a utilização da ferramenta parece não corresponder mais aos interesses dos programas, e apenas Leandro, do Telecentros Porto Alegre frisou a importância de acabar com o "analfabetismo digital", de preparar o usuário para o mercado de trabalho, assim como de "afastar o jovem e o adolescente do mundo da criminalidade". Para Fabrício a preocupação maior do programa é a possibilidade do cidadão ter acesso ao conhecimento, e assim transformar a comunidade em que vive: "Num aspecto geral, se a gente conseguisse que toda a comunidade onde a gente tivesse o projeto, tivesse uma luz do conhecimento, essa comunidade seria mais capaz, e estaria se organizando de uma forma melhor para resolver os seus problemas. No final, a gente teria uma cidade melhor". Esse discurso mostra a crença de que o acesso a essas novas tecnologias pode transformar o mundo a partir das mudanças individuais e do estabelecimento de redes de comunicação e informação.

Já os coordenadores do Acessa SP apresentam uma preocupação maior com o potencial do programa para a articulação da comunidade, para o estabelecimento de redes, o desenvolvimento de projetos e a produção de conteúdo local. "Hoje, o Acessa está caminhando num sentido dessa cultura digital (...) está ficando mais on-line, entendeu? Hoje, o portal já está querendo ser mais interativo, já está querendo desenvolver uma relação não só com o monitor, mas com o usuário, com a rede”, explica Drica. 
Existe também a compreensão de que os programas são uma forma de relacionamento entre o governo e o cidadão: "No Acessa você tem a comunidade podendo usufruir dos serviços eletrônicos do governo. Porque não adianta, se o governo é moderno, se você pode tirar um B.O. eletrônico, são quase 500 serviços eletrônicos que o cidadão pode ter sem precisar pegar fila, eu tenho que levar isso à comunidade, então eu tenho que abrir postos", argumenta Maria Amélia.

De forma geral, os coordenadores acreditam que esses objetivos estão sendo atingidos, porém ainda é difícil medir os seus impactos, devido à falta de mecanismos de gerenciamento eficientes, no caso de Porto Alegre, ou de metodologias capazes de mesurar o impacto, como cita Drica, do Acessa SP. 


\section{Quadro 30. Motivação para a criação do programa - Coordenadores}

\begin{tabular}{|c|c|c|}
\hline CPA & Nome & ação do programa? Quando foi criado? \\
\hline \multirow[t]{2}{*}{$\begin{array}{l}\text { Acessa São } \\
\text { Paulo }\end{array}$} & $\begin{array}{l}\text { Maria } \\
\text { Amélia }\end{array}$ & $\begin{array}{l}\text { Eu conversei muito com o Kobashi e o Fernando a respeito disso e eu acho que eles estão muito mais aptos do que eu, pra responder. Eu acho que eles sentiram a necessidade, assim } \\
\text { como eu farejei essa necessidade em outros programas pela demanda, na prática. Tem muita demanda, não tem oferta, e eu ia no Palácio: "pelo amor de Deus, me dá mais ‘8 ou } \\
\mathbf{8 0} \text { ', me põe em mais escolas”, implorava para as diretoras abrirem... possivelmente o mesmo sentimento os levou a isso. }\end{array}$ \\
\hline & $\begin{array}{l}\text { Ricardo } \\
\text { Kobashi }\end{array}$ & 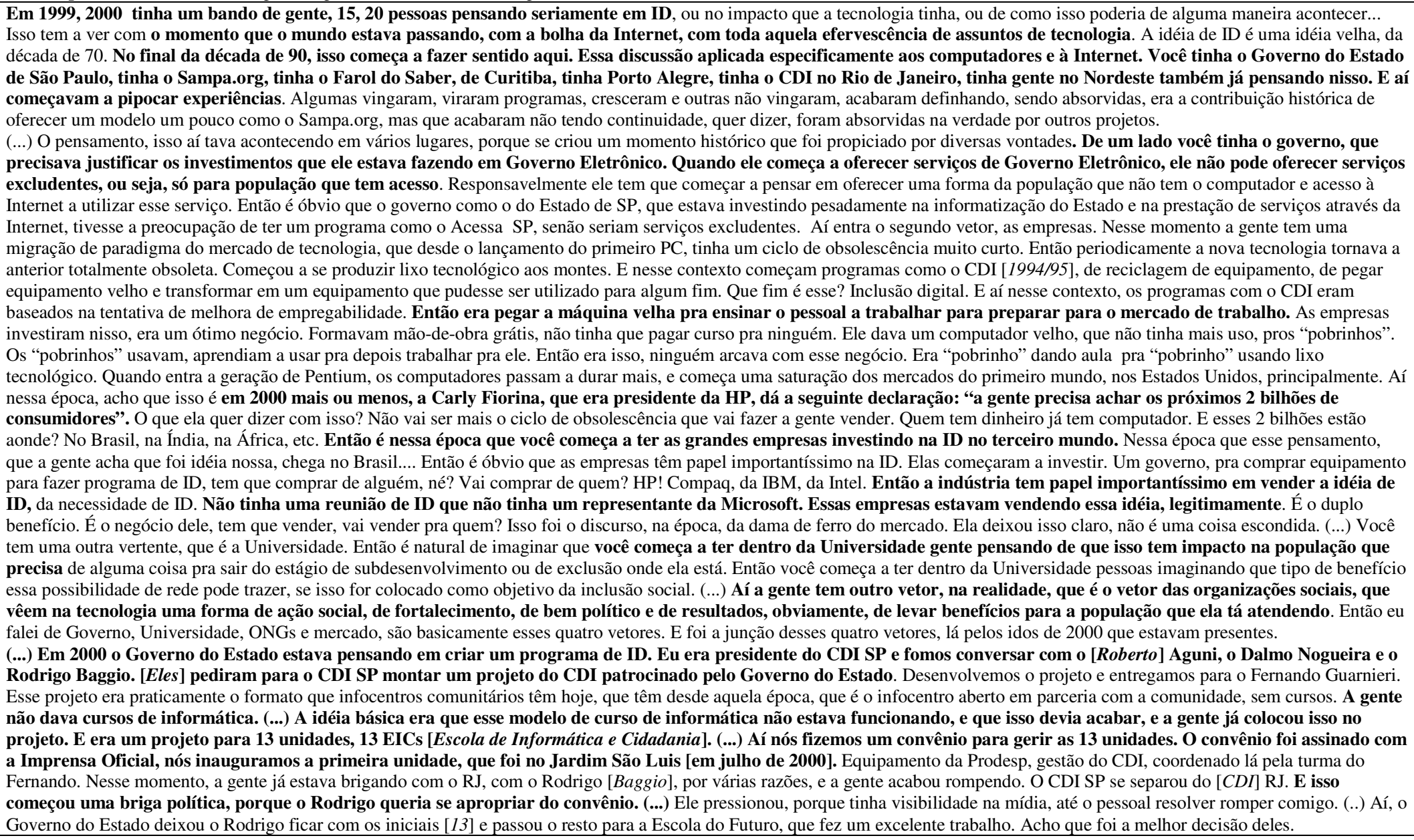 \\
\hline
\end{tabular}




\begin{tabular}{|c|c|c|}
\hline CPA & Nome & Qual foi a principal motivação para a criação do programa? Quando foi criado? \\
\hline & $\begin{array}{l}\text { Drica } \\
\text { Guzzi }\end{array}$ & $\begin{array}{l}\text { Tinha um contexto no próprio Governo do Estado, de Governo Eletrônico, de desenvolvimento. E então o contraponto social disso tudo era a ID, investir na ID como política } \\
\text { pública, não deixar que o mercado... esse é o ponto, você começar a perceber que o mercado não vai dar conta. Óbvio, por todas as intenções no mercado... e simplesmente as } \\
\text { pessoas não vão ter dinheiro para ter. (...) Então ficou cada vez mais evidente que essa questão de ID era uma questão importante, estratégica, de política pública e destinação } \\
\text { orçamentária. Aí entra essa mudança de paradigma do governo, que pára (...) de olhar para si para olhar para fora. (...) Toda essa mudança de paradigma na questão pública implica, } \\
\text { quase que naturalmente, em você ampliar os canais de relação com o cidadão. Uma das formas, é claro, é você utilizar as novas tecnologias. (...) Aí começou o programa. Tinha } \\
\text { uma questão forte na democratização dos saberes e, mais do que isso, da articulação desses saberes locais, entendeu? Uma comunidade tem seus conhecimentos, não aquele do } \\
\text { diploma, é um conhecimento de experiência de vida. E como a gente faz, utilizando novas tecnologias, para dar visibilidade para a própria comunidade? [Mostrar] que ela sabe tudo } \\
\text { aquilo... porque um sabe um, outro sabe outro, no final, todo mundo sabe muita coisa. Isso é uma visão utópica, inclusive, mas é essa a visão. }\end{array}$ \\
\hline \multirow{2}{*}{$\begin{array}{l}\text { Digitando o } \\
\text { Futuro }\end{array}$} & $\begin{array}{l}\text { Rosane } \\
\text { Pólli }\end{array}$ & $\begin{array}{l}\text { Do Digitando foi justamente isso, a oferta [de acesso], a parte da ID mesmo. Atender essa grande oferta pensando principalmente nesses bairros mais distantes, pessoas de baixa renda } \\
\text { que pudessem ter acesso ao computador. A Secretaria da Educação fez o contrato com o ICI, que era uma firma terceirizada que fazia esse serviço, [foi quem montou], quem } \\
\text { chamava estagiário, contratava, depois treinava. [Foi o Poder Público que decidiu montar o programa] Nós começamos com as reunióes já no mês de fevereiro de } 2000 \text { e a partir daí } \\
\text { começou a pipocar com os computadores indo aos poucos para os Faróis. Nós já tínhamos a estrutura dos Faróis, o que facilitou a montagem. }\end{array}$ \\
\hline & $\begin{array}{l}\text { Fabrício } \\
\text { Zanini }\end{array}$ & $\begin{array}{l}\text { A prefeitura naquele momento estava começando a disponibilizar muitas informações via Internet. Ela enxergava esse processo de inclusão não só como um processo de } \\
\text { responsabilidade social, mas também queria aproximar o cidadão do governo na parte de serviços, que o município na época estava começando a implantar. De } 2000 \text { até o ano } \\
\text { passado, quem fazia a coordenação do dia-a-dia era o ICI mais a [Secretaria da] Educação. Por que isso? Porque é um projeto feito em parceria e o ICI não só fez a infra-estrutura na } \\
\text { época, mas ele começou a fazer parte desse processo de gestão, porque esse projeto virou um dos projetos de responsabilidade social do ICI. }\end{array}$ \\
\hline $\begin{array}{l}\text { Telecentros } \\
\text { POA }\end{array}$ & $\begin{array}{l}\text { Leandro } \\
\text { Silva }\end{array}$ & $\begin{array}{l}\text { A informação que se tem é que o primeiro telecentro que nós temos é o telecentro no Chico Mendes, onde existe uma série de problemas relativos à violência, que é o foco da } \\
\text { Secretaria, atender às questões de segurança urbana. Havia um foco de violência, aquela comunidade demandou o projeto para a Administração Municipal. Assim, tivemos em } 2001 \text { a } \\
\text { primeira unidade. Foi de uma maneira crescente a instalação das unidades. De } 2001 \text { a } 2004 \text { teve a massificação do acesso para as camadas mais populares. Hoje, começa a segunda } \\
\text { parte do programa, a manutenção e efetivação do programa, a estruturação da matriz pedagógica, as questões legais, a questão da captação de recurso, a manutenção dos } \\
\text { equipamentos, a renovação do parque de máquinas. Esse segundo passo (...) é bem mais difícil, a gente pode assim considerar. [No início da gestão], em janeiro de } 2005 \text {, tínhamos } 17 \\
\text { telecentros regulares, e outros } 17 \text { irregulares, ou seja, sem convênio, sem repasse de recurso efetivo mensal, com uma série de dificuldades estruturais. Hoje, são } 28 \text { com convênio e com } \\
\text { repasse de recurso mensal regular para a manutenção de bolsas (R\$1.080,00 a } 1.380,00) \text {, isso com todas as garantias: Internet, enfim, a parte da manutenção. A meta para o ano de } 2006 \text { é } \\
\text { de } 40 \text { unidades. Temos como efetivá-la, recurso nós temos já no PPA, o Plano Plurianual. }\end{array}$ \\
\hline
\end{tabular}


Quadro 31. Objetivos do programa - Coordenadores

\begin{tabular}{|c|c|c|}
\hline $\boldsymbol{C P A}$ & Nome & ctos que ele pretende causar na comunidade? Ele está alcançando esses objetivos? \\
\hline \multirow[t]{2}{*}{$\begin{array}{l}\text { Acessa São } \\
\text { Paulo }\end{array}$} & $\begin{array}{l}\text { Maria } \\
\text { Amélia }\end{array}$ & $\begin{array}{l}\text { O macro é colocar à disposição da população novas ferramentas de tecnologia. Pra mim, nós estamos vivendo a revolução tecnológica, revolução digital, o mundo não é o mesmo } \\
\text { depois da Internet. Então vocế está dando acesso às novas tecnologias que vão dar para a população novas oportunidades, novos horizontes, e vão deixá-las num patamar mínimo } \\
\text { de ascensão social, de contatos com a cultura e até com a literatura... (...) O Rede de Projetos, na minha opinião, é o grande objetivo que a gente gostaria de ter. Assim como a } \\
\text { Internet é uma rede macro, nós gostaríamos que a comunidade formasse uma rede entre elas [porque] se a gente não se der a mão, se não houver a troca de informaçoes, vocêe } \\
\text { fica isolado, não cresce no ritmo que poderia. Então a Rede de Projetos é para que as pessoas pensem as suas comunidades e usem os postos do Acessa como ponto de apoio para um } \\
\text { trabalho integrado. (...) E tem o Governo Eletrônico. Dentro do Acessa você tem a comunidade podendo usufruir dos serviços eletrônicos do governo. Porque não adianta, se o governo } \\
\text { é moderno, se você pode tirar um B.O. eletrônico, são quase } 500 \text { serviços eletrônicos que o cidadão pode ter sem precisar pegar fila, eu tenho que levar isso à comunidade, então eu } \\
\text { tenho que abrir postos. (...) Eu acho que sim, [vem alcançando seus objetivos]. Há dois meses, começou, a partir da capacitação do Governo Eletrônico, um grupo, que é uma rede de } \\
\text { comunicação entre os monitores. Eu não participo dessa rede por falta de tempo, mas eu recebo e leio 70\% das trocas. Ontem eu entrei, era a menina de Paraguaçu Paulista falando para } \\
\text { uma outra: "calma, é assim mesmo, cai mesmo o link, não cai só á, cai em todo lugar, cai na sua casa, então não precisa se apavorar. Que bom, quando você estiver apavorada, escreve que } \\
\text { a gente te acalma". Aí eu não agüentei e escrevi, que maravilha, né? Isso é uma coisa muito simples que eu estou contando, porque outras, eu tenho visto o camarada dar dicas técnicas: } \\
\text { "olha, faz isso, pede pro técnico fazer isso, se o usuário não consegue ir por aqui, vai por ali". }\end{array}$ \\
\hline & $\begin{array}{l}\text { Ricardo } \\
\text { Kobashi }\end{array}$ & 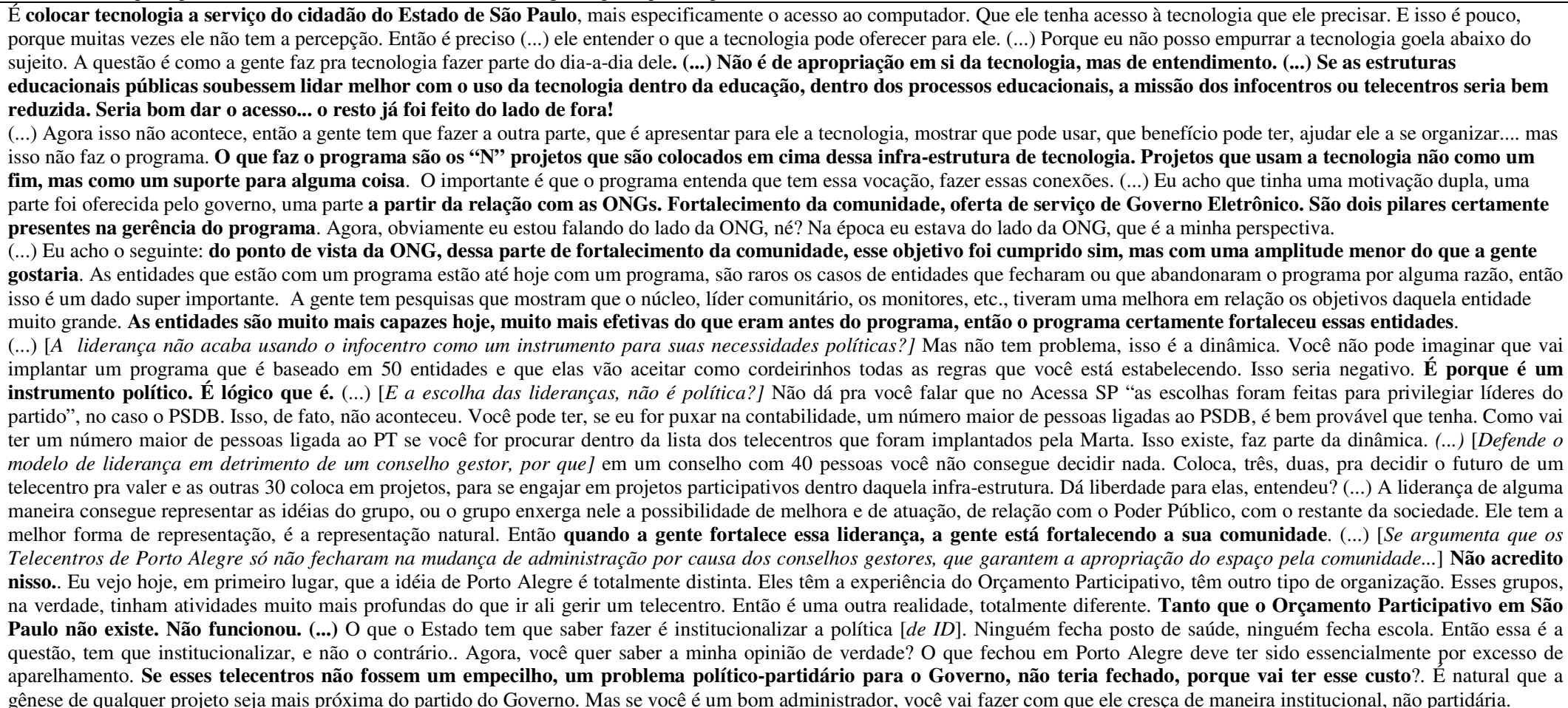 \\
\hline
\end{tabular}




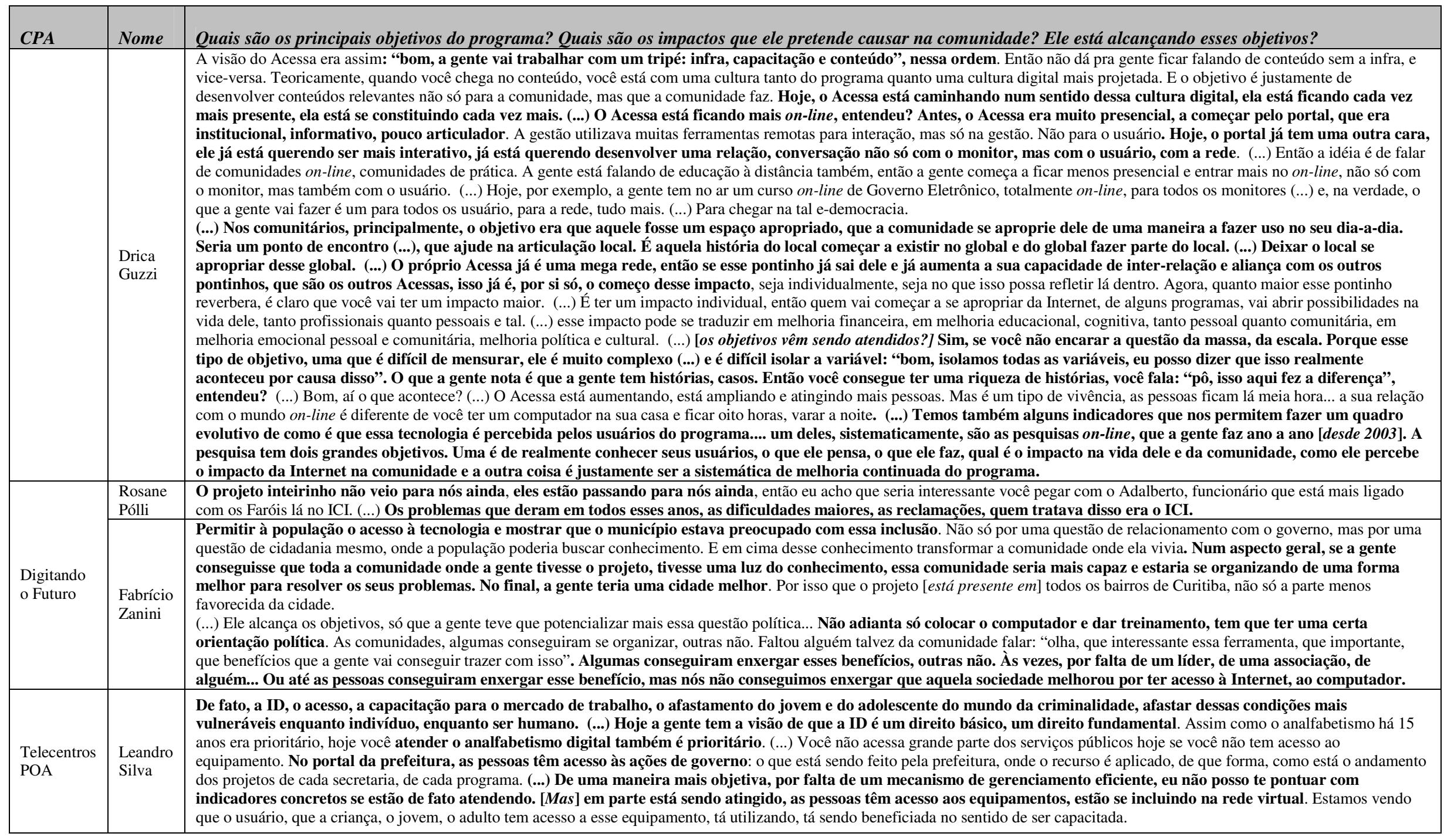


Quadro 32. Capacitação do usuário e desenvolvimento de atividades locais - Coordenadores

\begin{tabular}{|c|c|c|c|}
\hline CPA & Nome & $\begin{array}{l}\text { A coordenação se ocupa da capacitação do usuário e do desenvolvimento de } \\
\text { atividades no local? }\end{array}$ & $\begin{array}{l}\text { Se sim, quais são as atividades pedagógicas (ou não) desenvolvidas no } \\
\text { programa? Quem é o responsável pelo desenvolvimento destas atividades? }\end{array}$ \\
\hline \multirow[t]{3}{*}{$\begin{array}{l}\text { Acessa São } \\
\text { Paulo }\end{array}$} & $\begin{array}{l}\text { Maria } \\
\text { Amélia }\end{array}$ & $\begin{array}{l}\text { Nesse programa se ocupa [da capacitação dos monitores] e isso foi um foco bastante forte. Na } \\
\text { verdade, essa foi uma solicitação feita: nós queremos ampliar a capacitação, porque é uma coisa } \\
\text { que eu acredito, porque não é fácil ficar lá na ponta. Esse pessoal está lidando, muitas vezes, } \\
\text { com a extrema miséria do lado. Então você tem que dar um suporte psicológico, você tem } \\
\text { que dar ferramenta pra esse monitor, pra quem está lá na ponta. Eu não acredito que se possa } \\
\text { viabilizar qualquer coisa nessa direção se você não preparar o indivíduo. Até pra lidar com } \\
\text { valores, né? Apresentar para esse pessoal o Estatuto da Criança e do Adolescente, mostrar como } \\
\text { lidar com os deficientes (...), porque isso tudo é inclusão, todos merecem ter acesso à Internet. (...) } \\
\text { [Estão capacitando o usuário também?] Não. Nós estamos começando a capacitar as } \\
\text { lideranças... Ainda não podemos chegar a essa pretensão, porque é complicado. O que o } \\
\text { usuário está tendo é acesso a alguns pequenos cursos que tem no site, mas capacitar o } \\
\text { usuário não. O que acontece é que o monitor, ao ser capacitado, tem uma atuação exemplar, } \\
\text { como exemplo (...) ele amplia o horizonte por osmose. (...) [E o que acontece com um novo } \\
\text { usuário sem nenhuma experiência?] O monitor tá lá para isso, é uma tarefa dele. Tem até uma } \\
\text { história de um senhor, acho que é no metrô Sé. Ele chegou lá, tinha uns } 70 \text { anos e falou: "olha, } \\
\text { meus filhos tão querendo que eu compre um computador e eu não quero gastar dinheiro sem saber } \\
\text { se eu vou me dar bem com essa máquina, então eu vim aqui pra testar". E ficou indo vários dias } \\
\text { até que comprou um computador. Normalmente tem pessoas que não têm em casa, dependendo da } \\
\text { faixa etária, você precisa ensinar o bê-a-bá. Com o Rede de Projetos está acontecendo isso } \\
\text { [capacitação básica aos usuários em horários específicos]. Muitas entidades estão apresentando } \\
\text { projetos para isso. (...) Os [Infocentros] Comunitários estão uma oitava acima, mas agora estamos } \\
\text { conseguindo implantar isso no interior, que não tinha... não tinha nem capacitação e nós já estamos } \\
\text { no módulo três da capacitação. }\end{array}$ & $\begin{array}{l}\text { IOs monitores têm quatro módulos de capacitação, desenvolvidos pela Escola do } \\
\text { Futuro, da USP: I - Inclusão Digital e Acessa Livre, explica a dinâmica de } \\
\text { funcionamento de um Posto Acessa SP e apresenta as ferramentas necessárias para o } \\
\text { trabalho dos monitores. II - Agentes de Inovação e Governo Eletrônico, trata da } \\
\text { cultura da inovação, destacando o papel do monitor como Agente de Inovação e } \\
\text { apresenta um conjunto de iniciativas com foco no cidadão que se viabiliza pelo uso } \\
\text { das tecnologias. III - Produção colaborativa, destaca o software livre, as } \\
\text { ferramentas de colaboração e a propriedade intelectual nestes tempos de cultura } \\
\text { livre, e apresenta a Rede de Projetos, estimulando novos usos para os postos Acessa. } \\
\text { IV - Excelência no Atendimento e voluntariado]. (...) [O monitor é sempre estimulado } \\
\text { a trazer as novidades?] É lógico, aliás é pra isso essas capacitações. Nesse grupo, } \\
\text { quando nós demos a capacitação sobre Governo Eletrônico (...) dobrou o número de } \\
\text { usuários. Nós estamos abrindo a cabeça do monitor, ele é a nossa ferramenta para } \\
\text { estimular essa comunidade a potencializar o uso da Internet, sem ser com essas } \\
\text { coisas lugares-comum [MSN, Orkut, etc] que são, por enquanto, o ponto alto, } \\
\text { mas que eu acho que foi a isca, entendeu?. }\end{array}$ \\
\hline & $\begin{array}{l}\text { Ricardo } \\
\text { Kobashi }\end{array}$ & $\begin{array}{l}\text { Não. Mas temos parceria com a Escola do Futuro, com a Fundap... O que a gente está } \\
\text { fazendo é o seguinte: a gente está procurando utilizar a Internet para oferecer uma gestão } \\
\text { transparente e participativa. Então a gente põe um blog que é escrito pelos coordenadores. } O \\
\text { usuário pode comentar, reclamar, tudo aquilo. }\end{array}$ & $\begin{array}{l}\text { Só pra acabar a parte do blog, o que acontece, tem esse blog e aí agora eu vou } \\
\text { começar a postar sobre as decisões que a gente toma nos programas. E vamos ver } \\
\text { que tipo de comentário a gente tem dos monitores e dos usuários. A gente vai se } \\
\text { aproximando do dia-a-dia. Agora eu vou começar a falar sobre os programas que a } \\
\text { gente está fazendo, falar sobre os problemas operacionais que a gente teve. E a gente } \\
\text { também tem um fotolog. }\end{array}$ \\
\hline & $\begin{array}{l}\text { Drica } \\
\text { Guzzi }\end{array}$ & $\begin{array}{l}\text { Sim, muitas. Tem as capacitações [dos monitores]. O monitor é o multiplicador. E para o } \\
\text { usuário, a gente tem as apostilas, caderno eletrônico, os mini cursos... O próprio portal [do } \\
\text { Acessa] está começando a articular mais conteúdos, blogs... (...) A questão do curso entra muito } \\
\text { numa percepção de "eu não sei, eu vou aprender com o curso, o outro vai me ensinar, o outro que } \\
\text { tem o saber, me dá"... (...) O grande problema do curso não é tanto ele em si, mas o que ele } \\
\text { gera de ilusão. Que eu vou conseguir emprego... Conseguir emprego, né? "Eu tenho o } \\
\text { certificado, escrevo casa com "z", mas tudo bem, eu tenho o curso do Word". (...) [O que a } \\
\text { pessoa que nunca usou a Internet precisa] é de uma estratégia de sensibilização. É por isso que } \\
\text { vem o PIM [Passaporte de Internet e Multimídia, programa que entre outros tinha o objetivo de } \\
\text { registrar as habilidades aprendidas e as atividades realizadas na Internet, através de uma forma } \\
\text { lúdica de auto-aprendizado, lançado em } 2004 \text { e descontinuado]. }\end{array}$ & $\begin{array}{l}\text { [Além das capacitações], tem a Rede de Projetos [usuários apresentam projetos } \\
\text { comunitários para uso do infocentro] }\end{array}$ \\
\hline
\end{tabular}




\begin{tabular}{|c|c|c|c|}
\hline$C P A$ & Nome & $\begin{array}{l}\text { A coordenação se ocupa da capacitação do usuário e do desenvolvimento de } \\
\text { atividades no local? }\end{array}$ & $\begin{array}{l}\text { Se sim, quais são as atividades pedagógicas (ou não) desenvolvidas no } \\
\text { programa? Quem é o responsável pelo desenvolvimento destas atividades? }\end{array}$ \\
\hline \multirow[b]{2}{*}{$\begin{array}{l}\text { Digitando o } \\
\text { Futuro }\end{array}$} & $\begin{array}{l}\text { Rosane } \\
\text { Pólli }\end{array}$ & $\begin{array}{l}\text { Há cursos para os usuários, que eram responsabilidade do ICI e agora passam a ser } \\
\text { responsabilidade da Gerência de Faróis. }\end{array}$ & $\begin{array}{l}\text { Teve um projeto Luz das Letras, que era parte da alfabetização de adultos, isso } \\
\text { era feito nos Faróis. Acho que há uns três anos atrás, mais ou menos, usando os } \\
\text { micros do Farol lá no mezanino, mas esse projeto era do governo, acabou } \\
\text { passando... }\end{array}$ \\
\hline & $\begin{array}{l}\text { Fabrício } \\
\text { Zanini }\end{array}$ & $\begin{array}{l}\text { Até dezembro a gente está com parceria com algumas Universidades onde os alunos estavam } \\
\text { promovendo treinamento de forma gratuita para a população. Por exemplo, na semana que } \\
\text { vem tem o CDI num lugarzinho onde se promove a semana de ID. A gente participava fortemente } \\
\text { desses eventos, tentamos levar profissionais que dessem palestras do que era ID, para ver como } \\
\text { estava melhorando esse processo como um todo. }\end{array}$ & $\begin{array}{l}\text { Curso com uma carga horária de } 10 \text { a } 20 \text { horas, dependendo do módulo, com } \\
\text { apostilas, com uma ferramenta de e-learning. Fazíamos parcerias para que isso } \\
\text { acontecesse em todos os cantos, sob a coordenação do ICI. }\end{array}$ \\
\hline $\begin{array}{l}\text { Telecentros } \\
\text { POA }\end{array}$ & $\begin{array}{l}\text { Leandro } \\
\text { Silva }\end{array}$ & $\begin{array}{l}\text { Nós não desenvolvemos atividades in loco. Estamos articulando parceiros. [Haverá uma } \\
\text { Conferência Municipal de Ciência e Tecnologia nos próximos dias], onde vai ter várias temáticas: } \\
\text { e-gov, cidadania, empreendedorismo nos ambientes de ID, as questões de pedagogia, tipo de } \\
\text { oficina... Porque hoje ainda não tem uma linha-mestra na questão digital, porque a equipe é muito } \\
\text { pequena, são somente quatro pessoas junto à coordenação do projeto para todas as unidades da } \\
\text { cidade. Então foi dada prioridade pelas questões estruturais, conveniais, legais... A gente depende } \\
\text { de muitos parceiros, o projeto só se sustenta através de parceiros. A prefeitura não pode } \\
\text { gerir todas as áreas. }\end{array}$ & $\begin{array}{l}\text { Se a comunidade resolve usar a sala para cursos de informática, não há } \\
\text { problema, porque em média os telecentros funcionam } 12 \text { horas por dia. O uso é } \\
\text { livre... A gestão é coletiva (...) É a entidade que vai disponibilizar oficinas de } \\
\text { informática básica para a comunidade com os fins pedagógicos, as características } \\
\text { locais que ela achar importante. [jovens, público vulnerável...]. Para impressão existe } \\
\text { uma taxa simbólica para o custeio. }\end{array}$ \\
\hline
\end{tabular}


Como foi apresentado no quadro anterior, a capacitação dos usuários é tanto um objetivo dos programas - talvez um dos mais básicos - como uma necessidade, para que o cidadão possa efetivamente usufruir dos benefícios trazidos pela informática e pelo acesso à Internet (quadro 32). Entretanto, a maneira como esse conhecimento deve ser adquirido, a forma como deve ser aplicado e a responsabilidade pela instrução do usuário são vistas de maneiras muito distintas pelos programas investigados.

No Acessa SP não são oferecidos cursos básicos ao usuário iniciante, mas há uma ampla estratégia de capacitação do monitor e das lideranças comandada pela Escola do Futuro da USP, desde o início do programa. “O monitor é o multiplicador”, explica Drica, é ele quem vai ensinar os primeiros passos na rede para aqueles que nunca tiveram o contato com o computador, assim como ser uma referência para o usuário. "Ele é a nossa ferramenta para estimular essa comunidade a potencializar o uso da Internet... ele amplia o horizonte por osmose", diz Maria Amélia. Para os usuários que já navegam o Acessa SP oferece mini-cursos e apostilas no site, e a possibilidade de se desenvolver atividades coletivas usando a infra-estrutura do infocentro - que podem inclusive ser cursos - através da Rede de Projetos. "O próprio portal [do Acessa] está começando a articular mais conteúdos, blogs...”, conta Drica, argumentando que os cursos criam a falsa expectativa para o usuário de que com um certificado ele vai conseguir arrumar um emprego. "O grande problema do curso não é tanto ele em si, mas o que ele gera de ilusão”, pondera. Para ela, o que o novo usuário precisa é de uma estratégia de sensibilização para o uso da infra-estrutura, e não de cursos.

No Digitando o Futuro, durante a coordenação do ICI, o programa oferecia cursos com módulos de até 20 horas e ferramentas de e-learning em parceria com algumas Universidades. Sob a nova coordenação esses cursos passam a ser responsabilidade da Gerência de Faróis do Saber. Nenhuma menção foi feita com relação ao treinamento dos monitores. Nos Telecentros POA não há atividades pedagógicas desenvolvidas pela coordenação, nem para usuários, nem para monitores. "Hoje ainda não tem uma linhamestra na questão digital, porque a equipe é muito pequena, são somente quatro pessoas junto à coordenação do projeto para todas as unidades da cidade. A gente depende de muitos parceiros... A prefeitura não pode gerir todas as áreas", tergiversa Leandro. Entretanto, as entidades que abrigam as unidades do programa têm liberdade para oferecer "oficinas de informática básica para a comunidade com os fins 
pedagógicos, as características locais que ela achar importante", completa. As associações normalmente têm parcerias com diferentes ONGs, como a Pensamento Digital, que elaboram o programa pedagógico nas unidades, incluindo ainda temas como cidadania e empreendedorismo.

Segundo os coordenadores entrevistados, as atividades na Internet mais realizadas pelos usuários nos CPAs (quadro 33) são Orkut, MSN, e-mail, bate-papo e pesquisa, com exceção do Digitando o Futuro, que proíbe sites de relacionamento e comunicação multimídia: "Eles procuram muito agendar horário para ficar no bate-papo, e quem precisa realmente para pesquisa, acaba tendo dificuldade de agendamento e a gente começou a ter bastante reclamação", conta Rosane, explicando que no momento a coordenação discute se deve ou não permitir esse acesso. "Eu realmente acho que a gente deve deixar livre, porque também é uma forma de expressão", completa. Os coordenadores do Acessa SP defendem o uso dessas ferramentas de comunicação: "Quando ele está num chat, ele está se relacionando, ele está se apropriando de uma ferramenta, ele está se desenvolvendo, se expressando", conclui Drica. A redação e envio de currículos também se constituem como práticas constantes em todos os programas. Consideradas atividades mais "nobres", assim como o acesso a serviços de governo eletrônico, elas justificam o investimento nos programas. "Se você tem um indivíduo hoje que está fora do mercado de trabalho porque ele não está capacitado adequadamente, então a gente tem que tentar instrumentalizar esse sujeito", argumenta Leandro. Todos restringem o acesso a conteúdos pornográficos e há limitação para jogos, que variam em cada CPA.

Para os coordenadores, o uso dado aos CPAs pelos usuários correspondem - total ou parcialmente - aos objetivos dos programas. As atividades lúdicas e de relacionamento são consideradas importantes porque desenvolvem o raciocínio, as habilidades de trabalho em rede e em colaboração. "Você quer que o cara conheça pessoas, saiba se comunicar, forme comunidades, participe, vença as barreiras físicas e as barreiras de renda? Isso tudo ele faz no Orkut. Mas por que é mal visto? Porque é uma atividade de lazer, não é uma atividade que tem fundo profissional", argumenta Kobashi. Partilhando do mesmo ponto de vista, Drica complementa que o uso pode corresponder parcialmente se for considerado que “ (...) a Internet tem um monte de outras coisas que 
ele pode desenvolver e aprender. Ele podia se aproveitar mais da rede em termos de informação, em termos de abrir espaço...”. E então apresenta o grande problema para essa apropriação: “As pessoas têm uma questão cultural muito complicada. (...) Estamos falando de um nível educacional [muito baixo]. É uma dificuldade de leitura complicada. A dificuldade de produção de sentido é algo de você ficar estupefato", relata. Para Leandro, a única preocupação é que o telecentro não se transforme em uma "Lanhouse pública”.

Com relação ao impacto da Internet no consumo e produção de informação (quadro 34), é unânime a afirmação de que o acesso contribui para o consumo de informação, porém em diferentes níveis. Maria Amélia, Rosane e Fabrício argumentam que agora o usuário tem acesso a um universo maior e mais rico de informações, principalmente o de baixa renda, que não tem condições de comprar jornais e revistas. Para Kobashi, a Internet obriga a pessoa a ler, principalmente a meninada que não têm o hábito da leitura:

Você abre o site e o que você faz?, você tem que ler. Então, se ele começa pelo futebol, ótimo. Não podemos esquecer [que] essa meninada tem um interesse, você não vai mudar o interesse dela com inclusão digital. Ele vê a notícia do time dele (...) Porque senão ele só ia escutar rádio e ia conversar com os amigos e não ia aprender. Porque o jornal ele não lê. Então ele vai entrar onde tiver conteúdo grátis pra ele ler sobre o time. Ele combina a manchete, vai ver uma outra coisa, ele vai pro fraquíssimo conteúdo que a gente tem para essa população.

Drica lembra entretanto que a experiência de consumo de informação do usuário no CPA não é a mesma de quem fica uma tarde inteira navegando em casa. " $E$ diferente (...) um menino que está lá acessando 30 minutos por vez, com um menino que está lá acessando seis horas por dia a Internet. Eu não posso comparar. Essa questão do tempo digital é o tempo que você fica submerso, é o tempo de mergulho, faz diferença, não tem jeito".

Segundo Leandro, em Porto Alegre, onde a participação popular em questões políticas é maior, a busca de informação tem objetivos mais específicos: "As unidades em Associações de Moradores que têm algum programa de geração de trabalho e renda vão ali buscar informações para o benefício dessas associações, dessas cooperativas", diz. 
No que tange a produção de informação, a contribuição dos programas se limita à disponibilização de ferramentas e, em alguns casos, ao desenvolvimento de atividades que incentivem a prática da expressão escrita e da comunicação. No caso do Acessa SP, a coordenação vem estimulando a participação de monitores - e usuários - nos blogs desenvolvidos no website do programa para a troca de experiência e informações. Kobashi lembra, entretanto, que são poucos os produtores de informação, em qualquer segmento da sociedade:

[O usuário vai] comentar no blog, mas não escrever blog. Acho que essa é a diferença. (...) O que eu quero dizer é que esse protagonismo, não é pra todo mundo, não é? (...) Por que eu vou querer que o Zezinho lá abra um blog, por quê? Você precisaria de blog? Cansa ter blog, dá um enorme de um trabalho, você tem que ter um objetivo muito forte. (...) Mas se alguém quiser, tem que ter condições de fazer, entendeu?

Para Drica já é possível se identificar bons resultados nas atividades desenvolvidas no programa através da Rede de Projetos: "No primeiro ciclo, já temos 38 projetos prontos funcionando, e mais 42 projetos esperando para entrar no funcionamento. Só nisso, são quase 100 projetos. Isso tudo é produção de conteúdo local...”, contabiliza.

Para Fabrício essa contribuição é muito pequena, e "algumas comunidades desenvolveram de forma espontânea e não controlada alguns sites hospedados em servidores gratuitos...”. Leandro acrescenta que essa prática depende da capacitação e do interesse do usuário, e que "cada comunidade utiliza o equipamento de uma maneira". 


\section{Quadro 33. Atividades realizadas na Internet - Coordenadores}

\begin{tabular}{|c|c|c|}
\hline CPA & Nome & incia, quais são as atividades na Internet mais realizadas nos centros públicos pelos usuários? Elas correspondem aos objetivos do programa? \\
\hline \multirow{3}{*}{$\begin{array}{l}\text { Acessa São } \\
\text { Paulo }\end{array}$} & $\begin{array}{l}\text { Maria } \\
\text { Amélia }\end{array}$ & $\begin{array}{l}\text { E-mail, MSN, Orkut... é o que mais tem, não tem nada mais a acrescentar. Com o tempo, a gente pretende mostrar que tem outras opções [de atividades]. É assim, não é patrulha, a gente } \\
\text { quer mostrar, mas a gente não pode direcionar o uso, entendeu? Mas a moçada quer blog, quer o Orkut. } \\
\text { [Essas atividades correspondem aos objetivos do programa], está dando certo. Porque se você faz parte de um Orkut ou de um blog, você tem acesso a outras coisas, é muito rico o que } \\
\text { se passa nessas comunidades, amplia o horizonte do mesmo jeito, então eu acho que sim. Tanto que nós não estamos mudando de estratégias, nós só estamos tentando cada vez arejar } \\
\text { mais, mostrar mais, mas eu acho que está totalmente no caminho. É o que eles querem. }\end{array}$ \\
\hline & $\begin{array}{l}\text { Ricardo } \\
\text { Kobashi }\end{array}$ & $\begin{array}{l}\text { Olha, a gente tem os best-sellers assim, né? Currículo é um best-seller. Orkut é um best-seller. Concursos de maneira geral, todos os concursos que aparecem, porque agora todo mundo } \\
\text { faz cadastro pela Internet. (...) O Orkut na verdade foi uma bênção para as pessoas. O cara aprende a trabalhar em rede na Internet com um objetivo muito claro, que no caso dele é se } \\
\text { dar bem, é arrumar uma namorada, arrumar uma turma pra sair. Aprende a fazer isso independente da classe social, do lugar onde mora, etc., você se comunica com o Brasil } \\
\text { inteiro, com quem fale em língua portuguesa. Você quer que o cara conheça pessoas, saiba se comunicar, forme comunidades, participe, vença as barreiras físicas e as barreiras de renda? } \\
\text { Isso tudo ele faz no Orkut. Mas por que é mal visto? Porque é uma atividade de lazer, não é uma atividade que tem fundo profissional. Mas essa atividade de lazer o habilita, } \\
\text { naquela ferramenta, naquelas dinâmicas de troca de informação, de agrupamento, de colaboração, a fazer isso com qualquer outro objetivo, não só o o de arrumar namorada. Para } \\
\text { essas pessoas, pra essa molecada, você ter um grupo de conversa, de troca, é super importante. Porque ela passa a ter uma referência mais ampla. Isso é inclusão. }\end{array}$ \\
\hline & $\begin{array}{l}\text { Drica } \\
\text { Guzzi }\end{array}$ & $\begin{array}{l}\text { E-mail, chat, bate-papo, jogo, pesquisa escolar... Orkut agora também. Currículo também aparece, mas não... antes vem o e-mail. Mas buscar emprego sempre está presente... [Esses usos } \\
\text { correspondem aos objetivos do projeto?] Parcialmente. Quando ele está num chat, ele está se relacionando, ele está se apropriando de uma ferramenta, ele está se desenvolvendo, se } \\
\text { expressando, enfim. Então, nesse sentido, ele corresponde totalmente, 100\%. No jogo também, ele está desenvolvendo uma série de estratégias de raciocínio... Mas a questão é parcial } \\
\text { porque (...) a Internet tem um monte de outras coisas que ele pode desenvolver e aprender. Ele podia se aproveitar mais da rede em termos de informação, em termos de abrir espaço... Sabe } \\
\text { qual é o problema? As pessoas têm uma questão cultural muito complicada. Existe uma coisa meio submissa, sabe? Ela fala assim: “não me falaram como é”... Você fica naquele } \\
\text { quadrado... Mas é claro, a gente não pode esquecer uma coisa fundamental, que é o nível educacional das pessoas. Estamos falando de um nível educacional [muito baixo]. É uma } \\
\text { dificuldade de leitura complicada. A dificuldade de produção de sentido é algo de você ficar estupefato. }\end{array}$ \\
\hline \multirow[b]{2}{*}{$\begin{array}{l}\text { Digitando } \\
\text { o Futuro }\end{array}$} & $\begin{array}{l}\text { Rosane } \\
\text { Pólli }\end{array}$ & $\begin{array}{l}\text { Olha, os Faróis atendem mais o Ensino Fundamental, essa é a nossa maior clientela. A faixa etária é mais de jovens. O que eles realmente querem é o Orkut, isso aí que nós até não } \\
\text { estamos deixando acessar no momento, porque o que acontece é o seguinte: eles procuram muito agendar horário para ficar no bate-papo, e quem precisa realmente para } \\
\text { pesquisa, acaba tendo dificuldade de agendamento e a gente começou a ter bastante reclamação. No momento é uma discussão se nós continuamos deixando ou não. Eu realmente acho } \\
\text { que a gente deve deixar livre, porque também é uma forma de expressão. Então é mais usado para pesquisa, é para a pesquisa que eles precisam realmente, e jogos também. Alguns jogos sã } \\
\text { permitidos, não todos. Os sites pornô são bloqueados. Também fazem muita impressão de currículo, e isso corresponde com os objetivos iniciais do projeto. }\end{array}$ \\
\hline & $\begin{array}{l}\text { Fabrício } \\
\text { Zanini }\end{array}$ & $\begin{array}{l}\text { O pessoal usa bastante para fazer algumas pesquisas escolares, para ficar navegando em sites... principalmente assim, a Ana Maria Braga fala que tem alguma coisa, o pessoal va } \\
\text { Vai ter show do Sandy \& Júnior, a meninada vai. O nosso maior público até o ano passado eram jovens } 11 \text { a } 17 \text { anos, então, o que eles querem: Esporte, música, coisas que às vezes até } \\
\text { uma outra mídia, como a TV esteja forçando... Nem sempre [as atividades correspondem aos objetivos do projeto]. Mas se você pegar o foco de ID, essas pessoas estão sendo } \\
\text { incluídas. Talvez hoje elas não estejam utilizando da forma mais adequada, mas quando elas precisarem, ela conhecem o canal, sabem como buscar. Tivemos que implementar algumas } \\
\text { limitações por uma questão técnica, de limitação de recurso. Por maior que seja a nossa rede, a gente tem sempre uma demanda maior do que a oferta, e esses programas - MSN, Orkut, etc. } \\
\text { - estavam consumindo muita banda. O serviço estava muito lento para os outros usuários. E começamos a ter muita reclamação: poxa, eu quero fazer uma pesquisa, eu quero entrar num } \\
\text { serviço e tem lá um menino de } 12,13 \text { anos que tá lá no Orkut ou no MSN mandando bala. Então a gente tinha esse parâmetro: "pô, mas ele tá se incluindo, mas ao mesmo tempo ele está"... } \\
\text { então a gente teve muitos problemas. }\end{array}$ \\
\hline $\begin{array}{l}\text { Telecentros } \\
\text { POA }\end{array}$ & $\begin{array}{l}\text { Leandro } \\
\text { Silva }\end{array}$ & $\begin{array}{l}\text { Cada local é diferenciado. Cada realidade é diferenciada. Alguns telecentros têm um perfil mais pedagógico, são efetivamente muito mais oficinas do que acesso livre. Somente acesso } \\
\text { pornografia é proibido. Algumas unidades permitem (MSN, Orkut), outras não. (...) Eu posso dizer de uma maneira geral o que se percebe. Até por não ter uma matriz definida, uma linha } \\
\text { mestra. E isso a gente não quer simplesmente impor, porque alguns têm a visão de que tem que deixar o equipamento ali para a pessoa fazer o que ela bem entender, com algumas restrições } \\
\text { sem uma orientação adequada para isso. Só que essa é uma visão um pouco de uma Lanhouse pública, a gente quer diferir disso, a gente quer que ele tenha um fim pedagógico adequado } \\
\text { Que esse recurso público seja investido adequadamente. Outras acham que devem sim, tem que possibilitar àquele indivíduo que jamais teve acesso a isso. Nós pensamos que, de fato, tem } \\
\text { que atender aos fins pedagógicos. Se esse usuário estiver num estágio mais avançado, acho que até pode ter acesso a essas outras questóes que são, dentro da ID, questões de lazer } \\
\text { culturais, mais de redes de relacionamentos (MSN, Orkut, bate-papo). Mas, se você tem um indivíduo hoje que está fora do mercado de trabalho, porque ele não está capacitado } \\
\text { adequadamente, então a gente tem que tentar instrumentalizar esse sujeito pelos mais diferentes mecanismos para que ele se enquadre naquilo que o mercado de trabalho hoje exige. } \\
\text { Isso é um exemplo, mas pontualmente se acessa, são feitas pesquisas escolares, currículos. }\end{array}$ \\
\hline
\end{tabular}




\begin{tabular}{|c|c|c|c|}
\hline CPA & Nome & $\begin{array}{l}\text { De que maneira você imagina que o programa contribui para o consumo de } \\
\text { informação pela comunidade local? }\end{array}$ & $\begin{array}{l}\text { De que maneira você imagina que o programa contribui para a produção de } \\
\text { informação pela comunidade local? }\end{array}$ \\
\hline \multirow{3}{*}{$\begin{array}{l}\text { Acessa São } \\
\text { Paulo }\end{array}$} & $\begin{array}{l}\text { Maria } \\
\text { Amélia }\end{array}$ & $\begin{array}{l}\text { Ele pode consumir, ele pode abrir uma revista Veja, um jornal, pega as principais } \\
\text { manchetes, tudo o que tem a respeito de literatura, enfim, eu acho que contribui } \\
\text { totalmente. Eu não vou comparar ao rádio, porque o rádio é imbatível nessas } \\
\text { comunidades, mas eu acho que contribui até pra uma seleção melhor de informações do } \\
\text { que a própria televisão. Por exemplo: você pega um blog dum jornalista, você tem uma } \\
\text { informação muito melhor do que a que você tem no jornal. Aí o nosso menino da } \\
\text { periferia vai ter acesso a esses blogs. }\end{array}$ & $\begin{array}{l}\text { Ele contribui como uma ferramenta, porque dentro do projeto você está potencializando, } \\
\text { né? Eu acho que fomenta bastante. Já temos sites criados, Votuporanga tem um site... } \\
\text { Contribui muito, porque é a chance que eles têm, né? (...) Nesse processo, eu estou lidando } \\
\text { com ser humano. Então tem monitores que são [bons] e tem monitores médios e tem } \\
\text { monitores que não dão. Alguns nós trocamos, outros é o prefeito que contrata, não dá pra fazer } \\
\text { o que a gente pensa, a gente aponta, mas tudo isso vai depender (...) da pessoa que está lá, com } \\
\text { a sensibilidade toda, sem obrigar, sem induzir, propiciando, a palavra é essa. }\end{array}$ \\
\hline & $\begin{array}{l}\text { Ricardo } \\
\text { Kobashi }\end{array}$ & $\begin{array}{l}\text { Sim. (...) o bate-papo, o computador aumentou o índice de leitura da molecada. (...) } \\
\text { Internet é sobre leitura, né? Você abre o site e o que você faz?, você tem que ler. } \\
\text { Você começa a ler e não tem o que fazer. E essa meninada não lê. E quando ele } \\
\text { começar a entender um texto de futebol, de política, de filosofia, o cara já começou a } \\
\text { entender um texto. Então, se ele começa pelo futebol, ótimo. Não podemos esquecer } \\
\text { [que] essa meninada tem um interesse, você não vai mudar o interesse dela com } \\
\text { ID. Ele vê a notícia do time dele (...) Porque senão ele só ia escutar rádio e ia conversar } \\
\text { com os amigos e não ia aprender. Porque o jornal ele não lê. Então ele vai entrar onde } \\
\text { tiver conteúdo grátis pra ele ler sobre o time. Ele vai no Orkut pra ele poder ficar } \\
\text { azarando com a meninada. Ele combina a manchete, vai ver uma outra coisa, ele vai } \\
\text { pro fraquíssimo conteúdo que a gente tem para essa população. }\end{array}$ & $\begin{array}{l}\text { Na realidade, ajuda a absorção de informação. Ele só produz quando ele absorve. É o } \\
\text { passo } 1 . \text { E o passo } 2 \text { é o que a gente tem que tenta mostrar, é como você pode disseminar a } \\
\text { informação através da Internet. A gente está tentando, no nosso dia-a-dia: com blog, } \\
\text { fotolog, com o nosso próprio site. (...) Isso é um objetivo que a gente persegue } \\
\text { insistentemente, mas que é muito difícil, porque tem que querer. A gente está dando as } \\
\text { ferramentas, a gente vai provocando... O projeto de ID não pode ser apoiado em notícias, } \\
\text { numa agênncia de notícia... Você consegue ter alguns [produtores de informação]..(...) O } \\
\text { Acessa SP procura ser o local que abraça os projetos das comunidades. E a gente tem que } \\
\text { tomar muito cuidado para não inverter isso, pra gente não ser "outros projetos". Nós somos } \\
\text { viabilizadores desses projetos. (...) } O \text { O usuário vai] comentar no blog, mas não escrever blog. } \\
\text { Acho que essa é a diferença. (...) O que eu quero dizer é que esse protagonismo, não é pra todo } \\
\text { mundo, não é? (...) Por que eu vou querer que o Zezinho lá abra um blog, por quê? Você } \\
\text { precisaria de blog? É chato ter blog, cansa ter blog, dá um enorme de um trabalho, você tem } \\
\text { que ter um objetivo muito forte. (...) Mas se alguém quiser, tem que ter condições de fazer, } \\
\text { entendeu? }\end{array}$ \\
\hline & $\begin{array}{l}\text { Drica } \\
\text { Guzzi }\end{array}$ & $\begin{array}{l}\text { Eu acho que ele contribui sim. Contribui, por mais que fiquem em Chat. Mas é } \\
\text { diferente (...) um menino que está lá acessando } 30 \text { minutos por vez, com um } \\
\text { menino que está lá acessando seis horas por dia a Internet. Eu não posso comparar. } \\
\text { Essa questão do tempo digital é o tempo que você fica submerso, é o tempo de } \\
\text { mergulho, faz diferença, não tem jeito. Tem gente que não atravessa a rebentação, } \\
\text { entendeu? Você põe o pé, vai lá, mas não mergulhou. Se você não tem tempo, você não } \\
\text { consegue ter um nível de apropriação desse negócio. Agora, esse cara que tem acesso } \\
\text { ao infocentro, ele está mais exposto à informação sim, isso sem dúvida, querendo } \\
\text { ou não, ele está se informando um pouco mais.. Mesmo nesses } 30 \text { minutos, que é um } \\
\text { mergulhinho, repetidamente, ele vai avançando, entendeu? Aos poucos, ele vai } \\
\text { entrando no mar. (...) Então, na somatória, ele está entrando mais. Alguns estão } \\
\text { fazendo um uso melhor ou pior disso, mais uma vez, é muito pessoal... (...) E a } \\
\text { questão não é só a informação em si, é a questão da simultaneidade das } \\
\text { informações, do Chat, da conversa. Você faz tudo ao mesmo tempo. E isso faz } \\
\text { diferença. Essa é uma habilidade cognitiva nova que está se instalando. }\end{array}$ & $\begin{array}{l}\text { O Acessa hoje tem alguns programas oficiais que estimulam essa produção. Ele trabalha } \\
\text { com várias formas e táticas para o estímulo da produção de conteúdo. Então seja num } \\
\text { programa como uma Rede de Projetos, que é justamente você dar a oportunidade das pessoas } \\
\text { construírem os seus projetos e conteúdos utilizando essas tecnologias, seja quando o próprio } \\
\text { site começa a querer conversar mais, saber o que você pensa, pra onde você pode ir. Por } \\
\text { exemplo, a Rede de Projetos retomou. No primeiro ciclo, já tem } 38 \text { projetos prontos } \\
\text { funcionando, e mais } 42 \text { projetos esperando para entrar no funcionamento. Só nisso, são } \\
\text { quase } 100 \text { projetos. Isso tudo é produção de conteúdo local, porque efetivamente, o que a } \\
\text { gente dá são as ferramentas e aconselhamentos, mas a idéia, o conteúdo é tudo local. }\end{array}$ \\
\hline
\end{tabular}




\begin{tabular}{|c|c|c|c|}
\hline CPA & Nome & $\begin{array}{l}\text { De que maneira você imagina que o programa contribui para o consumo de } \\
\text { informação pela comunidade local? }\end{array}$ & $\begin{array}{l}\text { De que maneira você imagina que o programa contribui para a produção de } \\
\text { informação pela comunidade local? }\end{array}$ \\
\hline \multirow[b]{2}{*}{$\begin{array}{l}\text { Digitando } \\
\text { o Futuro }\end{array}$} & $\begin{array}{l}\text { Rosane } \\
\text { Pólli }\end{array}$ & $\begin{array}{l}\text { Eles têm todas as chances à mão, né? Eu acho que aumentou bastante. Inclusive, eles } \\
\text { são muito mais críticos em relação ao uso dessas informações. Nós ainda defendemos } \\
\text { a parte de baixo da biblioteca e do mezanino, nós ocupamos igual, nós queremos } \\
\text { que usem igual, tanto a parte dos livros quanto a parte de informática. Uma coisa } \\
\text { não substitui a outra. }\end{array}$ & Alguns Faróis têm jornalzinho. \\
\hline & $\begin{array}{l}\text { Fabrício } \\
\text { Zanini }\end{array}$ & $\begin{array}{l}\text { Eu acho que contribui muito, para ver o que acontece. Na maioria das situações hoje, } \\
\text { quando você quer ter uma informação real de forma rápida, o melhor meio é a Internet. } \\
\text { Se você perdeu a Fórmula 1, que aconteceu no domingo, você quer saber depois o que } \\
\text { aconteceu, você vai buscar na Internet. Ainda mais pessoas de baixa renda que não } \\
\text { têm acesso a comprar um jornal. Ela consegue todas as informações, tudo o que } \\
\text { acontece no mundo via Internet, através de sites como UOL, Folha On-line... Essa } \\
\text { é uma das grandes mágicas da Internet. }\end{array}$ & $\begin{array}{l}\text { Hoje, ele praticamente não contribui. Algumas das comunidades desenvolveram de } \\
\text { forma espontânea e não controlada alguns sites hospedados em servidores gratuitos, que } \\
\text { tentam formar uma comunidade daquele local. Até hoje, não sei te dizer se existe algum } \\
\text { controlado ou não, mas em algum momento do projeto, a gente tinha mais de dez locais que } \\
\text { tinham sites. O site do Farol, eles chamam de Farol Rocha Povo. Então tudo o que } \\
\text { acontecia naquele local, naquela comunidade, os eventos, aniversários, problemas na } \\
\text { comunidade ou se tinha alguém na comunidade pra lançar um livro, publicavam lá. É um } \\
\text { mecanismo que chegou a ser usado. (...) A gente tinha um projeto incentivando isso, dar uma } \\
\text { certa padronizada e oferecer essa hospedagem. }\end{array}$ \\
\hline $\begin{array}{l}\text { Telecentros } \\
\text { POA }\end{array}$ & $\begin{array}{l}\text { Leandro } \\
\text { Silva }\end{array}$ & $\begin{array}{l}\text { Contribui. A cidade de Porto Alegre hoje tem esse diferencial de participação popular, } \\
\text { tem esse diferencial mais avançado nas questões políticas de participação. Conforme o } \\
\text { interesse da comunidade, ela tem ido ao telecentro para gestionar (sic) e buscar } \\
\text { algumas soluções (...). Tipo, as unidades em Associações de Moradores que têm } \\
\text { algum programa de geração de trabalho e renda ou espaços comunitários vão ali } \\
\text { buscar informações para o benefício dessas associações, dessas cooperativas. } \\
\text { Divulgam na Internet, no mínimo fazem uma homepage, para assim se utilizar e buscar } \\
\text { esse conhecimento. As questões acadêmicas e escolares também. }\end{array}$ & $\begin{array}{l}\text { Isso vai se dar a partir da própria capacitação e interesse desse usuário. Porque hoje em } \\
\text { dia tem pessoas que só têm interesse em ir ali e acessar o equipamento, mandar e-mail e } \\
\text { minimamente acessar alguma coisa e ir embora para a sua casa. Alguns outros locais } \\
\text { conseguem desenvolver uma cultura de que ele tem que saber lidar com o equipamento, saber } \\
\text { lidar com a tecnologia, saber pesquisar, investigar, desenvolver isso. Daí você consegue } \\
\text { trabalhar a busca de conhecimento, do desenvolvimento mais cidadão, mais humano dessa } \\
\text { pessoa. Por isso que o projeto é diferenciado em cada comunidade. Cada comunidade de } \\
\text { Porto Alegre tem uma maneira de pensar, e cada comunidade utiliza o equipamento de } \\
\text { uma maneira. }\end{array}$ \\
\hline
\end{tabular}




\begin{tabular}{|c|c|c|}
\hline CPA & ome & coordenação já identificou impactos do programa nos usuários e na comunidade local? Quais? \\
\hline \multirow{3}{*}{$\begin{array}{l}\text { Acessa São } \\
\text { Paulo }\end{array}$} & $\begin{array}{l}\text { Maria } \\
\text { Amélia }\end{array}$ & $\begin{array}{l}\text { Tem sim, tem o caso lá no Pontal do Paranapanema, um senhor aposentadíssimo de } 70 \text { e tantos anos que ia lá e começou a pesquisar piscicultura e montou um sistema de criação no } \\
\text { sítio dele, empregou um monte de gente. (...) São os que viram cases... Tem um camarada que usa para vender camiseta. } \\
\text { Isso não tem uma metodologia aplicada, são cases.... (...) Mas isso não está computado de uma forma organizada, nós estamos caminhando para isso, mas não há uma metodologia, } \\
\text { mas isso que você tá falando existe. }\end{array}$ \\
\hline & $\begin{array}{l}\text { Ricardo } \\
\text { Kobashi }\end{array}$ & $\begin{array}{l}\text { Teve uma série de impactos positivos, tem mil exemplos, mil cases que a gente pode usar, citar para cada aspecto que a gente quiser analisar. Mas o fato é que a gente não tem } \\
\text { nenhum sistema, nenhuma métrica para que a gente tenha capacidade de medir isso de fato, nem de comparar isso no tempo ou com outros programas. Então, a bem da } \\
\text { verdade, são avaliações completamente subjetivas. Tem que ter [um sistema de] avaliação, tem que ter métrica. (...) } \\
\text { (...) Não tira o menino da rua, não diminui a criminalidade, não aumenta a empregabilidade. Esses fatores são regidos por outras variáveis que esmagam a capacidade de um } \\
\text { infocentro, de um telecentro, de agir sobre isso. Então o ganho é realmente mínimo: "ah, esse cara deixou de ser criminoso porque ele veio hoje num telecentro perto da casa dele". (...) } \\
\text { Isso não dá pra saber, isso é conversinha (...). Se programa de ID diminuísse a criminalidade, está tudo resolvido. Vamos encher o morro, a favela de coisas e acabou. Pra que } \\
\text { guarda? Pra que política de emprego? Pra que escola? }\end{array}$ \\
\hline & $\begin{array}{l}\text { Drica } \\
\text { Guzzi }\end{array}$ & $\begin{array}{l}\text { Já. [Está na] Ponline. Quando você pergunta: “você acha que a Internet fez bem pra você, pra sua vida pessoal?", } 64 \% \text { acha. Por que, né? Ele acha que consegue se relacionar melhor } \\
\text { com as pessoas. Por quê? Pelo fato dele se sentir com mais acesso à informação, ele já tem mais ponto de contato para troca, isso é muito legal. } \\
\text { (...) Mas quando você vê o negócio da renda, você percebe que [é ambíguo] Porque a gente faz a pergunta "ah Mariana, melhorou o relacionamento? Tem mais emprego? } \\
\text { Sim... mas melhorou sua condição financeira?". A resposta é não. } \\
\text { (...) Você só vai conseguir medir o impacto, o impacto mesmo real gerado você vai conseguir ver nas historinhas. Seria uma loucura [a coordenação] falar assim: "não, com essa } \\
\text { tecnologia eles vão sair da rua". Você não consegue afirmar isso de uma maneira categórica, porque a questão é bem mais sistêmica também. Não sei, depende da situação. Como é que } \\
\text { você vai medir isso? Existem outros programas entrando ali, então é muito complicado. Mas você tem relatos maravilhosos, de uma riqueza incrível, e que isso não é nada, é esse que é } \\
\text { o ponto. } \\
\text { (...) Capacitação é um bom caso. (...) a gente começa a preparar as pessoas, começa a dar um nível de capacitação, o que acontece? Os monitores arrumam outros empregos. } \\
\text { Eles vão ganhar mais e tal, isso é muito legal. Apesar de perder, ao mesmo tempo está formando, isso é concreto, tem um impacto concreto. Você melhora a empregabilidade das } \\
\text { pessoas que estão ali, isso aí você consegue medir. }\end{array}$ \\
\hline \multirow[b]{2}{*}{$\begin{array}{l}\text { Digitando o } \\
\text { Futuro }\end{array}$} & $\begin{array}{l}\text { Rosane } \\
\text { Pólli }\end{array}$ & -1-- \\
\hline & $\begin{array}{l}\text { Fabrício } \\
\text { Zanini }\end{array}$ & $\begin{array}{l}\text { No começo do projeto (...) a gente teve muita iniciativa positiva. "Ah, graças ao projeto eu consegui arrumar um emprego, porque estava no jornal de domingo que tinha que } \\
\text { mandar o currículo via e-mail, ou que tinha que se cadastrar em tal local". Então a gente teve muito feedback da comunidade em relação a isso, porque conseguiu algum } \\
\text { trabalho pelo projeto. A gente teve muito feedback assim: "o meu filho consegue fazer pesquisa porque tem a Internet". E a própria rede de ensino daquela região acaba incentivando a } \\
\text { busca de alguma informação, de alguma coisa via Internet, pois sabia que naquele local existia um ponto gratuito de acesso. }\end{array}$ \\
\hline $\begin{array}{l}\text { Telecentros } \\
\text { POA }\end{array}$ & $\begin{array}{l}\text { Leandro } \\
\text { Silva }\end{array}$ & $\begin{array}{l}\text { Tem muitos casos de inclusão no mercado de trabalho sim. Agora, pontuar quantos casos, isso é um trabalho muito manual de cada entidade que a gente tem construído, pouco } \\
\text { a pouco, cada entidade, de acordo com a realidade de cada um... }\end{array}$ \\
\hline
\end{tabular}


Com relação à contribuição dos programas de inclusão digital para o desenvolvimento social, político e econômico os entrevistados são unânimes em dizer que existem muitos "casos" de impacto positivo, mais que ainda não existe uma metodologia capaz de avaliar criticamente e de identificar as transformações proporcionadas por esses programas nas comunidades em que estão inseridos. " $A$ questão é bem mais sistêmica também. Como é que você vai medir isso? Existem outros programas entrando ali, então é muito complicado. Mas você tem relatos maravilhosos, de uma riqueza incrível", defende Drica. Sempre crítico, Kobashi é categórico ao afirmar que impactos existem, mas que a inclusão digital não é a solução para os problemas sociais e econômicos dessas regiões periféricas:

(...) Não tira o menino da rua, não diminui a criminalidade, não aumenta a empregabilidade. Esses fatores são regidos por outras variáveis que esmagam a capacidade de um infocentro, de um telecentro, de agir sobre isso. Então o ganho é realmente mínimo: 'ah, esse cara deixou de ser criminoso porque ele veio hoje num telecentro perto da casa dele...'. Isso não dá pra saber, isso é conversinha (...). Se programa de inclusão digital diminuísse a criminalidade, está tudo resolvido. Vamos encher o morro, a favela de coisas e acabou. Pra que guarda? Pra que política de emprego? Pra que escola?

No que diz respeito à oportunidade de geração de renda e emprego (quadro 35), foram identificadas muitas histórias de inserção no mercado de trabalho, mas não efetivamente uma melhora nas condições financeiras dos indivíduos ou da comunidade. Segundo Drica, no caso do Acessa SP, o que a coordenação consegue medir concretamente é o número de monitores que, melhor capacitados, conseguiram novos empregos.

Já o aumento nas oportunidades de educação, acesso à informação e cultura (quadro 36) são mais facilmente identificados, pois o simples acesso à Internet já representa a porta de entrada para o conhecimento, mas a sua apropriação e o seu uso dependem das características individuais de cada um. Em geral, todos os entrevistados apontam para a idéia de crescimento, no que se refere à educação, de uma semente que será colhida nos próximos anos "porque você vê muitas crianças de 6, 7, 8 anos que estão começando a se alfabetizar e ao mesmo tempo (...) se incluir digitalmente. Essa é a grande magia que às vezes o Poder Público não consegue enxergar, mas que a gente tem certeza de que lá na frente isso vai ser uma diferença muito grande", diz Fabrício. Mas a verdadeira "mágica", no entanto, fica por conta da profunda revolução social e econômica que 
essas ferramentas podem trazer através da possibilidade de democratização do "meio de produção" mais importante da atualidade, que é a informação.

\begin{abstract}
Historicamente falando, pela primeira vez o meio de produção mais importante de informação, que é a Internet...., aquele que está sendo mais valorizado, não é mais um bem material, é uma coisa democrática, que qualquer um pode ter, ou quase todo mundo pode ter. (...) Antes você precisava ter a terra, depois você precisava ter um tear, depois você precisava ter uma fábrica... essas coisas que dominaram os ciclos econômicos. E a posse disso se concentrava na mão de poucos. O que está transformando a sociedade hoje é uma coisa muito barata, mais acessível do que ter uma fábrica, do que ter a terra. (...) Se a gente está vivendo num ciclo econômico baseado na informação, nas propriedades intelectuais (...) hoje a gente tem uma oportunidade. O capital necessário para você controlar o meio de produção do momento, deste ciclo, é muito pequeno, reflete Kobashi.
\end{abstract}

E essa possibilidade de ascensão social, que exige um intervalo de tempo para ser efetivada - mesmo que bem menor no contexto atual de mudanças culturais - já pode ser notada quando o usuário do CPA percebe que seus filhos têm a possibilidade de participar do mesmo universo dos jovens de classe social mais elevada.

Por exemplo, uma usuária que vai lá mais por causa do filho dela, ela acha que é muito legal, porque ela já começa a conseguir perceber que o filho dela tem uma chance de se ligar na Internet de uma maneira igual a um menino do Morumbi. E isso pra ela é de muito valor, entendeu? Ela fala: “isso é muito legal, porque o meu filho tem uma chance”. É uma oportunidade. Além dela falar que ele não vai estar na rua, né?, argumenta Drica.

A contribuição dos programas de ID para a conscientizaçãa social e a participaçãa política (quadro 37) já é mais difícil de identificar, por mais que a Internet seja um instrumento em potencial para articulação das comunidades e o relacionamento com o Poder Público. Para alguns coordenadores existe um esclarecimento maior, as comunidades que já eram organizadas passam a ter um novo instrumento de trabalho, a liderança que consegue um CPA para a sua associação se fortalece. Mas a tecnologia não transforma o usuário: "Uma pessoa que tem "drive”, ela se junta na Internet, ela vai potencializar essa característica. [E a que não tem, não vai.] É esse tipo de distinção que a gente tem que fazer, senão você vai falar que a tecnologia vai pegar um cara que é reativo, ressentido e vai fazer um milagre. E não vai fazer", reflete Drica, ao apontar que a Internet pode facilitar o relacionamento entre as pessoas, "aumentando sua rede social". 


\begin{tabular}{|c|c|c|}
\hline CPA & Nome & lentificou impactos do programa nos usuários e na comunidade local? Quais? \\
\hline \multirow{3}{*}{$\begin{array}{l}\text { Acessa São } \\
\text { Paulo }\end{array}$} & $\begin{array}{l}\text { Maria } \\
\text { Amélia }\end{array}$ & [ver quadro 33] \\
\hline & $\begin{array}{l}\text { Ricardo } \\
\text { Kobashi }\end{array}$ & $\begin{array}{l}\text { A tecnologia é transformadora, ela é determinante (...). Historicamente falando, pela primeira vez o meio de produção mais importante de informação, que é a Internet, o meio } \\
\text { de comunicação mais importante, aquele que está sendo mais valorizado, não é mais um bem material, é uma coisa democrática, que qualquer um pode ter, ou quase todo } \\
\text { mundo pode ter. (...) Antes você precisava ter a terra, depois você precisava ter um tear, depois você precisava ter uma fábrica... essas coisas que dominaram os ciclos econômicos. E a } \\
\text { posse disso se concentrava na mão de poucos. O que está transformando a sociedade hoje é uma coisa muito barata, mais acessível do que ter uma fábrica, do que ter a terra. (...) Se a } \\
\text { gente está vivendo num ciclo econômico baseado na informação, nas propriedades intelectuais (...) hoje a gente tem uma oportunidade. (...) Não precisa muito para uma pessoa } \\
\text { ter issso à sua disposiçãa. (...) o cara não precisa nem ter, ele pode só ter acesso, ter condiçóes de. Então a gente cria uma oportunidade para ele. O capital necessário para você } \\
\text { controlar um meio de produção do momento, deste ciclo, é muito pequeno. (...) Hoje informação já vale dinheiro. [E como estimular esses novos usuários a produzir?] Isso já } \\
\text { não é mais uma questão de ID. Isso é uma questão de projeto de país. Você tem um plano de desenvolvimento do país, esse plano tem que contemplar a produção de } \\
\text { informação (...) de maneira democrática. Não concentrando, mas distribuindo. (...) A gente está falando de um plano de desenvolvimento de um país, que obviamente tem que ter } \\
\text { uma vertente educacional, negócios, relações exteriores, tecnológicas... }\end{array}$ \\
\hline & $\begin{array}{l}\text { Drica } \\
\text { Guzzi }\end{array}$ & $\begin{array}{l}\text { Por exemplo, uma usuária que vai lá mais por causa do filho dela, ela acha que é muito legal, porque ela já começa a conseguir perceber que o filho dela tem uma chance de se } \\
\text { ligar na Internet de uma maneira igual a um menino do Morumbi. E isso pra ela é de muito valor, entendeu? Ela fala: "isso é muito legal, porque o meu filho tem uma } \\
\text { chance". É uma oportunidade. Além dela falar que ele não vai estar na rua, né? }\end{array}$ \\
\hline \multirow[b]{2}{*}{$\begin{array}{l}\text { Digitando } \\
\text { o Futuro }\end{array}$} & $\begin{array}{l}\text { Rosane } \\
\text { Pólli }\end{array}$ & $\begin{array}{l}\text { Eu acho que as pessoas cresceram muito depois que começaram a usar esses computadores, quando começou a chegar nos Faróis. E até em relação aos funcionários do próprio } \\
\text { Farol, porque nós tivemos casos de funcionárias que tinham medo do computador no começo, tinham muitas dificuldades, não queriam acessar. Essas pessoas, nós vimos mais } \\
\text { de perto o quanto elas cresceram depois que começaram a usar, que perderam esse medo. Tem muito pessoal de idade, tem o EJA, que são as turmas de jovens e adultos nas } \\
\text { escolas que agendam para levar seus alunos. Eu acho que as pessoas têm uma coisa maravilhosa em mãos, elas sabem que podem usar e que aos poucos, todo mundo vai usar } \\
\text { computador. Hoje, criança sabe mais do que adulto. Eles estão incentivando, a criança mesmo está incentivando o uso. O que você cresce é uma coisa fora de série. }\end{array}$ \\
\hline & $\begin{array}{l}\text { Fabrício } \\
\text { Zanini }\end{array}$ & $\begin{array}{l}\text { Só que ao mesmo tempo você percebe que essa semente é uma coisa que Curitiba vai colher não só agora, mas nos próximos 10, } 15 \text { anos. Porque você vê muitas crianças de } 6 \text {, } 7 \text {, } \\
8 \text { anos que estão começando a se alfabetizar e ao mesmo tempo estão começando a se incluir digitalmente. Essa é a grande magia que às vezes o Poder Público não consegue } \\
\text { enxergar, mas que a gente tem certeza de que lá na frente isso vai ser uma diferença muito grande. Não tem limite de idade. As crianças começam a utilizar com } 5 \text { anos às vezes ou } \\
\text { até com } 4 \text { anos. Tem pai que não tem computador em casa, vai acessar a Internet, leva a criança... que já está vendo o computador, como um mundo mágico. E quando ele tiver um pouco } \\
\text { mais de idade, ele vai começar a utilizar e garantir seu futuro lá na frente, no mercado de trabalho ou na escolha de uma profissão. [Porque para] ele não é um bicho de sete cabeças, é } \\
\text { uma coisa que é natural para ele. Internet, e-mail, teclado faz parte do dia-a-dia dele. Não na casa dele, às vezes nem na escola dele, mas ele tem um ponto no bairro dele onde } \\
\text { ele tem acesso livremente. }\end{array}$ \\
\hline $\begin{array}{l}\text { Telecentros } \\
\text { POA }\end{array}$ & $\begin{array}{l}\text { Leandro } \\
\text { Silva }\end{array}$ & $\begin{array}{l}\text { Sim, a inclusão, o acesso, a permanência. Tem casos que já foram divulgados em livros. Tem um exemplo no Parque Chico Mendes de uma usuária que estava desempregada... (...) } \\
\text { [Hoje não possui um canal de comunicação ou uma ferramenta de gerenciamento das unidades. Ele conta que o sistema está sendo desenvolvido pela Procempa e quando estiver pronto } \\
\text { será muito mais fácil divulgar e estimular os resultados positivos e impactos.] }\end{array}$ \\
\hline
\end{tabular}




\begin{tabular}{|c|c|c|}
\hline CPA & Nome & A coordenação já identificou impactos do programa nos usuários e na comunidade local? Quais? \\
\hline \multirow{3}{*}{$\begin{array}{l}\text { Acessa São } \\
\text { Paulo }\end{array}$} & $\begin{array}{l}\text { Maria } \\
\text { Amélia }\end{array}$ & [ver quadro 32] \\
\hline & $\begin{array}{l}\text { Ricardo } \\
\text { Kobashi }\end{array}$ & $\begin{array}{l}\text { Mas se eu fortaleço um líder comunitário é pra quê? Pra ele ser político, pra ele fazer política, pra ele conseguir mais praquela comunidade, pra ele conseguir melhores resultados (...) A } \\
\text { gente tem pesquisas que mostram que o núcleo, líder comunitário, os monitores, etc., tiveram uma melhora em relação os objetivos daquela entidade muito grande. As } \\
\text { entidades são muito mais capazes hoje, muito mais efetivas do que eram antes do programa, então o programa certamente fortaleceu essas entidades. [Fala sobre a relação do } \\
\text { envolvimento de partidos políticos e a agregação de lideranças]. Quando a gente fortalece aquela comunidade é pra ela se livrar do assistencialismo. } \\
\text { (...) Eu acho que sim, isso acontece. Eu diria a você pelo seguinte: para as pessoas que já estão de alguma maneira protegidas da criminalidade, que têm condições um pouco melhores } \\
\text { de emprego, os programas de ID, de uma forma geral, dão mais condições, facilitam a vida, ampliam o entendimento, etc. Mas essa franja social, esses caras do limite, são esses } \\
\text { caras que não sabem nem falar direito, que vão pro crime, etc., esses caras aí a gente não atinge. Com raras exceções (...) Não são os programas de ID que dão acesso à Internet. } \\
\text { Esses programas não têm essa capacidade. Ele melhora a vida de muita gente, mas não dessa franja que não tem a menor condição de arrumar um emprego, de evitar de ir pro } \\
\text { crime.... se não tiver um acompanhamento grande. }\end{array}$ \\
\hline & $\begin{array}{l}\text { Drica } \\
\text { Guzzi }\end{array}$ & $\begin{array}{l}\text { O Manuel Castells falou uma coisa: a Internet não vai mudar nada em termos de sociabilização da pessoa. O que isso quer dizer? Uma pessoa que tem “drive”, ele se junta na } \\
\text { Internet, ele vai potencializar essa característica. [E o que não tem, não vai.] É esse tipo de distinção que a gente tem que fazer, senão você vai falar que a tecnologia vai pegar } \\
\text { um cara que é reativo, ressentido e vai fazer um milagre. E não vai fazer. } \\
\text { (...) E tem uma outra coisa também. A gente tem mania de querer ver tudo agora, né? Se a gente está falando de impacto e mudança de modo de vida, a gente está falando de vários } \\
\text { níveis, cultural, educacional (...) Você tem que ter um distanciamento histórico um pouco maior. Não dá mais para fazer programa de ID...sem medir capital social. Porque um } \\
\text { dos efeitos que a Internet chega ou não é justamente nessa capacidade de articulação, informação, capacidade de se juntar e fazer um negócio. Então se a gente quer medir esse tipo de } \\
\text { coisa, os parâmetros para isso são do capital social. Mas, por exemplo, aqui no Brasil a gente não tem. A gente não tem um programa de ID que entra nesse nível de investigação. } \\
\text { (...) Tem a questão de conhecer gente. Todos os monitores falam que conheceram gente pela Internet. Monitores e usuários. Se é gente, é um impacto, entendeu? Você aumenta sua } \\
\text { rede social. O que a tecnologia está trazendo é um outro tipo de comunidade que a gente não chama nem de comunidade, é a rede social. A rede social é menos aquela história da } \\
\text { comunidade solidária corporativa, de todo mundo se ajudando. Então você começa a medir o impacto na comunidade não através do impacto na comunidade como uma coisa } \\
\text { abstrata, mas você começa a perceber esse impacto através das mudanças das redes sociais das pessoas. }\end{array}$ \\
\hline \multirow{2}{*}{$\begin{array}{l}\text { Digitando } \\
\text { o Futuro }\end{array}$} & $\begin{array}{l}\text { Rosane } \\
\text { Pólli } \\
\end{array}$ & O povo hoje está muito mais esclarecido com relação aos direitos, deveres, aos fatos. \\
\hline & $\begin{array}{l}\text { Fabrício } \\
\text { Zanini }\end{array}$ & $\begin{array}{l}\text { Existe uma articulação da comunidade [em alguns Faróis], em outros não. Então têm locais onde a Associação de Moradores promove atividades, ou têm ONGs fortes, e } \\
\text { outras que praticamente zero de atividade. (...) Porque os Faróis são espaços públicos onde eu posso promover atividades de ID, culturais, dessa ordem. Fazer um abaixo-assinado } \\
\text { para que melhorem a iluminação da rua e transmitir via Internet, ou criar um site... Você vê a diferença da apropriação do espaço público. }\end{array}$ \\
\hline $\begin{array}{l}\text { Telecentros } \\
\text { POA }\end{array}$ & \begin{tabular}{|l} 
Leandro \\
Silva \\
\end{tabular} & Individualmente o que se percebe é através das oficinas mais pontuais. Algumas têm muito mais ênfase nas questões de cidadania, lá você trabalha esses aspectos. \\
\hline
\end{tabular}




\section{Quadro 38. Benefícios dos programas de Inclusão Digital - Coordenadores}

\begin{tabular}{|c|c|c|}
\hline$C P A$ & Nome & $\begin{array}{l}\text { Para você, qual é o maior beneficio que o programa trouxe para o usuário? E para a } \\
\text { comunidade? }\end{array}$ \\
\hline \multirow{3}{*}{$\begin{array}{l}\text { Acessa São } \\
\text { Paulo }\end{array}$} & $\begin{array}{l}\text { Maria } \\
\text { Amélia }\end{array}$ & $\begin{array}{l}\text { Acesso. A oportunidade do acesso. Isso é um benefício de inclusão, se sentir incluído. Você } \\
\text { imagina um jovem sabendo tudo isso, porque a televisão mostra, os outdoors mostram, as revistas } \\
\text { mostram, e ele não poder experimentar? Acesso mesmo, a oportunidade. }\end{array}$ \\
\hline & $\begin{array}{l}\text { Ricardo } \\
\text { Kobashi }\end{array}$ & $\begin{array}{l}\text { Eu acho que é fazer com que a tecnologia não seja impedimento para o desenvolvimento } \\
\text { pessoal ou da comunidade. É aquela história de que a tecnologia não joga só no time do adversário, } \\
\text { ela joga no seu também. Acho que esse é o grande benefício. (...) O que acontece é que se você tem } \\
\text { um cara que usa muito, esse "usa muito" cria uma vantagem competitiva para esse cara em } \\
\text { qualquer situação: emprego, social, etc. Então você precisa zerar essa vantagem competitiva. }\end{array}$ \\
\hline & $\begin{array}{l}\text { Drica } \\
\text { Guzzi }\end{array}$ & $\begin{array}{l}\text { Pro usuário é o acesso. É ele para ele poder acessar tudo, ele se sentir parte. Na comunidade, } \\
\text { Internet com acesso de graça para algumas pessoas é maravilhoso, a comunidade sai ganhando. } \\
\text { Agora, a grande questão é: qual é o raio que está atingindo? Essa comunidade está onde na } \\
\text { região? }\end{array}$ \\
\hline \multirow[b]{2}{*}{$\begin{array}{l}\text { Digitando } \\
\text { o Futuro }\end{array}$} & $\begin{array}{l}\text { Rosane } \\
\text { Pólli }\end{array}$ & $\begin{array}{l}\text { É a ID, né? Eu acho que a ID vem fazer com que o usuário cresça realmente, conheça, saiba os } \\
\text { seus direitos e deveres, pra mim é mais uma questão de cidadania do que... explorar o mundo, ter a } \\
\text { chance de explorar o mundo. }\end{array}$ \\
\hline & $\begin{array}{l}\text { Fabrício } \\
\text { Zanini }\end{array}$ & $\begin{array}{l}\text { Eu acho que é esse ganho ao acesso à informação de uma forma real, de forma muito mais } \\
\text { rápida que os outros meios conseguem transmitir. O outro grande ganho seria realmente essa } \\
\text { parte da inclusão das pessoas, talvez não nesse momento usando da melhor forma, mas sabendo } \\
\text { que existe a ferramenta. Perceberem a potencialidade dessa ferramenta, que é o acesso ao } \\
\text { computador e à Internet, e que isso em algum momento vai fazer diferença na vida delas. }\end{array}$ \\
\hline $\begin{array}{l}\text { Telecentros } \\
\text { POA }\end{array}$ & $\begin{array}{l}\text { Leandro } \\
\text { Silva }\end{array}$ & $\begin{array}{l}\text { São vários benefícios. Por exemplo, agora em dezembro formamos um grupo de } 70 \text { pessoas em um } \\
\text { curso de cidadania. Esse indivíduo que hoje está participando dessa oficina, está desenvolvendo a } \\
\text { questão de cidadania, de direitos humanos, já está gerando e consumindo conhecimento. }\end{array}$ \\
\hline
\end{tabular}

De maneira geral, a "oportunidade do acesso" à Internet é considerado o maior dos benefícios trazidos pelos programas de Inclusão Digital investigados (quadro 38). Esta presente também no discurso dos coordenadores a idéia de "incluir" o cidadão, fazer com que ele "se sinta parte" do processo, "tenha a chance de explorar o mundo". Rosane e Leandro comentam o potencial dessa ferramenta em fazer com que o cidadão "conheça seus direitos e deveres", para o desenvolvimento da "cidadania". Kobashi completa afirmando que o grande diferencial oferecido "é fazer com que a tecnologia não seja impedimento para o desenvolvimento pessoal ou da comunidade (...) ...se você tem um cara que usa muito, esse 'usa muito' cria uma vantagem competitiva em qualquer situação: emprego, social, etc. Então você precisa zerar essa vantagem competitiva". 


\section{Quadro 39. Desafios do programa - Coordenadores}

\begin{tabular}{|c|c|c|}
\hline CPA & Nome & pulsionar a produção e o consumo de informação pelos usuários? \\
\hline \multirow{3}{*}{$\begin{array}{l}\text { Acessa São } \\
\text { Paulo }\end{array}$} & $\begin{array}{l}\text { Maria } \\
\text { Amélia }\end{array}$ & $\begin{array}{l}\text { Nós estamos pensando em usar alguma experiência [do Acessa] no Parque da Juventude [Antigo complexo prisional do Carandiru reurbanizado e transformado em centro de lazer, } \\
\text { esportes e cultura] que é ampliar o uso do computador. Não só Internet grátis, mas fazer webdesign, ajudar o camarada a potencializar o uso daquela tecnologia. (...) Tem } \\
\text { também a nova unidade no Fontes do Ipiranga, antiga unidade da Febem na Imigrantes. (...) Um grande desafio é de continuidade, um grande desafio em qualquer programa do Governo } \\
\text { Estadual é continuidade. Esperamos que a comunidade se aproprie do programa. Ao fortalecer essa comunidade com sentido de pertencimento, de apropriação do programa, você } \\
\text { dá à comunidade um senso de responsabilidade que vai levá-la a lutar pela continuidade. Esse é um desafio que a gente sabe que existe. Tem decreto, a gente assina um convênio, } \\
\text { então tem formas de possibilitar a continuidade, mas ninguém garante. Você conhece os políticos do Brasil, não existem leis que garantam a continuidade de programas. Isso é uma } \\
\text { fragilidade brasileira, não é só desse programa. }\end{array}$ \\
\hline & $\begin{array}{l}\text { Ricardo } \\
\text { Kobashi }\end{array}$ & $\begin{array}{l}\text { A gente vai abrir duas coisas agora que são super importantes: o Parque Estadual do Fontes do Ipiranga, que era a Febem Imigrantes e é até meio simbólico... E o Parque da Juventude, } \\
\text { que era onde tinha o Carandiru. Qual é a idéia? No Fontes do Ipiranga tem lá o Grupo Corpo, Projeto Guri, tem um montão de outras ONG's que trabalham, né? Então o que a gente } \\
\text { quer fazer? A gente quer ser o braço tecnológico dessas entidades. A gente quer que o Acessa aprenda a dar suporte para outros projetos, o que a gente quer é que as ONGs } \\
\text { aprendam a utilizar essa tecnologia fora dela. E no Parque da Juventude nós vamos ter o Centro de Mídia Digital, de vídeo, de áudio, de blog, de site, de software livre. E aí, se } \\
\text { alguém precisar, ele vai lá e pede alguma coisa, e a gente vai preparar gente pra poder oferecer. A idéia é que já seja uma coisa mais de alta tecnologia. (...) Você precisa esvaziar sua } \\
\text { alma, sabe? Você precisa diminuir o tamanho pra você conseguir ajudar os outros. Pra você ver que a sua missão não é "ser", mas é "viabilizar". (...) Então, se você conseguir oferecer } \\
\text { os equipamentos, é bacana, mas aí tem o seguinte: aí você vai incentivar aquela expressão, mas isso aí já é pra poucos. Se você tem um grupo de dança, se esse grupo de dança quer } \\
\text { fazer, quer ter um vídeo. Então arruma alguém que queira fazer vídeo e junta um grupo de dança. Aí o grupo de dança tem um vídeo feito por alguém que quer fazer o vídeo. O que não } \\
\text { dá, o que eu acho um equívoco, é que o que muita gente tem feito é querer fazer com que o grupo de dança aprenda com o vídeo, entende? (...) Eu acho que o grande desafio do } \\
\text { projeto é ser maleável o suficiente para receber bem as diferentes demandas que a sociedade tem. É ser um excelente parceiro tecnológico do líder comunitário, (...) do grupo } \\
\text { de ballet... O mais importante é ele ter essa predisposição. E dar acesso à informação, dar condiçées de disposição de conteúdo que as comunidades produzem. }\end{array}$ \\
\hline & $\begin{array}{l}\text { Drica } \\
\text { Guzzi }\end{array}$ & $\begin{array}{l}\text { O Acessa está ampliando [sua atuação] em projetos como o Parque da Juventude. ... vai ser Acessa também, mas com formatos diferenciados, vai ser um local imenso, com } 120 \\
\text { máquinas, focado no jovem, (...) com multimídia, desenvolvimento de software, de soluçôes. (...) O Acessa está se voltando para atender às necessidades digitais de outros } \\
\text { programas, das entidades comunitárias... Para você sacar a necessidades, também tem todo um processo de identificação. Porque o que os programas de ID confundem é que eles } \\
\text { querem fazer um nego que gosta de dançar (...) produzir website. E ele não quer produzir website. Ele precisa de um website, entendeu? Pra ele, vai ser legal se ele puder } \\
\text { divulgar o que ele faz, divulgar o grupo de dança dele, só que ele não quer fazer o website. (...) E é claro que o desafio do Acessa é ampliar a rede, ampliar o grau, a } \\
\text { ressonância desses postos no local, é ampliar essa questão do local no global, sabe? Realmente fortalecer esse tipo de coisa... }\end{array}$ \\
\hline \multirow[b]{2}{*}{$\begin{array}{l}\text { Digitando } \\
\text { o Futuro }\end{array}$} & $\begin{array}{l}\text { Rosane } \\
\text { Pólli }\end{array}$ & $\begin{array}{l}\text { Eu acho que a expansão dele mesmo. A expansão no final de semana para todas as escolas abrirem, para que todas as pessoas de outras escolas tenham o uso do computador, em todos } \\
\text { os Faróis. Que sejam dados cursos com certificado, que são muito importantes, e que os equipamentos sejam sempre atualizados. }\end{array}$ \\
\hline & $\begin{array}{l}\text { Fabrício } \\
\text { Zanini }\end{array}$ & $\begin{array}{l}\text { Um dos grandes desafios é realmente ampliar e se manter tecnicamente atualizado: o governo investir em computadores, conexão.... é um projeto que não é barato. E realmente, } \\
\text { cada vez mais fazer essa ponte com a comunidade e a toda essa infra-estrutura que existe, mostrar o que isso realmente pode trazer de benefício para a comunidade. Então um passo é } \\
\text { promover a inclusão, e num segundo passo, realmente mostrar o que isso pode trazer de benefícios reais para aquela comunidade. }\end{array}$ \\
\hline $\begin{array}{l}\text { Telecentros } \\
\text { POA }\end{array}$ & $\begin{array}{l}\text { Leandro } \\
\text { Silva }\end{array}$ & $\begin{array}{l}\text { No primeiro momento da nossa gestão, nós procuramos regularizar as unidades que estavam irregulares. Algumas tinham problemas financeiros, débito com órgãos estaduais, } \\
\text { federais ou até mesmo municipais, o que inviabilizou a constituição do convênio, porque a gente não pode repassar esse recurso para uma entidade que tem problema de idoneidade ou de } \\
\text { inadimplência. (...) Mas a gente continua gestionando (sic) com elas para tentar abrir mais unidades, manter aquelas que existiam, e regularizar aquelas que estavam irregulares. } \\
\text { O segundo momento foi flexibilizar uma série de dificuldades que a Lei de licitações apresenta, a 8636... [através] de um parecer da Procuradoria do Município. No caso de convênio, } \\
\text { que é o caso dos telecentros, pedimos somente os documentos básicos de cada entidade: ata de eleição, estatuto, CNPJ. Todos os documentos de regularidade fiscal não são mais } \\
\text { necessários hoje, então vai facilitar reabrir todas aquelas unidades que estavam com dificuldade. (..) Hoje você faz o curso, sai com o teu certificado, vai com teu diploma debaixo do } \\
\text { braço lá para a sua casa, e lá tu continua com os mesmos problemas sociais, continua desempregado, teus filhos continuam com fome, tu continua sem emprego. E não é aberta a vaga no } \\
\text { mercado de trabalho. Tu simplesmente vai, faz o curso e volta, não é estimulada a criação de vagas, de oportunidades de renda. (...) Vamos oferecer um curso mais adequado para a } \\
\text { realidade atual (...) deixar o indivíduo pronto para ser absorvido pelo mercado de trabalho, com um certificado [reconhecido]. Você vai capacitar, vai permitir que ele acesse } \\
\text { e, depois de ser capacitado, depois de ser instrumentalizado, vai ter esse aporte de cultura, conhecimento, essa questão mais cidadã. Depois vai ser muito mais fácil desse } \\
\text { indivíduo ser incluído, uma inclusão social de fato, além da inclusão digital. }\end{array}$ \\
\hline
\end{tabular}


Segundo os coordenadores, o maior desafio dos programas de inclusão digital (quadro 39) é definitivamente a sua expansão. Não apenas o aumento do número de unidades e a atualização contínua dos equipamentos, mas principalmente a ampliação da "ressonância" da rede, o fortalecimento da comunidade local e o uso da tecnologia para a promoção da inclusão social, e não apenas digital. Para Fabrício isso significa "mostrar o que [essa infra-estrutura] realmente pode trazer de benefício para a comunidade". Rosane e Leandro entendem que o importante é a oferta de cursos que preparem o indivíduo para o mercado de trabalho.

Hoje vocêfaz o curso, sai com o teu certificado, vai com teu diploma debaixo do braço
lá para a sua casa, e lá tu continua com os mesmos problemas sociais, continua
desempregado, teus filhos continuam com fome, tu continua sem emprego. E não é
aberta a vaga no mercado de trabalho. Não é estimulada a criação de oportunidades
de renda. (...) Vamos oferecer um curso mais adequado para a realidade atual (...)
deixar o indivíduo pronto para ser absorvido pelo mercado de trabalho, com um
certificado [reconhecido], planeja Leandro.

Drica e Kobashi, críticos do modelo "curso-certificado", vão além. Para eles o papel do programa é ser "um parceiro tecnológico para a comunidade", viabilizando as demandas da sociedade. "A gente quer que o Acessa aprenda a dar suporte para outros projetos" já em desenvolvimento nas comunidades, explica Kobashi.

A continuidade do programa é outro desafio lembrado por Maria Amélia, um grande desafio de qualquer programa público. "Ao fortalecer essa comunidade com sentido de pertencimento, de apropriação do programa, você dá à comunidade um senso de responsabilidade que vai levá-la a lutar pela continuidade", afirma, lembrando que mesmo a assinatura de um decreto ou de um convênio não garante a sua manutenção. "Você conhece os políticos do Brasil, não existem leis que garantam a continuidade de programas. Isso é uma fragilidade brasileira, não é só desse programa", completa. É por este motivo que Kobashi defende a institucionalização da política de inclusão digital (ver quadro 31). "Ninguém fecha posto de saúde, ninguém fecha escola", argumenta. Ao comentar o impacto da mudança de gestão municipal no programa Telecentros POA, que culminou no fechamento de várias unidades - segundo Leandro por irregularidades nas entidades onde estavam instaladas - Kobashi ponderou que o motivo deve ter sido excesso de "aparelhamento". "Se esses telecentros não fossem um empecilho, um problema político-partidário para o Governo, não teriam fechado. Por que vai ter esse custo? É natural que a gênese de qualquer projeto seja mais próxima do partido do Governo, mas se você é um bom administrador, você vai fazer com que ele cresça de maneira institucional, não partidária", defende. 


\subsection{Discurso dos monitores}

Nesta seção será apresentado o resultado das entrevistas realizadas com monitores das três CPAs, durante as quais foi colhida a opinião dos mesmos sobre: o conceito de inclusão digital; os objetivos dos programas em que estão inseridos; suas responsabilidades em cada CPA; as atividades realizadas pelos usuários na Internet; o impacto da Internet no consumo e produção de informação; os benefícios do programa para o usuário, assim como sua contribuição para o desenvolvimento social, político e econômico da comunidade; e a avaliação desses monitores sobre os programas onde trabalham.

\section{Quadro 40. Perfil Monitores}

\begin{tabular}{|c|c|c|c|}
\hline CPA & Unidade & Nome & \\
\hline \multirow{4}{*}{$\begin{array}{l}\text { Acessa } \\
\text { São } \\
\text { Paulo }\end{array}$} & \multirow[b]{2}{*}{$\begin{array}{l}\text { Inf. } \\
\text { SAVIC }\end{array}$} & Kleber & $\begin{array}{l}\text { Kleber Palma Nascimento Cardoso, } 22 \text { anos, estudante do } 3^{\circ} \text { ano de Educação Física, } \\
\text { trabalha no infocentro há } 4 \text { anos. Antes era estagiário na Sabesp, foi indicado pelo pai, } \\
\text { Nivaldo Cardoso, líder da entidade, quando o Acessa SP foi montado no local. }\end{array}$ \\
\hline & & Rodrigo & $\begin{array}{l}\text { Rodrigo Ferreira Nascimento, } 22 \text { anos, estudante, trabalha no Acessa SP há } 4 \text { anos e um } \\
\text { mês. Antes de ser contratado como monitor era office-boy. Foi indicado pela liderança da } \\
\text { associação comunitária que abriga o infocentro. Quando chegou conhecia muito pouco de } \\
\text { informática, "Acho que não chegava nem no nível de usuário, muito pouco mesmo, mas } \\
\text { tinha a vontade, eu gostava”, conta. Fez o treinamento da Escola do Futuro, e com seu } \\
\text { salário começou a se aperfeiçoar, fez cursos de informática, e há dois anos estuda inglês e } \\
\text { processamento de dados: "já consigo programar tranqüilo já", se orgulha, feliz por fazer o } \\
\text { que gosta. }\end{array}$ \\
\hline & \multirow{2}{*}{$\begin{array}{l}\text { Inf. } \\
\text { Piracicaba }\end{array}$} & Paula & $\begin{array}{l}\text { Paula Okuda, } 29 \text { anos, auxiliar de biblioteca e funcionária da Prefeitura de Piracicaba. } \\
\text { Cursou Ciências da Computação. É a monitora responsável pelo Acessa SP local há } 5 \\
\text { anos, desde que o infocentro foi montado na cidade, em julho de } 2000 .\end{array}$ \\
\hline & & Junior & $\begin{array}{l}\text { Júnior Batista da Silva, } 19 \text { anos, estudante de Sistema de Informações. É monitor há } 3 \\
\text { meses, contratado pela prefeitura através de um programa de estágio firmado com o CIEE } \\
\text { - Centro de Integração Escola-Empresa. }\end{array}$ \\
\hline \multicolumn{2}{|c|}{ Digitando o Futuro } & Eliélcio & Eliélcio Skrodk Antunes, 17 anos, estudante e estagiário no Farol do Saber há 2 meses. \\
\hline \multicolumn{2}{|c|}{ Telecentros POA } & Cinara & $\begin{array}{l}\text { Cínara da Costa Ortiz, } 27 \text { anos, fez curso de informática, é monitora há } 2 \text { anos. Também é } \\
\text { responsável pelo curso de capacitação básica dos usuários e oficinas. }\end{array}$ \\
\hline
\end{tabular}

Em geral, os monitores são jovens, estudantes de ensino médio ou superior, que já possuíam interesse em informática, mas se aperfeiçoaram a partir do envolvimento com os programas (quadro 40). Os monitores dos CPAs comunitários - no caso o Infocentro SAVIC, de São Paulo, e o Telecentro de Porto Alegre - geralmente são indicados pela liderança das entidades que mantêm as unidades. Kleber Cardoso e Rodrigo Nascimento, ambos com 22 anos e monitores do Infocentro SAVIC, na zona norte de São Paulo, são estudantes universitários. Cinara Ortiz, 27 anos, monitora Telecentro de Porto Alegre, é técnica em informática. No Infocentro Municipal de Piracicaba a responsável pelo programa, Paula Okuda, 29 anos, é funcionária da Prefeitura e a única com curso superior completo na área de Ciências da Computação. Os demais monitores são estagiários do ensino médio, como Junior Batista, 19 anos. Em Curitiba, no 
Digitando o Futuro, os monitores são sempre estagiários do ensino médio, entre eles Eliélcio Antunes, 17 anos.

Quadro 41. Definição de Inclusão Digital - Monitores

\begin{tabular}{|c|c|c|c|}
\hline CPA & Unidade & Nome & O que significa inclusão digital para você? \\
\hline \multirow{4}{*}{$\begin{array}{l}\text { Acessa } \\
\text { São } \\
\text { Paulo }\end{array}$} & \multirow[b]{2}{*}{$\begin{array}{l}\text { Inf. } \\
\text { SAVIC }\end{array}$} & Kleber & $\begin{array}{l}\text { A maneira que as pessoas pobres ou ricas têm para participar desse mundo } \\
\text { informatizado. }\end{array}$ \\
\hline & & Rodrigo & $\begin{array}{l}\text { ID para mim é uma maneira das pessoas conhecerem uma nova era, entrando em um novo } \\
\text { mundo, que é a informática, que para mim, é o futuro. Na verdade, eu acho que as } \\
\text { pessoas têm que tomar muito cuidado com isso. Porque apesar de ser o futuro de tudo, de } \\
\text { aproximar as pessoas, ela também afasta, né? Porque a partir do momento em que você tem } \\
\text { uma Internet que consegue chegar a qualquer lugar do mundo, é muito mais fácil você } \\
\text { entrar no Orkut e comentar com o pessoal: "Rodrigo, você não deixa scrap pra ninguém", } \\
\text { "pô, mas você vai me deixar um abraço pelo Orkut se você pode ir na minha casa, me } \\
\text { chamar pra gente conversar?". Então ela aproxima, ela consegue aproximar as pessoas, mas } \\
\text { ela também afasta os mais próximos. }\end{array}$ \\
\hline & \multirow[t]{2}{*}{$\begin{array}{l}\text { Inf. } \\
\text { Piracicaba }\end{array}$} & Paula & $\begin{array}{l}\text { É o meio de passar o que tem na Internet, os benefícios, para as pessoas que não têm } \\
\text { Internet. É passar esse meio da Internet, de navegação para essas pessoas mais } \\
\text { carentes que não têm acesso. Você envolvê-las nesse meio de comunicação que está } \\
\text { evoluindo muito rápido. }\end{array}$ \\
\hline & & Junior & $\begin{array}{l}\text { É igual a Internet a ID. Ter um site que nem o do Acessa, eu tenho que incluir eles lá, então } \\
\text { quer dizer que é uma ID lá. Eles não têm essa informação lá e agora eles estão tendo }\end{array}$ \\
\hline \multicolumn{2}{|c|}{ Digitando o Futuro } & Eliélcio & É um projeto que divulga a Internet entre as pessoas de baixa renda social \\
\hline \multicolumn{2}{|c|}{ Telecentros POA } & Cinara & $\begin{array}{l}\text { Bom, é tudo, né? A gente depende do computador agora para tudo agora aqui. Se tu } \\
\text { fizer um relatório, não faz mais à mão... Agora mesmo, a gente está fazendo esse cadastro, } \\
\text { para procurar endereço, mandar e-mail para as pessoas que moram longe. }\end{array}$ \\
\hline
\end{tabular}

Para os monitores entrevistados o conceito de Inclusão digital (quadro 41) remete à idéia de participar de um "de um novo mundo", do "futuro". Também está presente a preocupação de "passar o que tem na Internet, os benefícios" para "pessoas carentes que não têm acesso", de "ter informação".

Os objetivos dos programas (quadro 42) são percebidos em geral como "trazer" as pessoas de baixa renda para "descobrir a Internet", "trazê-los mais perto do futuro", apresentar uma "ferramenta" que pode oferecer "novas oportunidades de emprego", “levar conhecimento", "usar a Internet para benefício próprio". É como se o acesso à Internet possibilitasse a descoberta de um novo mundo. Os monitores do Acessa SP, com exceção do estagiário de Piracicaba, são mais articulados, sendo que os meninos de São Paulo apresentam um cenário um pouco "deslumbrado" do potencial da ferramenta. Paula Okuda, responsável pelo Infocentro de Piracicaba, questiona as capacitações dos monitores e afirma que a nova gestão do programa está querendo transformá-los em “agentes políticos”, pois, segundo ela, levar a Internet até as comunidades é um "jogo político", pois "essa é uma questão, eu acho, que para vereador, para serviço social...”. Em Porto Alegre a visão é mais a de ensinar, ensinar aprendendo. Os mais 
jovens, estagiários e estudantes do ensino médio, tiveram dificuldade em responder a pergunta, no caso Eliélcio, do Digitando o Futuro, e Junior, do Infocentro de Piracicaba.

\begin{tabular}{|c|c|c|c|}
\hline CPA & Unidade & Nome & Quais são os objetivos do programa? \\
\hline \multirow{4}{*}{$\begin{array}{c}\text { Acessa } \\
\text { São } \\
\text { Paulo }\end{array}$} & \multirow[b]{2}{*}{$\begin{array}{l}\text { Inf. } \\
\text { SAVIC }\end{array}$} & Kleber & $\begin{array}{l}\text { Na visão do programa é ID, pra que as pessoas de baixa renda, que não têm condições de } \\
\text { comprar um computador, que nunca viram um computador na vida. Trazê-las para o } \\
\text { infocentro para descobrir essa ferramenta que é a informática, que é o computador, a } \\
\text { Internet. }\end{array}$ \\
\hline & & Rodrigo & $\begin{array}{l}\text { Aproximá-las e trazê-las cada vez mais perto de um futuro que está para chegar, está } \\
\text { chegando cada dia mais, que todo mundo depende disso. Todo mundo não, mas uma boa } \\
\text { parte da população depende disso para sobreviver, as empresas dependem disso para } \\
\text { continuar crescendo. Hoje em dia, você pode ver, banca de jornal que não tem computador } \\
\text { para conseguir controlar o seu estoque, fecha. Então as pessoas dependem disso para } \\
\text { continuar trabalhando, é uma maneira delas conseguirem novas oportunidades de } \\
\text { emprego. }\end{array}$ \\
\hline & \multirow[t]{2}{*}{$\begin{array}{l}\text { Inf. } \\
\text { Piracicaba }\end{array}$} & Paula & $\begin{array}{l}\text { Eu acho que essa é uma coisa muito pessoal, porque, por exemplo, eu fui nessa última } \\
\text { capacitação, e eu tenho sentido que o Acessa SP está se tornando uma coisa meio política. } \\
\text { (...) Então eles têm interesse em passar a Internet para as pessoas? Têm. Eles querem levar } \\
\text { conhecimento e inclusão digital para as pessoas? Sim. Mas ao mesmo tempo, é que } \\
\text { nem eu falei para a minha diretora, eles estão tentando transformar a gente em agente } \\
\text { político, entendeu? Então, por um lado, eles têm o interesse em levar a Internet. No } \\
\text { começo, era aquela coisa de levar a Internet à população, "para as pessoas". Depois, } \\
\text { quando trocou essa administração agora, que houve essa troca de funcionários, eles } \\
\text { mudaram a visão. Eles querem também passar a Internet para as pessoas que não têm } \\
\text { acesso, fazer com que as pessoas cada vez mais utilizem, cada vez mais usem a Internet } \\
\text { para benefícios próprios, publicação de projeto, eles querem fazer que a Internet se torne } \\
\text { uma coisa do dia-a-dia da pessoa. (...) eles querem que o infocentro interaja com as } \\
\text { comunidades. O que eu entendo é que essa é uma questão, eu acho que para vereador, } \\
\text { para serviço social, para secretário fazer, não, eles querem que o monitor faça parte } \\
\text { disso (...). É que nem o cara falou: "vocês têm que sair do infocentro e vocês têm que } \\
\text { trazer a comunidade para dentro", mas espera á, a gente tem vários tipos de } \\
\text { comunidade dentro de uma cidade. Nós estamos no centro, nós não sabemos o que está } \\
\text { acontecendo lá na periferia. Isso eu senti que é um jogo político. }\end{array}$ \\
\hline & & Junior & O objetivo do programa é (...) ajudar as pessoas que vêm e que não sabem mexer. \\
\hline \multicolumn{2}{|c|}{ Digitando o Futuro } & Eliélcio & Não sabe \\
\hline \multicolumn{2}{|c|}{ Telecentros POA } & Cinara & Sempre ensinar. A gente está atendendo, ensina, mas também aprende com as crianças. \\
\hline
\end{tabular}

Com relação às responsabilidades dos monitores no programa (quadro 43), são visíveis basicamente duas posturas: de um lado "educar digitalmente", "ensinar" e "ajudar", e de outro "monitorar o uso correto dos equipamentos" e "o comportamento do usuário na Internet", e "cuidar para não haver depredações dos equipamentos”. A primeira postura é comum a todos os monitores entrevistados, com exceção de Eliélcio. A segunda representa o discurso dos mais jovens e que tiveram dificuldade em definir inclusão digital: o próprio Eliélcio, o estagiário Junior, do Infocentro de Piracicaba, e também de Cinara, de Porto Alegre, que resume suas responsabilidades em "ensinar $e$ monitorar". 


\begin{tabular}{|c|c|c|c|}
\hline$C P A$ & Unidade & Nome & Quais são as suas responsabilidades no programa? \\
\hline \multirow{4}{*}{$\begin{array}{l}\text { Acessa } \\
\text { São } \\
\text { Paulo }\end{array}$} & \multirow{2}{*}{$\begin{array}{l}\text { Inf. } \\
\text { SAVIC }\end{array}$} & Kleber & $\begin{array}{l}\text { Cuidar dos usuários, atender bem, ajudar, ser bastante compreensivo. Eu sou responsável } \\
\text { pelo CJ [Centro de Juventude], eu cuido das crianças, ensino a entrar em site... }\end{array}$ \\
\hline & & Rodrigo & $\begin{array}{l}\text { Eu me sinto responsável por parte da educação do pessoal dentro dessa área de } \\
\text { informática. Se a pessoa morar num bairro carente, ela depende muito de alguém auxiliando, } \\
\text { então eu me sinto responsável por nessa parte de educar digitalmente. }\end{array}$ \\
\hline & \multirow[b]{2}{*}{$\begin{array}{l}\text { Inf. } \\
\text { Piracicaba }\end{array}$} & Paula & $\begin{array}{l}\text { Eu sou responsável pela sala, tanto pelos estagiários, pelo equipamento, pela parte técnica } \\
\text { (...) até por problemas que acontecem no dia-a-dia com o usuário. }\end{array}$ \\
\hline & & Junior & $\begin{array}{l}\text { Eu sou aquele que não nega ajuda para ninguém. A pessoa chega lá, eu vou e ajudo. Ontem } \\
\text { chegou uma moça fazendo trabalho. Ela não sabe mexer, só que ela não queria mexer, então } \\
\text { ela vem direto para mim: "será que você poderia me ajudar? Só fazer essa pesquisa para } \\
\text { mim". Aí lá se vai o monitor ajudá-la a fazer a pesquisa e um trabalho, porque normalmente a } \\
\text { turma vem fazer trabalho e não sabe mexer no computador. }\end{array}$ \\
\hline \multicolumn{2}{|c|}{ Digitando o Futuro } & Eliélcio & $\begin{array}{l}\text { Verificar se os usuários estão agindo corretamente na Internet, não entrando em sites } \\
\text { pornográficos e jogos, que pesa muito na rede, e a prefeitura não tem disponibilidade de uma } \\
\text { rede mais forte. Aí eu tenho que monitorar serviços como jogos, chat, mensagem instantânea e } \\
\text { cuidar para que ninguém deprede os microcomputadores. }\end{array}$ \\
\hline \multicolumn{2}{|c|}{ Telecentros POA } & Cinara & Ensinar e monitorar. \\
\hline
\end{tabular}


Quadro 44. Atividades realizadas na Internet - Monitores

\begin{tabular}{|c|c|c|c|c|}
\hline CPA & Unidade & Nome & $\begin{array}{l}\text { Quais são as atividades (e/ou ferramentas) mais procuradas pelos } \\
\text { usuários no programa? }\end{array}$ & $\begin{array}{l}\text { Quais são as atividades relacionadas à produção e ao consumo de } \\
\text { informação mais desenvolvidas no programa? }\end{array}$ \\
\hline \multirow{4}{*}{$\begin{array}{l}\text { Acessa } \\
\text { São } \\
\text { Paulo }\end{array}$} & \multirow[b]{2}{*}{$\begin{array}{l}\text { Inf. } \\
\text { SAVIC }\end{array}$} & Kleber & $\begin{array}{l}\text { Orkut, chat, MSN, e-mail e ferramentas de buscas. Sites de empregos, editores } \\
\text { de textos, currículos, esses negócios. Jogos raramente, mas sexta e sábado tem } \\
\text { muita gente que só vem para jogar [jogos são permitidos somente nestes dias]. } \\
\text { Criamos a regra porque tem um monte de gente que vem pro Acessa SP pra trabalhar, } \\
\text { fazer sites, comprar alguma coisa. Alguns compram CDs. Não escutam rádio por falta } \\
\text { de plug-in. Poucos usam serviços de governo eletrônico, e neste caso pedem para o } \\
\text { monitor imprimir o documento. }\end{array}$ & $\begin{array}{l}\text { Usam muito o Orkut, as salas de bate-papo, o MSN. Algumas lêem sites de revistas e } \\
\text { jornais. Uma ou outra têm blog. Somente um usuário tem um website, de comércio } \\
\text { eletrônico. }\end{array}$ \\
\hline & & Rodrigo & $\begin{array}{l}\text { Depende muito da faixa etária. A gente pega a molecadinha pequena, de } 11 \text { a } 16 \text { anos, } \\
\text { que nunca tinha mexido num computador, eles vão atrás de bate-papo, é fatal, é } \\
\text { uma fase que eu acho que todo mundo passou, essa coisa de bate-papo. Orkut, } \\
\text { começam a usar um pouco mais velhos. Com 16, } \mathbf{1 8} \text { anos, eles começam a entrar } \\
\text { em alguma pesquisa, se interessar por alguma coisa, (...) cinema, coisas gratuitas, } \\
\text { parques de diversões para eles irem. Já os adultos vêm mesmo para procurar serviço, } \\
\text { ou até para fazer algum tipo de pesquisa. Eles pesquisam bastante. (...) E usam } \\
\text { serviços de governo eletrônico, tem bastante inscrição. Segunda via de conta de } \\
\text { água, luz, telefone. Nessa semana, a gente teve uma demanda muito grande de } \\
\text { pessoas fazendo inscrições para a CDHU e recadastrar os bilhetes da SP Trans. }\end{array}$ & $\begin{array}{l}\text { Eles praticam quase todas [as atividades citadas]. Acho que, na realidade, o que eles } \\
\text { praticam involuntariamente é a parte de pesquisar alguma coisa, de ver notícia. } \\
\text { Nosso público é jovem, então a gente vê que a juventude de hoje é desinteressada em } \\
\text { pesquisar, em olhar outro dia no geral. (...) Política, nada. O povo é acostumado com } \\
\text { o "não vai dar certo", ou não tem esperança de que vai dar certo, então acaba não se } \\
\text { preocupando com a política. Mas eles fazem blog, eles estão sempre visitando blogs, } \\
\text { todas as informações no geral, né? Criam websites. A questão de música e de } \\
\text { rádio...eles gostam muito de pegar MP3 na Internet para escutar. E criam HDs virtuais. }\end{array}$ \\
\hline & \multirow[t]{2}{*}{$\begin{array}{l}\text { Inf. } \\
\text { Piracicaba }\end{array}$} & Paula & $\begin{array}{l}\text { Aqui é mais sala de bate-papo, muita sala de bate-papo, agora esse Orkut e MSN } \\
\text { que estão no auge, mas a gente também tem o pessoal que procura emprego, que } \\
\text { vem fazer pesquisa. Jogo não, porque a gente não permite, se a gente deixasse o } \\
\text { jogo, já teria virado uma Lanhouse (...) Tem pessoas que vêm procurar música, tem } \\
\text { muito músico da cidade que vem aqui pegar letra de música para ensaiar em casa, tem } \\
\text { muitas mulheres que vêm buscar receitas de culinária. }\end{array}$ & $\begin{array}{l}\text { E-mail, Orkut, MSN... A gente tem o pessoal que vem ler a revista da cidade, eles } \\
\text { descem, pegam o jornal no andar de baixo, o jornal da cidade, aí eles vêm aqui só } \\
\text { para passar e-mail, então eu considero como uma pessoa que lê jornal, não na } \\
\text { Internet, mas lê. Tem uns estagiários meus que (...) fizeram o blog deles, mas o usuário } \\
\text { em si.Tem usuário que já tem o blog, não veio construir aqui, ele já tem o blog de fora e } \\
\text { veio acessar aqui dentro, não que eles tenham construído aqui. Também nunca teve “vou } \\
\text { hospedar a minha página, como eu faço?", isso nunca aconteceu aqui dentro, nunca } \\
\text { vieram pedir. }\end{array}$ \\
\hline & & Junior & $\begin{array}{l}\text { Orkut, MSN e trabalho. Muita gente vêm aqui ver trabalho. Nunca viu ninguém } \\
\text { fazendo curso ou usando serviços de governo. }\end{array}$ & $\begin{array}{l}\text { Escrever...principalmente currículo, vêm muita gente fazer currículo. Escrevem e-mail, } \\
\text { bate-papo, Orkut, MSN. Mas não são todos que escrevem blog não. Website aqui eu } \\
\text { nunca vi, mas eu acho que tem um usuário que freqüenta aqui que tem uma página. E } \\
\text { escutar rádio, nossa! É o que mais tem lá! Tem gente que lê.... }\end{array}$ \\
\hline \multicolumn{2}{|c|}{ Digitando o Futuro } & Eliélcio & $\begin{array}{l}\text { Fazem mais pesquisa da escola mesmo. Muito trabalho escolar. Mas também tem } \\
\text { divulgação de cultura, como arte, música e outras coisas, como esporte. }\end{array}$ & $\begin{array}{l}\text { O MSN, que seria o programa de mensagem instantânea é o mais divulgado. É } \\
\text { proibido porque pesa muito a rede. O Orkut é um site muito pesado porque é feito } \\
\text { em Flash, daí também pesa muito a rede, também é proibido. Sala de bate-papo, só } \\
\text { do Digitando o Futuro mesmo que é permitido. Mas de acordo com os usuários, } \\
\text { ninguém entra. (...). Pode escrever e-mail, pode entrar em qualquer e-mail. Não se escuta } \\
\text { rádio também, porque agora é linux. }\end{array}$ \\
\hline \multicolumn{2}{|c|}{ Telecentros POA } & Cinara & É mais Internet. Orkut, Fotolog, MSN, é mais isso. E claro que tem a pesquisa... & Blog, quase todos os meninos têm. \\
\hline
\end{tabular}


Segundo os monitores, as atividades mais realizadas na Internet (quadro 44) estão relacionadas à comunicação, com destaque para o site de relacionamento Orkut (5 citações), o MSN (4) e os chats (3). As pesquisas (escolares, de emprego ou em geral) vêm em segundo (4 citações) e o acesso a serviços de Governo eletrônico em terceiro (duas citações). Rodrigo Nascimento, do Acessa SP, lembra que existem diferenças de acordo com a faixa etária:

A gente pega a molecadinha pequena, de 11 a 16 anos, que nunca tinha mexido num
computador, eles vão atrás de bate-papo, é fatal, é uma fase que eu acho que todo mundo
passou, essa coisa de bate-papo. Orkut, começam a usar um pouco mais velhos. Com 16,
18 anos, eles começam a entrar em alguma pesquisa, se interessar por alguma coisa, (...)
cinema, coisas gratuitas, parques de diversões para eles irem. Já os adultos vêm mesmo
para procurar serviço, ou até para fazer algum tipo de pesquisa. Eles pesquisam bastante.
(..) E usam serviços de governo eletrônico, tem bastante inscrição. Segunda via de conta
de água, luz, telefone.

No Digitando o Futuro, programa que apresenta maiores restrições de uso - Orkut, MSN e programas multimídia não são permitidos - pesquisa e e-mail são praticamente as únicas atividades realizadas. Comércio eletrônico é muito raro ou praticamente inexistente em todos os programas, de acordo com os monitores. Jogos em geral são restritos a horários específicos ou simplesmente proibidos, "se a gente deixasse o jogo, já teria virado uma Lanhouse...", afirma Paula Okuda, do Infocentro de Piracicaba, que funciona no prédio de uma Biblioteca Municipal, onde devido à localização da CPA, há muito incentivo à leitura e à realização de trabalhos escolares.

Entre as atividades relacionadas à produção e consumo de informação destacam-se novamente o Orkut, chat e MSN. A leitura de sites, jornais e revistas acontece, mas muitas vezes de forma involuntária, através das páginas dos provedores. Muitos visitam blogs, mas poucos têm a sua página pessoal na Internet, com destaque para Porto Alegre, onde a monitora Cinara informou que "quase todos os meninos têm blog”. 


\begin{tabular}{|c|c|c|c|c|}
\hline$C P A$ & Unidade & Nome & $\begin{array}{l}\text { Você acredita que o programa contribui para o consumo de informação pela } \\
\text { comunidade local? Como? }\end{array}$ & $\begin{array}{l}\text { Você acredita que o programa contribui para a produção de } \\
\text { informação pela comunidade local? Como? }\end{array}$ \\
\hline \multirow{4}{*}{$\begin{array}{l}\text { Acessa } \\
\text { São } \\
\text { Paulo }\end{array}$} & \multirow[b]{2}{*}{$\begin{array}{l}\text { Inf. } \\
\text { SAVIC }\end{array}$} & Kleber & $\begin{array}{l}\text { Eu acho que sim. Acho que qualquer coisa que está na primeira página, quando ela } \\
\text { conecta, a primeira página ela vai e vê no Acessa SP, então qualquer site que ela entrar, até no } \\
\text { chat ela vai começar a ler, tudo errado, mas ela vai ler alguma coisa. }\end{array}$ & $\begin{array}{l}\text { Eu acho que sim. Elas escrevem e-mail, chat... No Orkut elas escrevem pra } \\
\text { caramba. Tem duas pessoas aqui no infocentro que sabem fazer sites. } \\
\text { Começaram aqui, depois, no caso do Marcelo, ele começou a fazer sites } \\
\text { procurando aqueles Webaula, depois ele fez um curso fora de Java, Linux, esses } \\
\text { negócios. }\end{array}$ \\
\hline & & Rodrigo & $\begin{array}{l}\text { Sim, com certeza. Involuntariamente. Você entrar num site para procurar uma coisa que } \\
\text { nem era o que eles estão procurando, ou até mesmo na hora de entrar em uma sala de bate- } \\
\text { papo, é inevitável eles entrarem na sala do UOL antes. Então eles vêem alguma } \\
\text { informação que eles acham interessante, que seja sobre futebol, que seja sobre artista, que } \\
\text { seja sobre Big Brother, seja sobre o que for, mas involuntariamente, eles estão consumindo } \\
\text { alguma informação dessa maneira, por passar o olho na tela: "pô, isso aqui é legal, antes de } \\
\text { entrar na sala de bate-papo, vou dar uma olhada." }\end{array}$ & $\begin{array}{l}\text { Tem usuários que gostam, que têm blog, que gostam de postar sempre e } \\
\text { todo dia. Quando eu estou em casa, conectado na Internet, os usuários que } \\
\text { estão no MSN falam: “olha Rodrigo, eu postei alguma coisa nova no meu } \\
\text { blog, vai lá dar uma olhada", eles acham legal a gente olhar, dar opinião. Tem } \\
\text { usuário que mantém um site, e aprenderam a criar o site aqui. Eles começaram a } \\
\text { estudar HTML aqui através da webaula, aprenderam por aqui. Criaram um site } \\
\text { e até hoje eles postam, alguns usuários dessa época ainda fazem isso. }\end{array}$ \\
\hline & \multirow[t]{2}{*}{$\begin{array}{l}\text { Inf. } \\
\text { Piracicaba }\end{array}$} & Paula & $\begin{array}{l}\text { Eu acredito que sim, porque por mais que a pessoa tenha vindo aqui na sala, que seja para ela } \\
\text { ver o e-mail dela, ela nunca senta na frente do computador, vê o e-mail e vai embora. } \\
\text { Porque para ela entrar no e-mail dela, ela tem que entrar num provedor, já no provedor } \\
\text { existem informaçôes do dia-a-dia, ali ela começa a rolar, aos poucos ela vai descobrindo... } \\
\text { ao invés dela vir e ficar } 10 \text { minutos no e-mail dela, ela passa a ficar 20, no dia seguinte ela } \\
\text { fica 30, porque ela começa a ver outros links, então eu acredito que incentiva sim. Para quem } \\
\text { não tem costume de ler jornal, de ler revista, a página inicial do provedor de e-mail deles [é a } \\
\text { entrada], porque a primeira coisa que eles fazem quando chegam dentro do posto é ver o e- } \\
\text { mail deles. Automaticamente eles entram no provedor do e-mail dele. Se ele vai ter que ver } \\
\text { algum tipo de informação, essa informação está ali na entrada, porque quando você } \\
\text { carrega a página, as informações estão ali. De repente, você vê uma foto de uma onça que } \\
\text { morreu no meio da estrada. Eles param para olhar a foto e ver a notícia, eles vão e eles lêem. } \\
\text { (...) }\end{array}$ & $\begin{array}{l}\text { Isso eu não notei muito, acho que é uma coisa muito pessoal. Pelo menos assim, } \\
\text { em termos de pedir ajuda para nós, não. A gente tem alguns jornalistas, } \\
\text { escritores, então eles escrevem na máquina deles, eles vêm em sites que } \\
\text { podem publicar o arquivo, alguma coisa assim, então eles vêm com o } \\
\text { arquivo pronto, eles só usam por questão mesmo de envio. Agora, a pessoa } \\
\text { sentar aqui e ficar digitando, isso eu nunca vi, nunca presenciei. Se as pessoas } \\
\text { passaram a escrever mais, isso eu não sei. }\end{array}$ \\
\hline & & Junior & $\begin{array}{l}\text { Acho que sim. Ah, tem pessoas que lêem as notícias, eu já vi gente lendo notícias aqui. Ali } \\
\text { pelo menos. Mas raramente é um dos oito que está lá, no máximo é um que lê. }\end{array}$ & $\begin{array}{l}\text { [As pessoas] escrevem, principalmente currículo, vêm muita gente fazer } \\
\text { currículo. Mais do que lêem. [Escrevem] no Orkut, envolve o mundo da } \\
\text { Internet. }\end{array}$ \\
\hline \multicolumn{2}{|c|}{ Digitando o Futuro } & Eliélcio & $\begin{array}{l}\text { Com certeza, porque eu realmente aprendi a mexer no computador no Farol. Digamos que de } \\
\text { informática eu sei mais do que o avançado já. Eu me vejo num ponto bom quanto a isso, } \\
\text { porque o programa Digitando o Futuro foi a minha inclusão social, digamos assim, me } \\
\text { incluíram diretamente à sociedade na informática, na tecnologia. Agora eu me vejo outra } \\
\text { pessoa. }\end{array}$ & $\begin{array}{l}\text { Sim. Mais uma vez, eu aprendi a criar sites no Farol também. Eu não sei quanto } \\
\text { aos outros, mas eu conheço muitas pessoas que também aprenderam a mexer no } \\
\text { Farol e fazem sites. Mas eu não vejo muita coisa de digitar, é mais copiado... }\end{array}$ \\
\hline \multicolumn{2}{|c|}{ Telecentros POA } & Cinara & $\begin{array}{l}\text { Com certeza. Eles chegam aqui para procurar informação... o que eles procuram mais } \\
\text { agora é placa de carro para saber se está atualizado, eles mandam currículo. }\end{array}$ & $\begin{array}{l}\text { Eles olham notícias no Terra, sobre Porto Alegre, sobre signo, sobre jovens... } \\
\text { eles entram no site direto. } \mathbf{E} \text { quase todos os meninos têm blog... }\end{array}$ \\
\hline
\end{tabular}


Todos os monitores afirmam que o programa no qual trabalham contribui muito para o consumo de informação na comunidade local (quadros 45), mesmo que involuntariamente. Três entre eles, os mais articulados - Kleber, Rodrigo e Paula explicam que o maior impacto é justamente a leitura involuntária da página do próprio programa (no caso do Acessa SP) ou do fornecedor de e-mail, que costuma ser o primeiro a ser checado quando alguém senta na frente do computador. "Ali a pessoa começa a rolar, aos poucos ela vai descobrindo... ela começa a ver outros links...", descreve Paula. O fornecedor de serviços e-mail representa assim o indutor, a porta de entrada da Internet para esses usuários, e é a sua capacidade de chamar a atenção que fará com que a leitura e a busca de informação sejam despertadas. Já a contribuição do programa para a produção de conteúdo local não é tão evidente, muito pelo contrário. Em geral as atividades de escrita dos usuários se resumem ao e-mail, ao chat e Orkut - e em alguns casos à redação de currículo e blogs.

De acordo com os monitores, a relação dos usuários com o programa é muito boa (quadro 46), o CPA se transformou em um "ponto de encontro" da juventude local, um "ponto de apoio". Eles demonstram que existe uma valorização do espaço por parte da comunidade, que se preocupa inclusive em "cuidar" dos equipamentos. Somente Eliélcio, afirmou que os "usuários não estão bem por dentro do programa” e que "a única coisa que eles sabem é que é para Internet”.

Já o maior benefício que o programa trouxe para a comunidade é, para os monitores, indiscutivelmente a própria Internet, a possibilidade do acesso à tecnologia, à informática. O sentimento de inclusão é expresso dessa apropriação: “me senti incluído na sociedade tecnológica. Informática é que nem o bê-a-bá ultimamente, se você não souber o básico, você está excluído da sociedade”, afirma Eliélcio.

Kleber e Cinara também observam claramente os benefícios do programa para o "aumento da auto-estima" e a "diminuição da criminalidade" na comunidade. "Tiramos muita gente da rua", afirma Cinara, identificando o papel do programa como responsável pelo resgate da cidadania no entorno do telecentro. "Quando ele senta num computador, acho que eles incorporam alguma coisa. A pessoa pode ser a mais horrível possível, mas quando entra num chat e vai conversando com outras pessoas, acho que aumenta a auto-estima dele lá, ele fala 'pô meu, eu conversei com essa 
menina, não acredito que eu fiz isso"', conta Kleber. Rodrigo aponta ainda a superação da burocracia na solução de problemas cotidianos, como a emissão da segunda via de uma conta, como um dos aspectos mais positivos do programa.

Houve uma grande dificuldade dos monitores para identificar qual a contribuição dos programas de inclusão digital para o desenvolvimento social, político e econômicos da comunidade (quadro 47). No que diz respeito às oportunidades de geração de renda e emprego, Kleber, Rodrigo e Cinara citam a possibilidade de se conseguir um emprego melhor ou uma alguma forma de renda, no caso o exemplo de um usuário que criou uma loja virtual para vender cartões telefônicos. Também foi citada a maior facilidade para elaborar e enviar currículos. No que tange as oportunidades de educação e acesso à informação e cultura, o aumento do "interesse pela leitura" foi citado por Rodrigo e Paula. Kleber mencionou o interesse por "voltar a estudar" e Cinara "o modo de tratar as pessoas". Eliélcio afirma que a Internet por si só já é uma forma de acesso à cultura. E com relação à conscientização social e participação política, apenas Rodrigo conseguiu responder, afirmando que com o programa a comunidade tem um ponto de apoio "para se encontrar e aprender". 


\section{Quadro 46. Benefícios dos programas de Inclusão Digital - Monitores}

\begin{tabular}{|c|c|c|c|c|}
\hline CPA & Unidade & Nome & Qual é a relação do programa com as comunidades onde ele se encontra? & $\begin{array}{l}\text { Para você, qual é o maior benefício que o programa trouxe para } \\
\text { o usuário? E para a comunidade? }\end{array}$ \\
\hline \multirow{4}{*}{$\begin{array}{l}\text { Acessa } \\
\text { São } \\
\text { Paulo }\end{array}$} & \multirow{2}{*}{$\begin{array}{l}\text { Inf. } \\
\text { SAVIC }\end{array}$} & Kleber & $\begin{array}{l}\text { É ótimo, o pessoal vem pra cá. Às vezes tem gente que nem vem pra cá pra acessar, vem pra } \\
\text { conversar. (...) Eles cuidam pra caramba do infocentro. Quando um começa a bater muito no } \\
\text { mouse, outro fala: "vai quebrar o negócio aí!" }\end{array}$ & $\begin{array}{l}\text { Ah, eu acho que eles aumentaram a auto-estima, porque muitas pessoas } \\
\text { falam: "pô, eu nunca vou ter chance de mexer num computador", aí vêm } \\
\text { pra cá e falam "nossa, me ensina, estou precisando". E quando ele senta } \\
\text { num computador, acho que eles incorporam alguma coisa. A pessoa pode } \\
\text { ser a mais horrível possível, mas quando entra num Chat e vai conversando } \\
\text { com outras pessoas, acho que aumenta a auto-estima dele lá, ele fala "pô } \\
\text { meu, eu conversei com essa menina, não acredito que eu fiz isso". E eu } \\
\text { acho que diminui pra caramba [a criminalidade no bairro]. }\end{array}$ \\
\hline & & Rodrigo & $\begin{array}{l}\text { Eles têm um ponto de encontro onde foi formado muito círculo de amizade, pelo que eu vejo nas } \\
\text { ruas, gente não se conhecia, era capaz de ser vizinho, hoje são amigos que se encontram direto, } \\
\text { que saem juntos. Então, além de ser um ponto de encontro é um ponto de apoio onde eles } \\
\text { também conseguem aprender. Aqui a relação é bem aberta, a gente trabalha bem aberto com o } \\
\text { pessoal, eles sabem a nossa maneira de trabalhar aqui, então eles aceitam legal. Sobre as pessoas } \\
\text { que participam, no começo era um grupo mais seleto, uma comunidade menor aqui da região } \\
\text { mesmo. A gente tinha um telecentro aqui perto. Depois que esse telecentro fechou, a nossa área } \\
\text { expandiu demais. Então a gente pega pessoas de áreas que ficam bem distante daqui. }\end{array}$ & $\begin{array}{l}\text { Para o usuário? Olha, eu acho que só de ter trazido os computadores para } \\
\text { cá para eles conhecerem um pouco da informática já foi um grande } \\
\text { benefício para os usuários aqui da região (...) Para a comunidade? Bom, } \\
\text { acho que a burocracia diminuiu um pouco, né? (...) Foi a questão da } \\
\text { burocracia, eles viviam reclamando que "ah, eu tenho que ir na Sabesp } \\
\text { para tirar uma segunda via de conta, eu tenho que enfrentar uma fila, chego } \\
\text { lá e ninguém acaba resolvendo", "tenho que ir do outro lado da cidade para } \\
\text { conseguir resolver o meu problema", agora eles conseguem resolver pelo } \\
\text { computador. Então é a questão burocrática. }\end{array}$ \\
\hline & \multirow[t]{2}{*}{$\begin{array}{l}\text { Inf. } \\
\text { Piracicaba }\end{array}$} & Paula & $\begin{array}{l}\text { Quando o infocentro chegou aqui na cidade, já existia Lanhouses. Quando as pessoas precisavam, } \\
\text { elas já pagavam para usar. A única coisa que o infocentro fez é que aqui é gratuito, as pessoas não } \\
\text { precisam pagar. Ela usa os } 30 \text { minutos dela, que eu acho que é o tempo suficiente para o que ela } \\
\text { precisa, mesmo porque a gente tinha o Correio, que tinha Internet gratuita. (...) Então é difícil dizer } \\
\text { para você se modificou, porque como eu falei, Piracicaba tem muita Lanhouse, então tem muita } \\
\text { gente que vai lá, porque lá ela tem muito mais privacidade. Aqui não tem privacidade, (...) e tem } \\
\text { pessoas que querem acessar coisas que não pode, então ele prefere pagar e ir para a LAN do que } \\
\text { ficar aqui. Ou ele fala que demora muito, que o micro é devagar, é ultrapassado... Mas para esse } \\
\text { pessoal que não tinha acesso, isso mudou, porque a gente percebe que as pessoas têm usado } \\
\text { mais computador, eles têm procurado emprego, eles têm evoluído para o mercado. }\end{array}$ & $\begin{array}{l}\text { Eu acho que trazer a Internet para as pessoas que não têm acesso. } \\
\text { Porque eu mesma, eu sou formada em Ciências da Computação, quando eu } \\
\text { comecei a fazer minha faculdade, eu não tinha computador na minha } \\
\text { casa. Eu só fui ter computador depois de três anos da faculdade. Então } \\
\text { durante os meus três primeiros anos na faculdade, o único computador que } \\
\text { eu tinha era o da escola. E eu não tinha acesso a nenhum outro lugar. Eu } \\
\text { sentia a dificuldade de você necessitar de um computador e você não ter. } \\
\text { Aqui, agora eu acho que ele ajuda as pessoas. }\end{array}$ \\
\hline & & Junior & Acho que tem alguns que têm uma relação, sim (...) mas tem alguns que nem vêm falar com você. & Benefício? É a Internet, não tem como. \\
\hline \multicolumn{2}{|c|}{ Digitando o Futuro } & Eliélcio & $\begin{array}{l}\text { Normalmente são pessoas daqui mesmo, Jd Pinheirinho, mas tem pessoas de outras partes da } \\
\text { cidade, que vêm aqui. Porque eu não sei, sendo que o Farol tem muitos lugares. Então o projeto } \\
\text { Digitando o Futuro foi bem divulgado, está bem amplo, e algumas bibliotecas também têm } \\
\text { informatização. Agora, a relação do projeto com os usuários, eu acho que os usuários não estão } \\
\text { bem por dentro do projeto. A única coisa que eu acho que eles sabem é que o programa é para a } \\
\text { Internet, a Internet deles, a única coisa que eles entendem. }\end{array}$ & $\begin{array}{l}\text { Pro usuário foi o que trouxe para mim também, porque eu me senti } \\
\text { inclú́do na sociedade tecnológica, eu acho que é a mesma coisa, porque } \\
\text { falou em computador hoje, todo mundo tem que saber, é que nem o bê-a- } \\
\text { bá. Informática é que nem o bề-a-bá ultimamente, se você não souber o } \\
\text { básico, você está excluído da sociedade. }\end{array}$ \\
\hline \multicolumn{2}{|c|}{ Telecentros POA } & Cinara & $\begin{array}{l}\text { Eles adoram, tanto é que eles "ah, tá fechado, mas deixa eu ficar um pouquinho aî". É um ponto de } \\
\text { encontro. }\end{array}$ & $\begin{array}{l}\text { Tiramos muita gente da rua. Há vezes que eles vêm aqui para utilizar } \\
\text { como ponto de encontro, eles se encontram aqui, eles conversam, } \\
\text { entram na Internet, riem bastante, estão mesmo em casa. Tiramos um } \\
\text { pouco aquele tumulto que tinha nas esquinas e esses meninos que } \\
\text { estavam todos nas esquinas cheirando, eles vêm todos aqui, depois vai } \\
\text { cada um para a sua casa. }\end{array}$ \\
\hline
\end{tabular}




\section{Quadro 47. Contribuição dos programas de ID para o desenvolvimento social, político e econômico - Monitores}

\begin{tabular}{|c|c|c|c|c|c|}
\hline \multirow[b]{2}{*}{ CPA } & \multirow[b]{2}{*}{ Unidade } & \multirow[b]{2}{*}{ Nome } & \multicolumn{3}{|c|}{ Com base na sua experiência diária, você já identificou impactos do programa na comunidade local? Quais? } \\
\hline & & & Oportunidade de geração de renda e emprego & $\begin{array}{l}\text { Oportunidades de educação, acesso à informação } \\
\text { e cultura }\end{array}$ & Conscientização social e participação política \\
\hline \multirow{4}{*}{$\begin{array}{c}\text { Acessa } \\
\text { São } \\
\text { Paulo }\end{array}$} & & Kleber & Conseguir um emprego melhor. & Eu acho que voltar a estudar. & [não respondeu $]$ \\
\hline & $\begin{array}{l}\text { Inf. } \\
\text { SAVIC }\end{array}$ & Rodrigo & $\begin{array}{l}\text { Impacto social sim, tem. Bom, aumento de renda eu não } \\
\text { posso dizer, mas a gente tem uma pessoa no infocentro, o } \\
\text { Carlos, que veio aqui atrás de emprego, foi difícil, ele não } \\
\text { conseguiu arrumar emprego e o que ele fez? Ele abriu sua } \\
\text { própria loja virtual. Então hoje ele tem uma loja virtual } \\
\text { onde ele vende cartões telefônicos e vende para Portugal, } \\
\text { vende para a Argentina, vende para os Estados Unidos. E } \\
\text { não são quantias pequenas. Ele começou do nada e hoje } \\
\text { ele tem a sua própria e-commerce. }\end{array}$ & $\begin{array}{l}\text { Vontade de estudar, eu posso não concordar, mas o } \\
\text { interesse por leitura, sim }\end{array}$ & $\begin{array}{l}\text { Eles têm um ponto de apoio e um ponto para se } \\
\text { encontrar também, onde foi formado muito círculo } \\
\text { de amizade, pelo que eu vejo nas ruas, gente não se } \\
\text { conhecia, era capaz de ser vizinho, hoje são amigos } \\
\text { que se encontram direto, que saem juntos. Então, } \\
\text { além de ser um ponto de encontro é um ponto de } \\
\text { apoio onde eles também conseguem aprender. }\end{array}$ \\
\hline & \multirow[t]{2}{*}{$\begin{array}{l}\text { Inf. } \\
\text { Piracicaba }\end{array}$} & Paula & [não respondeu $]$ & $\begin{array}{l}\text { Eu acho que a sala aqui incentivou mais as pessoas a } \\
\text { utilizar mais os livros. Porque a sala está em uma } \\
\text { biblioteca. [Se não estivesse], as pessoas iriam lá, } \\
\text { usariam os computadores, talvez lessem, talvez eles } \\
\text { colocassem alguma sala de espera, alguma revista, algum } \\
\text { jornal para eles lerem e ficaria ali, mas não que fosse } \\
\text { incentivado que as pessoas lessem mais, pegassem mais o } \\
\text { hábito pela leitura. }\end{array}$ & [não respondeu $]$ \\
\hline & & Junior & [não respondeu $]$ & [não respondeu] & [não respondeu] \\
\hline \multicolumn{2}{|c|}{ Digitando o Futuro } & Eliélcio & $\begin{array}{l}\text { Fica mais fácil de mandar currículo, se for currículo on- } \\
\text { line. }\end{array}$ & $\begin{array}{l}\text { A Internet é um tipo de cultura. Então eu acho que } \\
\text { como as pessoas não estavam habituadas à Internet, acho } \\
\text { que teve uma compensação de cultura, sendo que muda o } \\
\text { vocabulário pra caramba das pessoas. E as pessoas } \\
\text { ficam em casa, meio preguiçosas, por conta da Internet } \\
\text { (...). O hábito mais freqüente mesmo é conversar. Imagina } \\
\text { você pagar um absurdo de telefone para ligar para os } \\
\text { Estados Unidos, sendo que no sistema do Farol é de } \\
\text { graça. }\end{array}$ & [não respondeu $]$ \\
\hline \multicolumn{2}{|c|}{ Telecentros POA } & Cinara & $\begin{array}{l}\text { Às vezes tem gente que vem aqui para enviar currículo, } \\
\text { né... e muitos conseguem emprego. }\end{array}$ & $\begin{array}{l}\text { Muita coisa mudou nas pessoas, a educação, o jeito de } \\
\text { tratar, a gente vê [que eles estão mais educados]. E a } \\
\text { gente trata com todo o tipo de gente... A gente tem que } \\
\text { saber como tratar, e eles são bem tratados. }\end{array}$ & [não respondeu] \\
\hline
\end{tabular}




\section{Quadro 48. Avaliação dos programas de Inclusão Digital - Monitores}

\begin{tabular}{|c|c|c|c|}
\hline$C P A$ & Unidade & Nome & $\begin{array}{l}\text { Na sua opinião, o programa atende bem às necessidades do cidadão? Em } \\
\text { caso negativo, o que poderia ser feito para atendê-lo melhor? }\end{array}$ \\
\hline \multirow{4}{*}{$\begin{array}{l}\text { Acessa } \\
\text { São } \\
\text { Paulo }\end{array}$} & \multirow[b]{2}{*}{$\begin{array}{l}\text { Inf. } \\
\text { SAVIC }\end{array}$} & Kleber & $\begin{array}{l}\text { Atende. Mas podia ter mais cursos. As pessoas vêm pra cá pensando que vai ter aula. A } \\
\text { gente explica que não é aula de informática, que não tem como eu ficar só do lado dele, } \\
\text { porque outro vai me chamar, então eu vou ter que ir pra lá (...) Eu só posso dar uma } \\
\text { noção de Internet para eles. Tem muitos senhores que sentam nos computadores e os } \\
\text { olhos de alguns deles até brilham, porque nunca sentou num computador, nunca viu nada, } \\
\text { às vezes eles ficam até com medo de mexer. [E se o infocentro fechasse?] Ah, eu ia } \\
\text { chorar... }\end{array}$ \\
\hline & & Rodrigo & $\begin{array}{l}\text { Completamente, no meu ponto de vista, sim. Tem suas falhas, claro, como em todo } \\
\text { programa. [Para melhorar] eu daria um pouco de instrução para o próprio usuário, a } \\
\text { gente liberar um tempo para dar aula ou formar os monitores para dar aula. O } \\
\text { Acessa funciona todo dia, mas acho que a gente pega muita gente sem instrução nenhuma, } \\
\text { entendeu? Aquele cara que você fala: "ah, você precisa colocar o mouse ali", ele tira o } \\
\text { mouse de cima da mesa e encosta na tela do monitor. Então você pegar e separar um } \\
\text { tempo maior, tal dia por semana a gente vai dar uma instrução básica, vai dar aula } \\
\text { mesmo para essas pessoas que não têm conhecimento nenhum. }\end{array}$ \\
\hline & \multirow[t]{2}{*}{$\begin{array}{l}\text { Inf. } \\
\text { Piracicaba }\end{array}$} & Paula & $\begin{array}{l}\text { Atende, dentro dos } 30 \text { minutos eu acho que atende. Eu costumo falar que o brasileiro } \\
\text { nunca está contente com as coisas. Se você dá um computador, ele quer dois, se você dá } \\
\text { dez, ele quer vinte... (...), mas eu acho que os } 30 \text { minutos que eles têm aqui são suficientes } \\
\text { pelo que as pessoas vêm fazer aqui. Eles sempre pedem para aumentar o tempo, sabe? } \\
\text { Aí eu falo: "você já imaginou, eu ponho uma hora aqui de uso. Enquanto você tá usando, } \\
\text { você tá bem. E na hora que você chegar e todos os computadores estiverem ocupados e } \\
\text { você precisar usar, você vai ficar uma hora?" }\end{array}$ \\
\hline & & Junior & Atende \\
\hline \multicolumn{2}{|c|}{ Digitando o Futuro } & Eliélcio & $\begin{array}{l}\text { As básicas, sim. Eu acho que é esse o ponto em que o projeto quer buscar, que seria } \\
\text { incorporar a informática no dia-a-dia das pessoas e ver que informática e computador não } \\
\text { é coisa de outro mundo, que só nerds conseguem mexer. [Algo podia melhorar?] Com o } \\
\text { projeto Digitando o Futuro, não, mas eu acho que a prefeitura não tem condição de ensino } \\
\text { da informática. Porque não adianta, mesmo se você colocar um computador na frente } \\
\text { de uma pessoa, e ela não saber o que fazer. Poderiam fazer um projeto a mais, mas é } \\
\text { outro projeto. }\end{array}$ \\
\hline \multicolumn{2}{|c|}{ Telecentros POA } & Cinara & $\begin{array}{l}\text { Com certeza. O problema é que o telecentro está com um problema que às vezes estraga } \\
\text { os computadores, um monte de gente quer usar, a gente tem aqueles } 10 \text { computadores } \\
\text { certinhos, a gente saca dois ou três, diminui, fica aquele tumulto aqui no telecentro. É } \\
\text { muito tumulto para esperar os outros. O problema mesmo é o computador. }\end{array}$ \\
\hline
\end{tabular}

A avaliação dos programas de Inclusão Digital, segundo os monitores (quadro 48), é muito positiva: eles atendem plenamente as necessidades dos cidadãos. Mas, seria importante oferecer um pouco mais de instrução ou noções básicas para os usuários. " $a$ gente pega muita gente sem instrução nenhuma, entendeu? Aquele cara que você fala: 'ah, você precisa colocar o mouse ali', ele tira o mouse de cima da mesa e encosta na tela do monitor...", explica Rodrigo. Foi lembrada também a grande procura por cursos, e mencionada a possibilidade de se desenvolver um programa complementar de ensino que atendesse essa procura. Cinara mencionou problemas constantes com os equipamentos, que acabam criando dificuldades no atendimento, pois a procura é muito grande. Mas de maneira geral, o programa atende o objetivo de "incorporar a informática no dia-a-dia das pessoas", como ilustra Eliélcio. 


\subsection{Discurso dos usuários}

Nesta parte serão apresentados os resultados da pesquisa on-line realizada com usuários das três unidades investigadas, que nos possibilitou caracterizar o perfil do usuário dos programas selecionados e recolher seu ponto de vista sobre: o conceito de inclusão digital; as atividades realizadas nos CPAs e na Internet; o impacto da Internet no consumo e produção de informação; os benefícios do programa para o usuário, assim como sua contribuição para o desenvolvimento social, político e econômico da comunidade; a avaliação desses usuários sobre os programas de inclusão digital; e o uso de telefones móveis para o acesso à Internet.

\section{Perfil dos respondentes}

Gráfico 1. Faixa etária

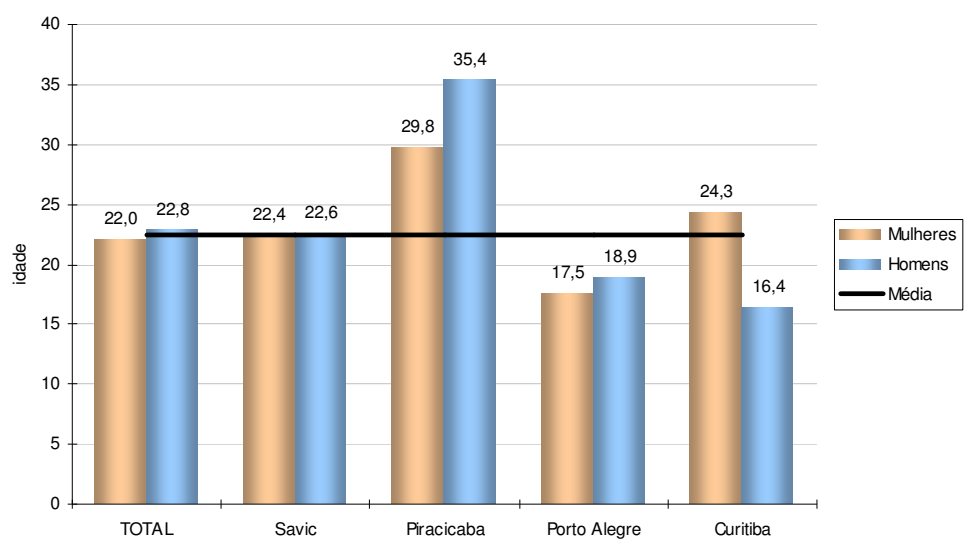

Gráfico 2. Sexo

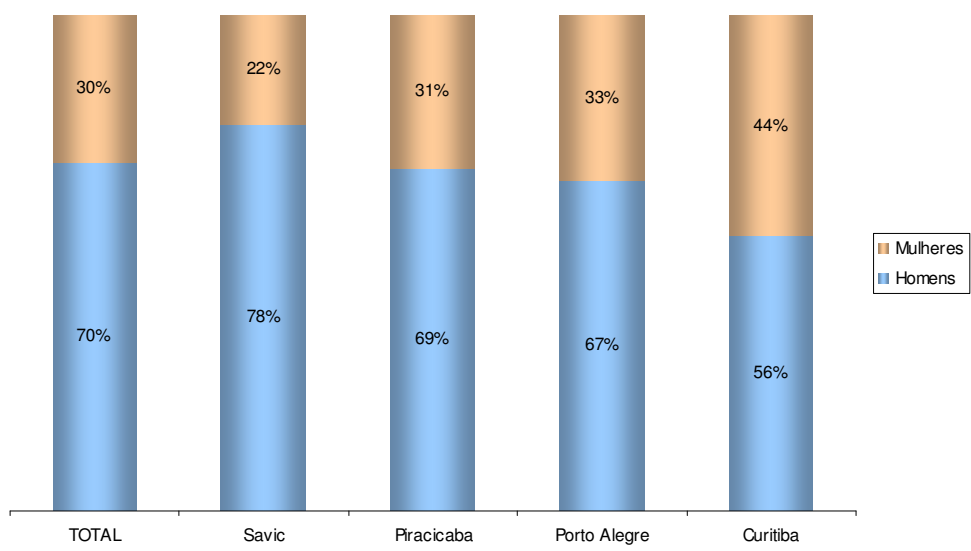


Gráfico 3.

Escolaridade

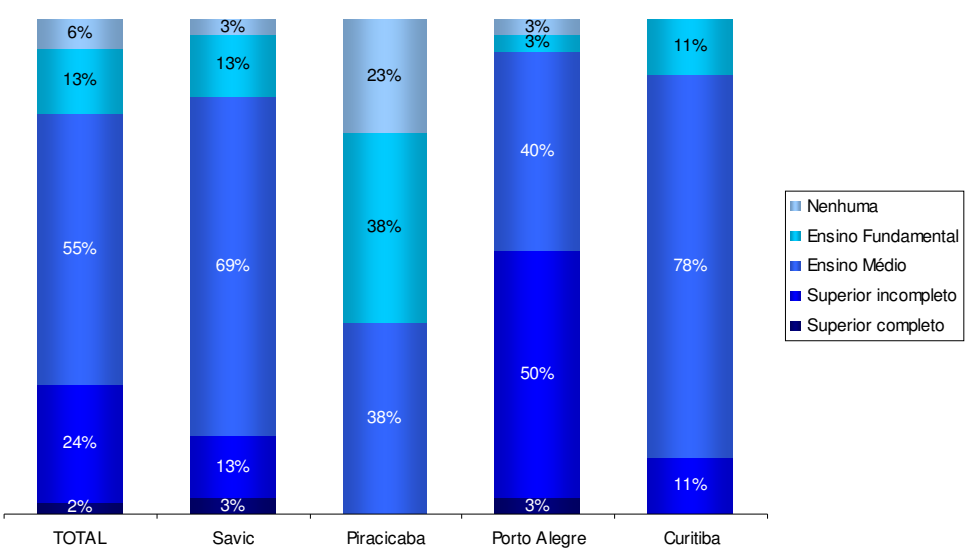

Gráfico 4. Ocupação

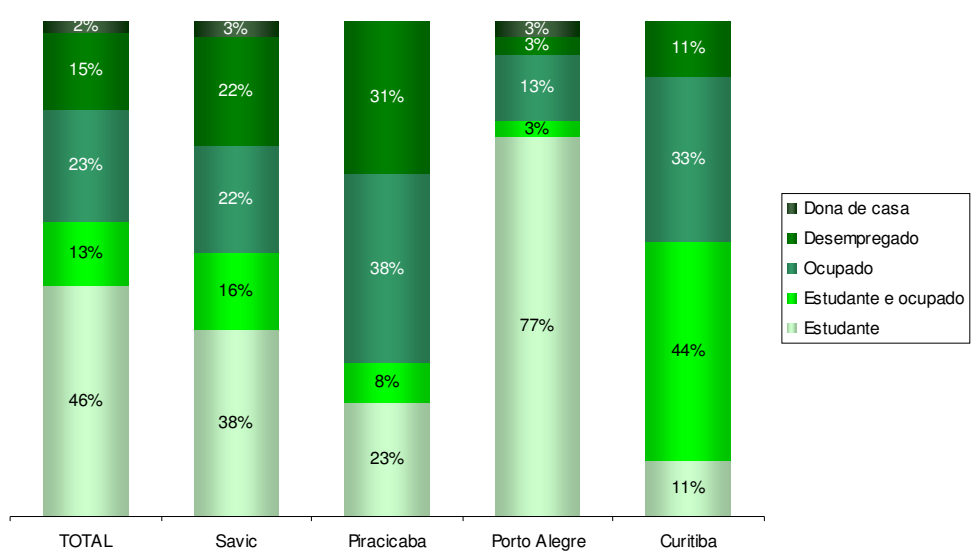

Quadro 49. Membro de partido político, associações de bairro, conselhos ou outras atividades comunitárias

\begin{tabular}{|l|l|l|l|l|l|}
\hline & TOTAL & SAVIC & PIRACICABA & POA & CURITIBA \\
\hline Homens & 16 & 4 & 6 & 6 & 0 \\
\hline Mulheres & 4 & 0 & 1 & 2 & 1 \\
\hline Total & 20 & 4 & 7 & 8 & 1 \\
\hline
\end{tabular}

O perfil médio do usuário dos CPAs estudados é definido por indivíduos do sexo masculino (70\% dos usuários que responderam o questionário), com idade média de 22,5 anos, estudante e empregado. O Infocentro de Piracicaba é o que recebe usuários com a maior média de idade verificada, 33,5 anos. Já em Porto Alegre e Curitiba estão os mais jovens, com idades médias de pouco mais de 18 anos.

Cerca de $55 \%$ dos respondentes possuem até o ensino médio completo, $24 \%$ têm nível superior incompleto e $2 \%$ terminaram a universidade. Apenas $13 \%$ informaram possuir apenas o fundamental completo e $6 \%$ afirmaram nunca ter ido à escola. Em Porto Alegre estão os usuários com mais anos de educação: $50 \%$ freqüentam ou já 
freqüentaram uma universidade. No outro extremo, em Piracicaba, 38\% possuem no máximo o ensino fundamental e $23 \%$ declararam nunca ter ido à escola.

A maior parte dos respondentes declarou ser estudante (48\%), sendo que outros $13 \%$ informaram estudar e trabalhar. Desempregados representam 15\% da amostra, e somente trabalhadores, $23 \%$. Apenas $2 \%$ se declarou dona de casa. No Infocentro de Piracicaba, freqüentado pelos usuários mais velhos, está a maior taxa de trabalhadores (38\%) e também de desempregados, 31\%. Já em Porto Alegre foi encontrado o maior número de estudantes em tempo integral (77\%), enquanto em Curitiba foi detectada a maior concentração de estudantes ocupados (44\%). No total, $24 \%$ dos respondentes informou ser membro de partidos políticos, associações de bairro, conselhos ou outras atividades comunitárias, sendo que, desse total, $80 \%$ são homens.

\section{Definição de Inclusão Digital}

No que diz respeito à compreensão do termo "inclusão digital", deve-se tomar em consideração que durante a aplicação do questionário piloto, no Infocentro SAVIC, recebi vários comentários de usuários sobre a dificuldade em compreender o conceito. Por sugestão de um deles, inclusive, substituímos a pergunta "Para você, o que significa inclusão digital?” por “O que a Internet significa para você?”. Essa adequação, entretanto, nos trouxe uma dificuldade maior para a construção do discurso dos usuários com relação ao termo.

No quadro 50 será apresentada uma síntese das respostas obtidas nas duas situações. De maneira geral, os usuários do Infocentro SAVIC compreendem inclusão digital como "ter acesso e saber usar o computador", "ter acesso à Internet", "ter acesso à informática" e até mesmo "estar inserido no mundo digital". Também está presente a idéia de "conhecer o mundo", de ter "oportunidade para aprender", e de "ter informação". Já os usuários dos demais CPAs identificam a Internet principalmente com um "meio de informação e comunicação". Também é compreendida como uma "ferramenta de trabalho e de pesquisa", "conhecimento" e "diversão". Nota-se que a visão é extremamente positiva a ampla, pois para alguns ela é "tudo", "minha vida", e fortemente influenciada pela mídia: "o mundo na era digital em nosso redor". 


\section{Quadro 50. Definição de Inclusão digital - Usuários}

Para você, o que significa inclusão digital ${ }^{79}$

A comunidade se incluir na informatica

que esta nos incluindo na parte de informatica

Significa que pessias que não sabem informatica, aprendam e se incluam digitalmente

poder conhecer o mundo

possilbiltar a todas as pessoas o acesso a Internet -3 respostas

acho que um programa que permite o acesso das pessoas a intenet.

melhora o dezenpenho

Acesso aos meios de comunicação digital e compra de equipamentos

Pessoas que não tiveram oportunidade de aprender, sobre o munda da informática

saber ultilisar um $\mathrm{pc}$

incluir as pessoas digitalmente

uma rede de tecnologias

Significa que todos possão utilizar ou ter acesso ao computador(Ex:Internet),Etc

significa que todos possão ter acesso a um computador

Internet

ter acesso a Internet e ao conhecimento que ela possa me oferecer

inserção para poder acessar o computador e aprender o que ele pode fazer por voce.

Seria uma pesquisa para você se aprimorar

$\mathrm{O}$ acesso da população na Internet e acesso a infomática.

oportunidades para conhercer o mundo digital

as pessoas aprenderem informatica

fornecer informações para todos cidadãos

a inclusao dr pessoas a computadores sem ter condições de ter um computador

Significa estar inserido no mundo on-line

É um meio que as pessoas pobre ou não tem de fazer parte do mundo digital

Explorar novos caminhos

Disponibilizar acesso a tecnologia (como a informática) a toda comunidade independente de condição finaceira ou escolaridade.

significa um progeto para todas as pessoas

É tudo isso...

Inclusão digital é uma união da população com a Internet

Não sabe/não respondeu - 5 respostas

\section{O que a Internet significa para você??}

significa uma forma de aprendizado e uma maneira de ir a varios lugares do mundo sem sair dacadeira.

um meio de informação e comunicação - 8 respostas

meio de comunicação onde podemos falar com pessoas de todo o mundo e podemos tambem participar, usufruir de muitas meio de comy
atividades.

tudo -2 respostas

significa um curtiçao na minha vida exp; um hobby

muitas coisa, por exemplo:ficar sabendo das últimas noticias que acontece no dia-a-dia,isso é muito importante.

Significa á visitsão de um cheio de novidades eoprtunidades!

É um meio de comunicação na qual estão conectados redes do mundo inteiro. É onde eu posso fazer qualquer tipo de pesquisa onde pago minha contas, etc...

Um meio de informação, pesquisa de informação e interação com várias pessoas em todos os lugares do mundo

ferramenta de trabalho, contato com o mundo

A maneira mais rápida e econômica de conseguirmos nos comunicar e nos informar.

o mundo na era digital em nosso redor

trabalho -2 respostas

É um meio mais facil tudo o que eu quiser eu acho na Internet faço pesquisas

informação e evolução - 2 respostas

significa poder esta diante de todas informação ddo que esta acontecendo no mundo globalizado.

dar oportunidades $\mathrm{p} /$ pessoas que necessitamde uma qualificacão melhor $\mathrm{p} / \mathrm{o}$ mercado de trabalho

dar uma oportunidade de aprendizado a quem nao tem posibilica

minha vida

Um meio de cominicação com pessoas longe de vc.Etanbe um meio de trabalho e de pesquiza.

conheser um mundo por dentro de uma tela e pessoas!!!

Muita coisa boa, quando eu tenho que pesquisa alguma matéria e estudar e quando quero falar com minhas amigas no Orkut conhecimento -4 respostas

forma de comunicação ...tecnologia avancada.

diversão -4 respostas

Internet e para mim uma fora otima de divulga ra cultura, ja que os jovens de hj nao estao muito mais querendo ir ou entrar em uma biblioteca para ler livros.

Não sabe/não respondeu -4 respostas

${ }^{79}$ As respostas foram abertas e mantidos os textos da maneira como foram digitados pelos usuários. 


\section{Uso Geral e Atividades Realizadas}

Há quanto tempo você freqüenta este centro público de acesso à Internet?

Gráfico 5. Tempo de uso do CPA

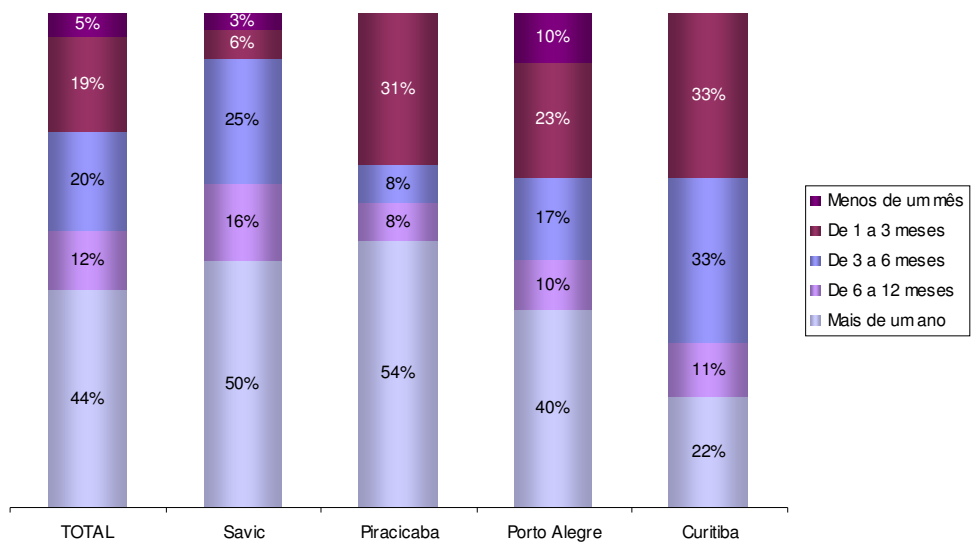

Quantas vezes você vai ao centro público de acesso?

Gráfico 6. Freqüiência de uso do CPA

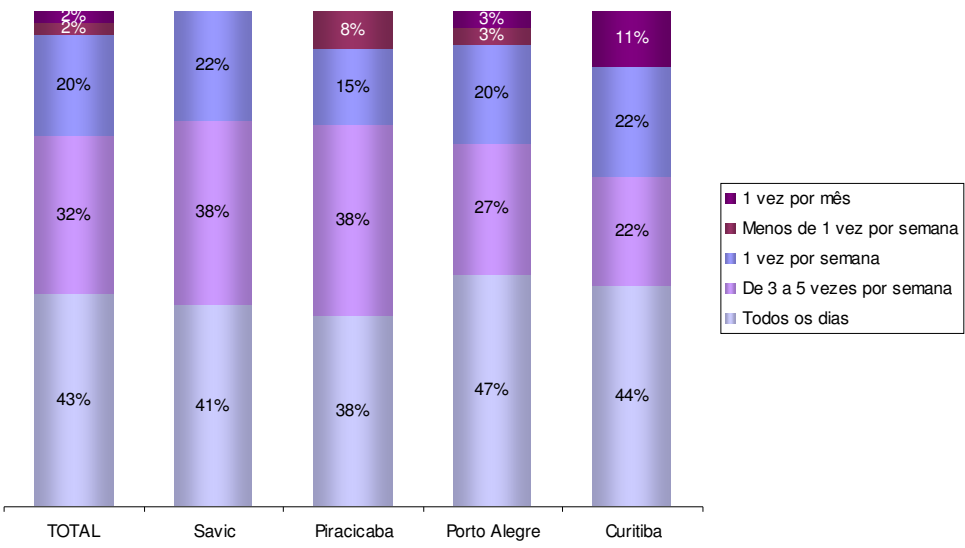

Quais as atividades que você realiza nesse centro público de acesso usando o computador, sem acesso à Internet? (Respostas múltiplas)

Gráfico 7. Atividades realizadas no computador, sem acesso à Internet

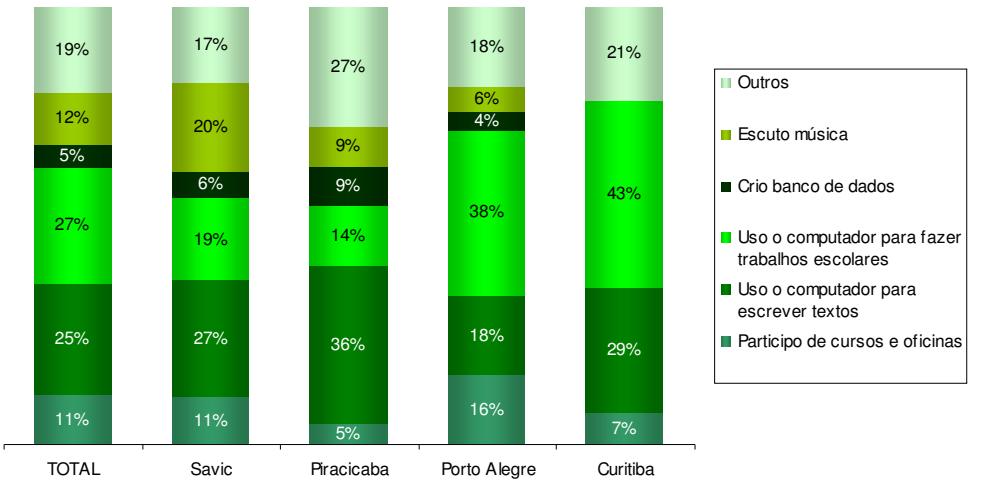


Há quanto tempo você usa a Internet?*

Gráfico 8. Tempo de uso da Internet

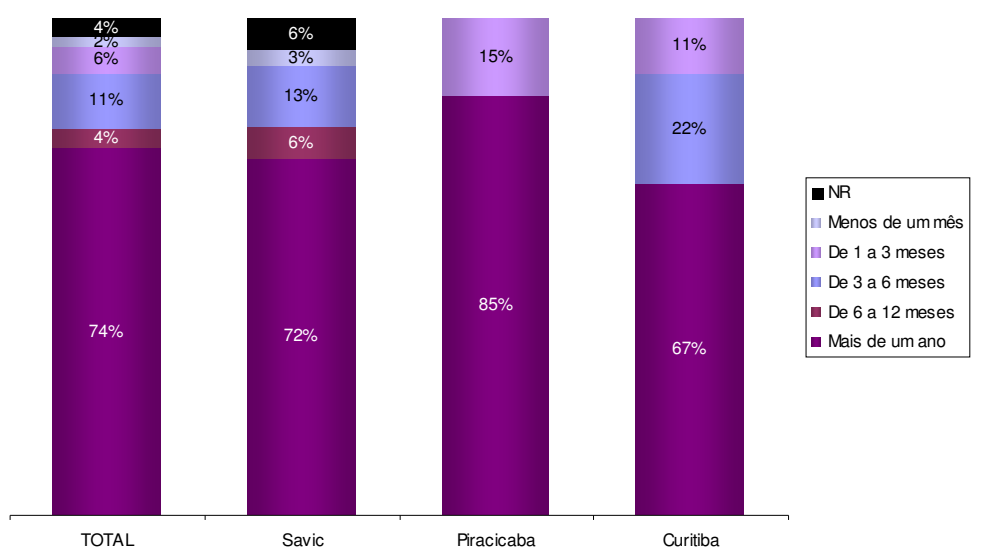

O que você faz na Internet? (Respostas múltiplas)*

Gráfico 9. Atividades na Internet

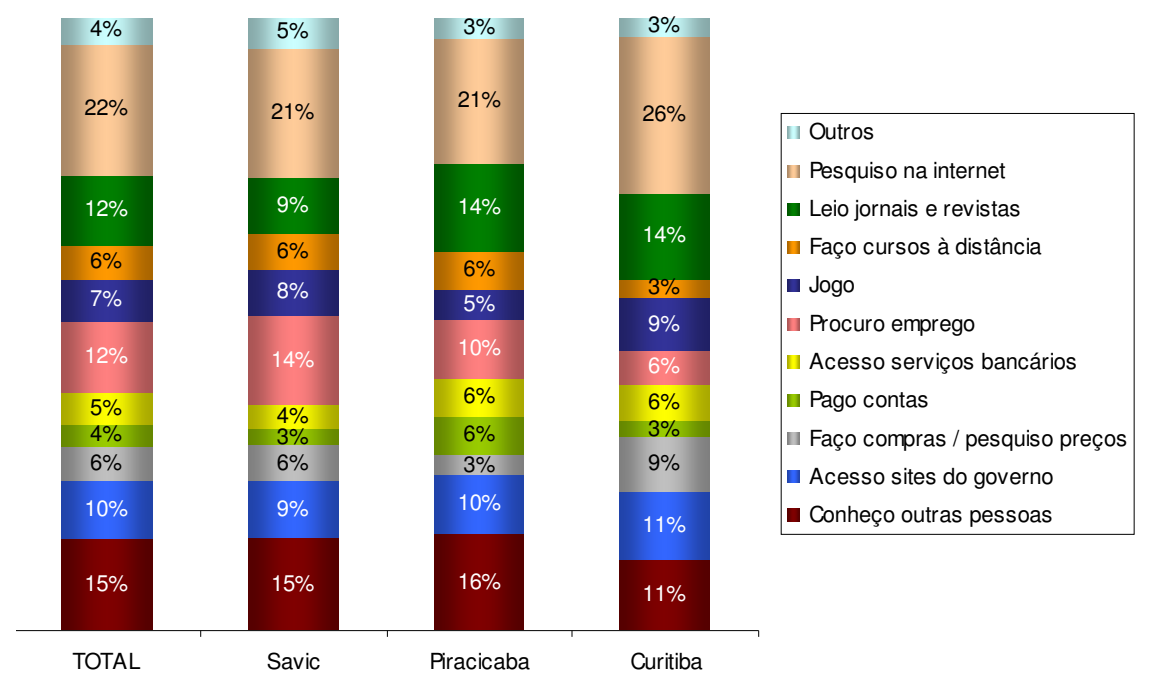

A maior parte dos respondentes informou utilizar os CPAs há mais de um ano (44\%), e a grande maioria é usuário freqüente: $43 \%$ vão todos os dias e $32 \%$, de três a cinco vezes por semana. Somente $4 \%$ afirmou ir ao CPA menos de uma vez por semana.

As principais atividades realizadas no CPA usando o computador, mas sem acesso à Internet, são basicamente para fins educacionais: $27 \%$ fazem trabalhos escolares e $25 \%$ produzem textos. Em Porto Alegre e Curitiba, unidades que concentram o maior número de jovens estudantes, estão as maiores taxas de utilização dos computadores para as tarefas escolares, $38 \%$ e $43 \%$, respectivamente.

Com relação ao uso da Internet, 74\% dos respondentes informaram navegar na rede há mais de um ano, há mais tempo inclusive do que freqüentam os CPAs, e as principais atividades realizadas são muito parecidas no Infocentro SAVIC, no Infocentro de 
Piracicaba e no Digitando o Futuro ${ }^{80}$ : realizar pesquisas (22\%), conhecer outras pessoas (15\%), ler jornais e revistas (12\%), procurar emprego (12\%) e acessar sites do governo $(10 \%)$

\section{Impacto da Internet na produção de informação pelo indivíduo}

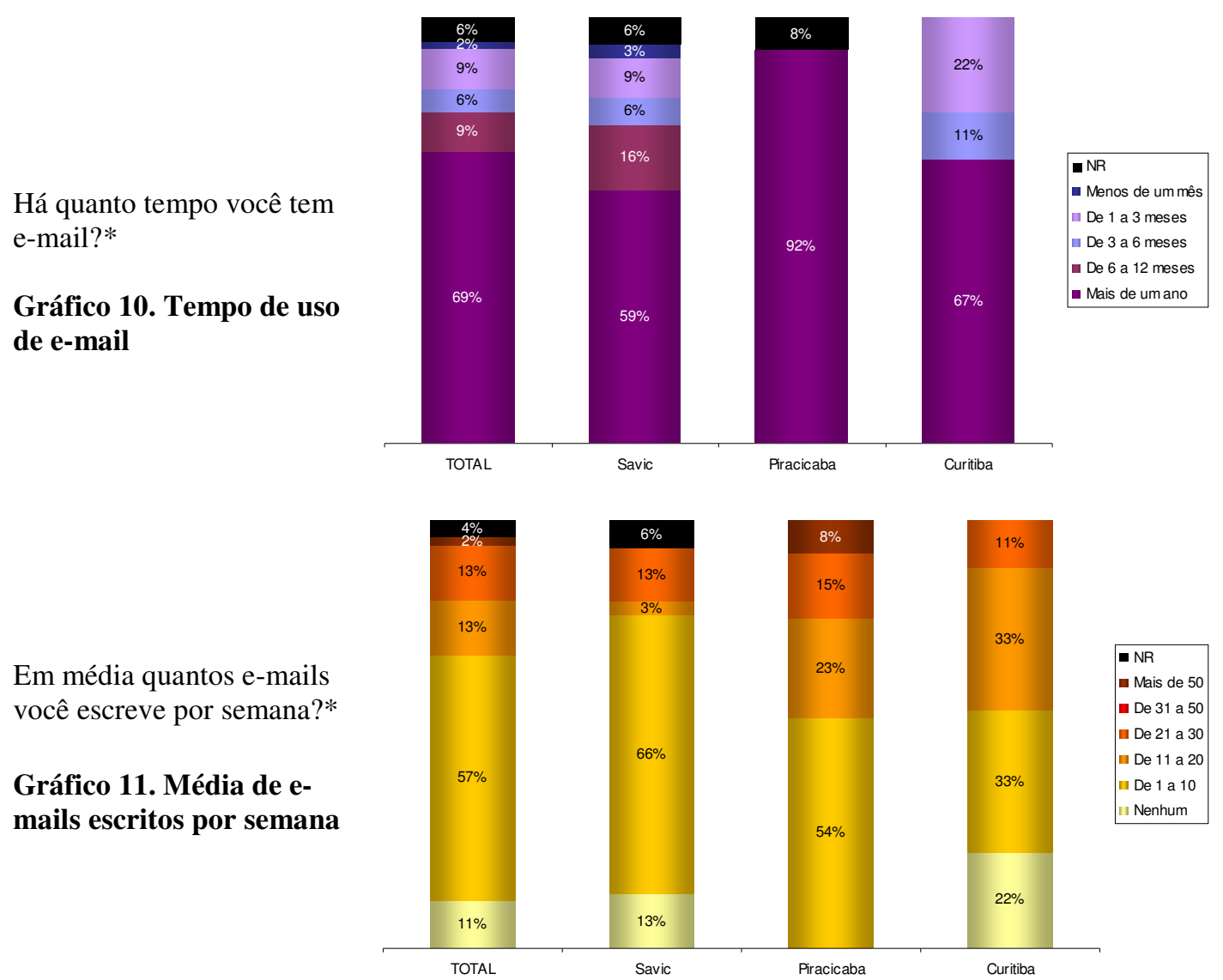

Todos os respondentes declararam possuir conta de e-mail, e a grande maioria (69\%) mantém seu endereço eletrônico há mais de um ano. Em Piracicaba, esse índice chega a 92\%. Do total de respondentes, 57\% afirmaram escrever até 10 e-mails, por semana, enquanto $13 \%$ escrevem de 11 a 20 e outros $13 \%$, até 30 mensagens.

\footnotetext{
${ }^{80}$ Infelizmente, por problemas técnicos no questionário, os usuários dos Telecentros de Porto Alegre não responderam várias questões $(*)$.
} 
E quantos e-mails você recebe em média por semana, sem contar mensagens indesejáveis ou spams?*

Gráfico 12. Média de emails recebidos por semana

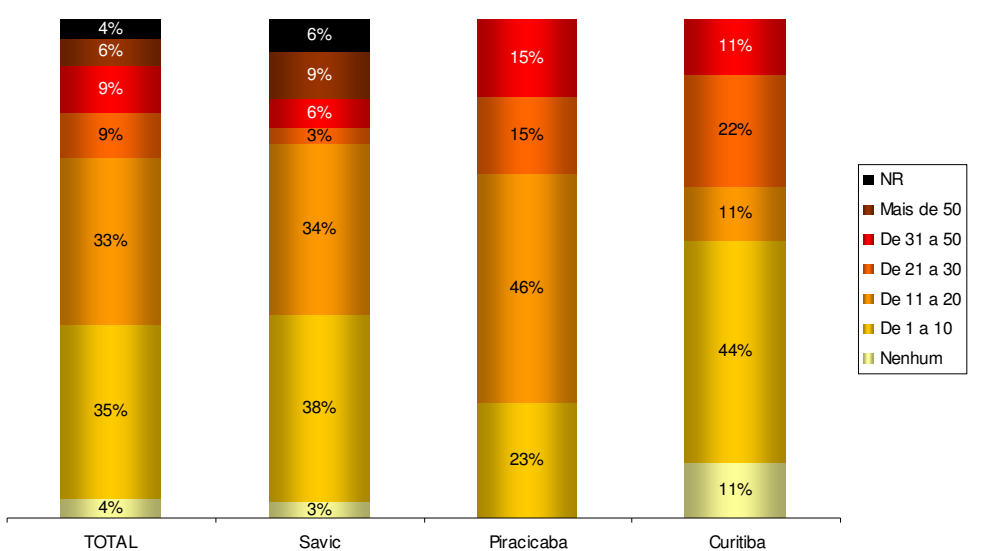

Já o número de mensagens recebidas (excluindo spams) parece ser ligeiramente maior, $57 \%$ recebem mais de 20 e-mails por semana, e $6 \%$ chegam a receber mais de 50.

Você desenvolve ou publica algo na Internet (Sites, blog, Orkut, etc)?

Gráfico 13. Publicação na Internet

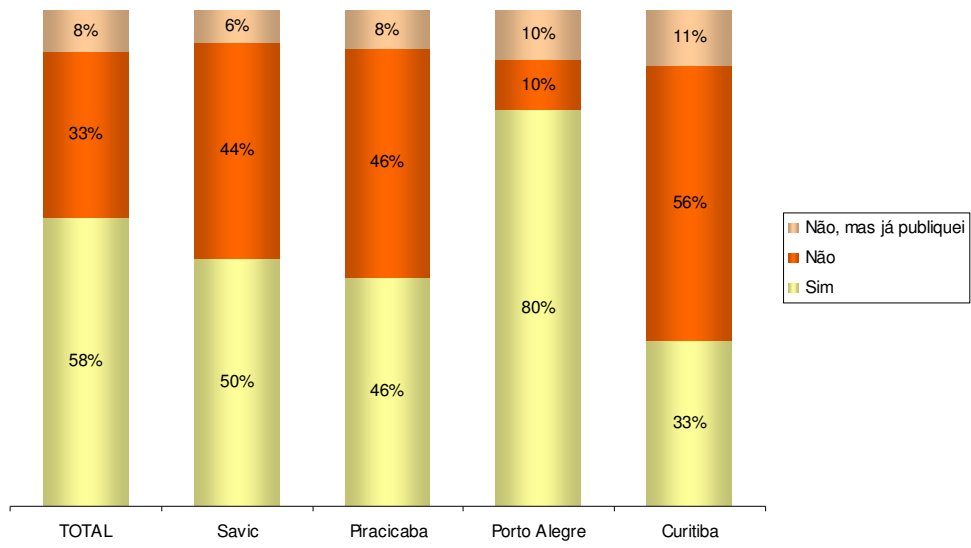

Se a resposta for sim, o que você já publica? (Respostas múltiplas)*

Gráfico 14. Tipo de publicação na Internet

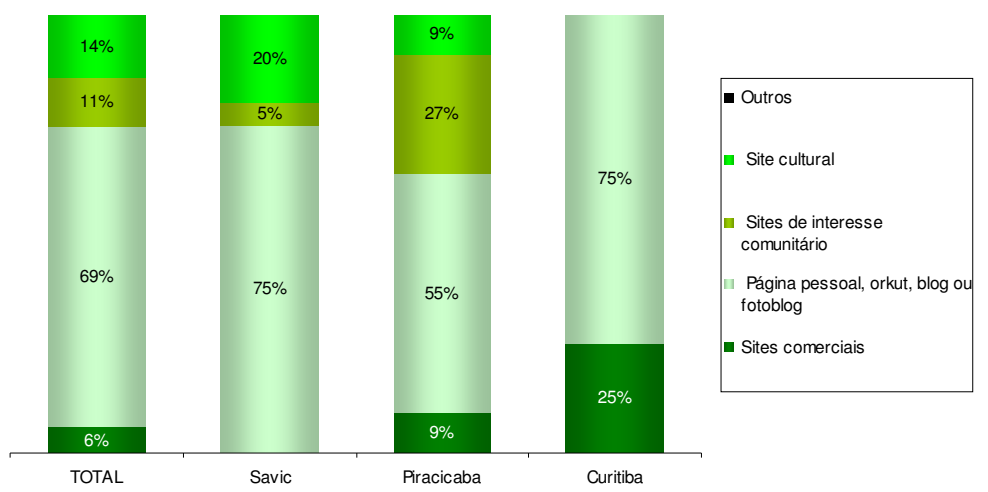


E há quanto tempo você publica algo na Internet?*

Gráfico 15. Tempo de publicação na Internet

Se você nunca publicou na Internet, quais os motivos?*

Gráfico 16. Razões porque não publica na Internet
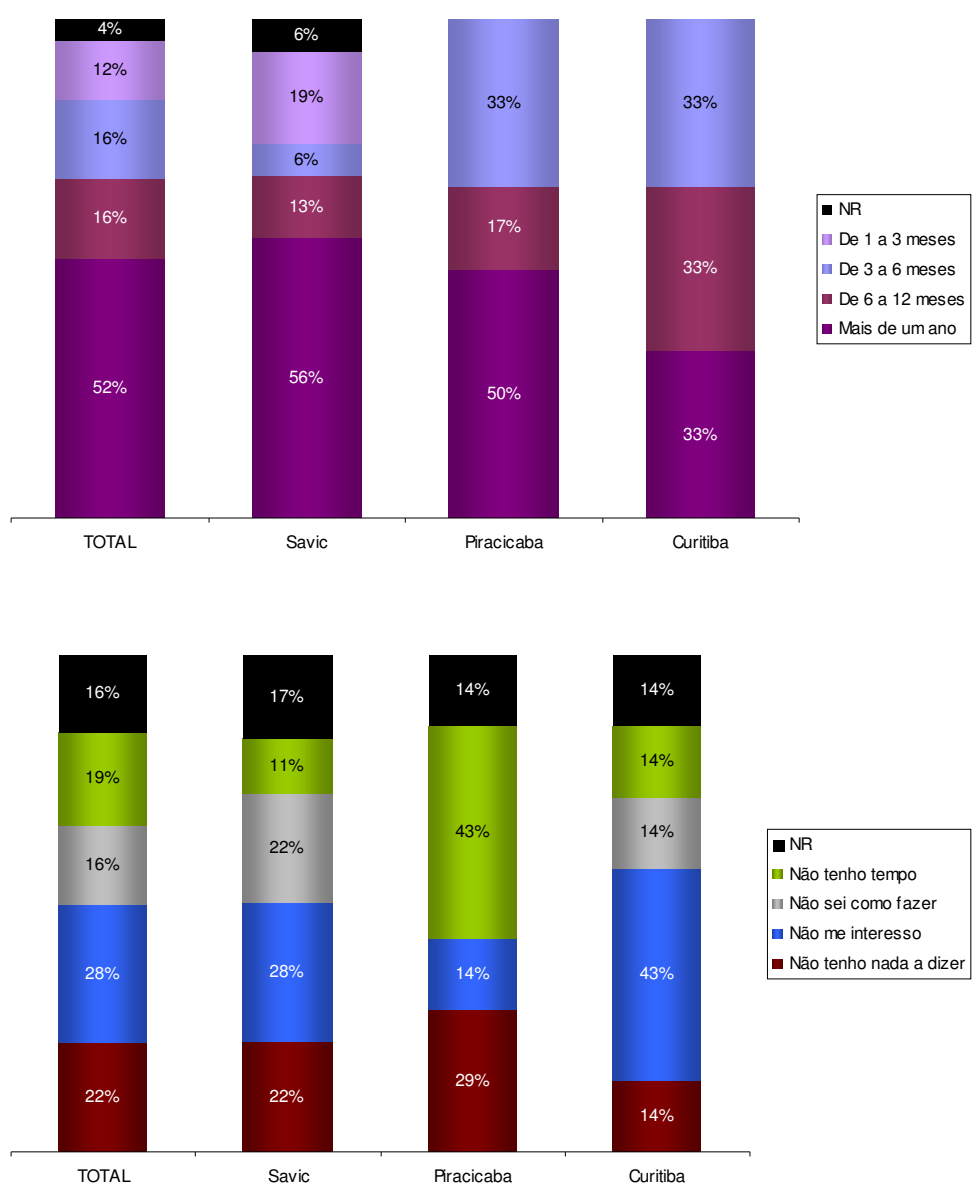

Sobre o desenvolvimento ou publicação de conteúdo na Internet, 58\% dos respondentes afirmaram que publicam algo. Essa proporção pode chegar a 90\% em Porto Alegre, se considerarmos os $10 \%$ que já publicaram algum material, mas não o fazem mais. Em Curitiba somente $33 \%$ responderam de forma positiva. Páginas pessoais, Orkut, blogs ou fotologs são responsáveis por $69 \%$ das publicações. Somente $11 \%$ dos usuários dos CPAs investigados declararam publicar sites de interesse comunitário e 14\%, sites culturais. E 52\% declararam realizar essas publicações na Internet há mais de um ano. Entre aqueles que nunca publicaram algo na rede, os motivos apontados são: falta de interesse (28\%), não ter nada a dizer (22\%) e falta de tempo (19\%). Em Curitiba o desinteresse chega a $43 \%$, enquanto em Piracicaba é a falta de tempo que atinge esse percentual. 
Você ou sua comunidade tem histórias e/ou notícias para contar?

Gráfico 17. Existência de histórias da comunidade para contar

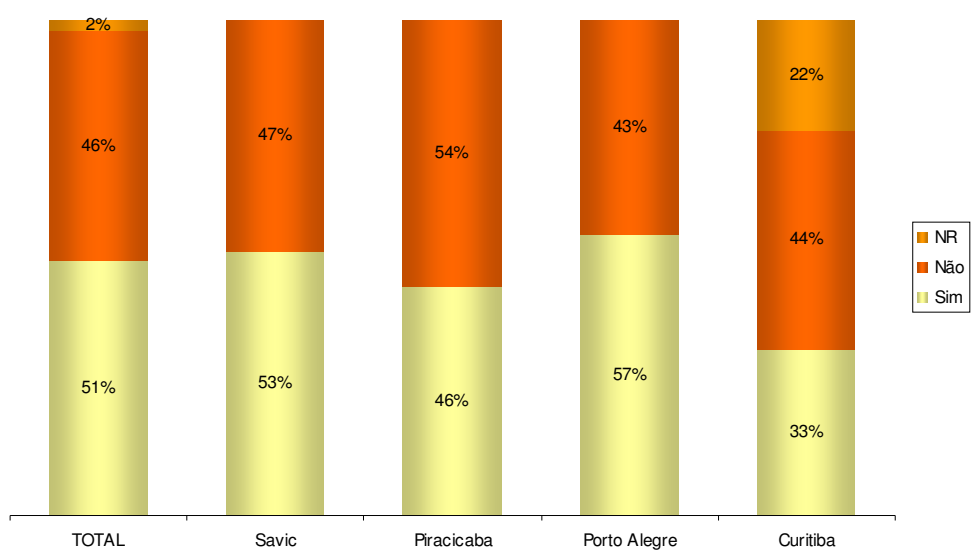

Se sim, você gostaria de escrever e publicar essas histórias e notícias na Internet?*

Gráfico 18. Intenção de publicar histórias sobre a comunidade

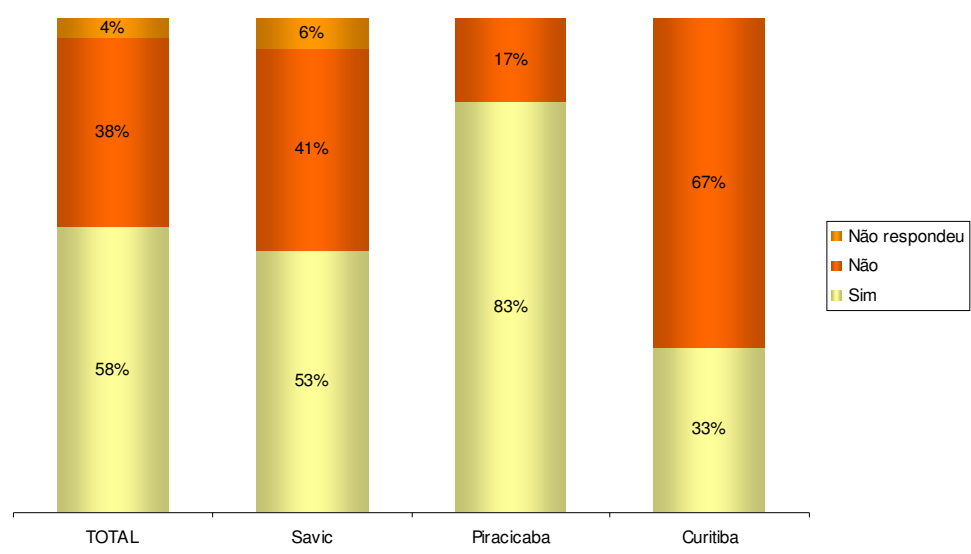

De acordo com os respondentes, a comunidade - ou ele próprio - tem histórias ou notícias para contar (51\%). Desse total, 58\% gostaria de publicá-las na Internet, um percentual que chega a $83 \%$ em Piracicaba e somente a 33\% em Curitiba.

Há algum meio de comunicação sendo produzido em sua comunidade (rádio, TV, jornal, site, outros)?

Gráfico 19. Existência de meio de comunicação produzido na comunidade

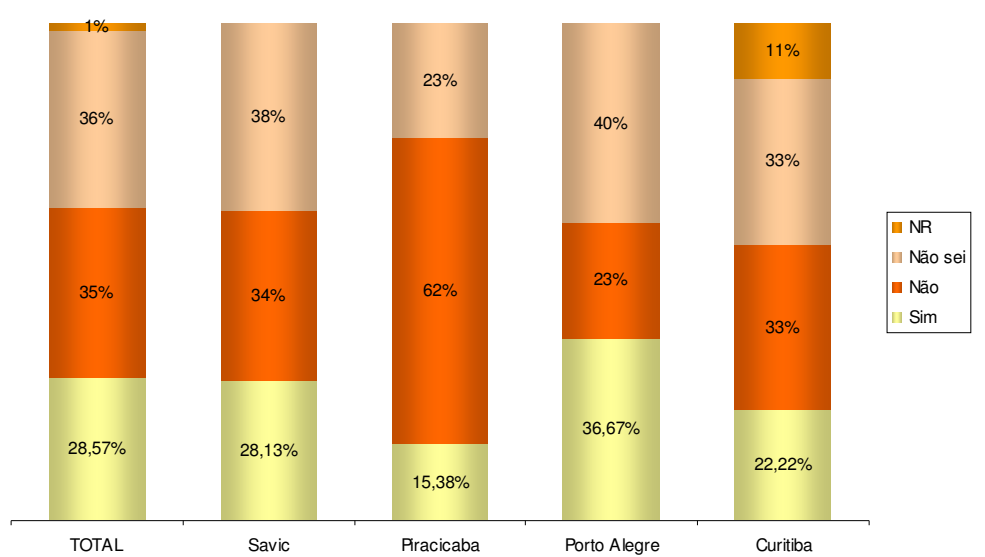


Se a resposta for sim, qual?*

Gráfico 20. Tipo de meio de comunicação produzido na comunidade

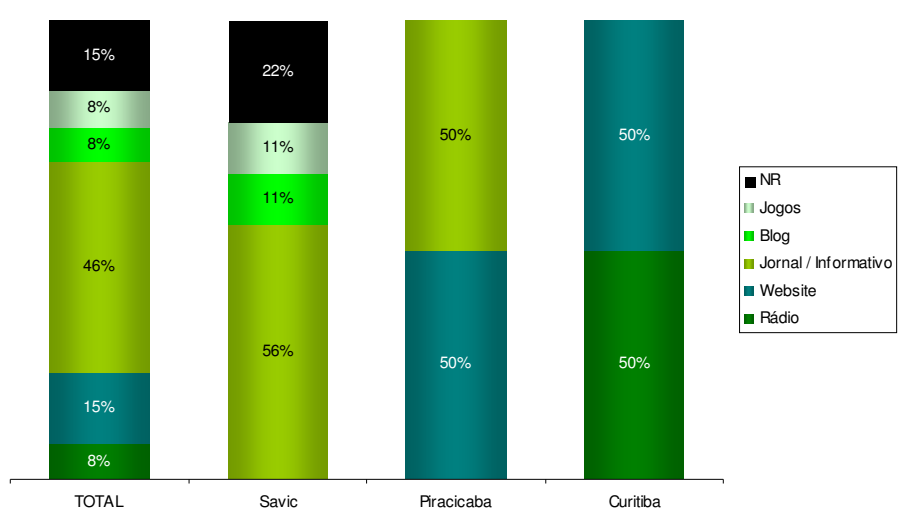

E há quanto tempo ele é produzido?*

Gráfico 21. Tempo de existência do meio de comunicação

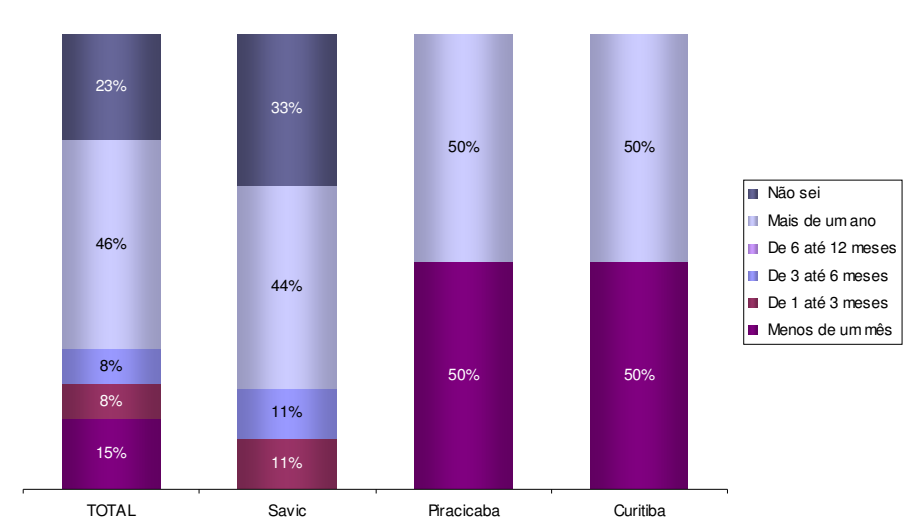

Somente $28 \%$ dos respondentes afirmaram conhecer algum meio de comunicação sendo produzido pela comunidade, enquanto $35 \%$ afirmam que não existe e $36 \%$ não sabem. Entre que conhecem, $46 \%$ informaram a existência de algum jornal ou informativo e $15 \%$, de algum website, sendo que os mesmos existem há mais de um ano, de acordo com $46 \%$ das respostas.

Você é parte da equipe que produz esse meio de comunicação?

\section{Gráfico 22. Participação na} equipe de produção do meio de comunicação

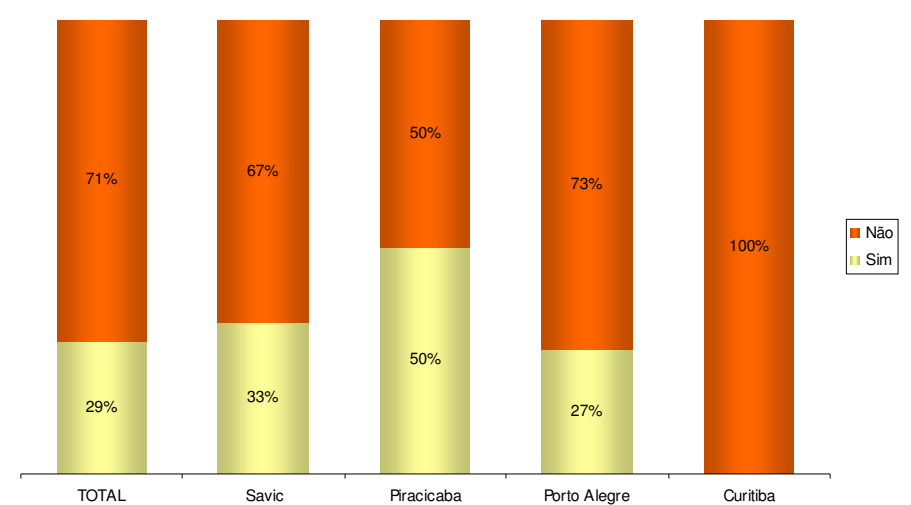

Mais de $70 \%$ dos respondentes não faz parte da equipe que produz aquele meio de comunicação na comunidade, e destes, somente $11 \%$ gostaria de fazer. 
Que assuntos ou fatos da sua comunidade são divulgados nestes meios de

comunicação?

Gráfico 23. Assuntos divulgados no meio de comunicação

Quais assuntos não são divulgados, mas você gostaria que fossem?

Gráfico 24. Assuntos não divulgados no meio de comunicação

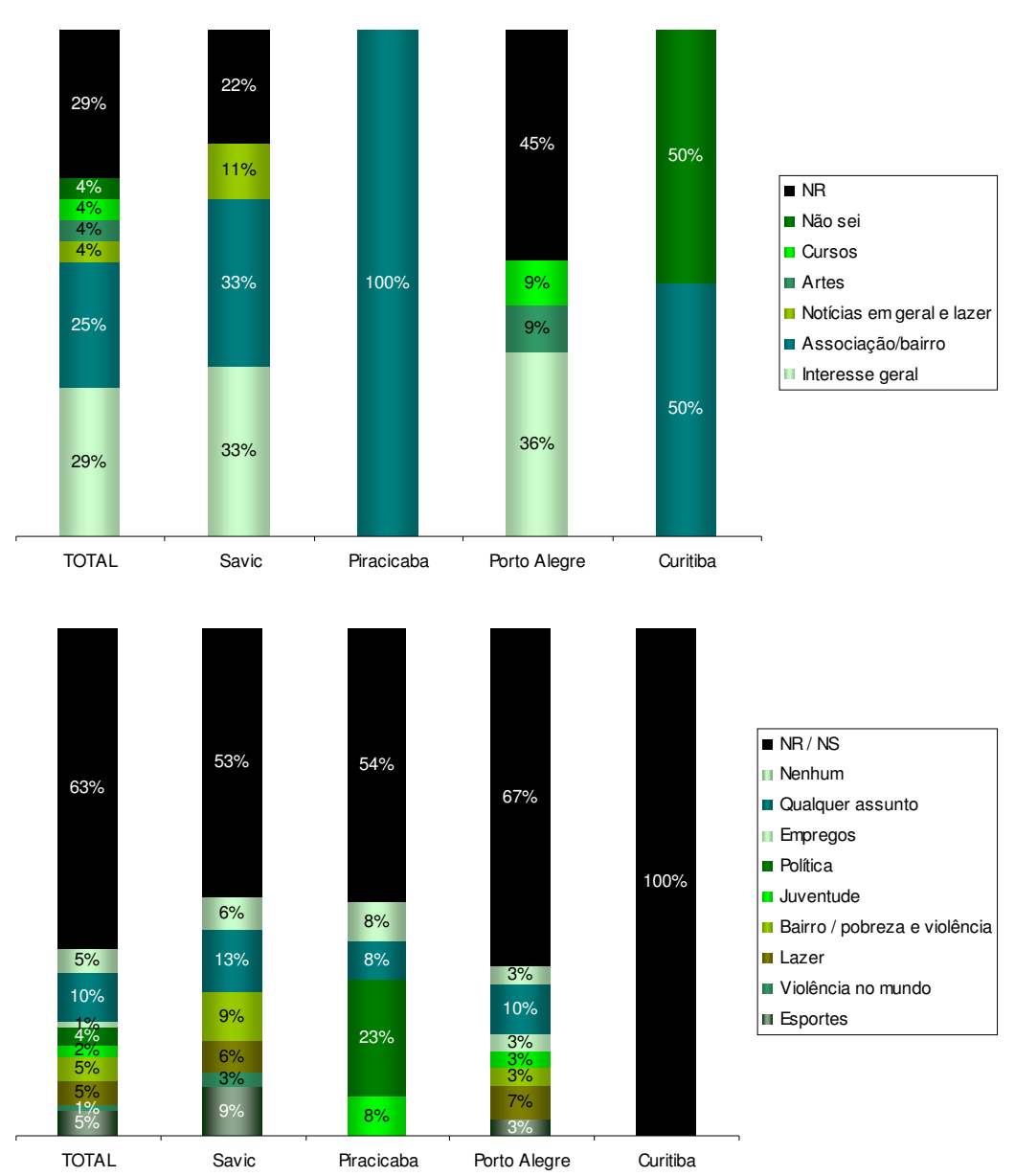

Os assuntos mais abordados nesses veículos são os de interesse geral (29\%) e aqueles que se referem à associação ou ao bairro onde o CPA está localizado (25\%). A falta de interesse por esses meios de comunicação se reflete na falta de interesse para que algum novo assunto seja divulgado: 63\% não sabe ou não respondeu.

Você participa de espaços virtuais de discussão na Internet (salas de bate papo, fórum, mensagens instantâneas)?

Gráfico 25. Participação em espaços virtuais de discussão

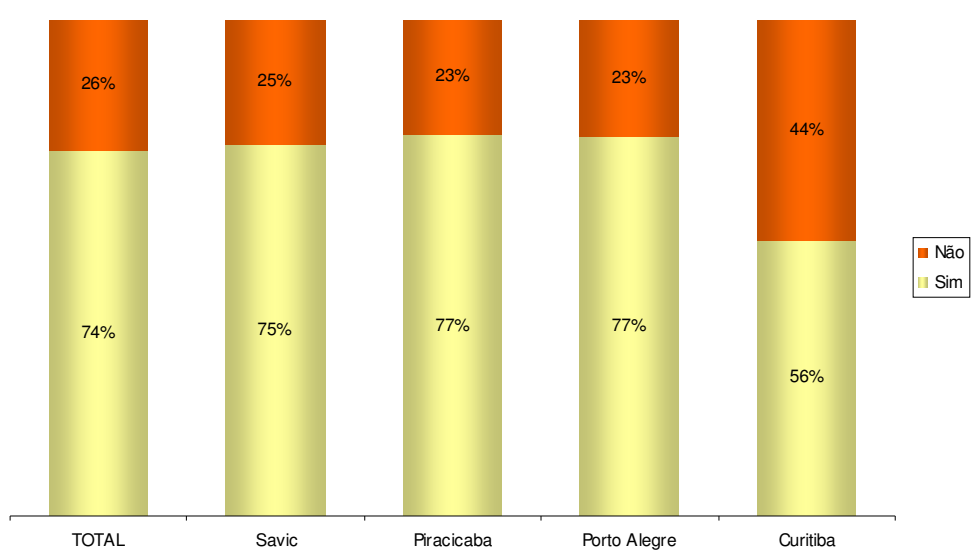


Se a resposta for sim, de quais espaços virtuais participa? (Respostas múltiplas)*

Gráfico 26. Espaços virtuais de discussão freqüentados

E há quanto tempo você participa desses espaços virtuais de discussão?*

Gráfico 27. Período de tempo que freqüenta espaços virtuais de discussão

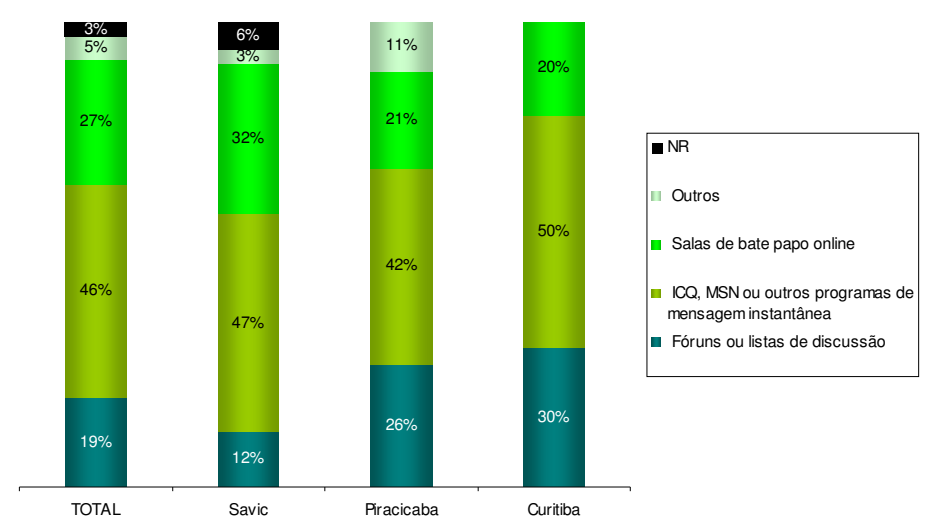

Se você não participa de espaços virtuais de discussão na Internet, quais os motivos? (Respostas múltiplas)*

Gráfico 28. Razões porque não participa de espaços virtuais de discussão
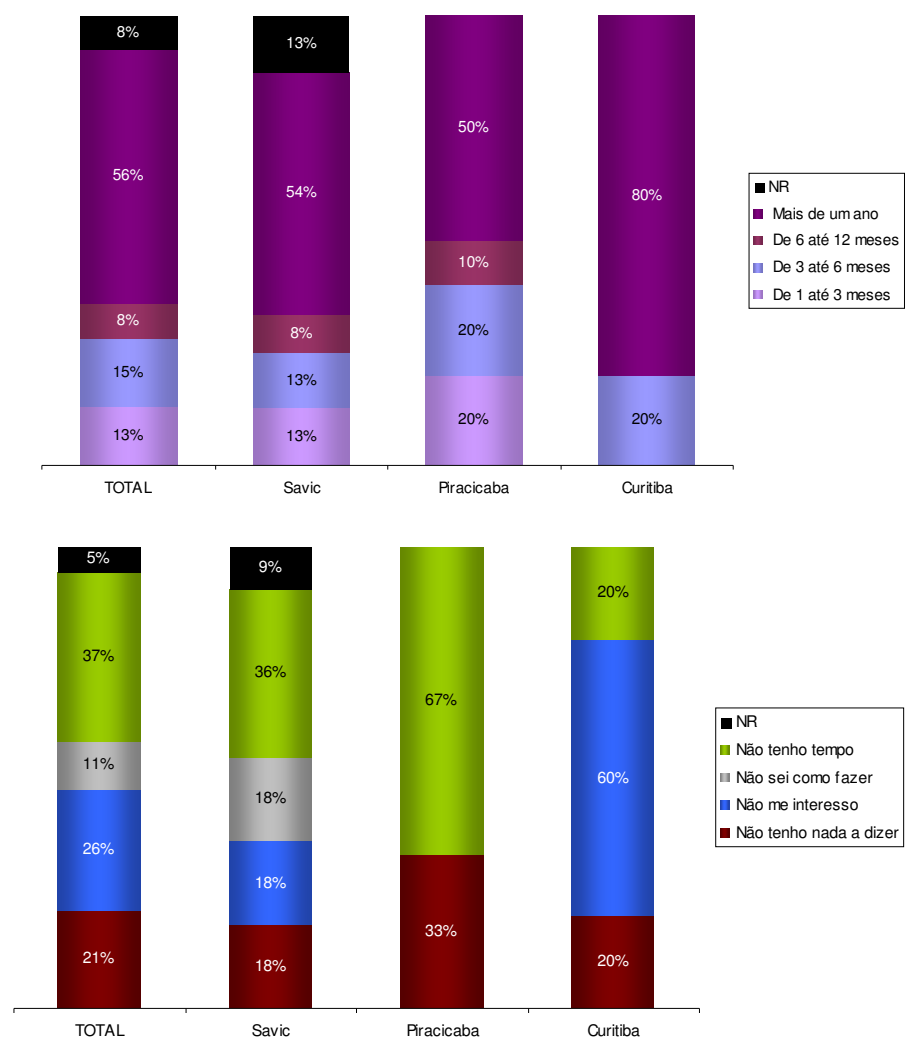

A presença em espaços virtuais de discussão na Internet é grande por parte dos respondentes, $74 \%$. Percentual que só varia em Curitiba, onde cai para 56\%. Entre as atividades realizadas, a grande maioria utiliza programas de mensagens instantâneas como MSN e ICQ (46\%) e salas de bate-papo on-line (27\%). E 56\% dos respondentes informaram realizar essas atividades há mais de um ano. Entre os $26 \%$ que não utilizam, os motivos apontados foram a falta de tempo (37\%), a falta de interesse (26\%) e a falta do que dizer (21\%). Em Piracicaba a falta de tempo chega a $67 \%$ e em Curitiba a falta de interesse bate os $60 \%$. 


\section{Impacto da Internet no consumo de informação pelo indivíduo}

Você costuma ler jornais ou revistas?

\section{Gráfico 29. Hábitos de} leitura

Antes de freqüentar o centro público de acesso, você já lia jornais ou revistas?

Gráfico 30. Hábitos de leitura antes de frequientar o CPA
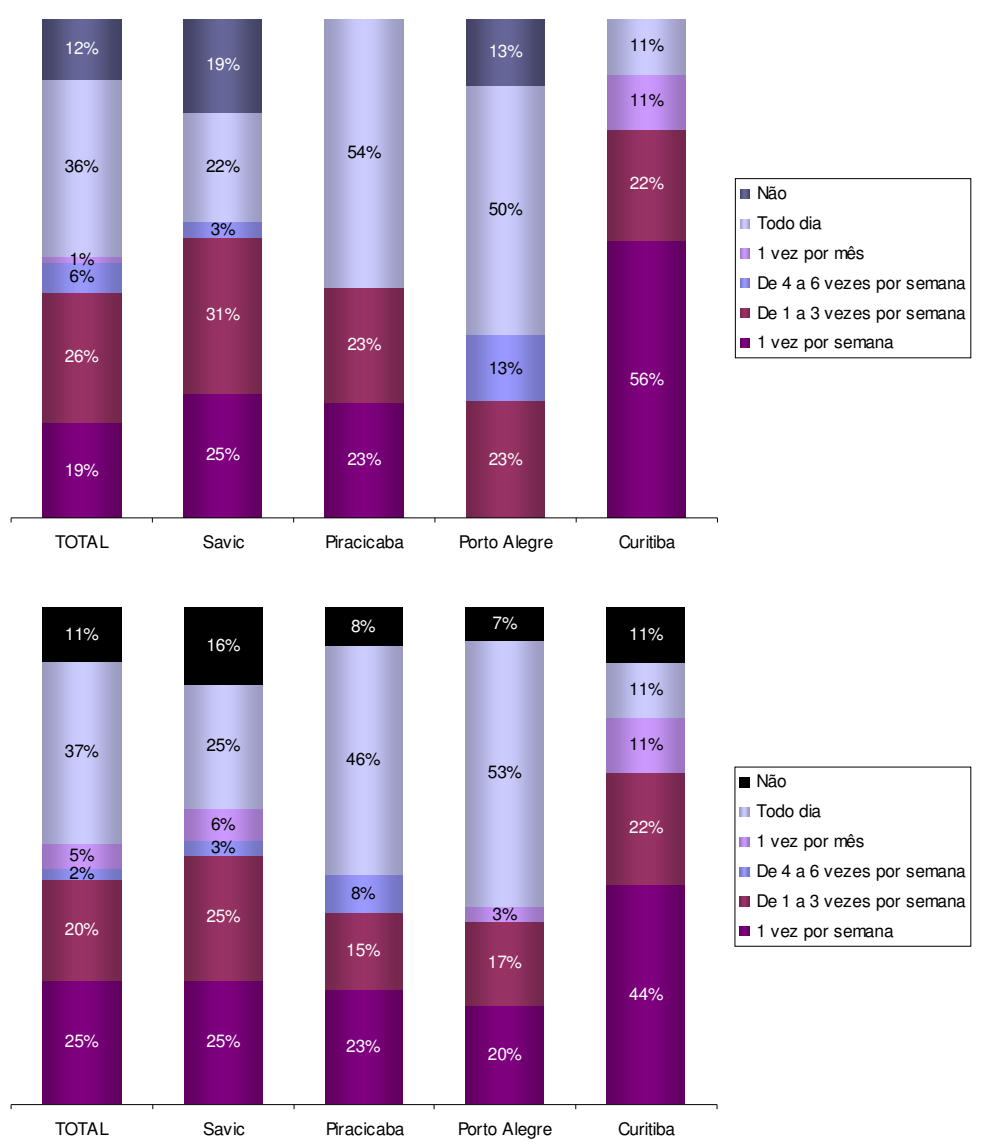

Antes de freqüentar o centro público de acesso, você ouvia mais ou menos o rádio?

\section{Gráfico 31. Hábitos com relação ao rádio}

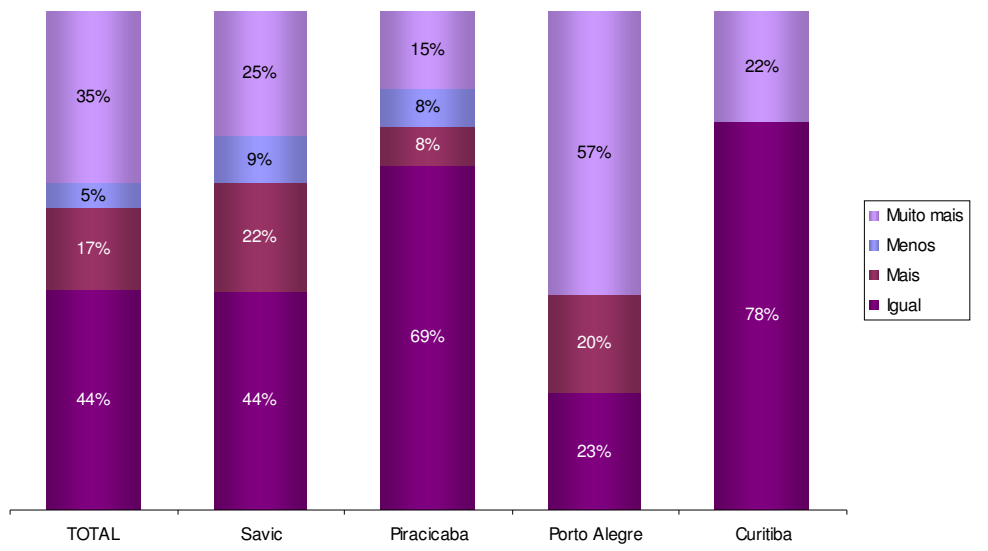

Entre os respondentes, $88 \%$ dos usuários informaram ler jornais e revistas, sendo que $36 \%$ lê todos os dias, $26 \%$, de 1 a 3 vezes por semana, e $19 \%$, uma vez por semana. O maior número de leitores diários está em Curitiba, 56\%, sendo que 100\% dos usuários do Digitando o Futuro e do Telecentros de Porto Alegre informaram ler notícias pelo menos uma vez por semana. Entre os leitores, $11 \%$ declarou ter adquirido o hábito depois de freqüentar o CPA, já a freqüência da atividade não se alterou entre aqueles que já o tinham. 
Antes de freqüentar o centro público de acesso, você assistia mais ou menos televisão?

Gráfico 32. Hábitos com relação à televisão

Você se sente mais ou menos informado usando a Internet?

\section{Gráfico 33. Relação da} Internet com o "se sentir informado"
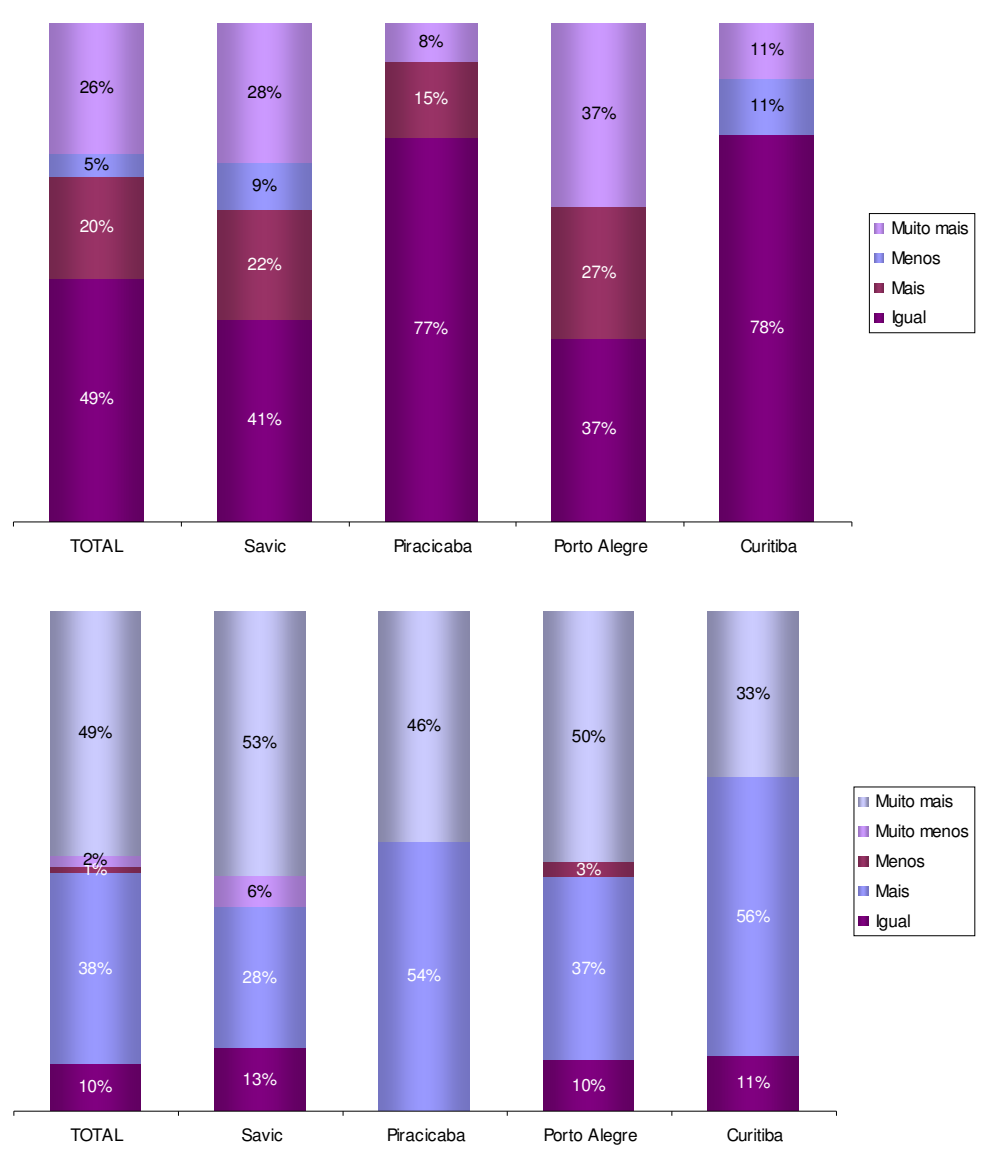

A maior parte dos usuários informou que ouvia mais (17\%) ou muito mais (35\%) rádio antes de freqüentar o CPA, enquanto $44 \%$ disse ouvir com a mesma freqüência, e somente $5 \%$ disseram que ouviam menos. O mesmo acontece com a televisão: $20 \%$ dos usuários responderam que assistiam mais (20\%) ou muito mais (26\%) televisão antes, enquanto $49 \%$ assistem na mesma frequiência, e 5\% passou a assistir depois que começou a freqüentar o CPA. De maneira geral, o usuário se sente muito mais (49\%) ou mais $(38 \%)$ informado usando a Internet do que antes, sendo que em Piracicaba a soma das duas respostas chega a $100 \%$. Nos outros CPAs, cerca de $10 \%$ acreditam que o nível de informação não se alterou, e apenas $3 \%$ do total declarou se sentir menos informado. 
VI. Contribuição dos projetos de ID para o desenvolvimento político, econômico, social e intelectual do individuo

Você considera que o acesso à Internet mudou a sua vida?*

Gráfico 34. Impacto da Internet na vida do usuário

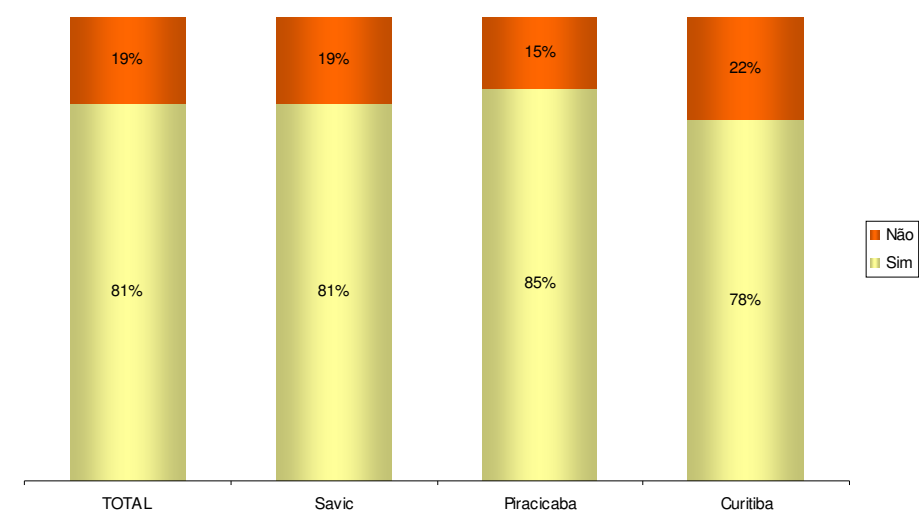

Se a resposta for sim, dê uma nota de 1 a 5 ao lado de cada afirmação abaixo, sendo 5 para concordo plenamente e 1 para discordo completamente.*

Gráfico 35. Contribuição para o desempenho profissional

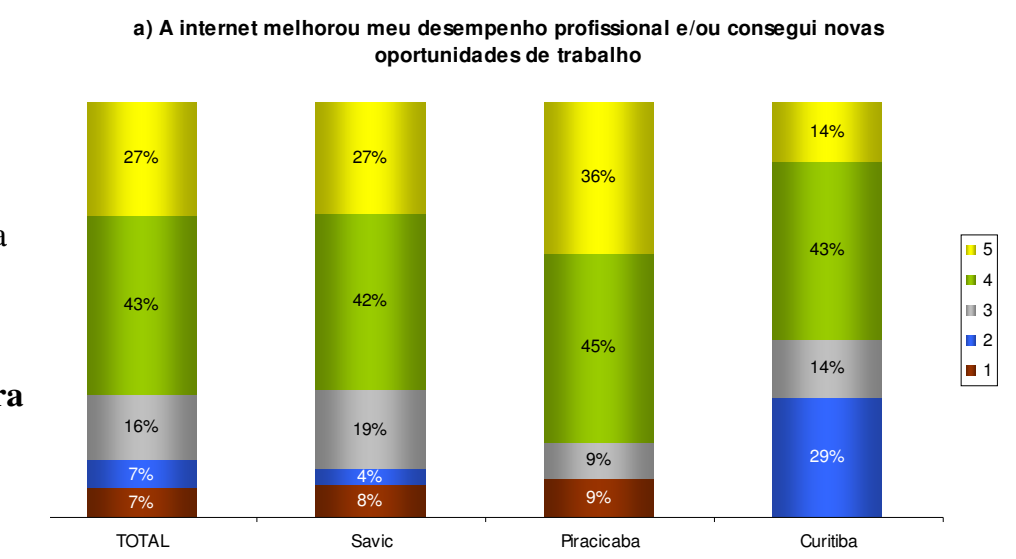

b) Tenho mais facilidade em aprender e/ou voltei a estudar

Gráfico 36. Contribuição para o aprendizado

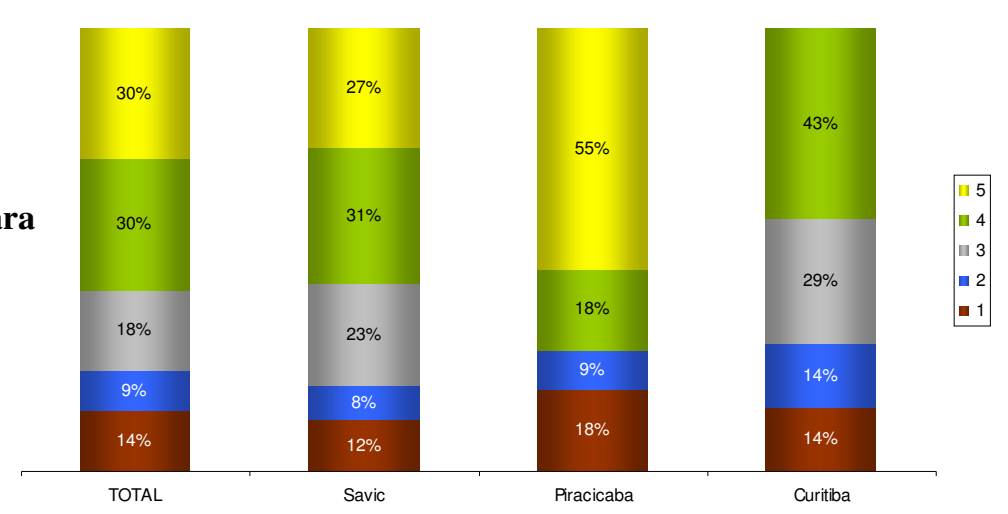

A maioria dos usuários (81\%), considera que o acesso à Internet mudou suas vidas. Segundo eles, as contribuições dos projetos de inclusão digital para seu desenvolvimento político, econômico, social e intelectual (considerando uma escala de 1 a 5, onde 1 significava "discordo plenamente" e 5 "concordo plenamente") foram as seguintes : 
- $70 \%$ afirmam (notas 4/5) que a Internet melhorou seu desempenho profissional e/ou ajudou a consegur novas oportunidades de trabalho, 14\% discordam (notas $1 / 2)$;

- $60 \%$ alegam (notas $4 / 5$ ) ter mais facilidade em aprender e/ou ter voltado a estudar, sendo que em Piracicaba aqueles que concordam plenamente com a afirmação (nota 5) chegam a 55\%. Do total de respondentes, $23 \%$ discordaram (notas 1/2) da afirmação;

Gráfico 37. Contribuição para o exercício da cidadania

Gráfico 38. Contribuição para o lazer

Gráfico 39. Contribuição para o relacionamento com amigos e família
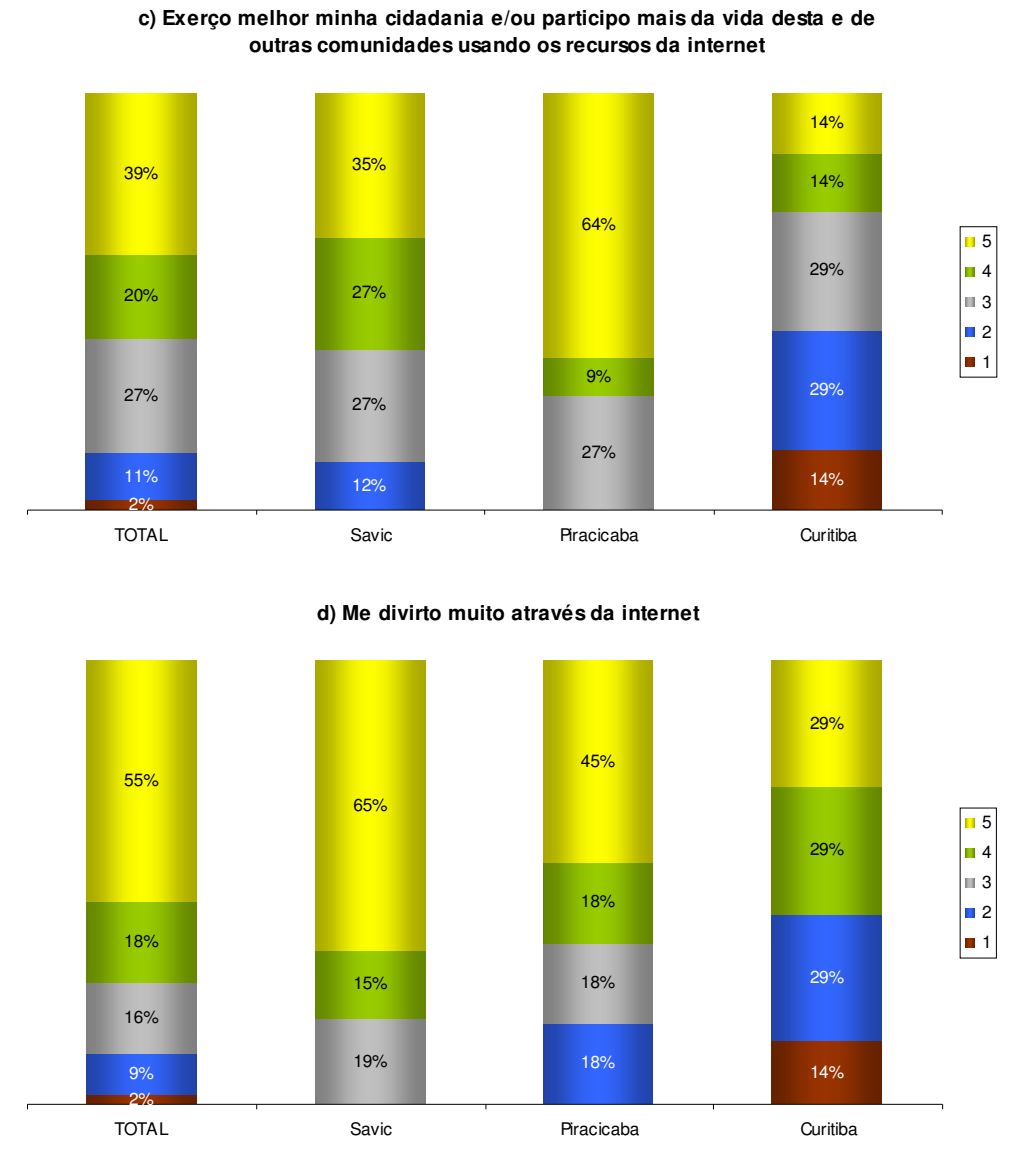

e) Conheci novos amigos através da internet, passei a me comunicar mais com amigos e familiares

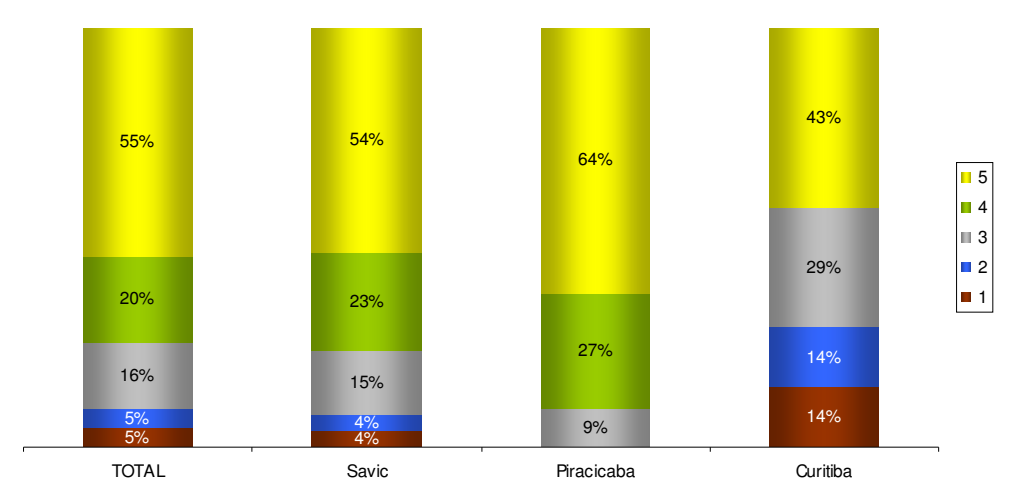


- $59 \%$ afirmam (notas $4 / 5$ ) que exercem melhor sua cidadania e/ou participam mais da vida desta e de outras comunidades usando os recursos da Internet. Em Piracicaba, os que concordam plenamente (nota 5) chegam a 64\%. Em Curitiba estão as médias mais baixas: $43 \%$ atribuíram notas $1 / 2$;

- $73 \%$ alegam se divertir muito através da Internet (notas $4 / 5$ ), percentual que chega a $80 \%$ no Infocentro SAVIC;

- $75 \%$ consideram (notas $4 / 5$ ) que através da Internet conheceram novos amigos e passaram a se comunicar mais com amigos e a família.

$\mathrm{O}$ acesso à Internet te computador?

\section{Gráfico 40. Intenção de} aquisição de computador incentivou a comprar um

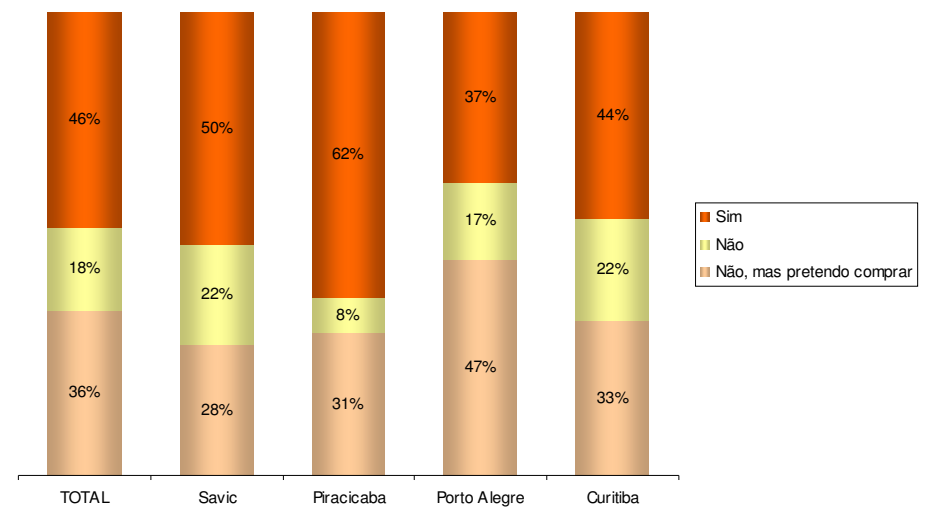

O acesso à Internet incentivou $46 \%$ dos usuários a comprar um computador, outros $36 \%$ pretendem comprá-lo. Em Piracicaba, a resposta positiva chegou a $62 \%$.

Além da Internet, que outras atividades você realiza no centro público de acesso? (Respostas múltiplas)

Gráfico 41. Atividades realizadas no CPA, sem computador e Internet

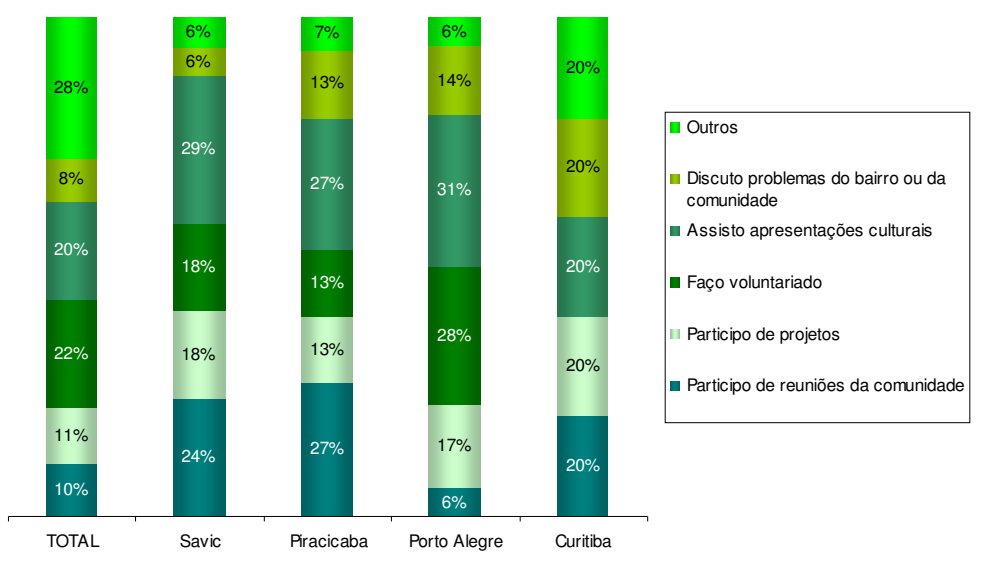

Além do acesso à Internet, os respondentes declararam que freqüentam o CPA principalmente para realizar ações de voluntariado (22\%) e assistir apresentações culturais (20\%). 


\section{Benefícios dos projetos de ID para a comunidade}

Você acha que a Internet mudou a vida da sua comunidade?*

Gráfico 42. Impacto da Internet na comunidade

Se a resposta for sim, dê uma nota de 1 a 5 ao lado de cada afirmação abaixo, sendo 5 para concordo plenamente e 1 para discordo completamente.*

Gráfico 43.

Contribuição para a situação econômica

Gráfico 44.

Contribuição para a articulação da comunidade

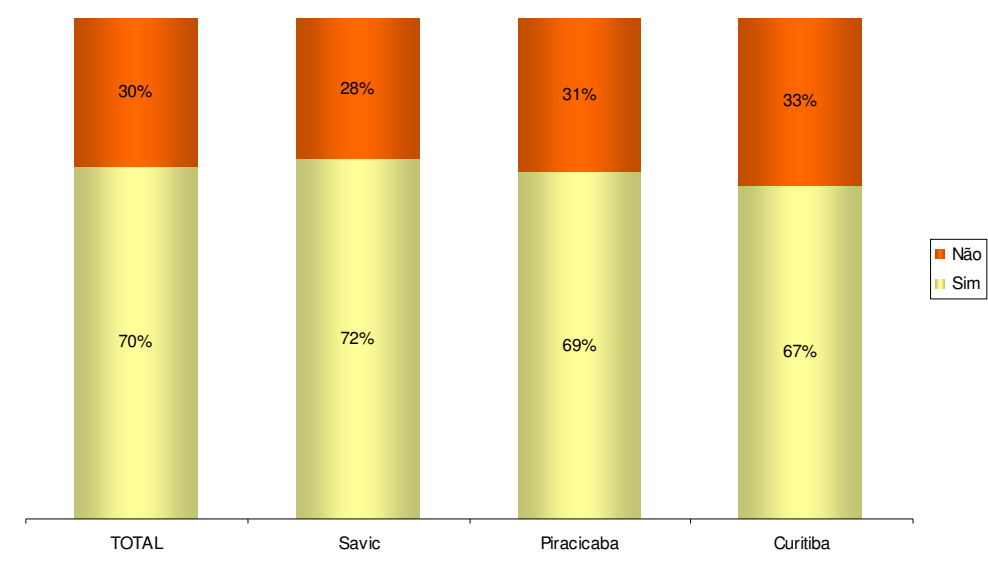

a) as condições econômicas da comunidade melhoraram (mais oportunidades de emprego, qualificação, melhores salários, etc)

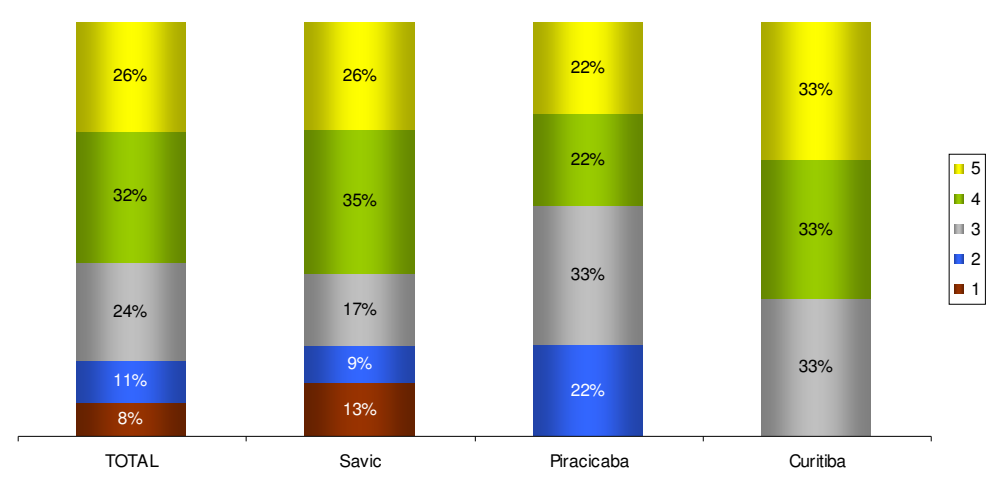

b) A comunidade está mais articulada (as pessoas passaram a se conhecer melhor e a resolver problemas do bairro em conjunto)

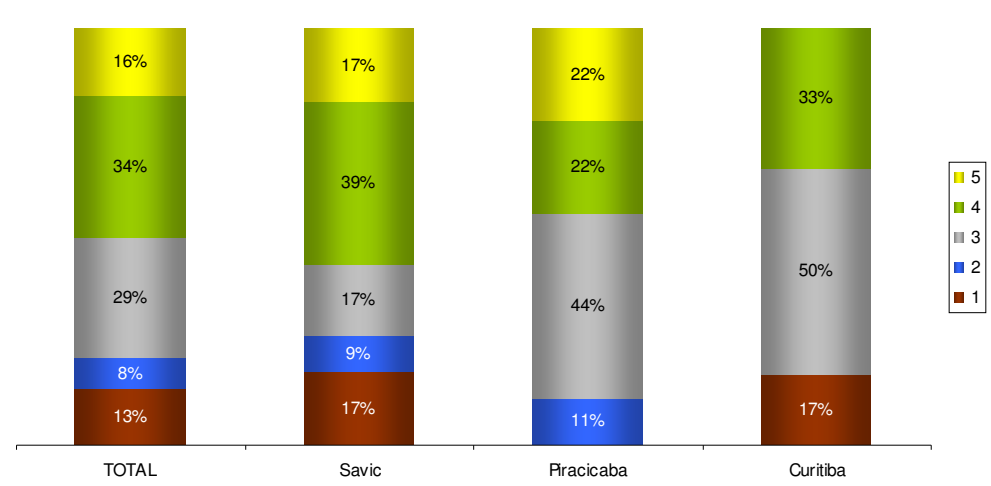

Grande parte dos usuários (70\%), acredita que a Internet mudou a vida da sua comunidade. Para eles, os benefícios dos projetos de inclusão digital para a comunidade (considerando uma escala de 1 a 5 , onde 1 significava "discordo plenamente" e 5 "concordo plenamente") foram: 
Gráfico 45.

Contribuição para o lazer da comunidade

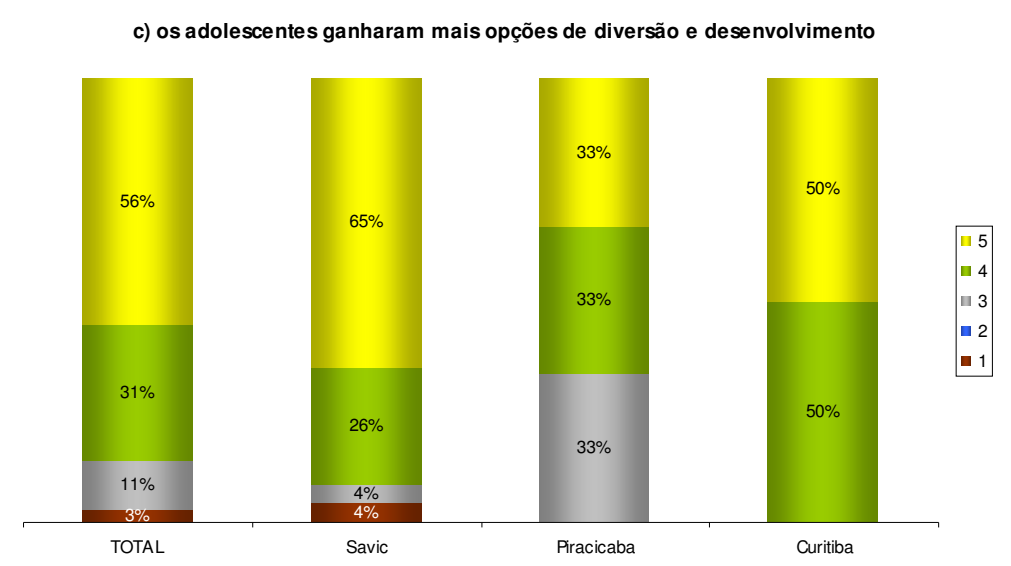

- $58 \%$ dos respondentes declararam que as condições econômicas da comunidade melhoraram (notas 4/5), enquanto 19\% discordam da afirmação (notas 1/2);

- $50 \%$ dos usuários concordam (notas 4/5) que a comunidade está mais articulada (as pessoas passaram a se conhecer melhor e a resolver os problemas do bairro em conjunto), e outros $21 \%$ discordam (notas $1 / 2$ );

- $86 \%$ dos respondentes (notas 4/5) estão de acordo com a afirmação de que "os adolescentes ganharam mais opções de diversão e desenvolvimento" e apenas $3 \%$ discordam (notas $1 / 2)$.

\section{Avaliação do usuário com relação ao projeto de ID}

Na sua opinião, o programa atende bem as suas necessidades de uso da Internet?

\section{Gráfico 46. Avaliação dos} programas de inclusão digital

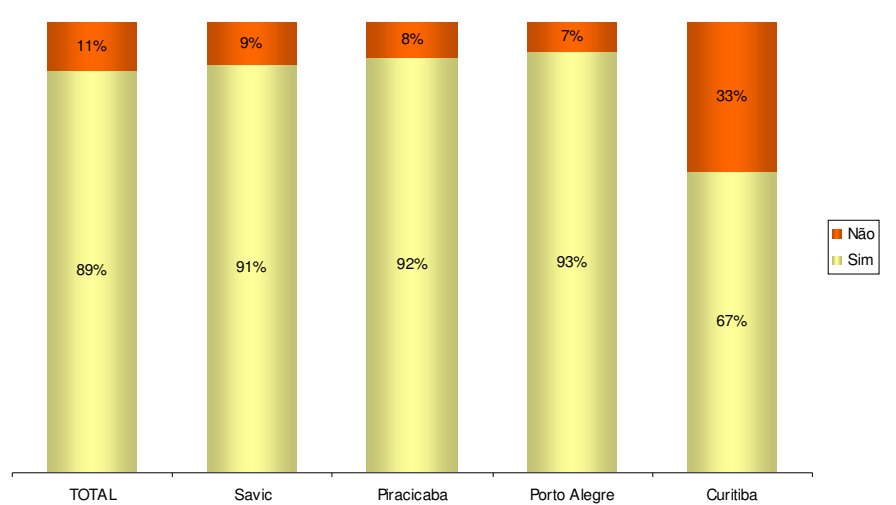

De maneira geral, os usuários têm uma avaliação extremamente positiva dos programas de inclusão digital, e $89 \%$ afirmam que o mesmo atende bem as suas necessidades de uso da Internet. Entre os $11 \%$ que discordam, as sugestões de melhoria foram: "ampliação", "mais máquinas", "acesso multimídia com gravadores de CD e webcam" e "menos restrições de uso". 


\section{Quadro 51. Significado do Centro Público de Acesso - Usuários}

Para mim, este centro público de acesso é um espaço onde eu posso... ${ }^{81}$

me comunicar com outras pessoas, ter a oportunidade de arranjar emprego, poder exercitar meu

ingles conversando com amigos no exterior, estar a par com o que acontece no mundo, poder

exercer minha opinião

ser mais informado

participar de várias atividades

conversar com minha irm

executar minhas tarefas

pesquisar mais rápido

aprender (3)

ajudar os outros a aprenderem e suprimir suas necessidades com relação ao computador/Internet

ficar mais informada do meu dia a dia

aprender e passar conhecimentos e me comunicar com mais facilidade

me distrair e ampliar meus conhecimentos

me comunicar com as pessoas

pesquisar tudo o que eu preciso

ter o mundo digital en minhas mãos

contruir uma nova vida

acessar a Internet

participar com meus amigos.

me comunicar, me divertir e saber mais.

mecher na Internet

pesquisar tudo que eu preciso

fazer trabalhos escolares.

pesquisar e aprender sobre tudo.

acessar, me comunicar com outras pessoas etc.

me informar e me comunicar.

realisa minhas funções diarias e poder me tornar uma pessoa melhor

pesquisar e me atualizar sobre diversos assuntos

me espandir para o mundo!

estudar e conhecer amigos

me comunicar com o mundo (5)

me divertir e me atualizar.

almente me sinto bem informada.

me informar mais

me comunicar com outras pessoas e principalmente mandar meus curriculos para as empresas

ter mas convivio e responsadilidade com a minha comunidade

solucionar os meus problemas, de trabalho,pesquisas e outras coisas.

me comunicar e procurar empregos

tr ascesso a qualquer tipo d informação.

faser minhas pesquisas na Internet com mais fasilidade. eu tenho certesa que e o maior meio de comunicaçã do mundo

estudar e me divertir

trabalhar ao meu favor

interagir com meus amigos e aprender mais

conhecer pessoa, estudar

aprender fazendo.

me atualizar frequentemente

me divertir, comunicar, fazer novas amizades e novos contatos para emprego.

melhorar os meus conhecimentos

me enganjar e participar ativamente da comunidade.

conhecer mais pessoas,me divertir etc

usar a Internet

usa computador

melhorar o meu conhecimento e desnvolver-me com pessoa

desenvolver minhas qualidades como ser humano

me comunicar com outras pessoas e fazer trabalho de escola.

conhecer pessoas novas a cada dia,aprender alguma coisa útil.

conhecer pessoas e adquirir conhecimento.

aprender a pesquisar o que eu quero

execer as minhas atividades rpofissinais com mais facilidade.

adquirir mais conhecimento para utiliza-lo no meu dia a dia

procuro emprego e aprender

me divertir e esquecer os problemas

um local muito bom

fazer minhas coisa na net

trabalhar melhor as minhas ideias

encontrar amigos

incluir-me mais ainda na sociedade

trabalhar, ajudando os usuarios a enriquecer seu conhecimento e sua cultura

estar em contato contínuo com pessoas, e acesso ráipido à informações em geral

usar a Internet e fazer parte da inclusão digital

me divirto e me torno um cidadao bem informado

aprende diversas coisa com um meio de comunicação chamado Interne

ter mais conhecimento (3)

conhecer pessoas, discutir muita coisa boa e me manter informado sobre o que rola em várias partes do mundo

ter acesso digital

Não respondeu (3)

${ }^{81}$ As respostas foram abertas e mantidas os textos da maneira como foram digitados pelos usuários. 
Ao completar a frase "Para mim, este centro público de acesso é um espaço onde eu posso", percebe-se que para os usuários o CPA é a porta de entrada para o mundo (quadro 51), o aprendizado e o conhecimento. É principalmente um ambiente de comunicação e sociabilização: é através dele que o usuário vai "estar com amigos", "conhecer pessoas", se "divertir e esquecer os problemas". E também um local de "pesquisa", de "execução de tarefas", de acesso à informação, onde eu posso "construir uma vida nova", "desenvolver minhas qualidades como ser humano" e "me tornar uma pessoa melhor".

\section{Quadro 52. Impacto da Internet na vida do usuário e da comunidade - Usuários}

\section{Você gostaria de dizer algo mais sobre o impacto da Internet em sua vida e na de sua comunidade? ${ }^{8}$}

que mudou definitivamente as pessoas que acessam ao centro porque aqui elas fazem qualquer tipo de pesquisa

Eu acredito que a Internet pode evoluir cada vez mais no sentido da verdadeira inclusão digital. Inclusão não é só possuir computadores mas transformar em espaço de aprendizado de tecnologias e potencializar as informaçÃ $\mu$ es da Web para mudar a vida das pessoas. Os Telecentros podem ser mais dinâmicos e mais também mas formativos, com amplo acesso de todos, não apenas aguardando que as pessoas apareçam no telecentro mas trazendo-as para cá.

sou outra pessoa nelhor

É uma forma de inclusao social

facilidade de acesso a varias informações

só posso dizer que foi a maior criação do século XX, uma comunidade tão gigante e ao mesmo tempo tão simples.

tinha ki c' mais rapida a Internet

e o mundo digital

Vejo a Internet como um otimo veiculo para a informação, entretanto não vejo nas iniciativas de inclusão digital potencial transformador na consciencia das pessoas. Me parece que tais iniciativas buscam nmais o oportunismo das verbas públicas do que a inclusão.

A Internet faz com que as pessoas saibam mais e ficam informados sobre oque esta acontecendo no mundo.

muitos garotos ficam atirado ai pelas ruas mas com o chegar dos computadores eles começaram a vim para o telecentro

foi muito legal agente pode a sesar tudo a que eu quizer.

eu so tenho a diser que o tele centro esta ajudando muitas pessoas !!!

eu acho que não!

acho q a comunidade adorou ter o tele centro,pois podem fazer coisas inportantes.Como:procurar oportunidades d empregos e outras coisas mais...E isso valeu!!!!!!!!

é uma coisa normal hoje como qualquer outra.

isso é uma das coisas mais importantes que a comunidade tem, pois podemos fazer diversas coisas aqui no tele centro

só falta emprego

ela é muito importante para nós.

as pessoas ficaram mais emfodas com que acomtece

um inpacto manero todo mundo bem informado

foi ótimo

A Internet tem dois lados que devem ser estudados, ao mesmo tempo que ela tras para perto quem esta longe ela afasta quem esta perto.

$\mathrm{Na}$ minha vida facilitou muito em pesquisas, ficar por dentro das novidades do dia a dia, e na comunidade deu oportunidades para pessoas que nao tem acesso, principalmente para jovens tirando eles das ruas.

Só posso dizer que melhorou em muito

nao tenho palavras

desempenho e conhecimentos

vejo novas chances de emprego ,atraves dela

estamos felizes

é maravilhoso

não sabe/ não respondeu (54)

Em geral, a percepção do usuário sobre o impacto da Internet em sua vida e na de sua comunidade (quadro 52) é muito positiva. Ela parece ser considerada um meio de transformação, de "inclusão social", trazendo informação, chances de emprego e

${ }^{82}$ As respostas foram abertas e mantidas os textos da maneira como foram digitados pelos usuários. 
"tirando os jovens da rua". Muito poucas críticas foram feitas, mas merecem destaque os seguintes comentários: "só falta trazer emprego" e "ela trás para perto quem está longe mas afasta quem está perto”.

\section{Uso de telefone celular móvel}

Você possui telefone celular?**

Gráfico 47. Posse de celular

Se possui, você já enviou mensagens curtas de texto pelo celular?*

\section{Gráfico 48. Envio de SMS}

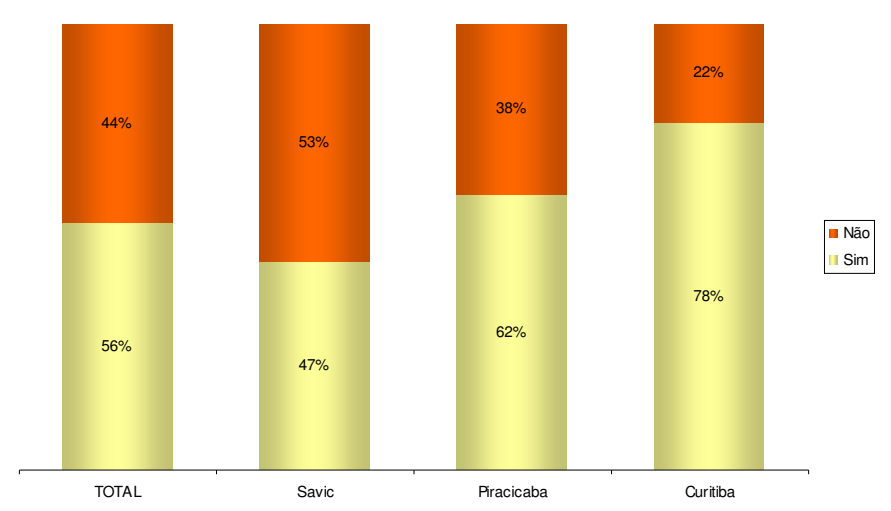

Se a resposta for sim, com que freqüência você as envia?**

\section{Gráfico 49. Freqüência de envio de SMS}
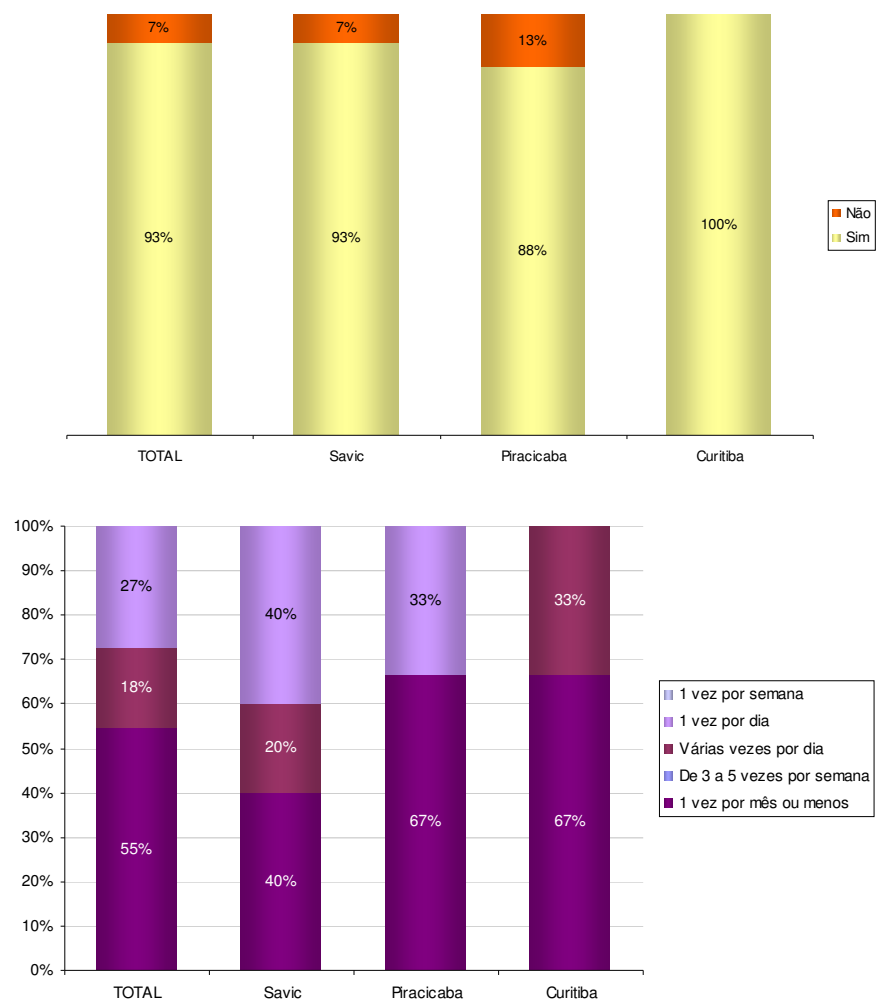

A maior parte dos usuários (56\%) também possui um celular. Destes, 93\% já enviaram e 90\% já receberam mensagens curtas de texto (SMS) pelo aparelho. Entre os que já enviaram, $55 \%$ declararam enviar mensagens uma vez por mês ou menos, $27 \%$ uma vez por semana e $18 \%$ várias vezes ao dia. Já a freqüência de recebimento é maior: $41 \%$ 
recebem SMS várias vezes ao dia, 22\% uma vez por semana e 19\%, de 3 a 5 vezes por semana.

Você já recebeu mensagens de texto pelo celular?*

Gráfico 50. Recebimento de SMS

Se a resposta for sim, com que freqüência você as recebe?*

\section{Gráfico 51. Freqüência de recebimento de SMS}

Você já navegou na Internet pelo celular?*

\section{Gráfico 52. Acesso à} Internet pelo celular
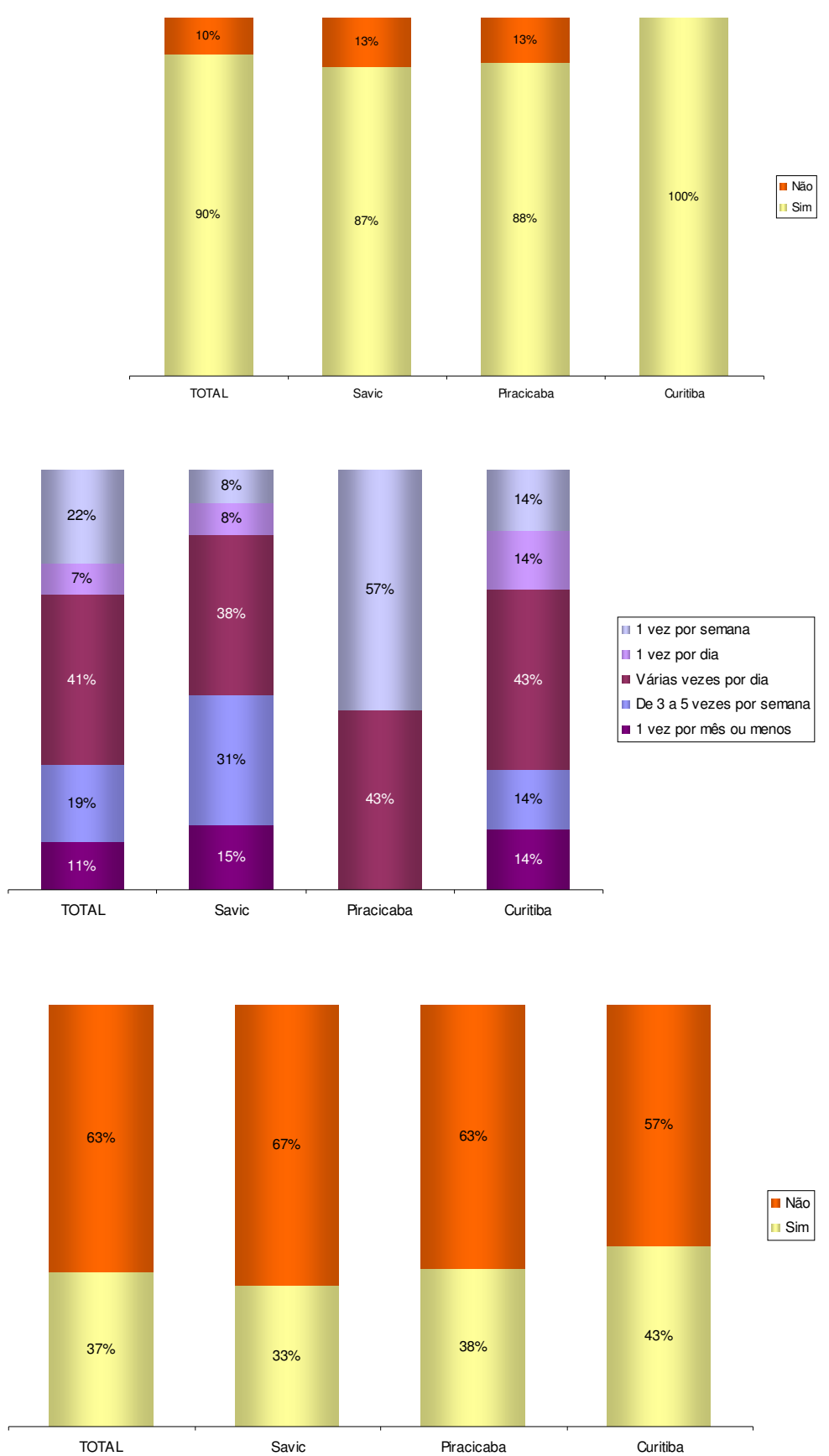

A navegação na Internet pelo celular já é menor, somente 37\% já fizeram a experiência em algum momento. Destes, 55\% navega pelo telefone móvel uma vez por mês ou menos, $27 \%$, uma vez por semana, e $18 \%$ acessam a rede pelo celular várias vezes por dia. As principais atividades realizadas são a leitura de notícias (22\%), o jogo (17\%) e o envio e recebimento de e-mail (17\%), segundo os respondentes. 
Se a resposta for sim, com que frequiência você

\section{Gráfico 53. Freqüiência do acesso à Internet pelo celular} navega?*

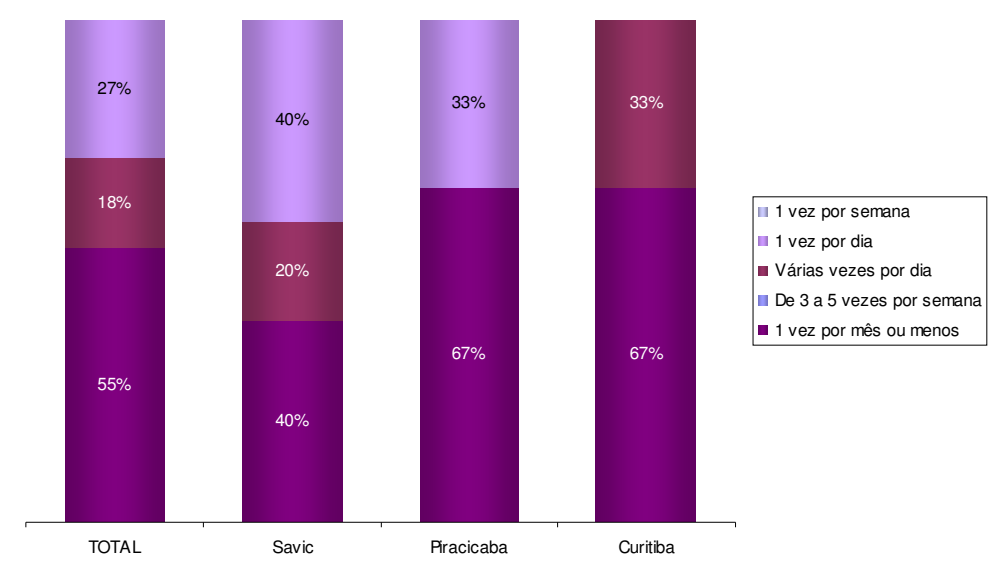

O que você faz quando navega na Internet pelo celular?*

Gráfico 54. Atividades na Internet pelo celular

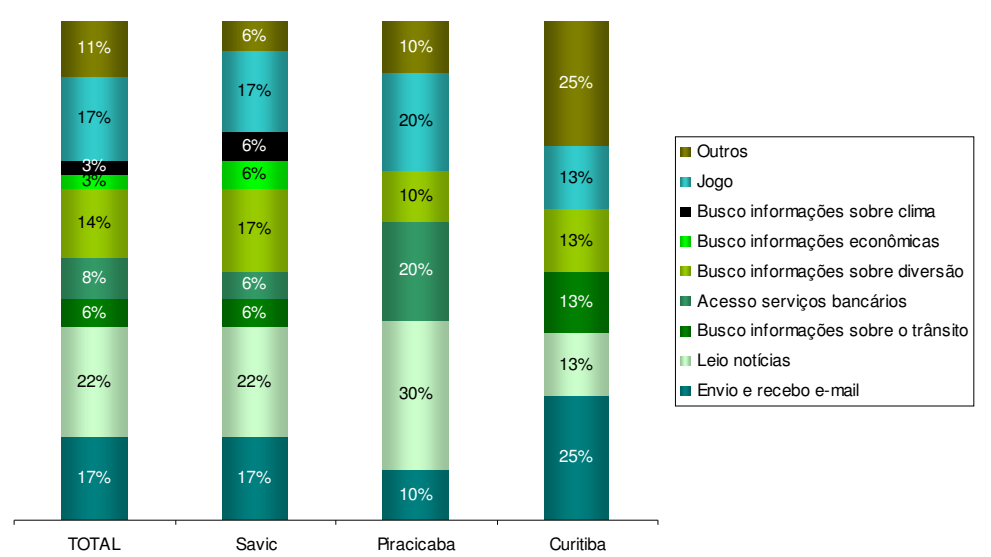

\subsubsection{Perfil médio do usuário}

De acordo com o este levantamento, o usuário dos CPAs em geral é homem, tem 22 anos, é estudante do ensino médio e trabalha. Para ele, a Internet é essencialmente um meio de comunicação e de informação, onde ele também pode se divertir e encontrar os amigos. Ele freqüenta o centro público há mais de um ano, diariamente, e quando não está conectado à rede, usa o computador para fazer trabalhos escolares. Na Internet ele navega também há mais de um ano, antes mesmo de freqüentar o CPA, principalmente para se comunicar com a turma. Ativo nos espaços virtuais de discussão desde que foi apresentado à Internet, não fica sem o MSN e as salas de bate-papo. Jornais e revistas on-line ele lê todos os dias, mas não foi com a Internet que adquiriu esse hábito. Rádio ele ouvia mais antes de freqüentar o CPA, mas o tempo em frente à televisão continua o mesmo. Entretanto, ele se sente muito mais informado agora, tendo acesso à Internet. Endereço eletrônico ele possui também há mais de um ano: costuma escrever até 10 e- 
mails por semana, e recebe em média duas vezes mais mensagens do que envia. Ele posta mensagens no seu Orkut, blog ou página pessoal com freqüência e tem algum interesse em contar ou escrever suas histórias e da comunidade na rede. Mas ele não conhece nenhum veículo de comunicação sendo produzido na vizinhança, e se conhecesse também não teria interesse em participar.

É, definitivamente a web mudou a sua vida: ajudou-o a conseguir um emprego ou melhorou seu desempenho profissional, ele agora tem mais facilidade para aprender até voltou a estudar! -, participa mais da vida da comunidade, se diverte e, acima de tudo, conhece novos amigos! E o acesso à rede mudou a vida da sua comunidade também: os jovens da região ganharam mais opções de diversão e ele até percebe alguma melhoria nas condições econômicas da vizinhança. Ele está muito satisfeito com os serviços oferecidos no CPA, mas sempre há espaço para melhoras: mais máquinas, instalações multimídia, acesso mais rápido... O CPA é a sua porta de entrada para o mundo, ele pode se comunicar com amigos, desenvolver suas habilidades, se "tornar uma pessoa melhor". Com a Internet, ele e seus vizinhos ganharam uma chance de entrar "no mundo digital”. E não é só no pelo computador do CPA que ele navega, com seu celular ele envia SMS e, vez outra, checa um e-mail, lê alguma notícia ou joga. 


\section{ANÁLISE DOS DADOS}

Quando passamos do discurso de mentores e coordenadores para o de monitores e usuários fazemos um mergulho do potencial teórico das tecnologias da informação até a realidade da população brasileira. As opiniões colhidas permitem observar que existe uma disparidade considerável entre o que mentores e coordenadores almejam em termos do salto qualitativo que o acesso à Internet pode oferecer às comunidades de baixa renda e o que os usuários realmente querem - ou ao menos percebem desse processo.

Produzir conteúdo e realizar projetos que propiciem efetivamente a inserção política e econômica na rede através das tecnologias disponíveis são objetivos que representam uma sofisticação no uso do equipamento que o usuário - principalmente aquele que geralmente não recebeu uma educação que motivasse a autonomia e o protagonismo sozinho não consegue alcançar. Essas populações são alijadas, historicamente, do acesso às fontes de informação e não dominam o processo de produção do conhecimento, ou seja, a transformação da informação em construção do conhecimento (SACRISTAN, 2001), portanto têm condições limitadas de se beneficiar da cultura da sociedade em rede $^{83}$.

Ao mesmo tempo, os mentores demonstram aspirações de desenvolvimento humano baseadas no potencial amplamente divulgado dessas tecnologias, mas que exigem muito mais do que o investimento em equipamentos, acesso e alfabetização digital, mas um aporte considerável em termos de capacitação - da forma mais abrangente -, e o comprometimento de coordenadores de programas de inclusão digital em fomentar esse potencial cognitivo. Como ressalta Warschauer (2006, p. 21):

“[...] o acesso significativo às TICs abrange muito mais do que meramente fornecer computadores e conexões à Internet. Pelo contrário, insere-se num complexo conjunto de fatores, abrangendo recursos e relacionamentos físicos, digitais, humanos e sociais. Para proporcionar acesso significativo a novas tecnologias, o conteúdo, a língua, o letramento, a educação e as estruturas comunitárias e institucionais devem todos ser levados em consideração".

\footnotetext{
${ }^{83}$ Aqui a referência é feita em relação aos conhecimentos passíveis de serem produzidos na rede, por que essas populações não são destituídas da capacidade de produzir conhecimentos em geral, particularmente aqueles necessários a sua sobrevivência.
} 
O autor defende a importância da tecnologia como vetor para a transformação social, da capacitação dos recursos humanos para que os indivíduos possam realizar suas próprias escolhas, da fluência tecnológica para inovar, produzir conteúdos e criar novos conhecimentos. Evidencia-se assim que, para uma pessoa participar, ser incluída na sociedade da informação, é necessário não apenas o conhecimento sobre um determinado assunto, mas a possibilidade de usar a habilidade adquirida para pensar e agir criativamente (RESNICK, 2001, 2002). Como sintetiza Castells, "a Internet é a expressão de nós mesmos através de um código de comunicação específico, que devemos compreender se quisermos mudar nossa realidade" (2003, p. 11).

Warschauer (2006) também aponta que não existe uma divisão binária entre ter informação e não ter informação, mas sim uma gradação baseada em diversos níveis de acesso à tecnologia da informação.

A TIC não existe como variável externa, a ser introduzida a partir do exterior, para provocar certas conseqüências. Ao contrário, está entrelaçada de maneira complexa nos sistemas e nos processos sociais. Além disso, do ponto de vista político, o objetivo da utilização da TIC com grupos marginalizados não é a superação da exclusão digital, mas a promoção de um processo de inclusão social (p.24).

Pois não é a falta de acesso que reduz as oportunidades na vida do cidadão, mas são justamente os cidadãos com menos oportunidades que terão dificuldades de acesso e uso da informática. Nesse sentido, destaca-se o papel potencial dos centros públicos de acesso como indutores da inclusão social - e a positividade do discurso de usuários e monitores com relação ao acesso à Internet ganha novas dimensões, pois reafirma o significativo papel dos CPAs - mesmo que o nível de expectativas de mentores e de alguns coordenadores ainda não venha sendo atingido.

Conceito de inclusão digital - As diferenças entre o potencial e a realidade da inclusão digital se refletem na própria compreensão do conceito entre nossos entrevistados: para usuários e monitores o termo remete à idéia de "saber usar o computador e ter acesso à Internet", e para alguns se amplia na perspectiva de "ter oportunidade de participar de um novo mundo, o mundo da informática". Os monitores têm a preocupação adicional de "levar a Internet para as pessoas que não têm acesso", e a compreensão de que o computador é uma ferramenta necessária para a execução de um número crescente de 
atividades cotidianas: "Se tu fizer um relatório, não faz mais à mão.... Agora mesmo, a gente está fazendo esse cadastro, para procurar endereço, mandar e-mail para as pessoas que moram longe", comenta Cinara, monitora do Telecentro Turma da Tuca, de Porto Alegre. Já para coordenadores e mentores, inclusão digital é um conceito mais amplo e em constante evolução, abrangendo desde a disponibilização do acesso à Internet, a capacitação do usuário e a profissionalização - objetivos considerados básicos -, até perspectivas mais complexas, como a articulação do indivíduo em rede, sua participação ativa no processo produtivo estabelecido pela sociedade da informação e a transformação da sua própria realidade. Para Rodrigo Assumpção, "é o reconhecimento de uma sociedade de que existe uma situação de exclusão digital e que essa situação tem que ser combatida com um processo de inclusão digital". Para isso, não basta fornecer acesso aos equipamentos e às linguagens àqueles que não têm, mas é necessário capacitá-los de forma a que eles possam processar e avaliar informações, processar e exprimir suas idéias.

Como visto no capítulo anterior, existe ainda uma certa divergência entre mentores em torno do termo "inclusão digital", deixando transparecer para alguns os interesses que motivam a iniciativa. Fernando Guarnieri questiona o "engessamento" do conceito, através da tentativa de conceituação do processo, que acaba por resumir o potencial de apropriação tecnológica e produção de conhecimento trazido pelas TICs à questão do acesso à tecnologia e à capacitação. Enquanto Gilson Schwartz se opõe a seu uso, pois para ele "inclusão digital é um slogan da indústria, para colocar as pessoas na dependência dessa infra-estrutura". Nesse sentido, Schwartz (2003) ${ }^{84}$ afirma que "a identificação de novas fronteiras de inclusão tornou-se portanto uma das mais poderosas ferramentas de marketing da indústria de tecnologias de informação e comunicação ([s.p.])". E mais recentemente, propõe o uso do termo "emancipação digital":

As redes de conhecimento contemporâneas são espaços de reconhecimento híbridos, nos quais pulsam fluxos de informação analógicos e digitais, locais e globais, controlados e autônomos, centralizados e descentralizados, certificados e anônimos. Participar dessas redes, ou seja, estar alfabetizado digitalmente, é, sem dúvida, uma inclusão. Mas não são triviais o sentido e o grau em que a chamada inclusão digital requer uma alfabetização mais complexa e contínua. [...] Propomos a alfabetização com caráter emancipatório [...] Uma inclusão com reconhecimento, promovendo a formação de identidades e a articulação de oportunidades de geração de emprego e renda, aliadas de modo sustentável ao

\footnotetext{
${ }^{84}$ Ver http://www.cidade.usp.br/impressaodigital/0503/infra/ Acesso em 15 de outubro de 2005.
} 
desenvolvimento da indústria e da tecnologia, com o fomento à pesquisa para a inovação nas universidades, escolas e centros de estudo ( 2005 , [s.p. $])^{85}$.

Produção e consumo de informação - $\mathrm{O}$ acesso público à Internet está mudando a relação das comunidades de baixa renda com a informação. Embora a produção de conhecimento não tenha sido alcançada plenamente, o usuário se sente muito mais informado, pratica suas habilidades de comunicação, articula idéias através do MSN e das salas de bate-papo, e se apresenta ao mundo pelo Orkut. Seu lugar no ciberespaço também está garantido pelo seu endereço digital - o e-mail, que de acordo com o mentor Rogério Santanna, muitas vezes é a única forma de identificação que indivíduos de baixa renda possuem. Segundo os resultados da pesquisa, muitos dos usuários dos CPA se descrevem como leitores diários de jornais e revistas ${ }^{86}$, hábito que afirmam não ter sido adquirido com a Internet. $\mathrm{O}$ acesso à rede não alterou também a sua rotina com relação à televisão, mas ele considera que passa menos tempo ouvindo rádio agora. Para os monitores, que acompanham o dia-a-dia dos centros públicos, a leitura por parte dos usuários acontece de forma involuntária, sendo que a porta de entrada para a sociedade de informação parece ser os portais de e-mail gratuito, a primeira atividade na rede de qualquer usuário, independente da classe social. O leitor "ciber-flâneur", como observa Lemos ([s.d.]), explora o ciberespaço através de hiperlinks. O usuário dos CPAs se informa através do passeio por manchetes e imagens, do vislumbre de notícias em tempo real que, segundo Becker ([s.d.]), o fascinam:

\begin{abstract}
$\mathrm{O}$ acesso dos moradores de periferia à Internet dissipa quaisquer dúvidas ainda existentes quanto ao valor da informação para os mais pobres. Diferentemente da afirmação de alguns autores de que os pobres atribuem pouco ou nenhum valor à informação - noção (liberal) convergente com o ideário de que os pobres são responsáveis pela sua pobreza, ou de que há uma "pobreza cultural, dotada de 'estoque simbólico restrito', decorrente (...) de experiência de vida "muito simples" -, cada vez mais as pessoas, em especial as mais pobres, buscam todas as formas de obter informação, pois esta passou a ser sinônimo tanto de sobrevivência quanto de competência.
\end{abstract}

$\mathrm{Na}$ opinião dos coordenadores, o acesso à Internet definitivamente contribuiu para o aumento do consumo de informação entre os freqüentadores dos CPAs, o que corresponde a um dos principais objetivos dos programas de inclusão digital que

\footnotetext{
${ }^{85}$ Ver http://cidade.usp.br/redemoinhos/?2005-09/analise/. Acesso em 5 de janeiro de 2007.

${ }^{86}$ Note-se que a pergunta não diferenciava o meio - papel ou virtual. O resultado também suscita uma certa curiosidade, devido às dificuldades conhecidas das populações de baixa renda a fonte de acesso de informação.
} 
oferecem acesso gratuito à população. Isso porque consideram que a realização de atividades lúdicas e de relacionamento são importantes para o desenvolvimento do raciocínio e das habilidades de articulação do usuário. Neste sentido, a pesquisa realizada entre usuários apontou que $58 \%$ dos respondentes publicam algum tipo de informação em blogs, Orkut ou fotologs.

Entretanto, coordenadores e menores concordam que o potencial da Internet para a produção de conhecimento não se resume na troca de bits. Como Warschauer aponta, "[...] o fato de que as crianças tenham o know-how de bater papo num computador não significa que saibam como escrever uma mensagem eficaz de correio eletrônico para uma empresa, uma instituição acadêmica ou um representante político” (2006, p. 163). Além disso, para coordenadores, os objetivos dos programas estão relacionados a oportunidades de inclusão social e cidadania, através da apropriação do ferramental digital para a inserção no setor produtivo, do desenvolvimento de uma maior autonomia no relacionamento com a sociedade e, ao menos, do uso dos serviços de governo eletrônico.

No que diz respeito à produção de conteúdo de interesse local, os resultados da pesquisa com usuários não são muito animadores. Apenas $11 \%$ dos usuários disseram publicar algum tipo de informação de interesse comunitário, sendo que os motivos alegados pela grande maioria que não publica foram "falta de interesse", "de tempo" ou "de assunto". Ao mesmo tempo, $51 \%$ dos respondentes disseram que a comunidade - ou ele próprio tem histórias ou notícias para contar, e destes, $58 \%$ teriam interesse em fazê-lo. Percebe-se então que existe uma motivação em potencial por parte dos usuários para a produção de conteúdo, mas limites talvez decorrentes das próprias dificuldades de expressão pela linguagem escrita, ou de se expor perante a comunidade, os impedem. Para Ricardo Kobashi, o importante não é que todos sejam produtores mas que, se houver interesse em fazê-lo, as condições sejam oferecidas.

Segundo Rodrigo Assumpção, são os usuários que conseguem utilizar o potencial da Internet para se transformar em produtores de informação que se destacam, conseguindo assim exercer alguma influência nas transformações sociais. Estes, os protagonistas, são poucos. Primeiro, porque o baixo nível de educação e a dificuldade na produção de conteúdo - resultado da baixa qualidade do ensino público e da dificuldade que essa 
população enfrenta para se manter na escola - é uma forte limitação. Segundo, porque nem todo cidadão - independente das oportunidades que teve na vida - é líder, e a tecnologia não altera as características individuais do usuário.

Contribuição para o desenvolvimento - De maneira geral, usuários e monitores dos centros públicos de acesso - normalmente membros das próprias comunidades atendidas - , têm uma visão muito mais positiva do "impacto" dos programas de inclusão digital em suas vidas e dos benefícios trazidos pelo acesso à Internet para o seu cotidiano e sua relação com o mundo, do que coordenadores e mentores, que se mostram mais preocupados em potencializar essa relação com a tecnologia, buscando sinais mensuráveis de transformações efetivas no que diz respeito ao desenvolvimento social, político e econômico dessas comunidades.

As perspectivas são distintas: para os beneficiários dos programas, cada dia é uma conquista, e vencer a barreira do acesso à infra-estrutura e da alfabetização digital já é uma grande vitória face à falta de oportunidades e disparidades econômicas e culturais da periferia. Já mentores e coordenadores estão motivados pelas etapas seguintes do processo de inclusão digital: a apropriação da tecnologia e a produção de conhecimento o que não deixa de ser natural, dado que são eles os responsáveis pela elaboração dos programas, assim como por sua expansão e continuidade, consideradas inquietudes adicionais, no caminho em direção a inclusão social.

Houve alguma dificuldade entre os monitores para identificar as contribuições dos programas de inclusão digital para o desenvolvimento de sua comunidade, no entanto foram citadas: "chances para a conquista de um bom emprego", "facilidades para envio de currículos", "interesse maior pela leitura", "retorno aos estudos", "aumento da autoestima" e "diminuição da criminalidade". Porém, ao falar de suas próprias experiências, os monitores mostraram com clareza o salto de qualidade que o uso das TICs provocou em suas vidas. Já os usuários, estimulados pelo questionário, responderam que o acesso à Internet foi responsável por mudanças profundas em seu cotidiano: acima de tudo "os adolescentes ganharam mais opções de diversão e desenvolvimento", mas a rede também "ampliou as opções de lazer e comunicação" e "melhorou as oportunidades de 
trabalho e de educação" de toda a comunidade. Entretanto, não necessariamente trouxe renda.

Coordenadores e mentores concordam que as possibilidades de diálogo entre o poder público e os jovens cresceram, mas não necessariamente que tenha havido uma queda na criminalidade resultante desta nova relação. Fernando Guarnieri exprime sua preocupação com relação ao assunto "[...] a gente não tem idéia, não tem nenhum indicador, é muito difícil medir isso. A gente não sabe se ele mudou a realidade dele por causa do infocentro, ou porque a escola melhorou, ou porque entrou uma empresa lá... [...], não temos como controlar as variáveis...”. Para os idealizadores e administradores dos programas, o que existe são histórias individuais de sucesso e cases que apontam para melhorias no desenvolvimento pessoal, de auto-estima e de empregabilidade. Também identificam de forma positiva as conquistas em termos de novas possibilidades de comunicação e de troca de informações, e o potencial enorme - ainda não lapidado para a articulação comunitária, a produção de informação e a percepção do seu papel dentro da sociedade. Analisando os vários discursos, podemos concluir que talvez a Internet não tire o jovem da rua, mas o centro público de acesso é sim um local seguro, que se transformou em opção de lazer e desenvolvimento para o jovem da periferia. "Além de um ponto de encontro é um ponto de apoio", diz Rodrigo, monitor do Infocentro SAVIC, mostrando como esse porto seguro é importante face ao movediço e fluido chão onde se assentam jovens da periferia das grandes cidades. Dai a importância de um ponto de apoio - onde se afirmar para se projetar. Beá Tibiriçá complementa esta visão: "Nem tudo o que se faz dentro de um telecentro ou na maioria deles tem a ver com a tecnologia propriamente dita, mas tem a ver com grupos de comunidades, com projetos locais, com o debate do desenvolvimento local. Então essas atividades passam a acontecer em torno do computador e em torno do telecentro”.

Articulação social e cidadania - A rede efetivamente traz novas dinâmicas de relacionamento e de interação, mas como mencionado anteriormente, não cria $o$ protagonismo - ela potencializa as características individuais de cada um. Os movimentos comunitários, por exemplo, existem muito antes do surgimento das tecnologias da informação, mobilizados pela capacidade de articulação de suas lideranças e por necessidades reais de cada localidade. Entretanto, como lembra Rodrigo 
Assumpção, "uma liderança talentosa com máquina é muito mais poderosa que uma liderança talentosa sem máquina”.

Além disso, é importante lembrar que o conceito de comunidade articulada é muito mais forte entre os indivíduos que habitam as regiões periféricas da cidade do que nas centrais, afirma Dimantas (2006, p. 29): “É a arquitetura de rede, não virtual e tão bem conhecida pelas lideranças comunitárias, que possibilita que eles consigam sobreviver com parcos recursos e ainda mobilizar moradores para mutirões, pressionar administradores públicos e serem peças importantes dentro do jogo político e eleitoral. As organizações comunitárias de baixa renda vivem da rede".

Essa observação aponta para o fato de que os centros públicos de acesso, como "pontos de encontro", tal como sugerido por alguns dos monitores, usuários e coordenadores, têm significativo papel naquilo que Rodrigo Baggio aponta como "formação de agentes de mudança", ao proporcionar, além do acesso à tecnologia, um espaço para reflexão coletiva. As novas ferramentas digitais possibilitam condições para se lutar contra a desigualdade, pois através da Internet é possível se buscar informações antes inacessíveis, construir relações, conhecer o mundo, expressar opiniões, interagir (SORJ, 2003) - mesmo que, como afirmam mentores e coordenadores, o potencial da rede como um instrumento de promoção da democracia ainda não tenha sido plenamente atingido.

Carlos Afonso resume de forma simples: "o que eu sei é que mudanças sociais existem”, e Beá Tibiriçá complementa, citando o exemplo de “comunidades indígenas do Peru que passaram a ter contato com comunidades indígenas do Canadá para trocar experiências desde como defender os seus direitos... até para fazer troca comercial de produto".

Motivações por trás da inclusão digital - Considerando que a instalação de centros públicos de acesso são iniciativas positivas, mas que não deixam de refletir o novo "modelo econômico globalizado" baseado na informação, as motivações de cunho político, econômicas e sociais para o desenvolvimento e expansão dessas experiências 
afloram juntamente com a questão: qual o sentido da disseminação desses equipamentos - computadores e acesso?

O discurso de mentores e coordenadores deixa claro que são as motivações políticas que vêm guiando o desenvolvimento de centros públicos de acesso e de iniciativas de inclusão digital no país: basicamente, os investimentos públicos em tecnologia da informação na modernização da máquina administrativa do Estado se justificam através da ampliação do acesso aos serviços de governo eletrônico a uma parcela maior da população. É claro que a perspectiva de democratização do acesso e de cidadania também permeia as ações do governo. Rogério Santanna lembra que o programa Telecentros Porto Alegre surgiu no final dos anos 1990, a partir de um posicionamento da própria comunidade, "uma das questões que apareceram no Orçamento Participativo naquela ocasião foi o questionamento da validade dos investimentos em Tecnologia da Informação do município frente às necessidades que a população mais pobre tinha de dispor de infra-estruturas mais básicas", conta.

Sérgio Amadeu conta que quando Marta Suplicy assumiu a Prefeitura de São Paulo, uma das primeiras preocupações foi a ampliação do acesso à rede de serviços e informações públicas que estava se desenvolvendo no município, "para que o Governo Eletrônico não privilegiasse o segmento A e B, que tem computador em casa. [...] E já que vai montar uma rede de acesso, essa rede podia trazer também a concepção que vem da comunidade se apropriar da tecnologia. Então montamos a rede de Telecentros”. E Fernando Guarnieri, responsável pela implantação do programa Acessa São Paulo, lembra que a motivação no governo do estado foi muito parecida, quando por volta de 1998, após acompanhar os projetos de governo eletrônico de vários países, o Governo do Estado decide colocar o seu o portal no ar: "A gente falou: 'vamos implantar esse tipo de sala para o pessoal acessar o nosso site e todos os serviços eletrônicos!' A gente queria revolucionar, na nossa cabeça a gente ia fazer uma grande revolução. O Dalmo [Nogueira] topou na hora a idéia. Aí como envolvia entidades comunitárias, ele viu que era um negócio muito legal, porque você ia fortalecer as entidades comunitárias", narra, mostrando também que a preocupação de se formar e fortalecer as lideranças esteve - e continua - presente. Neste sentido, Sérgio Amadeu lembra que "qualquer projeto tem um lado de decisões que envolvem política, no 
sentido de envolver o Estado enquanto instituição, ou envolver políticos, no mínimo para trazer o apoio ou para neutralizar possíveis ações negativas".

Desta maneira, mesmo não sendo regra, a implementação de novos CPAs se associa também a interesses de certa forma eleitorais, sendo que a abertura de uma nova unidade pode ser usada como moeda de troca político-partidária para deputados e políticos em geral. Como mencionou Reinhart (2006, comunicação pessoal), "A inauguração de cada novo telecentro é como um evento político". Assim como já o foram as escolas e os centros de saúde. Além disso, observa-se que é a vontade política dos mandantes em exercício - prefeitos, governadores, etc. - que viabiliza a realização e manutenção dos centros públicos, através do investimento e do estabelecimento de convênios e parcerias importantes para o funcionamento do mesmo. Ao mesmo tempo que garante o seu desenvolvimento, essa relação direta com a administração traz uma certa fragilidade aos programas, que por não serem frutos de uma política pública, estão sujeitos à descontinuidade ou falta de investimento, no caso de mudanças de partidos políticos na gestão do Governo em diferentes níveis, como é o caso do enfraquecimento do programa Telecentros em Porto Alegre, ou a mudança de direcionamento do Digitando o Futuro em Curitiba, que passou a se chamar Cidade do Conhecimento. É certo que o momento histórico deve ser bem posicionado quando tratamos de mudanças de gestão pública e seus desdobramentos, mas em geral percebe-se que o “desaparelhamento" de CPAs trazido pelas movimentações públicas, quando não traz a descontinuidade dos projetos, gera evasão de quadros, o sucateamento dos postos já implementados e a falta de investimento no modelo de atuação comunitária que vinha sendo desenvolvido, colocando a perder o investimento anteriormente realizado. Como já dissemos, é o interesse político no programa que garante os investimentos, financiamento e a sua continuidade.

Se são as vontades políticas e os interesses econômicos que, em última instância, conduzem o desenvolvimento de nossa sociedade - não é de se estranhar que os programas de inclusão digital representem para as grandes empresas de tecnologia ${ }^{87}$ principalmente em países em desenvolvimento - uma ótima possibilidade de ampliar

\footnotetext{
${ }^{87}$ Não era objeto desta pesquisa incluir o discurso das empresas, mas esta é uma questão que merece futuros desenvolvimentos.
} 
seus mercados, através da formação de novos consumidores e da aproximação com o Governo, o que garante o fornecimento de equipamentos para estas novas instituições públicas. "A disseminação acelerada dos meios de produção digitais em todos os setores da economia e da sociedade colocava para empresas e governos o imperativo de incluir 'no' digital tudo o que fosse relevante nas suas cadeias produtivas", explicita Schwartz (2003). Além disso, como lembra Ricardo Kobashi, são uma ótima oportunidade de se desfazer de "lixo tecnológico", citando o exemplo da doações feitas ao Comitê de Democratização da Informática por empresas de tecnologia na época em que participava da organização (ver quadro 30), e ainda lucrar em termos de imagem - através de programas de responsabilidade social. Paoli (2002) argumenta que a filantropia dirigida a grupos carentes da sociedade faz um grande bem às empresas, reforçando sua imagem institucional e melhorando seus negócios, o que não seria um problema "não fosse o fato de que a ação social empresarial também parece fazer parte não só das operações de lucro, mas também da afirmação do poder social sobre as comunidades em que atua, sobre as relações de trabalho que contrata e sobre as causas que abraça" (p. 394).

Neste cenário, é importante mencionar o papel da sociedade civil, que ao mesmo tempo é protagonista na concepção e administração de programas de inclusão social, através de iniciativas de organização do terceiro setor e de universidades, como sujeito das ações, na figura das comunidades de baixa renda atendidas. A participação das ONGs é crucial no cenário da inclusão digital no Brasil. Paoli (2002) explica que o modelo econômico neoliberal adotado pelos governos nos anos $1990 \mathrm{fez}$ com que demandas de cidadania e solidariedade surgissem, impelidas pela falta de investimento em obrigações públicas de proteção e garantia eficazes dos direitos sociais:

\footnotetext{
Esse quadro de imposições econômicas, heranças culturais e interesses particulares talvez nos ajude a entender a importância do surgimento relativamente recente de uma assim chamada 'sociedade civil' que, primeiramente através de movimentos sociais autônomos e politizados, e depois de organizações não-governamentais profissionalizadas, deslocou o ativismo político pela cidadania e justiça social para o ativismo civil voltado para a solidariedade social (p. 378).
}

Desta maneira, as entidades de terceiro setor são vistas como indutoras de programas de democratização da Internet, levando o acesso às TICs às comunidades, ao mesmo tempo que se estruturam através dos financiamentos envolvidos na alavancagem dos projetos nas comunidades em que atuam. As comunidades organizadas, por sua vez, cientes do 
potencial trazido por estas ferramentas, zelam pelos CPAs, ao mesmo tempo que enfrentam dificuldades para mantê-los. Como lembra Nivaldo Cardoso, líder comunitário da associação que abriga o Infocentro SAVIC, "infelizmente o Governo pensa nos projetos, mas não nas dificuldades da entidade. A gente sabe da importância da inclusão digital, enfim, por esse lado ele é excepcional. A Imprensa Oficial contrata os meninos, que estão gerenciando os projetos, mas o problema da energia todos os infocentros têm", lamenta. Este comentário sobre a dificuldade com a manutenção dos programas remete ao questionamento sobre a motivação da abertura dos CPAs. É mais fácil e interessante abri-los do que mantê-los. Mentores e coordenadores concordam que a grande dificuldade dos programas de inclusão digital é a sua sustentabilidade, e não a sua implementação. Rodrigo Assumpção alerta: "De maneira geral, o governo ainda não entendeu que os infocentros são uma necessidade tão grande quanto bibliotecas públicas ou escolas. [...] Programa público quer distribuir máquinas, no máximo pagar conexão e o resto é problema da sociedade, daquela associação, que mal consegue estruturar um programa de qualificação para aquilo".

Pelas entrevistas realizadas percebe-se que mentores e parte dos coordenadores identificam claramente as motivações envolvidas no processo, mas monitores e usuários não têm tanta consciência do conjunto. Se não fosse por vislumbres como o de Paula, monitora do Infocentro de Piracicaba, que comenta: "eles estão tentando transformar a gente em agentes políticos, entendeu?", acusando um tanto confusa a existência de interesses não explícitos sob a política de inclusão digital. Em geral, usuários e monitores continuam passivos expectadores, repetindo o "slogan" da mídia ao explicar a importância da Internet em suas vidas: "participar do mundo digital".

Todos estes interesses entretanto colocam a educação - principal recurso envolvido na efetiva democratização do acesso à sociedade da informação - em segundo plano. A questão educacional é muito séria. Além de ser limitante, ela pode ser intimidadora - se o líder comunitário não é capaz de usar o computador - ele vê seu potencial de liderança em cheque. Se não sabe escrever corretamente, não se sentirá a vontade para postar em um blog. Neste sentido, Warschauer (2006) comenta que a prática do letramento eletrônico "não envolve apenas a atividade individual de decodificar e codificar o texto, mas também a atividade social de exercer o controle. Como outras formas de 
letramento, não acarreta apenas a leitura da palavra, mas também a leitura do mundo, e, de certo modo, a escrita e reescrita do mundo" ( p. 164).

Conquistas e desafios da Inclusão Digital - São muitas as conquistas e maiores ainda os desafios dos programas públicos de acesso à Internet no cenário atual. Mesmo com a ausência de indicadores mensuráveis e com a consciência de que os casos isolados de sucesso é que fazem a história da inclusão digital no país, não podemos esquecer que em 2000 apenas 2,5\% dos brasileiros tinham acesso à Internet, principalmente nas classes A e B (TAKAHASHI, 2000). Hoje já são quase $27 \%$ de internautas, se considerarmos os indivíduos que tiveram acesso à rede pelo menos uma vez nos últimos três meses, segundo o CGI.br ${ }^{88}$. Um grupo ainda extremamente restrito - somente 3,5\% da população - já faz uso diário dos CPAs e possui a sua "carteira de identidade digital”, o endereço eletrônico, participando das redes virtuais, ainda que muitas vezes através da simples troca de bits. Esse já é um começo. Mas é impossível ignorar os 100 milhões de brasileiros (CGI.br, 2006) que nunca tiveram a oportunidade de participar dos processos produtivos estabelecidos através da rede, na chamada sociedade da informação. Segundo Afonso e Soares (2005, p. 27), ainda existe um grande número de brasileiros “condenados à exclusão eterna" devido à falta de acesso local à Internet em quase 2,4 mil municípios brasileiros:

“[...] pelo desejo das empresas de telecomunicações e de Internet, mais de 20 milhões de brasileiros estão e continuarão excluídos do acesso aos serviços que a telefonia celular e a Internet podem oferecer - serviços hoje essenciais, incluindo o acesso às crescentes facilidades de e-governo federais e estaduais [...]. E se incluirmos as áreas empobrecidas das cidades maiores, esse número de condenados à desconexão eterna eleva-se em várias vezes", denunciam.

Para os mentores entrevistados, é consenso que a ampliação do acesso de comunidades de baixa renda à Internet passa pela revisão e fortalecimento do atual modelo de parcerias -estabelecido normalmente pelo tripé Estado, iniciativa privada e terceiro setor - para a implementação e gestão dos programas de inclusão, através de políticas públicas articuladas. Beá Tibiriçá enfatiza: "Inclusão digital tem que ser entendida dentro do escopo da inclusão social. Deve ser tratada como política pública, como um direito do cidadão, e só tem sentido na medida em que você tiver envolvimento com a comunidade

\footnotetext{
${ }^{88}$ Pesquisa Sobre o Uso das Tecnologias da Informação e Comunicação no Brasil 2006. Disponível em http://www.cetic.br/usuarios/tic/2006/index.htm. Acesso em 29 de janeiro de 2007.
} 
que recebe o equipamento que vai proporcionar tecnologia para a inclusão digital'. A grande questão que se apresenta agora é formulada por Carlos Afonso: "Qual política pública? Qual o nível de envolvimento deve ser definido em uma estratégia nacional de inclusão digital na qual todos têm que participar, cada um no seu papel? Por exemplo, os empresários têm muito a ensinar, não é um sociólogo que vai lá ensinar empreendedorismo para a comunidade”.

A maior parte dos entrevistados acredita no fortalecimento da tríade, mas ainda não está claro como ela pode ser fortalecida através de políticas públicas sem contudo "amarrar" e burocratizar o processo. Poucas vozes dissonantes indicam que esse modelo não vêm surtindo o efeito esperado e que seus custos não justificam o investimento realizado. Reinhart (2006, comunicação pessoal) é um deles. Para o pesquisador, com exceção de experiências-piloto, os programas sustentados pelo modelo de parceria "governo-setor privado-ONG", no qual o Governo é responsável pela coordenação, e, em alguns casos, também pela infra-estrutura técnica, deixando com os demais parceiros a responsabilidade pelas instalações, salário dos funcionários, fornecimento de conteúdo, etc., não foram capazes de mostrar escalabilidade e sustentabilidade. "E os novos programas federais estão usando novamente o modelo de parceria”, sublinha.

É unânime a consciência de que há muitas tentativas, mas que a falta de uma estratégia nacional de inclusão digital está limitando o crescimento do acesso à rede no país. Essa falta de articulação - que deveria ser orquestrada pelo governo federal - passa principalmente pela frustração em relação aos recursos contingenciados no FUST. De um lado o Governo, através das inúmeras - e na maioria das vezes isoladas - ações apresentadas neste trabalho mostra sua preocupação e determinação em alavancar a infra-estrutura e o uso das redes, de outro, a burocracia, brigas pelo poder em diversos âmbitos, diferentes prioridades, dificuldades na liberação e descentralização de recursos, entre outros, atravancam o processo.

[O Governo Lula] não conseguiu ter uma política pública de inclusão digital, isso é um fato. Você tem muitas iniciativas de inclusão digital, mas elas não existem enquanto um programa de governo voltado para a inclusão digital. O que está acontecendo no Governo Federal é isso, você tem o PC Conectado, Casa Brasil, os telecentros de negócios do Furlan, os pontos de cultura que estão sendo implantados.. mas por que não são um projeto só?, questiona Tibiriça. 
À espera do plano nacional de inclusão digital - A necessidade de um de uma política pública mais consistente e de continuidade se traduz, de forma quase unânime, através de um plano nacional de inclusão digital e da formulação de uma lei de diretrizes e bases que assegure os direitos do cidadão e viabilize o processo de expansão das TICs, levando em consideração não somente o acesso público através de CPAs, mas uma infra-estrutura nacional de banda larga que conecte todo o país. É consenso também que o Estado deve ser o articulador e maestro dessa agenda digital, financiando o acesso gratuito também em escolas, bibliotecas e prédios públicos. Mas ele não deve nem pode - atuar sozinho. As empresas privadas devem participar tanto trazendo recursos para iniciativas públicas, como investindo na ampliação da rede de telecomunicações ou fomentando o acesso pago à Internet - a preços razoáveis - através de iniciativas privadas como lanhouses.

A inclusão digital está na moda, as empresas privadas e o terceiro setor estão motivados, o Governo tem mostrado preocupação, grande parte dos mentores de programas de inclusão digital no país estão hoje em cargos estratégicos na administração federal, estadual e municipal, então porque é que essa estratégia nacional e integrada não se materializa? O que aconteceu com o trabalho realizado por cerca de 150 especialistas que no início de 2000 se apresentou como a perspectiva de uma agenda digital para o país, com nome de Livro Verde?

A problemática questão da educação - que de tão deficitária no país, não só limita a apropriação das TICs como impede a conquista de garantias básicas e primárias para o cidadão - pode oferecer uma pista. O tempo de assimilação das novidades tecnológicas precisa ser considerado. A inclusão digital no Brasil começou através das escolas, com a implementação de laboratórios de informática através de programas como Parceiros do Futuro, no estado de São Paulo, abertos também ao uso da comunidade. Entretanto esse modelo apresentou alguns problemas, os professores não receberam capacitação adequada para usar as máquinas, os laboratórios permaneceram fechados, a motivação do Governo acabou desviada para os centros públicos de acesso, que ofereciam mais resultados políticos, mais atrativos a para mídia. A falta de clareza sobre o sentido do uso das TICs na escola, ampliou a força dos CPAs como espaço de experimentação dos jovens. A educação continua em segundo plano, mesmo que uma das maiores reivindicações dos usuários destes CPAs seja justamente a capacitação, o letramento 
digital, a chance de participar. Mas a educação sabe que os processos levam tempo para ser assimilados. Foram anos até que a legislação do sistema educacional fosse formulada conforme os preceitos da Constituição de 1988. Para que sua lei de diretrizes e bases fosse aprovada, para que efetivamente ela fosse tratada como um direito de todo cidadão. A tecnologia encurta distâncias, agiliza processos, mas a evolução da sociedade tem o seu próprio ritmo. O grande problema é que a "sociedade da informação" não pode esperar.

A televisão digital está chegando, o telefone celular está se transformando em um equipamento quase tão performático quanto um computador, de que maneira o cidadão irá interagir com estas máquinas? 


\section{CONSIDERAÇÕES FINAIS}

Muitos são os interesses que se ocultam por trás da inclusão digital. Mas Anderson, o usuário padrão que descrevemos no início desta trajetória, não está ciente. Para ele a possibilidade de acessar a rede diariamente, de encontrar seus amigos e de pertencer ao mundo digital é o que interessa. E, nesse sentido, ele é um incluído.

Entretanto, a chegada da inclusão digital dentro do contexto de globalização está em debate no país: o discurso tem grande potencial de se tornar uma política pública de desenvolvimento nacional ou pode se eternizar como mais um instrumento de rivalidades políticas. É a chegada de um conceito complexo, que vem na esteira de uma transformação econômica mundial, que traz uma proposta específica de relações, que é apropriada de maneiras diferentes pelos distintos atores desta tese. Os usuários de renda baixa que freqüentam os CPAs parecem não compreender plenamente as aspirações dos mentores com relação ao potencial das tecnologias, ao mesmo tempo que estes não estão levando em consideração as mudanças que a Internet já traz para a vida do usuário. Consideradas por estes últimos como muito significativas.

O abismo entre as expectativas indica o sério problema da escolaridade no país. Quanto maior o grau de escolarização formal, maior o potencial de desenvolvimento humano. $\mathrm{O}$ simples acesso não garante que a informação seja processada, assimilada, e que se transforme em conhecimento. Em consequiência disso, este trabalho indica que ainda não se pode perceber uma produção efetiva de conteúdos por parte dos usuários de CPAs, principalmente devido às dificuldades de letramento dos cidadãos de baixa renda que vivem em áreas de risco social, e que em sua grande maioria têm acesso limitado à educação formal de qualidade. Com o acesso à Internet, o que ocorre é o contato com diferentes fontes de informação e a ampliação das possibilidades de comunicação, através das mídias digitais. Para enfatizar este ponto, vale citar novamente a obra de Warschauer (2006), que foi um dos fios condutores desta tese:

Há uma grande diferença entre informação e conhecimento, e o letramento informacional é decisivo para a capacidade de transformar a primeira no segundo. Esse letramento está distribuído de modo desigual na sociedade, e cruza com outras formas de estratificação social. O fomento do letramento informacional deve ser um objetivo importante para projetos que buscam promover a inclusão social" (, p.159). 
Assim como as motivações políticas, que parecem dominar o cenário da inclusão digital no país, colocando em dúvida a verdadeira intenção por trás do desenvolvimento de novas iniciativas e da abertura de CPAs, os interesses econômicos devem ser colocados em evidência, sem contudo negar a importante contribuição do setor privado para a alavancagem do processo. As tecnologias da informação e da comunicação eliminaram fronteiras e colocaram o conhecimento no centro dos processos sociais e produtivos. Pela primeira vez na história a ferramenta que possibilita a produção dos bens de consumo mais importantes para o mercado global está acessível para uma parcela crescente da população. Todos estes deveriam ser argumentos suficientes para justificar investimentos em políticas públicas e numa estratégia nacional que amplie o acesso dos brasileiros à rede. Entretanto as divergências continuam a imperar, e a máquina burocrática do Estado não consegue se entender nem se articular com os demais setores da sociedade.

As iniciativas de inclusão digital que vem surgindo no país nos últimos anos ainda não foram capazes de incluir digitalmente uma parcela considerável da população, e apesar do potencial alardeado, apresentam resultados tímidos - e não mensuráveis - de contribuição para o desenvolvimento social, político e econômico tanto do indivíduo quanto da comunidade de baixa renda atendida por centros públicos de acesso. Isso coloca em questionamento os investimentos públicos que vem sendo aplicados na expansão destas iniciativas. Entretanto, as desigualdades sócio-econômicas brasileiras já mostraram que somente o acesso público e gratuito poderá incluir a significante parcela da população brasileira que vive com menos de um salário mínimo por mês. A menos que novas tendências tecnológicas como a televisão digital ou o telefone celular inteligente tenham o potencial de se difundir com mais facilidade - por já apresentarem uma alta penetração - neste universo de usuários.

Entretanto, a dificuldade de letramento continuará existindo, o que mostra que qualquer plano nacional de inclusão digital deve passar pelo investimento em educação - e não somente na difusão de uma infra-estrutura nacional de acesso em banda larga para o país, como vem sendo preconizado pelo governo. Não obstante, os centros públicos de acesso - principalmente os comunitários - continuam sendo um ponto de apoio importante para os jovens e sua comunidade, entretanto novas formas de inclusão 
precisam ser desenvolvidas para abarcar também a grande quantidade de adultos e iletrados que parecem não se sentir a vontade nestes ambientes de acesso. É preciso tomar cuidado para que a tecnologia não traga segregação, ao permitir que esse grupo se sinta excluído do processo.

O desenvolvimento de indicadores robustos, que sejam capazes de identificar a evolução das iniciativas de inclusão com o tempo e a sua contribuição para transformações locais é imprescindível para que os investimentos públicos em CPAs se justifiquem. As histórias de sucesso tendem a fazer com que se acredite nos resultados trazidos pelos CPAs, exemplos de superação e de transformação social - entretanto, estas não são a regra. E políticas públicas não podem ser defendidas com base nas exceções. Por isso, a despeito de seu potencial, até que métricas confiáveis sejam desenvolvidas, não é possível se afirmar que a existência de CPAs e do acesso à Internet promovam igualdade social e nem benefícios socioeconômicos para o conjunto dos indivíduos excluídos. O status quo parece se manter: grupos organizados na comunidade passaram a usar uma nova ferramenta de interação social e econômica. Quem se encontrava alheio ao processo, continua excluído.

Entretanto é importante ressaltar que o fato de comunidades e indivíduos estarem excluídos do processo não significa necessariamente que por isso suas condições de vida sejam piores ou que ele se sinta infeliz. A exclusão digital é somente mais uma vertente da exclusão social, e com esta segregação a população vive há muitos anos, e mesmo assim continua sendo reconhecida pela sua capacidade de desenvolver estratégias de sobrevivência física e psicológica. A tecnologia potencializa capacidades, mas não transforma pessoas. Não é a tecnologia que articula a comunidade, mas é a comunidade articulada quem se apropria da rede para facilitar seus processos. Talvez seja justamente ai que o investimento tenha que ser realizado: na articulação da comunidade, no fortalecimento das relações, na confiança (capital social) e na educação. Sem deixar entretanto de acompanhar a evolução tecnológica, que não para - é inerente ao seu processo de desenvolvimento a constante superação. Anderson também pode se superar. 


\section{REFERÊNCIAS BIBLIOGRAFICAS}

AFONSO, Carlos e SOARES, Luiz Fernando G. "Desenvolvimento humano e a apropriação das TICs". In: Pesquisa sobre o uso das tecnologias da informação e da comunicação 2005. São Paulo: CGI.br, 2006.

AFONSO, Carlos - GESAC, SCD, FUST, XPTO... e a inclusão digital? - Revista do Terceiro Setor. 13 de fevereiro de 2004.. Disponível em: < http://arruda.rits.org.br/notitia1/servlet/newstorm.notitia.apresentacao.ServletDeSec ao? codigoDaSecao $=11 \&$ dataDoJornal $=1076702448000>$ Acesso em 15 de janeiro de 2007

ALMEIDA, Maria Elizabeth Bianconcini de. "Letramento digital e hipertexto: contribuições à educação", in PELLANDA, Nize Maria Campos et allii. Inclusão digital: tecendo redes afetivas/cognitivas. Rio de Janeiro: DP\&A, p. 171-192, 2005.

BALBONI, Mariana Reis; SCHWARTZ, Gilson. "Citizenship and Digital Media Management”. In: Digital Cities III: Information Technologies for Social Capital: Cross-cultural Perspectives. Lecture Notes in Computer Science, Volume 3081, p. 407 a 416. Springer-Verlag, Amsterdam: Abril 2005.

BALBONI, Mariana Reis. Informática comunitária: casos concretos. Redemoinhos. São Paulo: ANO II - $\mathrm{N}^{\circ} 17-1^{\circ}$ a 15 de nov. 2002. Disponível em < http://www.cidade.usp.br/redemoinhos/1702/analise.php > Acesso em 15 de outubro de 2005

BID (Banco Interamericano de Desenvolvimento). Relatório Anual 2004. Disponível em $<$ http://enet.iadb.org/idbdocswebservices/idbdocsInternet/IADBPublicDoc.aspx?doc num $=516469>$. Acesso em 31 de janeiro de 2007.

BARROSO, João. Da exclusão escolar dos alunos à inclusão social da escola: que sentido para a territorialização das políticas educativas? Transcrição da palestra proferida no Fórum Nacional de Projectos (PEPT-2000) em 10 de setembro de 1996.

BECKER, Maria Lúcia. Inclusão digital e jornalismo: novos leitores, novas dificuldades e desafios na relação com a notícia e a forma de noticiar. [s.d.] Disponível em < http://reposcom.portcom.intercom.org.br/bitstream/1904/17331/1/R07871.pdf $>$ Acesso em 15 de janeiro de 2007.

BELL, Daniel. The coming of the post-industrial society. New York: Basic Books, 1973.

CADERNOS NAE. Brasil. NAE-SECOM. 2004. Disponível em < http://www.nae.gov.br/01brasil3t/01brasil3t.pdf >. Acesso em 31 de janeiro de 2007 .

CASTELLS, Manuel. A sociedade em rede. São Paulo: Paz e Terra 1999. 
CASTELLS, Manuel. A galáxia da Internet: Reflexões sobre a Internet, os negócios e a sociedade. Rio de Janeiro: Jorge Zahar, 2003.

CASTELLS, Manuel. O poder da Identidade. Rio de Janeiro: Paz e Terra, 2002.

CGI.br (Comitê Gestor da Internet no Brasil). Pesquisa sobre o uso das tecnologias da informação e da comunicação 2005. São Paulo: 2006.

COHN, Gabriel. A forma da sociedade da informação, in DOWBOR, Ladislau et al. (Orgs.) Desafios da Comunicação. Petrópolis: Vozes, 2001.

COMPAINE, Benjamin (org). The Digital Divide: Facing a crisis or creating a myth?. Cambridge (Mass): MIT Press, 2001.

CORRÊA, Elizabeth Nicolau Saad. Estratégias para mídia digital. Internet, informação e comunicação. São Paulo: SENAC, 2003.

DELGADILLO, Karin et al. Telecentros comunitários para o desenvolvimento humano: lições sobre telecentros comunitários na América Latina e Caribe. Rio de Janeiro: RITS, 2003. Disponível em < http://bboppi.rits.org.br/ > Acesso em 15 de outubro de 2005

DIAS, Lia Ribeiro (coord). Inclusão Digital: Com a palavra a sociedade. São Paulo: Plano de Negócios, 2003. (patrocínio Telefônica)

DOWBOR, Ladislau. A reprodução social: propostas para uma gestão descentralizada. 2 ed. Petrópolis: Vozes, 1999.

DOWBOR, Ladislau. Tecnologias do conhecimento: os desafios da educação. Petrópolis: Vozes, 2001.

DUARTE, Jorge; BARROS, Antonio (orgs). Métodos e Técnicas de Pesquisa em Comunicação. São Paulo: Editora Atlas, 2005.

DUARTE, Jorge. Entrevista em profundidade. In: DUARTE, Jorge; BARROS, Antonio (orgs). Métodos e Técnicas de Pesquisa em Comunicação. São Paulo: Atlas, p. 6283, 2005.

EISENBERG, José e CEPIK, Marco. Internet e as Instituições Políticas Semiperiféricas. In: EISENBERG, José e CEPIK, Marco (orgs.). Internet e Política, teoria e prática da democracia eletrônica. Belo Horizonte: UFMG, 2002, pp.293-314.

FONSECA JUNIOR, Wilson Corres. Análise de conteúdo. In: DUARTE, Jorge; BARROS, Antonio (orgs). Métodos e Técnicas de Pesquisa em Comunicação. São Paulo: Atlas, p. 280-304, 2005.

FREIRE, Paulo. Educação como Prática da Liberdade. Rio de Janeiro: Paz e Terra, $10^{\circ}$ edição, 1980. 
FREIRE, Paulo. Educação e Mudança. Rio de Janeiro: Paz e Terra, $18^{\circ}$ edição, 1991.

FREIRE, Paulo. Pedagogia do Oprimido. 36 ed. Rio de Janeiro: Paz e Terra, 2003.

GARNHAM, N. Universal Service. In: MELODY, W. H.(Ed.), Telecom Reform: Principles, Policies and Regulatory Practices (pp. 207-212). Lyngby: Den Private Ingeniorfond, Technical University of Denmark, 1997.

GENTILI, Pablo (org.). Globalização excludente: desigualdade, exclusão e democracia na nova ordem mundial. 3 ed. Petrópolis, RJ: Vozes, 2001.

HANSON, J., \& Narula, U. New Communication Technologies in Developing Countries. Hillsdale, NJ: Lawrence Erlbaum Associates (LEA), 1990.

HILLS, J. Universal Service : Connectivity and Consumer Rights. In: M. Christoffersen \& A. Henten (Eds.), Telecommunication : limits to deregulation? (pp. 131-148). Amsterdam: IOS Press, 1993.

HUDSON, Heather. Converging Technologies and Changing Realities: Toward Universal Access to Telecom in the Develping World. In: W. H. (Ed.), Telecom Reform: Principles, Policies and Regulatory Practices (pp. 395-404). Lyngby: Den Private Ingeniorfond, Technical University of Denmark, 1997a.

HUDSON, Heather. Global Connections. International Telecommunications Infrastructure and Policy. New York: Van Nostrand Reinhold, 1997b.

IANNI, Octavio. A sociedade global. 4 ed. Rio de Janeiro: Civilização brasileira, 1996.

IPEA (Instituto de Pesquisas Econômicas Aplicadas). Radar Social 2005. Disponível em < http://www.ipea.gov.br/ >

ITU (International Telecommunications Union). Outcome Documents. Genebra, 2006. Disponível em < http://www.itu.int/dms_pub/itu-s/opb/pol/S-POL-WSIS.OD-42006-PDF-E.pdf >. Acesso em 15 de janeiro de 2007.

ITU (International Telecommunications Union). World telecommunication development report 2006: measuring ICT for social and economic development. Genebra: 2006.

LEMOS, André. Ciber-flânerie. [s.d]. Disponível em < http://www.facom.ufba.br/ciberpesquisa/txt_and1.htm > Acesso em 15 de janeiro de 2007.

LÉVY, Pierre. As tecnologias da inteligência: o futuro do pensamento na era da informática. São Paulo: Editora 34, 1993.

LÉVY, Pierre. Cibercultura. 2.ed. São Paulo: Editora 34, 2000.

LÉVY, Pierre. A emergência do cyberspace e as mutações culturais. (2002) Transcrição da palestra proferida no SESC-SP em 29/08/2002. Disponível em < 
http://www.sescsp.org.br/sesc/images/upload/conferencias/35.rtf >. Acesso em 02 janeiro de 2007.

LOPES, Maria Immacolata Vassalo de. "Pesquisa de Comunicação: questões epistemológicas, teóricas e metodológicas". Revista Brasileira de Ciências da Comunicação, v.27, p. 13-39, jan./jun. 2004.

LOPES, Maria Immacolata Vassalo de. Pesquisa de Comunicação: formulação de um modelo metodológico. São Paulo: Edições Loyola, 1990.

LUDKE, Menga et al. Pesquisa em educação: abordagens qualitativas. São Paulo: EPU, 1986.

MARTIN-BARBERO, Jesus. Globalização comunicacional e transformação cultural. In: Por uma outra comunicação: Mídia, mundialização cultural e poder. Moraes, Denis de (org.). Rio de Janeiro: Editora Record, 2003.

MARTINI, Renato. Inclusão digital \& inclusão social. Revista Inclusão Social $\mathrm{N}^{\circ} 1$, Brasília, 2005. Disponível em < http://www.ibict.br/revistainclusaosocial/viewarticle.php?id=7\&layout=html > Acesso em 24 outubro de 2005.

MARTINS, José de Souza. Exclusão social e a nova desigualdade. São Paulo: Paulus, 1997.

MARTINS, José de Souza. Reflexão crítica sobre o tema da "exclusão social. In A Sociedade vista do abismo: novos estudos sobre exclusão, pobreza e classes sociais. Petrópolis: Vozes, 2002, pp. 25-47.

MATTELART, Armand. Les nouveaux scénarios de la communication mondiale: dangereux effets de la globalisation des réseaux. Le Monde Diplomatique 2 p. 24-25, agosto de 1995.

MATTELART, Armand. La mondialisation de la communication. Collection Que saisje? Paris: Presses Universitaires de France, 1996.

MELODY, W. H. The Information Society : The Transnational Economic Context and Its Implications. In: G. Sussman \& J. A. Lent (Eds.), Transnational Communications : Wiring the Third World (pp. 27-41). Newbury Park (CA), Sage, 1991.

MIRANDA, Sérgio. FUST, educação e o software livre, in SILVEIRA, Sérgio Amadeu da; CASSINO, João (orgs.). Software livre e inclusão digital. São Paulo: Conrad, p. 255-264, 2003.

MOREIRA, Sonia Virgínia. Análise documental como método e como técnica. In: DUARTE, Jorge; BARROS, Antonio (orgs). Métodos e Técnicas de Pesquisa em Comunicação. São Paulo: Atlas, p. 267-279, 2005. 
MORIN, Edgar et al. Educação e Complexidade: Os sete saberes e outros ensaios. São Paulo: Cortez, 2002a.

MORIN, Edgar. A Cabeça bem feita: repensar a reforma e reformar o pensamento. 6. ed. Rio de Janeiro: Bertrand Brasil, 2002b.

NORA, Simon., MINC, Alain. L'informatisation de la Société. Paris: La Documentation Française, 1978.

OECD (Organisation for Economic Co-operation and Development). Universal service obligations in a competitive telecommunications environment. (Information Computer Communications Policy 38). Paris : OECD, 1991.

PAOLI, Maria Célia. "Empresas e responsabilidade social: os enredamenos da cidadania no Brasil". In: SANTOS, Boaventura de Sousa (org.). Democratizar a democracia: os caminhos da democracia participativa. Rio de Janeiro: Civilização Brasileira, p. 373-418, 2002.

PETRAZZINI, Ben A. The political economy of telecommunications reform in developing countries: privatization and liberalization in comparative perspective. Westport: Praeger, 1995.

PISCIOTTA, A. A. 1997. Global Trends in Privation and Liberalization. In: MELODY, W. H (ed). Telecom Reform: Principles, Politics and Regulation. Lyngby: Technical University of Denmark, 1997.

PORCARO, Rosa Maria. Tecnologia da Comunicação $e$ Informação $e$ Desenvolvimento: Políticas e estratégias de inclusão digital no Brasil. Rio de Janeiro: Programa de Pesquisa de Desenvolvimento de Políticas, 2005.

REINHARD, Nicolau; MACADAR, Marie Anne. Telecentros Comunitários possibilitando a Inclusão Digital: um estudo de caso comparativo de iniciativas brasileiras. Salvador: Publicado nos anais do $26^{\circ}$ ENANPAD, set/2002.

REINHARD, Nicolau; MACADAR, Marie Anne. "Governance and Management in the São Paulo Public Telecenter Network". In: Information and Technology for Development”. Volume 12. N³. Omaha, NE: Wiley, p. 441-245, 2006.

RESNICK, Mitchel. Closing the Fluency Gap. Março de 2001. Disponível em < http://web.media.mit.edu/ mres/papers/cacm-3-01.htm > Acesso em 15 outubro de 2005.

SACRISTAN, J. G. Educar y convivir en la cultura global. Madrid: 2001.

SANTAELLA, Lucia. Comunicação e Pesquisa: projetos para mestrado e doutorado. $1^{\circ}$ ed. São Paulo: Hacker Editores, 2001.

SANTOS, Boaventura de Sousa (org.). Democratizar a democracia: os caminhos da democracia participativa. Rio de Janeiro: Civilização Brasileira, 2002. 
SANTOS, Rogério Santanna dos. A inclusão digital requer novo pacto social entre governos e sociedade. Revista Inclusão Social, v.1, n.1, 2005. Disponível em < http://www.ibict.br/revistainclusaosocial/viewarticle.php?id=1\&layout=html $>$. Acesso em 24 de outubro de 2005.

SANTUCHI, Cyntia et al. Letramento: Você Pratica? [s.d.] Disponível em http://www.eduquenet.net/letramento.htm/. Acesso em 30 de janeiro de 2007.

SCHWARTZ, Gilson. "Vida e política na Cidade do Conhecimento". In: TORQUATO, Cid (Org.) E-dicas: Desvirtualizando a nova economia. São Paulo: Usina do Livro, p. 203-212, 2002.

SCHWARTZ, Gilson. "Políticas públicas e Inclusão Digital". Redemoinhos. São Paulo: ANO III - $\mathrm{N}^{\circ} 10-16$ a 30 de junho. 2003. Disponível em < http://www.cidade.usp.br/impressaodigital/0503/infra.php > Acesso em 15 outubro de 2005.

SCHWARTZ, Gilson. "Emancipação digital e redes de conhecimento". Redemoinhos. São Paulo: ANO IV - $\mathrm{N}^{\circ} 9-16$ a 30 de junho. 2003. Disponível em < http://cidade.usp.br/redemoinhos/?2005-09/analise> Acesso em 5 de janeiro de 2007.

SELLTIZ, Claire et al. Métodos de Pesquisa nas Relações Sociais. $5^{\circ}$ ed. São Paulo: EPU, 1975.

SELLTIZ, Claire et al. Métodos de Pesquisa nas Relações Sociais. Volume 1 Delineamentos de Pesquisa. $2^{\circ}$ edição. São Paulo: EPU, 1987.

SILVEIRA, Sérgio Amadeu da. Exclusão Digital: a miséria na era da informação. São Paulo: Fundação Perseu Abramo, 2001.

SLTI (Secretaria de Logística e Tecnologia da Informação). Inclusão Digital - Governo Federal: Balanço e Perspectivas. (Documento de circulação interna). Brasília 2006.

SORJ, Bernardo.Brasil@povo.com. Rio de Janeiro: Zahar, 2003.

SORJ, Bernardo; GUEDES, Luís Eduardo. Exclusão digital: problemas conceituais, evidencias empíricas e politicas públicas, 2005. Disponível em: < http://www.bernardosorj.com/pdf/exclusaodigital_problemasconceituais.PDF > Acesso em 15 de outubro de 2005.

STAROBINAS, Lílian. "Paulo Freire e a Emancipação Digital". Redemoinhos. São Paulo: ANO IV - Nº 9 - Edição Especial - Novembro/dezembro de 2005. Disponível em < http://cidade.usp.br/redemoinhos/?2005-09/analise2 > Acesso em 15 de janeiro de 2007.

TAKAHASHI, Tadao (Org.). Sociedade a Informação no Brasil: livro verde. Brasília, Ministério da Ciência e Tecnologia, 2000. Disponível em < http://www.socinfo.org.br >. Acesso em 15 de janeiro de 2005.

TELETIME. Atlas Brasileiro de Telecomunicações. São Paulo: Glasberg, 2006. 
TEHRANIAN, M. Technologies of Power: Information Machines and Democratic Prospects. Norwood (NJ), Ablex Pub, 1990.

TRAVANCAS, Isabel. Fazendo etnografia no mundo da comunicação. In: DUARTE, Jorge; BARROS, Antonio (orgs). Métodos e Técnicas de Pesquisa em Comunicação. São Paulo: Atlas, p. 98-109, 2005.

UNCTAD (United Nations Conference on Trade and Development). Information Economy Report 2006. Disponível em < http://www.unctad.org/Templates/webflyer.asp?docid=7576\&intItemID=3991\&lang $=1 \&$ mode $=$ downloads $>$. Acesso em 15 de janeiro de 2007 .

WARSCHAUER, Mark. Tecnologia e inclusão social. São Paulo: Editora Senac São Paulo, 2006.

WARSCHAUER, Mark. Reconceptualizing thee Digital Divide. First Monday, Vol. 7, $\mathrm{N}^{\circ}$ 7, July 2002. Disponível em < http://www.firstmonday.dk/issues/issue7_7/warschauer/ > Acesso em 15 outubro de 2005.

WOODS, B. Communication, Tecnology and the Development of People. London: Routledge, 1993.

YAMAKODA, Eloi Juniti. O uso da Internet. - pp. In: DUARTE, Jorge; BARROS, Antonio (orgs). Métodos e Técnicas de Pesquisa em Comunicação. São Paulo: Atlas, p. 146-163, 2005. 


\section{TESES E DISSERTAÇÕES}

ASSUMPÇÃO, Rodrigo Ortiz. Além da Inclusão Digital: O Projeto sampa.org. São Paulo, 2001. Dissertação (Mestrado em Ciências da Comunicação) - Escola de Comunicações e Artes, Universidade de São Paulo. Disponível em < http://www.sampa.org >. Acesso em 15 de outubro de 2005.

BALBONI, Mariana Reis. Les politiques de télécommunications brésiliennes vers l'accès universel. Montreal: Universidade de Montreal, maio 1999. Dissertação (Mestrado em Ciências da Comunicação), Faculdade de Artes e de Ciências, Universidade de Montreal, 1999.

BECKER, Maria Lúcia. A periferia na cibercultura: técnica, política e exercício da cidadania nos bairros de Curitiba e São Paulo. São Paulo, 2005. Tese (Doutorado em Ciências da Comunicação) - Universidade de São Paulo.

BOSSIO, Juan. Social sustainability of telecentres from the viewpoint of telecentre operators: a case study from São Paulo, Brazil. Londres, London School of Economics, 2004. Dissertação de mestrado.

BRITO, Paulo. Um tiro no escuro: as estratégias e incertezas da inclusão digital no Brasil. São Paulo, 2005. Dissertação (Mestrado em Comunicação e Semiótica) Pontifica Universidade Católica de São Paulo.

CORRÊA, Elizabeth Nicolau Saad. As estratégias da desconstrução : sobre o uso de estratégias diferenciadas por empresas informativas na Internet. São Paulo, 2001. Tese de Livre-docência em Ciências da Comunicação, Escola de Comunicações e Artes, Universidade de São Paulo.

DIMANTAS, Hernani. Linkania: a sociedade da colaboração. São Paulo, 2006. Dissertação (Mestrado) - Pontifica Universidade Católica de São Paulo.

GUZZI, Adriana de Araújo. Participação Pública, Comunicação e Inclusão Digital. São Paulo, 2006. Dissertação (Mestrado em Comunicação Semiótica). Pontifícia Universidade Católica de São Paulo.

IIZUKA, Edson Sadao. Um Estudo Exploratório sobre a Exclusão Digital e as Organizações sem Fins Lucrativos da cidade de São Paulo. São Paulo, 2003. Dissertação (Mestrado em Administração Pública e Governo) - Fundação Getúlio Vargas.

LIMA, Ana Maria Moraes de Albuquerque. Inclusão Digital e Protagonismo Juvenil: um estudo em dois centros de tecnologia comunitária. São Paulo, 2005. Dissertação (Mestrado em Educação) - Pontifica Universidade Católica de São Paulo.

MACADAR, Marie Anne. Inclusão digital no Brasil: o processo de gestão de telecentros. São Paulo, 2004. Tese (doutorado). Faculdade de Economia, Administração e Contabilidade - FEA/USP. 


\section{LEITURAS COMPLEMENTARES}

BADILLA-SAXE, Eleonora. Las nuevas metáforas de la tecnologia. 2002. Disponível em < http://www.cientec.or.cr/ciencias/innovacion/metaforas.html > Acesso em 15 de outubro de 2005.

FILHO, André Barbosa; CASTRO, Cosette; TOME, Takashi. Mídias digitais: convergência tecnológica e inclusão social. São Paulo: Paulinas, 2005.

GUERREIRO, Evandro Prestes. Cidade digital: infoinclusão social e tecnologia em rede. São Paulo: Senac São Paulo, 2006.

GÓMEZ, Ricardo; BELTRÁN, Mauricio; BEAULIEU, Yves. Facing the screen: ICT in Latin America and the Caribbean. Malasya: GKP, 2003.

PELLANDA, Nize Maria Campos; SCHLÜNZEN, Eliza Tomoe Moriya; JÚNIOR, Klaus Schlünzen (orgs.). Inclusão digital: tecendo redes afetivas/cognitivas. Rio de Janeiro: DP\&A, 2005.

RESNICK, Mitchel. Rethinking Learning in the Digital Age. In: Global Information Technology Report 2001-2002: Readiness for the Networked World (GITR). 2002. Disponível em < http://www.cid.harvard.edu/cr/pdf/gitrr2002_ch03.pdf > Acesso em 15 outubro de 2005 .

\section{NOTÍCIAS EM PERÍODICOS DE REFERÊNCIA}

FOLHA ONLINE. "Desgastado, Gushiken deixa governo; cargo será ocupado por Oliva Neto". Folha de São Paulo, 13 de novembro de 2006. Disponível em < http://www1.folha.uol.com.br/folha/brasil/ult96u86646.shtml >. Acesso em 31 de janeiro de 2007.

KOBASHI, Ricardo. "Tecnologia a serviço da inclusão social”. O Estado de São Paulo, 02 de maio de 2005. Disponível em < http://www.link.estadao.com.br/index.cfm?id_conteudo=3568 >. Acesso em 31 de janeiro de 2007.

SIQUEIRA, Ethevaldo. "Com o iPhone, a Apple reinventa o telefone". O Estado de São Paulo, de 28 de janeiro de 2007.

STANTON, Michael. "De volta ao Fust". Agência Estado, 20 de janeiro de 2002. Disponível em < http://www.rnp.br/noticias/imprensa/2002/not-imp-020120.html. Acesso em 31 de janeiro de 2007. 


\section{PERIÓDICOS DE REFERÊNCIAS NA INTERNET}

Agência Estado

http://www.agestado.com.br

Boletim Prometeus

http://www.indecs.org.br/index.php?option=com_content\&task=section\&id=5\& Itemid $=27$

Jornal O Estado de São Paulo (OESP)

http://www.estado.com.br

Jornal Folha de São Paulo (FSP)

http://www.uol.com.br/fsp

Jornal Gazeta Mercantil

http://www.gazentamercantil.com.br

Jornal Le monde diplomatique

http://www.monde-diplomatique.fr

Jornal New York Times

http://www.nytimes.com

Revista sobre Tecnologia para Inclusão Digital "A Rede"

http://www.arede.inf.br/

Revista I - Coletiva

http://www.icoletiva.com.br/icoletiva/

Revista Inclusão Social

http://www.ibict.br/revistainclusaosocial/

Revista Istoé

http://www.zaz.com.br/istoe

Revista Telecom On-line

http://www.anatele.com.br

Revista da Sociedade Digital

http://www.bibvirt.futuro.usp.br/textos/hemeroteca/rsd/principal.html

Revista Veja

http://www.uol.com.br/veja 


\section{SITES DE REFERÊNCIA}

Agência Nacional de Telecomunicações (Anatel) :

http://www.anatel.gov.br

Banco Mundial - Projeto InfoDev :

http://www.worldbank.org/html/fdp/infodev/infodev.html

Biblioteca Micromundos

http://geocities.yahoo.com.br/bibliotecamicromundos/inclusao.htm

Casa Civil da Presidência da República :

http://www.presidencia.gov.br/casacivil/

Fórum de discussão "Inclusão Digital.org.br"

http://www.ciberforum.org.br/webboard/wbpx.isa/ inclusaodigital/

Fórum Nacional pela Democratização da Comunicação

http://www.fndc.org.br/

Laboratório de Inclusão Digital e Educação Comunitária (LIDEC)

http://www.lidec.futuro.usp.br/lidec.php

Ministério da Ciência e Tecnologia:

http://www.mct.gov.br

Ministério das Comunicações (Minicom) :

http://www.mc.gov.br

Ministério do Planejamento :

http://www.planejamento.gov.br/

Observatório de políticas públicas de infoinclusão (OPPI):

http://www.infoinclusao.org.br/

Observatório para a Sociedade da Informação na América Latina e Caribe

http://www.cepal.org/socinfo/osilac/

Portal Inclusão Digital

http://www.inclusaodigital.gov.br/

Portal de Inclusão Digital do Ministério das Comunicações:

http://www.idbrasil.gov.br/

Portal da inclusão social do IBICT - Instituto Brasileiro de Informação em Ciência e

Tecnologia do MCT

http://www.ibict.br/inclusaosocial/

Projeto Sampa.org: 
http://www.sampa.org/

Projeto Somos Telecentros:

http://www.tele-centros.org/

The Digital Divide Network

http://www.digitaldivide.net/

União Internacional Telecomunicações (UIT) :

http://www.itu.org 


\section{SITES DE PROJETOS DE INCLUSÃO DIGITAL}

Acessa São Paulo: http://www.acessasaopaulo.sp.gov.br

Casa Brasil

http://www.iti.br/twiki/bin/view/Main/CasaBrasil/

CDI - Rede Povos da Floresta

http://www.cdi.org.br/inst/port/floresta.htm

Cidade do Conhecimento

http://www.cidade.usp.br

Consulado da Mulher

http://www.consuladodamulher.com.br

Digitando o Futuro

http://www.digitandoofuturo.org.br

Estação Futuro

http://www.estacaofuturo.org.br / www.vivario.org.br

Garagem Digital

http://www.fundabrinq.org.br

Identidade Digital

http://www.identidadedigital.ba.gov.br

Ilhas Digitais

http://www.soma.ce.gov.br/programas/ilhas/inicial.asp

Índios On Line

http://www.indiosonline.org.br

Morro Digital

http://www.morrodigital.org.br/

Pipa Sabe

http://www.cidade.usp.br/

Programando o Futuro

http://www.programandoofuturo.org.br/

Projeto Navegar

http://www.navegaramazonia.org.br

Rede CDI

http://www.cdi.org.br

Rede Floresta - Topawa-Kaa 
http://www.iti.br/twiki/bin/view/REDEFLORESTA/ConteudoInstitucional Saúde e Alegria

http://www.saudeealegria.org.br

Telecentros Porto Alegre

http://www.telecentros.org.br

Telecentros SP

http://www.telecentros.sp.gov.br 
ANEXOS 
Anexo I - Projetos Identificados

\begin{tabular}{|c|c|c|c|c|c|c|}
\hline$N^{o}$ & Nome do Projeto & Região & Cidade/Estado & Instituição Mantenedora & $\begin{array}{l}\text { Natureza } \\
\text { iniciativa }\end{array}$ & Site \\
\hline 1 & Programando o Futuro & Centro-Oeste & $\begin{array}{l}\text { Cidades satélites do DF, } \\
\text { interior de GO e de MG }\end{array}$ & $\begin{array}{l}\text { Ong Programando o } \\
\text { Futuro }\end{array}$ & Terceiro Setor & www.programandoofuturo.org.br \\
\hline 2 & ComUnidade Brasil & Centro-Oeste & Cuiabá e região & Comunidade Solidária & Pública & $\begin{array}{l}\text { http://www.planejamento.gov.br/tecnologia_inform } \\
\text { acao/conteudo/noticias/comunidade_brasil.htm }\end{array}$ \\
\hline 3 & Pipa Sabe & Nordeste & Pipa (RN) & Cidade do Conhecimento & Terceiro Setor & www.cidade.usp.br \\
\hline 4 & $\begin{array}{l}\text { Rede Floresta - Topawa- } \\
\text { Kaa }\end{array}$ & $\begin{array}{l}\text { Norte e Centro- } \\
\text { oeste }\end{array}$ & $\begin{array}{l}\text { Boa Vista, Manaus, Porto } \\
\text { Velho, etc }\end{array}$ & Eletronorte & Pública & $\begin{array}{l}\text { http://www.iti.br/twiki/bin/view/REDEFLORESTA } \\
\text { /ConteudoInstitucional }\end{array}$ \\
\hline 5 & Morro Digital & Nordeste & Recife - PE & CENAP & Terceiro Setor & http://www.morrodigital.org.br/ \\
\hline 6 & Ilhas Digitais & Nordeste & Fortaleza e municípios & Governo do Ceará & Pública & www.soma.ce.gov.br/programas/ilhas/inicial.asp \\
\hline 7 & Casa Brasil & Nordeste & Valente (BA) & Governo Federal & Pública & $\begin{array}{l}\text { http://www.iti.br/twiki/bin/view/Main/CasaBrasil } \\
\text { / }\end{array}$ \\
\hline 8 & Saúde e Alegria & Norte & Santarém (PA) & Saúde e Alegria (PSA) & Terceiro Setor & www.saudeealegria.org.br \\
\hline 9 & $\begin{array}{l}\text { CDI - Rede Povos da } \\
\text { Floresta }\end{array}$ & Norte & Acre - Ashaninka & CDI e entidades parceiras & Terceiro Setor & $\begin{array}{l}\text { www.cdi.org.br } \\
\text { http://www.cdi.org.br/inst/port/floresta.htm }\end{array}$ \\
\hline 10 & Estação Futuro & Sudeste & Rio de Janeiro & Viva Rio & $\begin{array}{l}\text { Terceiro Setor e } \\
\text { empresas }\end{array}$ & www.estacaofuturo.org.br / www.vivario.org.br \\
\hline 11 & Telecentros SP & Sudeste & São Paulo & Município de SP & Pública & www.telecentros.sp.gov.br \\
\hline 12 & Acessa São Paulo & Sudeste & Cidade no Interior de SP & Gov. Estado de SP & Pública & www.acessasaopaulo.sp.gov.br \\
\hline 13 & Garagem Digital & $\begin{array}{ll}\text { Sudeste } & \mathrm{e} \\
\text { nordeste }\end{array}$ & SP e municípios do Ceará & HP e Fund Abrinq & Empresas & www.fundabrinq.org.br \\
\hline 14 & Telecentros Porto Alegre & Sul & Porto Alegre & Município de POA & Pública & www.telecentros.rs.gov.br \\
\hline 15 & Digitando o Futuro & Sul & Curitiba & Prefeitura de Curitiba & Pública & www.digitandoofuturo.org.br \\
\hline 16 & Consulado da Mulher & $\begin{array}{l}\text { S, Sudeste e } \\
\text { Norte }\end{array}$ & $\begin{array}{l}\text { Joinville, Manaus, São Paulo } \\
\text { e Rio Claro }\end{array}$ & Multibrás/Consul & Empresas & www.consuladodamulher.com.br \\
\hline
\end{tabular}




\section{Anexo II - Localização dos projetos identificados}

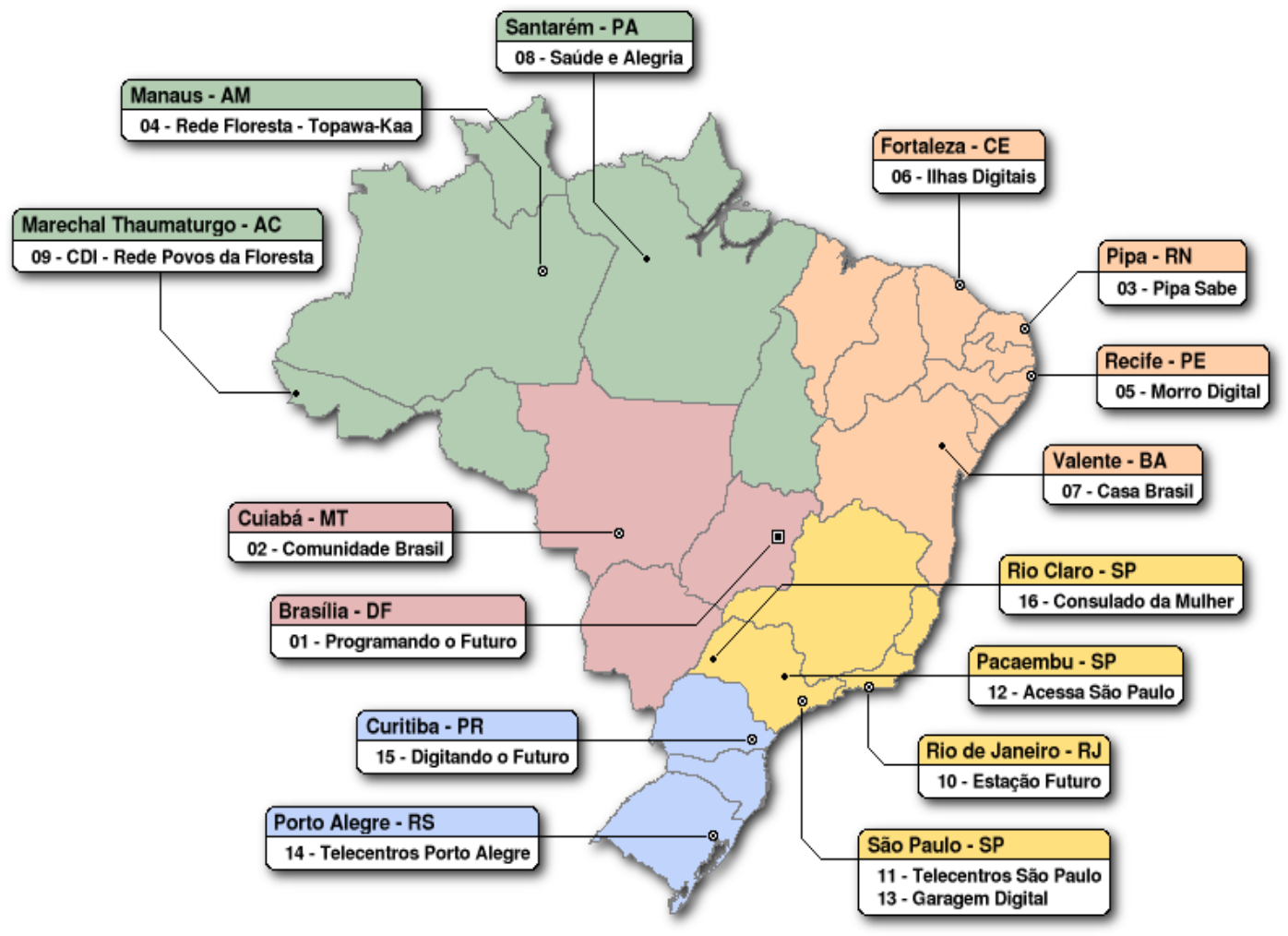




\section{Anexo III - Roteiro de entrevista com mentores}

1. Como você define inclusão digital?

2. Como você se envolveu com projetos de inclusão digital?

3. Quais são os principais objetivos dos programas públicos de inclusão digital?

4. Pela sua experiência, quais são as principais atividades das comunidades de baixa renda na Internet? E dos usuários de programas de inclusão digital na Internet? Existe diferença?

5. Na sua opinião, houve alguma mudança nos hábitos de consumo de informação desses indivíduos antes e depois da Internet? E nos hábitos de produção de informação? Caso a resposta seja afirmativa, como você descreve essas mudanças?

6. Qual o impacto dos programas públicos de acesso à Internet no desenvolvimento dos indivíduos que vivem em comunidades de baixa renda? Proporciona uma vida melhor? Aumenta as oportunidades de emprego e geração de renda? De cultura e de lazer?

7. Você acha que esses programas contribuem para o desenvolvimento da cidadania, para a participação política e a conscientização social desses indivíduos? Como?

8. Para você, qual o maior benefício que o projeto trouxe para o usuário? E para a comunidade?

9. Na sua opinião, as experiências de inclusão digital em desenvolvimento no país, mantidas pelo governo, são eficientes para aumentar o acesso das comunidades de baixa renda à informação?

10. Para você, a inclusão digital deve ser tratada como uma política pública? Qual é a sua opinião sobre iniciativas do terceiro setor e de empresas privadas?

11. Quais são os desafios para a inclusão digital no país hoje (questões políticas, econômicas, alfabetização)?

12. Em março de 2005 um editorial da revista The Economist afirmou que o grande vetor para a inclusão digital no mundo não é o computador nem a Internet, mas o telefone celular. Qual é a sua opinião?

13. Qual será o impacto da televisão digital nas comunidades brasileiras de baixa renda? Ela deverá favorecer ou desfavorecer a inclusão digital? Como? Você acha que a televisão digital manterá o padrão de relação entre os produtores e os consumidores de informação (concentração de poder das grandes empresas de mídia)?

Somente para o governo:

14. O projeto PC Conectado - Computador Para Todos está contribuindo para a inclusão digital? Quais são os primeiros resultados?

15. Como funciona o projeto "Casa Brasil"? Qual é a sua opinião sobre o programa?

16. Como o governo (federal, estadual e municipal) pretende viabilizar a inclusão digital no país? Quais são as prioridades dele? 
1. Como você define inclusão digital?

2. Como você se envolveu com projetos de inclusão digital?

3. Qual foi a principal motivação para a criação do projeto? Quando foi criado?

4. Quais são os principais objetivos do projeto? Quais são os impactos que ele pretende causar na comunidade? Ele está alcançando esses objetivos?

5. A coordenação se ocupa da capacitação do usuário e do desenvolvimento de atividades no local?

6. No caso de resposta afirmativa, quais são as atividades pedagógicas (ou não) desenvolvidas no projeto? Quem é o responsável pelo desenvolvimento destas atividades?

7. Na sua experiência, quais são as atividades na Internet mais realizadas nos centros públicos pelos usuários? Elas correspondem aos objetivos do projeto?

8. De que maneira você imagina que o projeto contribui para o consumo de informação pela comunidade local?

9. De que maneira você imagina que o projeto contribui para a produção de informação pela comunidade local?

10. A coordenação já identificou impactos do projeto nos usuários e na comunidade local? Quais? Houve aumento de conscientização social? Aumento de participação política? No desenvolvimento intelectual? Na geração de renda?

11. Para você, qual é o maior benefício que o projeto trouxe para o usuário? E para a comunidade?

12. Quais são os desafios do projeto para o futuro? Existem planos para impulsionar a produção e o consumo de informação pelos usuários? 
1. O que significa inclusão digital para você?

2. Quais são os objetivos do projeto?

3. Quais são as suas responsabilidades no projeto?

4. Quais são as atividades (e/ou ferramentas) mais procuradas pelos usuários no projeto?

5. Você acredita que o projeto contribui para o consumo de informação pela comunidade local? Como?

6. Você acredita que o projeto contribui para a produção de informação pela comunidade local? Como?

7. Qual é a relação do projeto com as comunidades onde ele se encontra?

8. Quais são as atividades relacionadas à produção e ao consumo de informação mais desenvolvidas no projeto? (escrever e-mail, participar de salas de bate-papo, participar de sites de relacionamento, usar programas de mensagem instantânea, escrever blogs, criar websites, ler jornais e revistas, escutar rádio, fazer cursos à distância, visitar sites de governo eletrônico, outros).

9. Com base na sua experiência diária, você já identificou impactos do projeto na comunidade local (aumento de conscientização social, aumento de participação política, desenvolvimento intelectual, geração de renda). Quais?

10. Para você, qual é o maior benefício que o projeto trouxe para o usuário? E para a comunidade?

11. Na sua opinião, o projeto atende bem às necessidades do cidadão? Em caso negativo, o que poderia ser feito para atendê-lo melhor? 


\section{Anexo VI - Questionário Usuários}

O formulário eletrônico elaborado para a aplicação do questionário estruturado dirigido aos usuários é mais extenso que o roteiro aberto dos grupos A, B e C. Entretanto, é importante salientar que ele é dinâmico e divido em módulo, e que, conforme a resposta dos usuários, o número total de questões a ser respondido é bem menor do que o total apresentado aqui.

\section{Parte 0. Apresentação}

Meu nome é Mariana Balboni, sou aluna de pós-graduação do programa de Ciência da Comunicação da Universidade de São Paulo e estou realizando uma pesquisa sobre o uso da Internet nos centros públicos de acesso em todo o país.

Gostaria de convidá-lo(a) a participar desta pesquisa, respondendo ao questionário, ao clicar no botão abaixo:

Se você tiver qualquer dúvida, fique à vontade para pedir auxílio ao (à) monitor(a) ou responsável pela sala.

O preenchimento do questionário pode levar cerca de 15 minutos, mas não desanime, sua colaboração é muito importante!

Muito obrigada!

Parte 1 - Identificação

Seu nome é (não é obrigatório)

Quantos anos você tem?

Qual o seu sexo? ( ) Feminino ( ) Masculino

Qual a sua escolaridade?

( ) Ensino Fundamental ___ série

( ) Ensino Médio ___ série

( ) Ensino Superior incompleto

( ) Ensino Superior completo

( ) Participo de projeto de educação popular/comunitária

( ) Nenhuma das respostas anteriores

Qual a sua principal ocupação? Marque quantas opções você quiser.

( ) Sou estudante

( ) Sou (exemplo: bancário/a, caixa, professor/a, etc)

( ) Sou dona de casa

( ) Estou desempregado/a

Você é membro de partidos políticos, participa de associações de bairro, conselhos ou outras atividades comunitárias?

( ) $\operatorname{Sim}$ ( ) Não ( )

Se a resposta for sim, qual? 
7. O que a Internet significa para você?

\section{Parte 2 - Uso Geral}

8. Há quanto tempo você freqüenta este centro público de acesso à Internet?

( ) Menos de um mês

( ) De 1 até 3 meses

( ) De 3 até 6 meses

( ) De 6 até 12 meses

( ) Mais de um ano

9. Quantas vezes você vai ao centro público de acesso?

( ) Todos os dias

( ) De 3 a 5 vezes por semana

( ) Uma vez por semana

( ) Menos de uma vez por semana

( ) Uma vez por mês ou menos

10. Quais as atividades que você realiza nesse centro público de acesso usando o computador, sem acesso à Internet? Marque quantas opções você quiser.

( ) Participo de cursos e oficinas

( ) Uso o computador para escrever textos

( ) Uso o computador para fazer trabalhos escolares

( ) Uso o computador para criar banco de dados ou planilhas eletrônicas

( ) Escuto música

( ) Outros. Quais?

11. Você usa a Internet?

( ) Sim ( ) Não ( ) (Se a resposta for não, pular para questão 33)

a) Se a resposta for sim, há quanto tempo?

Menos de um mês

() De 1 até 3 meses

( ) De 3 até 6 meses

( ) De 6 até 12 meses

( ) Mais de um ano

12) O que você faz na Internet? Marque quantas opções você quiser.

( ) Pesquiso na Internet

( ) Leio jornais e revistas

( ) Faço cursos à distância

( ) Jogo

( ) Conheço outras pessoas

( ) Acesso sites do governo (Imposto de renda, saldo do INSS , etc)

( ) Faço compras/ pesquiso preços

( ) Pago Contas

( ) Acesso os serviços bancários

( ) Procuro emprego

( ) Outros. Quais?

\section{Parte 3 - Comunicação}

13. Você tem e-mail?

( ) $\operatorname{Sim}$ ( ) Não 


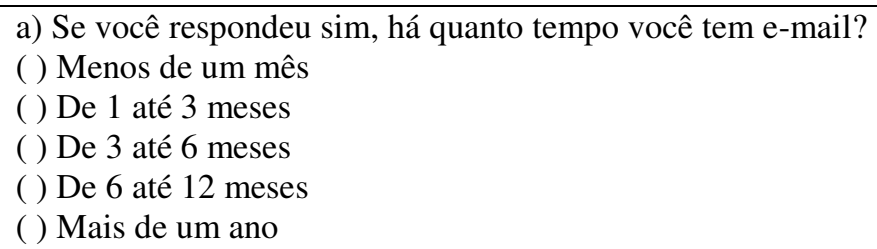

b) Em média quantos e-mails você escreve por semana?

( ) 0

( ) de 1 a 10

() de 11 a 20

( ) de 21 a 30

( ) de 31 a 50

( ) mais de 50

c) E quantos e-mails você recebe em média por semana, sem contar mensagens indesejáveis ou spams ? ( ) 0

( ) de 1 a 10

( ) de 11 a 20

( ) de 21 a 30

( ) de 31 a 50

( ) mais de 50

d) Se você não tem e-mail, escolha uma das alternativas:

( ) Não tenho, mas quero ter

( ) Não sei o que é e-mail

( ) Não tenho interesse em ter e-mail

14. Você desenvolve ou publica algo na Internet (Sites, blog, orkut, etc)?

( ) $\operatorname{Sim}$ ( ) Não

a) Se a resposta for sim, o que você já publica? Marque quantas opções você quiser.

( ) Sites comerciais

( ) Página pessoal, orkut, blog ou fotolog

( ) Sites de interesse comunitário

( ) Site cultural

( ) Outros. Quais?

b) E há quanto tempo você publica algo na Internet?

( ) Menos de um mês

( ) De 1 até 3 meses

( ) De 3 até 6 meses

( ) De 6 até 12 meses

( ) Mais de um ano

c) Se você nunca publicou na Internet, aponte os motivos:

( ) Não tenho nada a dizer

( ) Não me interesso

( ) Não sei como fazer

( ) Não tenho tempo

( ) Outros. Quais?

15. Você ou sua comunidade tem histórias e/ou notícias para contar?

( ) $\operatorname{Sim}$ ( ) Não

Se sim, você gostaria de escrever e publicar essas histórias e notícias na Internet?

( ) Sim ( ) Não 
16. Há algum meio de comunicação sendo produzido em sua comunidade (rádio, TV, jornal, site, outros)?

( ) $\mathrm{Sim}$

( ) Não

( ) Não sei

a) Se a resposta for sim, qual?

b) E há quanto tempo ele é produzido?

( ) Menos de um mês

( ) De 1 até 3 meses

( ) De 3 até 6 meses

( ) De 6 até 12 meses

( ) Mais de um ano

( ) Não sei

17. Você é parte da equipe que produz esse meio de comunicação?

( ) $\operatorname{Sim}$ ( ) Não

a) Se participa, o que você faz?

b) Há quanto tempo você participa dessa equipe?

( ) Menos de um mês

( ) De 1 até 3 meses

( ) De 3 até 6 meses

( ) De 6 até 12 meses

() Mais de um ano

c) Se não participa, gostaria de participar?

( ) $\mathrm{Sim}$

( ) Não

18. Que assuntos ou fatos da sua comunidade são divulgados nestes meios de comunicação? Diga quais

19. Quais assuntos não são divulgados, mas você gostaria que fossem? Diga quais

20. Você participa de espaços virtuais de discussão na Internet (salas de bate papo, fórum, mensagens instantâneas) ?

( ) Sim ( ) Não ( )

a) Se a resposta for sim, quais espaços virtuais participa? Marque quantas opções você quiser.

( ) Fóruns ou listas de discussão

( ) ICQ, MSN Messenger ou outros programas de mensagens instantânea

( ) Salas de bate papo on-line

( ) Outros. Quais?

b) E a quanto tempo você participa desses espaços virtuais de discussão?

( ) Menos de um mês

( ) De 1 até 3 meses

( ) De 3 até 6 meses

( ) De 6 até 12 meses

( ) Mais de um ano

c) Se você não participa de espaços virtuais de discussão na Internet, quais os motivos? Marque quantas opções você quiser.

( ) Não tenho nada a dizer

( ) Não me interesso 

( ) Não sei como fazer
( ) Não tenho tempo
( ) Outros. Quais?

\section{Parte 4 - Impacto da Internet na vida pessoal dos usuários}

21. Você costuma ler jornais ou revistas?

( ) Sim, todo dia

( ) Sim, em média uma vez por semana

( ) Sim, de 1 a 3 vezes por semana

( ) Sim, de 4 a 6 vezes por semana

( ) Sim, em média uma vez por mês

( ) Não

22. Antes de freqüentar o centro público de acesso, você lia jornais ou revistas?

( ) Sim, todo dia

( ) Sim, em média uma vez por semana

() Sim, de 1 a 3 vezes por semana

( ) Sim, de 4 a 6 vezes por semana

( ) Sim, em média uma vez por mês

( ) Não

23. Antes de freqüentar o centro público de acesso, você ouvia mais ou menos o rádio?

( ) Muito mais

( ) Mais

( ) Igual

( ) Menos

24. Antes de freqüentar o centro público de acesso, você assistia mais ou menos televisão?

( ) Muito mais

( ) Mais

( ) Igual

( ) Menos

25. Você se sente mais ou menos informado usando a Internet?

( ) Muito mais

( ) Mais

( ) Igual

( ) Menos

( ) Muito menos

26. Você considera que o acesso à Internet mudou a sua vida? ( ) $\operatorname{Sim}$ ( ) Não ( )

Se a resposta for sim, dê uma nota de 1 a 5 ao lado de cada afirmação abaixo, sendo 5 para concordo plenamente e 1 para discordo completamente.

a) A Internet melhorou meu desempenho profissional e/ou consegui novas oportunidades de trabalho

b) Tenho mais facilidade em aprender depois da Internet e/ou voltei a estudar

c) Exerço melhor minha cidadania e/ou participo mais da vida desta e de outras comunidades usando os recursos da Internet

d) Me divirto muito através da Internet

e) Conheci novos amigos através da Internet, passei a me comunicar mais com amigos e familiares

f) Se houver outra observação sobre como a Internet mudou sua vida, diga qual

27. O acesso à Internet te incentivou a comprar um computador?

( ) $\mathrm{Sim}$

( ) Não

( ) Não, mas pretendo comprar 


\section{Parte 5 - Impacto da Internet na vida da Comunidade}

28. Você acha que a Internet mudou a vida de sua comunidade?

( ) $\operatorname{Sim}($ ) Não

Se a resposta for sim, dê uma nota de 1 a 5 ao lado de cada afirmação abaixo, sendo 5 para concordo plenamente e 1 para discordo completamente.

a) As condições econômicas da comunidade melhoraram (mais oportunidades de emprego, qualificação, melhores salários, etc)

b) A comunidade está mais articulada, as pessoas passaram a se conhecer melhor e a resolver problemas do bairro em conjunto

c) Os adolescentes ganharam mais opções de diversão e desenvolvimento

d) Se houver outra observação sobre como a Internet mudou sua vida, diga qual

29. Além da Internet, que outras atividades você realiza no centro público de acesso? Marque quantas opções você quiser.

( ) Participo de reuniões da comunidade ou de conselhos municipais

() Participo de projetos

( ) Faço atividade de voluntariado

( ) Assisto apresentações culturais

( ) Discuto problemas do bairro ou da comunidade

() Outros. Qual?

( ) Não participo de outras atividades

30. Na sua opinião, o programa atende bem as suas necessidades de uso da Internet?

() $\mathrm{Sim}$

( ) Não

Se não, o que poderia ser feito para atendê-lo melhor?

31. Complete a frase: Para mim, este centro público de acesso é um espaço onde eu posso

\section{Parte 6 - Outras tecnologias}

32. Você possui telefone celular?

( ) Sim ( ) Não [se a resposta for não, pular para 36]

a) Se possui, você já enviou mensagens curtas de texto pelo celular?

( ) $\mathrm{Sim}$

( ) Não

Se a resposta for sim, com que frequiência você as envia?

( ) Uma vez por dia

( ) Várias vezes por dia

( ) Uma vez por semana

() De 3 a 5 vezes por semana

( ) Uma vez por mês ou menos

b) Você já recebeu mensagens de texto pelo celular?

( ) $\mathrm{Sim}$

( ) Não 
Se a resposta for sim, com que freqüência você as recebe?

( ) Uma vez por dia

( ) Várias vezes por dia

( ) Uma vez por semana

( ) De 3 a 5 vezes por semana

( ) Uma vez por mês ou menos

c) Você já navegou na Internet pelo celular?

( ) $\mathrm{Sim}$

( ) Não

Se a resposta for sim, com que freqüência você navega?

( ) Uma vez por dia

( ) Várias vezes por dia

( ) Uma vez por semana

( ) De 3 a 5 vezes por semana

( ) Uma vez por mês ou menos

d) O que você faz quando navega na Internet pelo celular?

( ) Envio e recebo e-mail

( ) Leio notícias

( ) Busco informações sobre o trânsito

( ) Acesso serviços bancários

( ) Busco informações sobre diversão (shows, cinema, teatro, bares, etc)

( ) Busco informações econômicas (cotação de moedas, rendimento poupança, etc)

( ) Busco informações sobre clima

( ) Jogo

( ) Outros. Quais?

33. Você gostaria de dizer mais alguma coisa sobre o impacto da Internet em sua vida e no de sua comunidade? 